\title{
Preservice Teacher Development of Perspectives towards Inquiry through Classroom Research
}

Jason Jude Smith

West Virginia University

Follow this and additional works at: https://researchrepository.wvu.edu/etd

\section{Recommended Citation}

Smith, Jason Jude, "Preservice Teacher Development of Perspectives towards Inquiry through Classroom Research" (2012). Graduate Theses, Dissertations, and Problem Reports. 216.

https://researchrepository.wvu.edu/etd/216

This Dissertation is protected by copyright and/or related rights. It has been brought to you by the The Research Repository @ WVU with permission from the rights-holder(s). You are free to use this Dissertation in any way that is permitted by the copyright and related rights legislation that applies to your use. For other uses you must obtain permission from the rights-holder(s) directly, unless additional rights are indicated by a Creative Commons license in the record and/ or on the work itself. This Dissertation has been accepted for inclusion in WVU Graduate Theses, Dissertations, and Problem Reports collection by an authorized administrator of The Research Repository @ WVU.

For more information, please contact researchrepository@mail.wvu.edu. 


\title{
Preservice Teacher Development of Perspectives towards Inquiry through Classroom Research
}

\author{
Jason Jude Smith \\ Dissertation submitted to the \\ College of Human Resources and Education \\ at West Virginia University \\ in partial fulfillment of the requirements \\ for the degree of \\ Doctor of Philosophy \\ in \\ Education \\ Diane Yendol-Hoppey, Ph.D., Chair \\ Sharon B Hayes, Ph.D. \\ Adriane A. Williams, Ph.D. \\ David T. Hoppey, Ph.D. \\ James F. Nolan, Ph.D. \\ Department of Curriculum and Instruction, Literacy Studies
}

Morgantown, West Virginia

2012

Keywords: Teacher Education, Action Research, Classroom Research, Inquiry Stance 


\title{
Abstract \\ Preservice Teacher Development of Perspectives towards Inquiry through Classroom Research
}

\begin{abstract}
Jason Jude Smith
In this study, I sought to understand how the preservice teachers I worked with, in a five year teacher education program, developed the perspectives and practices necessary to engage in classroom research. I used the literature on classroom research and my own experiences to frame three research questions. I wondered how preservice teachers developed perspectives towards inquiry through preservice classroom research experiences. I also asked how these developing perspectives towards inquiry were manifested as preservice teachers engaged in classroom research. Finally, I asked what barriers and facilitators affected the development of students' developing perspectives towards inquiry. To answer these questions I examined essays written by 84 students at the conclusion of their preservice program. Making use of narrative analysis, I came to see these essays as the first chapter of a "Life-Long Narrative" that describes how each student developed as a teacher, with an emphasis on how they addressed the dilemmas of teacher practice and student learning they faced. Through this analysis, I also found that embedded in many students' essays were two additional types of narratives. Many students developed one or more "Inquiry Narratives" that outlined how students made use of reflection and action in an effort to resolve the dilemmas they faced. Some students also were able to integrate their teaching and research practice, thereby developing "Classroom Research Narratives" which described systematic and intentional study of new practices designed to address the needs of students. For all students, there were factors that served as barriers or facilitators to the development of perspectives towards inquiry, and some students were able to overcome the barriers they faced, while others were not. In reporting the findings of my analysis, I developed each narrative, its elements and how the presence of these elements allowed students to demonstrate sophisticated perspectives towards inquiry and an ability to manifest perspectives through systematic and intentional classroom research. I also provided evidence of the interconnectedness of these perspectives and practices, and considered the implications of my study for those who help to develop teacher-researchers.
\end{abstract}




\section{Table of Contents}

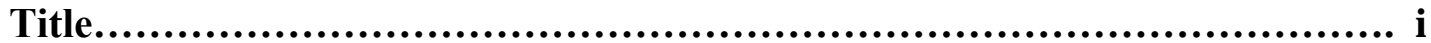

Abstract................................................................................. ii

Table of Contents................................................................ iii

List of Tables................................................................ vii

List of Figures............................................................... viii

Acknowledgements............................................................. ix

Chapter 1: Introduction........................................................... 1

Background and Statement of the Problem............................... 3

Statement of the Problem......................................... 4

Research Question........................................... 4

Methodology ...................................................... 5

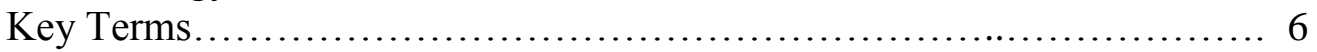

Classroom Research........................................... 7

Inquiry Stance................................................ 7

Reflective Practitioner......................................... 7

Perspectives towards Inquiry................................. 7

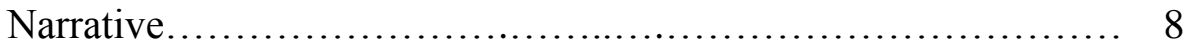

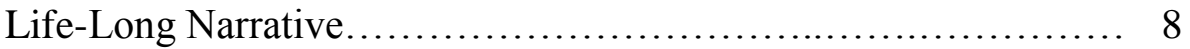

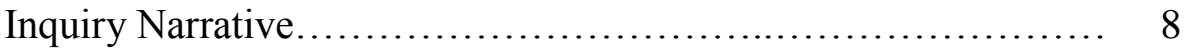

Classroom Research Narrative.................................. 9

Importance and Scope of This Study................................. 9

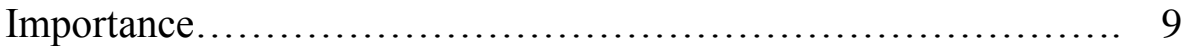

Scope........................................................... 10

Outline of the Dissertation............................................ 10

Chapter 2: The Theory, Processes and Products of Classroom Research........ 12

Procedures Guiding this Review ....................................... 12

Untangling the Terminology ............................................ 13

Action Research........................................ 14

Teacher Research, Practitioner Research, and Inquiry............. 15

Classroom Research.......................................... 17

Theories Underpinning Classroom Research.......................... 18

The Reflective Practitioner................................... 18

Inquiry as Stance........................................... 22

Integrating the Concepts of Reflective Practitioner and Inquiry as

Stance...................................................... 26

Practices Aligned with the Guiding Theories of Classroom Research........ 28

Reflecting on practice: From Dilemmas to Wonderings.............. 28

Examining existing literature - Moving from Wonderings to

Research Questions......................................... 31

Collecting and Analyzing Data - From Questions to Professional

Learning .................................................... 32

The Outcomes of Classroom Research............................... 35

Contextualized Professional Learning............................ 35

Making an Impact Outside the Classroom......................... 38 
Facilitators and Inhibitors to Classroom Research.................... 42

Collaboration................................................... 42

Time..................................................... 44

Working through Tensions in the Classroom Research Process..... 45

Facilitating Classroom Research in Preservice Teacher Education......... 49

Conclusion: The Impact of Classroom Research on the Development of

Preservice Teachers............................................ 52

Rethinking the Relationship between Classroom Research and

Practice................................................. 52

Preservice Teachers' Reflection through Classroom Research: A

Prelude..................................................... 54

Guiding Questions for this Study............................ 55

Chapter 3: Methods and Design............................................. 57

Paradigm, Theoretical Perspective, and Epistemology................ 58

Context....................................................... 60

Selection of Data Sources ........................................ 65

Participant Selection............................................... 67

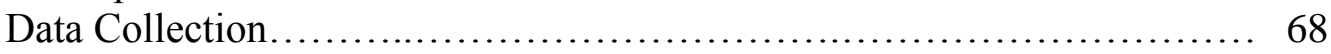

Data Analysis.................................................. 69

Coding of Documents....................................... 70

From Codes to Elements: The Process of Making Meaning......... 72

Returning to Codes from the Elements......................... 74

Role of the Researcher............................................. 75

Trustworthiness................................................ 77

Chapter 4: The Rise of Three Narratives - Developing Perspectives towards

Inquiry ................................................................... 81

One Essay, Multiple Narratives.................................. 81

The Life-Long Narrative $\ldots \ldots \ldots \ldots \ldots \ldots \ldots \ldots \ldots \ldots \ldots \ldots \ldots, 81$

The Inquiry Narrative........................................ 84

The Classroom Research Narrative............................. 87

Integrating the Three Narratives.................................... 90

Chapter 5: Developing the Inquiry Narrative................................... 95

Crafting Wonderings as the Abstract of the Inquiry Narrative............ 96

Constructing Research Questions as the Complicating Action of the

Inquiry Narrative............................................... 100

Collecting and Analyzing Data as the Evaluation of the Inquiry Narrative... 104

Using Findings as the Resolution of the Inquiry Narrative............... 107

Going beyond the Classroom: The Coda of the Inquiry Narrative.......... 114

Chapter 6: Developing the Classroom Research Narrative........................ 120

Teaching Practice: From Complicating Action to Evaluation in the

Classroom Research Narrative...................................... 122

Student Learning as Evaluation of the Classroom Research Narrative....... 127

Teachers Understanding Students as Resolution of the Classroom Research Narrative..................................................... 130

Chapter 7: Considering Evidence of Inability to Construct Narratives.......... 136

Evidence of Fracture in Inquiry Narratives......................... 136 
Wonderings without Dilemmas............................. 137

Underdeveloped Research Questions............................ 139

Unsystematic Piling up of Data............................... 142

Findings as an Endpoint..................................... 146

Minimizing the Scope of Classroom Research................... 149

Evidence of Fracture in the Classroom Research Narrative................ 151

Missing Teacher Practice Elements.......................... 152

Missing Student Learning Elements........................... 156

Missing Understanding Students Elements.................... 159

Chapter 8: The Exemplar Life-Long Narrative of Brian.................. 164

Chapter 9: Barriers and Facilitators to Developing Perspectives towards

Inquiry...................................................................... 180

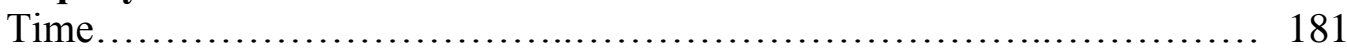

Time during Program as a Barrier............................ 181

Time during Program as a Challenge............................. 184

Time in the Future as a Barrier................................... 186

Time in the Future as a Challenge.............................. 188

Wonderings.................................................... 190

Wonderings as a Barrier..................................... 191

Wonderings as a Challenge................................... 193

Methodological Skills................................................. 195

Methodological Skills as a Barrier............................ 195

Methodological Skills as a Challenge......................... 197

Context.......................................................... 199

Contextual Factors as a Barrier............................... 200

Contextual Factors as a Facilitator........................... 202

Reflection as a Facilitator.......................................... 204

Classroom Research as Impetus for Reflection................. 205

Inquiry as a Cyclical Process................................ 207

Chapter 10: Synthesis of Findings.................................... 210

Perspectives towards Inquiry..................................... 210

Reflection as an Overarching Practice........................ 211

Reflection Leading to Action.................................... 213

Inquiry Leads to Classroom Research.......................... 213

Inquiry is a Cyclical Process.................................. 214

Practices Allowing for Narrative Elements and Dependent on Perspectives. 215

Finding Wonderings...................................... 216

Constructing Research Questions............................ 218

Designing Methodology...................................... 219

Using Data to Consider Professional Practice and Student Learning. 221

Making Work Public....................................... 222

Summary of Findings...................................... 223

Chapter 11: Implications and Conclusions................................ 225

Implications.................................................. 226

Emphasizing all Perspectives and Practices.................... 227

Empowering Preservice Teachers to see Barriers as Challenges..... 230 
Creating Structures that Facilitate Perspectives towards Inquiry.... 233

Promoting the Development of an Inquiry Stance................. 236

Future Research..................................................... 239

Limitations................................................ 239

Additional Research............................................ 241

Jason's Life-Long Narrative........................................ 244

References..................................................................... 248

Appendices....................................................................... 261

Appendix A: Assignment Description for Inquiry Synthesis Essay......... 261

Appendix B: Program Requirements Aligned with State Certification and

University Graduation Requirements............................... 262

Appendix C: Syllabus for the Inquiry Strand and The Teacher as

Researcher........................................................ 265

Appendix D: Exit Ticket for Tutors First Inquiry Activity................ 277

Appendix E: Mini-Inquiry Assignment Description..................... 278

Appendix F: Internship Inquiry Write-up Instructions.................... 280

Appendix G: Template for Internship Inquiry Write-up................ 282

Appendix H: Rubric for Internship Inquiry......................... 288

Appendix I: Sample Research Brief................................. 292

Appendix J: Syllabus for The Teacher as Leader......................... 294

Appendix K: Cover Letter for Informed Consent....................... 300

Appendix L: Notice of Informed Consent.......................... 301

Appendix M: Example of Memoing during Second Round of Coding..... 302

Appendix N: Organization of Codes using the Labov Narrative Elements... 303 


\section{List of Tables}

Table 2.1: Concepts that contribute to the development of perspectives towards

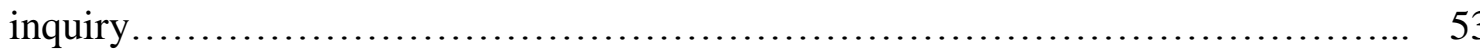

Table 3.1: Organization of codes by narrative type and narrative element........... 73

Table 3.2: Codes used to consider evidence of barriers and facilitators.............. 75

Table 5.1: Practices and perspectives of the Inquiry Narrative.................... 96

Table 5.2: Supporting practices in the Inquiry Narrative....................... 118

Table 6.1: Practices and perspectives of the Classroom Research Narrative.......... 122

Table 6.2: Supporting practices in the Classroom Research Narrative.............. 135

Table 10.1: Summary of perspectives towards inquiry required to provoke classroom research........................................................ 211

Table 10.2: Summary of practices required to engage in classroom research........ 217 


\section{List of Figures}

Figure 3.1: Developing an Inquiry Stance slide............................ 63

Figure 4.1: Narrative elements of a teacher-researcher's life-long narrative......... 84

Figure 4.2. Narrative Elements of a Teacher-Researcher's Inquiry Narrative....... 86

Figure 4.3. Narrative Elements of a Teacher-Researcher's Classroom Research

Narrative ............................................................. 89

Figure 4.4. Relationship between Life-Long Narrative and Inquiry Narrative........ 91

Figure 4.5. Relationship between Inquiry Narrative and Classroom Research

Narrative.............................................................

Figure 4.6. Integration of Life-Long Narrative, Inquiry Narrative and Classroom

Research Narrative .........................................................

Figure 8.1. Illustration of the integration of Inquiry Narratives and Classroom

Research Narratives in Brian's Life-Long Narrative... 


\section{Acknowledgements}

I would like to thank each of the members of my committee for their support as I prepared for, engaged in and wrote about my study. I feel so fortunate to have worked with such a talented, caring and supportive group of professionals. I would especially like to thank Dr. Diane Yendol-Hoppey, who has not only been a wonderful mentor and friend, but who has also provided me with a tremendous example to follow when I have my own doctoral students to support. Even though Diane was 1,000 miles away, it always felt like she was just around the corner.

I would like to thank the faculty and staff who work with the Benedum Collaborative for their support of my research. I would especially like to thank Dr. Sharon Hayes, who in addition to being a dear friend, has also been instrumental in shaping my research, as well as the teaching from which my research has come. I also want to thank Reagan Curtis for his continual guidance of my research and teaching and his willingness to always lend his expertise. I would also like to recognize my former students for their willingness to continually provide honest feedback in support of research and program improvement.

Finally, I would like to thank my mother, Constance Parrillo. Mom has been my favorite teacher, my best friend, my role model, and as she likes to put it, my "Number One Fan." Through thick and thin, success and failure, I have always had a shoulder to lean on. If we could clone my mother, we could solve most of the problems we face in education. But because there is only one of her, I cannot think how lucky I am to have her. 


\section{Chapter 1: Introduction}

Over a century ago, Dewey (1904) wrote of the "intellectual subserviency" of teachers. Dewey went on to say that through, "...the eagerness of those in authority to secure immediate practical results at any cost... and the willingness of our teaching corps to accept without inquiry or criticism any method or device which seems to promise good results," both teachers and those in positions of authority shared culpability for the lack of organic innovation in teaching (p. 16). While teachers have perhaps become more vocal in their displeasure of the top-down reforms put forth by both the academy, and increasingly, external actors, many teachers lack the skills to propose and systematically study alternatives, and even more do not have the ability to advocate for change in policy-making contexts (Desimone, 2002).

As those responsible for teacher education have sought to encourage teachers to improve their practice within the context of standards-based reform, there has been increased attention given to the infusion of classroom research in teacher education. Classroom research encourages teachers to reflect on their needs and the needs of their students; and to implement and investigate new practices. This approach allows teachers to problem-solve on their own and thereby build confidence in their own professional knowledge (Polanyi, 1958). Classroom research is a problem solving tool that helps to transform teaching and learning. Maxine Greene (1995) writes that "transformative pedagogies must relate both to existing conditions and something we are trying to bring into being, something that goes beyond a present situation" (p.51). She adds that these pedagogies are constructed when teachers turn their anxiety into plans of action and act consciously on these plans. It is the ability to recognize the dilemmas that are the source of one's anxiety, coupled with the ability to construct a plan of action, which highlight the goals of classroom research. 
While learning how to engage in classroom research may provide teachers with the skills to consider the effectiveness of new and existing practices, the considerations of an individual teacher in an individual classroom seldom have an impact on the larger educational context. If the work of teachers is to have a more global impact, cultivating those perspectives which can empower teachers to not only study their practice, but to share their work with others is essential (Cochran-Smith \& Lytle, 1993, 2009; Smith, 2011). Cochran-Smith and Lytle (1993, 2009) refer to this professional positioning as an Inquiry Stance.

Unfortunately, while the existing literature on classroom research suggests that there is tremendous potential for a system of education which allows teachers to both construct and consume knowledge, missing is an understanding of the ways in which preservice teachers engaging in classroom research begin to develop the perspectives that make reflection and action a part of their daily work as teachers. Further investigation of preservice teachers' research experiences is needed, so that not only the ability of novice teachers to engage in classroom research is considered, but also the ways in which both thinking about research and doing research impacts preservice teachers' understandings of what it means to have an inquiry stance towards teaching.

In this chapter, I provide the background that led me to consider the problem which underpins my study. I also define the problem and the research questions which guided my study, as well as introduce my theoretical framework and define key terms used throughout this dissertation. Finally, I briefly outline the remainder of this dissertation and consider the scope of the study. 


\section{Background and Statement of the Problem}

During the first semester of my doctoral study, my advisor introduced me to the concept

of classroom research. After expressing an interest in this practice, I was invited to participate in the work of the Center for School Improvement at the college. Through these interactions, I began to see both the promise of classroom research as a transformative teaching practice, and the difficulty in helping teachers to develop the practices necessary to engage in the systematic study of their own teaching (Cochran-Smith \& Lytle, 1993; Dana \& Yendol-Hoppey, 2009).

At the same time, I began to work with another doctoral candidate (referred to as Dr. Rutherford) who was in the process of defending her dissertation, but who was also very interested in classroom research. At the conclusion of my initial year of doctoral study, along with my advisor, I transferred to another university. As chance would have it, the doctoral candidate I had worked with, now an Assistant Professor, had accepted a position at the same university. We both immediately took an interest in the Inquiry Strand of one of our university's teacher education programs. This inquiry strand sought to develop preservice teacher engagement in classroom research.

As we collaborated with the instructor who taught the strand seminars, we began to problematize what we saw as an over-emphasis on practice, and only minimal attention to the theory which guided a robust understanding of classroom research. We both felt it was important to cultivate in students what Cochran-Smith \& Lytle $(1993,2009)$ refer to as an inquiry stance towards teaching. This stance is a "worldview" and "habit of mind" (Cochran-Smith \& Lytle, 2009 , p. 5) whereby reflection and action lead to systemic change in the classroom. The literature on classroom research often makes reference to an inquiry stance; however given the abstract nature of stance, there is a need for further focus on the development of those practices and 
perspectives which might lead to an inquiry stance. We further felt that students should be provided additional support that could help them become what Schön (1983) refers to as reflective practitioners. To accomplish these goals, we began to encourage changes to the inquiry strand, which we hoped would cultivate reflective practitioners with an inquiry stance towards their teaching.

\section{Statement of the Problem}

Over the next three years, Dr. Rutherford and I made significant changes to the inquiry strand of the program. In doing so, we continually felt the tension our students faced between the theoretical and the practical. These tensions were exacerbated by the push towards a more accountability-driven system of education. I began to wonder how well our students were progressing towards becoming the reflective practitioners we hoped to cultivate. Further, believing that if preservice teachers are to develop an inquiry stance they must first see inquiry as a practice used to systematically investigate other practices, I wondered to what extent, through learning and doing classroom research, were our students developing the perspectives necessary to someday actualize this stance. I felt that only when our students began to both understand the purpose of classroom research, and make use of classroom research as a viable teaching practice, would they begin to engage in the cyclical reflection and action needed to actualize CochranSmith and Lytle's concept of an inquiry stance. Thus, I decided to look at the work we asked our students to complete and investigate the ways in which they demonstrated perspectives that might lead to an inquiry stance, as well as how these perspectives developed over time.

\section{Research Questions}

Recognizing the gaps in the existing literature and the development necessary for preservice teachers to begin to see classroom research as an important everyday practice, I 
considered how I might better trace our students' development as they engaged in the process of classroom research, guided by reflection on practice. To better understand if our students were developing perspectives which could eventually lead them to an inquiry stance, I investigated the following research questions:

1. How do preservice teachers' perspectives towards inquiry develop through the process of engaging in classroom research?

2. How do preservice teachers manifest perspectives towards inquiry in practice as they engage in classroom research?

3. What barriers and facilitators impact the development of teachers' perspectives towards inquiry?

\section{Methodology}

In conducting this study, I examined the work produced by our students to understand the ways in which they developed perspectives towards inquiry, how these perspectives were manifested in practice, and what facilitators and barriers impacted the development of these perspectives. I was guided by an interpretivist paradigm (Crotty, 1998) and a constructivist perspective (Guba \& Lincoln, 1989).

In 1949, Max Weber wrote about the divergent needs of social science research and natural science research. As postulated by Weber, in conducting research on the learning processes of my students, I sought to interpret and understand the narratives they constructed, rather than simply describe the work they produced. In using an interpretivist framework (Crotty, 1998), I recognized that the ways in which I interpreted the work of my students were influenced by my own understandings and context. Further, because the narratives which I examined were a product of the students' contexts and understandings, constructivism provided the theoretical 
basis for the methods I used to collect and analyze my data (Guba \& Lincoln, 1989). Finally, in making clear the contextual factors which influenced my analysis, I recognized a constructionist epistemology which guided my way of knowing and understanding my students. Through the use of a constructivist perspective and a constructionist epistemology, I was provoked to consider the importance of both my students' and my context as I designed and implemented my study (Crotty, 1998; Patton, 2002).

After examining the many products produced by our students, I selected an essay written by all students after they completed their classroom research experiences. This "Inquiry Synthesis Essay" asked students to reflect on their experiences engaging in classroom research, throughout their time in the program (See Appendix A). Given my research questions and the story-like nature of the inquiry synthesis essay, narrative analysis emerged as an appropriate analysis tool for my study. According to Gall, Gall \& Borg (2007), this kind of analysis allows for the examination of the elements of a narrative to understand the ways in which participants organize their own experiences, including the social interactions which guide these experiences. My analysis made use of the framework developed by Labov (1972) to guide examination of the narrative elements present in students' essays. This process would eventually lead me to identify and define three distinct kinds of narratives which were often embedded in a student's inquiry synthesis essay. I believe these narratives, and the perspectives and practices necessary to construct them, inform the literature on classroom research, especially within the context of preservice teacher education.

\section{Key Terms}

As with many concepts which govern both educational theory and practice, there is not always agreement as to the definitions that should be used for given terms. Here I clarify key 
terms which will be used throughout this dissertation, and which are defined in different ways throughout the literature.

\section{Classroom Research}

Classroom research is systematic and intentional study by teachers about their own classroom work, through the use of a methodology that supports quality research and aligns with quality teaching practice.

\section{Inquiry Stance}

They key purpose of this study was to determine the ways in which students develop perspectives which suggest progress towards an inquiry stance. Cochran-Smith \& Lytle (2009) define an inquiry stance as:

A worldview and a habit of mind - a way of knowing and being in the world of educational practice that carries across educational contexts and various points in one's professional career and that links individuals to larger groups and social movements intended to challenge the inequities perpetuated by the educational status quo (p. 5).

\section{Reflective Practitioner}

In developing an inquiry stance, preservice teachers must learn to be reflective practitioners. In this study, the definition developed by Schön (1983) is used. He defines a reflective practitioner as one who "[has] a capacity for reflection on their intuitive knowing in the midst of action and sometimes [uses] this capacity to cope with the unique, uncertain, and conflicted situations of practice.” (p. 8-9)

\section{Perspectives towards Inquiry}

While this study aims to consider the development of perspectives that might lead to an inquiry stance as defined by Cochran Smith and Lytle (2009), I recognize that these perspectives 
are stepping stones to an inquiry stance. Thus, in using the phrase perspectives towards inquiry, I refer to those perspectives that provoke teachers to make reflection and action a part of their daily work (Schon, 1983), as well as allow them to think about and engage in systematic and intentional classroom research that impacts their understanding of, and capacity to actualize, an inquiry stance (Cochran-Smith \& Lytle 2009) towards their teaching.

\section{Narrative}

The essays that served as data in this study are viewed as student-constructed narratives. According to Reissman (1993), narratives are stories which follow some logical sequence. In this case, these stories are told in traditional written form (Patton, 2002).

\section{Life-Long Narrative}

Within the context of this study, the inquiry synthesis essays constructed by students are viewed as a first chapter of their Life-Long Narrative. A Life-Long Narrative is a story that details the dilemmas faced by a teacher, and includes the ways in which the teacher addressed these dilemmas.

\section{Inquiry Narrative}

For teachers who are able to make use of reflection and action (aligned with Schön's notion of a reflective practitioner) to address the dilemmas that arise during their career, an Inquiry Narrative is constructed and embedded in the larger Life-Long Narrative. Thus, I define an Inquiry Narrative is the story of how a teacher reflected on a dilemma and then took action including changes in practice and data collection and analysis on this practice in an effort to resolve the dilemma. 


\section{Classroom Research Narrative}

When teachers engage in systematic and intentional study as a way to solve a real-world dilemma, they also construct a Classroom Research Narrative that is embedded in their LifeLong Narrative and potentially aligned with an Inquiry Narrative. Thus, a Classroom Research Narrative is the story of a specific instance of classroom research which integrates teaching and research practice, using systematic data collection and analysis to generate meaningful findings.

\section{Importance and Scope of this Study}

The problem and research questions which guided my study arose out of my own experiences working with preservice teachers and a review of the literature which indicated both the importance of classroom research, and the limited understanding of how, through engaging in classroom research, preservice teachers develop perspectives towards inquiry. It is my hope that the findings of this study can contribute to the larger knowledge base on classroom research, especially to our understanding of preservice teacher development of those perspectives which can eventually lead to an inquiry stance.

\section{Importance}

As classroom research becomes a more prevalent practice in education, it is necessary to better understand the ways in which teachers develop as they study their own practice. While much of the conceptual work on classroom research highlights the importance of reflective practice and an inquiry stance towards teaching, the ways in which, through classroom research, preservice teachers develop the perspectives that can lead to an inquiry stance, has not been addressed empirically. Further, there is a need for more research which examines the ways in which preservice teachers learn to study their own practice. This study contributes to both of these areas of scholarship, and in doing so can serve to guide the efforts of others who seek to 
cultivate teacher-researchers; reflective practitioners who have an inquiry stance towards their own teaching, and who make use of classroom research to improve their practice.

\section{Scope}

While this study can contribute to the literature on classroom research, particularly preservice teacher classroom research, I recognize that the data analyzed in this study is collected from one context. As such, the findings are only generalizable when those who read them are able to pay careful attention to methods, and align these procedures with their own way of facilitating classroom research (Lieblich, Tuval-Mashiach, \& Zilber, 1998). In providing clarity as to: (1) the context of my study, (2) the experiences which served to drive the creation of products that were used as data, (3) my role as both a researcher and a facilitator of my students' learning, and (4) my own theoretical framework and epistemology, I hope to offer sufficient information for others to make use of my work.

\section{Outline of the Dissertation}

This dissertation is organized into 11 chapters. Chapter 2 makes use of the conceptual and empirical research that guided my understanding of perspectives towards inquiry to develop an understanding of the theories, practices and outcomes of classroom research. Special attention is paid to literature which specifically addresses classroom research in preservice education. Chapter 3 provides a detailed description of the methodology used in this study. The research context, participants, and data sources are described. Detail is provided characterizing the theoretical perspective and epistemology which guided my work, as well as the ways in which I utilized narrative analysis to look at my data. In Chapter 4, I develop the structure of the three narratives that emerged through my analysis. In Chapter 5, I provide evidence of the ways in which students developed Inquiry Narratives as they attempted to resolve real-world dilemmas 
through reflection and action. In Chapter 6, I provide evidence of the ways in which students developed Classroom Research Narratives as they engaged in systematic and intentional classroom research. Chapter 7 examines the ways in which many students demonstrated either a lack of sophistication in the perspectives towards inquiry they developed or a lack of ability to manifest perspectives into practice. In Chapter 8, I provide a detailed analysis of one student's (with the pseudonym Brian) essay. In doing so, I demonstrate how Brian was able to demonstrate sophisticated perspectives towards inquiry and an ability to manifest these perspectives into practice through systematic and intentional classroom research. In Chapter 9, I address the factors that were barriers and/or facilitators in the development of students' perspectives towards inquiry. In Chapter 10, I synthesize the findings of my study, integrating the evidence that provided answers to each of my research questions. Finally, in Chapter 11, I discuss the implications of my study for those who engage in, facilitate and research classroom research. 


\section{Chapter 2: Classroom Research as Practice for Reflective Practitioners}

In order to frame a study investigating the ways in which preservice teachers' classroom research experiences affect the development of perspectives towards inquiry necessary to have an inquiry stance, this chapter reviews the conceptual and empirical classroom research literature. In doing so, I organize the analysis of this literature by: (1) untangling and defining the terminology that guides this study; (2) discussing the theories which underpin classroom research; (3) examining the processes of classroom research aligned with these theories, (4) considering the products that emerge from meaningful classroom research, (5) identifying barriers and facilitators to classroom research, (6) considering additional supports needed when facilitating preservice teachers' classroom research, and (7) suggesting gaps in the literature that provoked my study.

\section{Procedures Guiding this Review}

My review of the literature began with an analysis of the scholarship which has guided both my teaching of, and research on classroom research. In addition, I conducted an online search using EBSCO Host for peer-reviewed articles published in 2000 or later using the key terms: "Practitioner Research," "Practitioner Inquiry," "Teacher Action Research," "Teacher Inquiry," "Classroom Research," "Teacher Research," and "Classroom Inquiry." These searches yielded a total of 447 articles. A review of each abstract allowed me to reduce my article pool to 97 relevant articles. Finally, a more thorough review of each article allowed me to identify 86 relevant articles that informed my understanding of classroom research, including many articles that specifically related to preservice teachers. The use of seven search terms was meant to ensure maximum coverage, and also reflected my recognition of the various ways in which classroom research, as defined in chapter 1, is named by researchers. The next section provides 
additional clarity as to the similarities and differences between the common terms used to describe practices similar to those which I investigated during this study.

\section{Untangling the Terminology}

Like many other professional teaching practices, classroom research is defined in different ways, and these definitions are tied to a myriad of terms which sometimes have similar meanings. As such, it is necessary to consider terms such as action research, practitioner research, teacher research, and inquiry in developing a clear definition of classroom research. In this section, I briefly illustrate the importance of providing clarity for these terms and then consider the genesis of the terms action research, practitioner research, teacher research, and inquiry. I then define the term classroom research, provide a rationale for its use in this study, and illustrate how it relates to other terms commonly used.

In this study, I primarily use the term classroom research and define classroom research as systematic and intentional study by teachers about their own classroom work, through the use of a methodology that supports quality research and aligns with quality teaching practice (see Cochran-Smith \& Lytle, 1993, 2009; Dana \& Yendol-Hoppey, 2009). However, even within the program which serves as the context for this study, multiple terms (e.g., action research, teacher research) have been used to refer to the collective experiences which are designed to allow preservice teachers to understand and engage in classroom research. While Price and Valli (2005) suggest that the various terms used to describe classroom research point to similar practices, others note that these terms are often constructed based on divergent orientations or traditions (Lytle, Portnoy, Waff, \& Buckley, 2009). The following sections examine these terms and their backgrounds. 


\section{Action Research}

Action research is one of the most common terms used to describe a process where teachers, as well as practitioners in many other fields, engage in research on their own day-today work. Kurt Lewin (1946) is generally considered to be the person who brought the term action research into the lexicon of research paradigms. Lewin (p. 202) described action research as "comparative research on the conditions and effects of various forms of social action and research leading to social action." Lewin began to view this work as a process that "gives credence to the development of powers of reflective thought, discussion, decisions and action by ordinary people participating in collective research on 'private troubles' that they have in common" (Adelman, 1993, p. 8). Kurt Lewin's action research cycle is used to facilitate the process of problematizing practice through social inquiry, thus providing a tool which, rather than more traditional empirical research, facilitates interpretative research that leads to action.

Beginning with Lewin's historical work (1946), action research has been considered a tool for provoking social reform and has been formed and informed by the work of advocates for social justice within and outside the field of education. Specific examples of action research as a tool for change and promoting social justice can be seen in the work of Paulo Freire. Freire (1970) saw what he referred to as participatory action research (PAR) as one way to mitigate the traditional authoritarian relationships pervasive in education (see also Kincheloe, 1991). FalsBorda (1987), a sociologist, who also developed programs which promoted PAR in Colombia, expanded the social reform work of Freire in South America.

In distinguishing action research from more traditional forms of research, key differences emerge related to the purpose of the study. While traditional forms of research seek to produce 
generalizable knowledge, action research seeks to solve problems which are of special importance to the researcher. In the field of education, action research is often seen as having a personal, political and professional purpose (Zeichner \& Noffke, 2001). Another distinguishing factor of action research is its cyclical nature. In this cycle, findings are followed by action, reflection, and modification of actions. There is also an understanding that an action researcher may enter this cycle at any point (Glanz, 1999). In sum, the action research movement has emphasized the importance of ordinary people solving personal, political, or professional dilemmas by engaging in a cyclical process that includes reflective thought, deliberation, decision-making, and collaboration to reform or improve conditions. This cyclical process, though designed to facilitate the research of practitioners in many disciplines, has found favor in the education community.

\section{Teacher Research, Practitioner Research, and Inquiry}

Given the intended purposes and processes of action research, those seeking to provoke reflection and action in educational practitioners have found many of the principles of action research translatable to school and classroom settings. The terms teacher research, practitioner research, and practitioner inquiry have all been developed to describe cyclical inquiry by teachers and other education professionals. Cochran-Smith and Lytle (1993, p. 23) define teacher research as, "systematic and intentional inquiry by teachers about their own school and classroom work." This definition is commonly cited when reference is made to the research of practicing teachers and other education professionals. Recognizing the role of practitioners outside of K-12 teachers, Cochran-Smith \& Lytle (2009) also make use of the term practitioner research, extending the definition of teacher research to include preservice teachers, administrators, teacher education faculty, and others involved in K-12 education. Recognizing 
the historical use of action research as a tool for addressing social injustice (Friere, 1970), Cochran-Smith and Lytle's encouragement of systematic study promotes the use of practitioner inquiry as a tool to advocate for issues of equity in schools.

Further language complications emerge when the term inquiry is substituted for research in school contexts. In an effort to provide a rationale for using the word inquiry as opposed to research, Dana and Yendol-Hoppey (2009) reference the "baggage" (p. 4) which comes along with the word research, as well as the impact this baggage can have when working with teachers. Cochran-Smith \& Lytle (2009) also recognize the interchangeable use of these words. Their use of the word research, rather than inquiry, is purposeful, as they seek to clarify that practitioner inquiry is not only a "form of professional development for individuals and groups" (p. IX), but also a "valuable mode of critique of the inequities in schools and society" (p. IX). The term practitioner inquiry may be seen as an overarching term which includes systematic study by educational practitioners who seek a variety of intended outcomes for such inquiry. These outcomes include professional development, personal development, addressing issues of equity, school reform and others (Cochran-Smith \& Lytle, 2009; Caro-Bruce, Flessner, Klehr, \& Zeichner, 2007; Cochran-Smith \& Lytle, 1993; 2009; Danielson, 2006; Yendol-Hoppey \& Dana, 2010).

Practitioner research, as described above, makes use of a cyclical and dilemma-driven research process similar to the process defined by Lewin (1946) as action research. In this process, the term practitioner is used instead of teacher, as a way to frame the process as one that is inclusive of all education professionals. The use of the term research instead of inquiry is often chosen to emphasize a purpose extending beyond individual learning. Further distinctions in terminology can also be used to situate the context within which this research occurs. 


\section{Classroom Research}

Throughout the remainder of this chapter, I make use of the term classroom research. I draw on Cochran-Smith \& Lytle's (2003) definition of teacher research, and making two distinctions. The first distinction is in defining the classroom as the specific context within which the research occurs. For example, many teachers experienced in the research process may look at school-wide issues such as drop-out prevention. However, for those new to teacher research, like the preservice teachers that were the subject of this study, the initial purpose of research is almost always the teacher's classroom practice (Prestage, Perks, \& Soares, 2003) and the learning of their students (Brookhart, Moss, \& Long, 2010).

The literature provides examples in which practitioner research in used in a multitude of educational contexts. Chubbuck (2010) sees practitioner research as a viable tool for studying, acting and reflecting both within and outside of the classroom. For many teachers however, the starting point for utilizing research as a teaching practice is within the classroom (Dana \& Yendol-Hoppey, 2008). This is especially true for preservice teachers who, through exposure to classroom research, may come to see research as one component of being a good teacher (Phillips \& Carr, 2010). Thus, by using the term classroom research, a distinction is made between research purposes which extend beyond the confines of an individual classroom, and those which are, at least initially, focused on day-to-day classroom interactions.

In looking across the work of the various traditions which guide this definition, key components of classroom research include the ability to see and reflect on problems of practice and student learning, taking action which aims to address these problems, studying the impact of this action, and then reflecting on the process in ways that lead to new action (Cochran-Smith \& 
Lytle, 1993; 2009; Dana \& Yendol-Hoppey, 2009; Lieberman, 2009; Phillips \& Carr, 2010). I make a second distinction to capture each of these abilities. Thus, in this review the use of the term classroom research, while based on the definition of teacher research developed by Cochran-Smith \& Lytle (1993, p.5), is broadened to, "systematic and intentional study by teachers about their own classroom work, through the use of a methodology that supports quality research and aligns with quality teaching practice." Having untangled the language influencing my use of the term classroom research and defining the term classroom research for this study, I now describe the theories underpinning classroom research.

\section{Theories Underpinning Classroom Research}

This section examines the key theories which underpin classroom research. In the last decade, classroom research has gained traction as a viable professional learning tool that helps teachers systematically study their own practice (Caro-Bruce, 2008; Lieberman, 2009). This movement provides a rationale for promoting and studying classroom research. Two theoretical concepts, and the seminal works from which they arose, provide insight into our understanding of this movement, and into the relevance of classroom research in contemporary educational settings. These concepts include the reflective practitioner as defined by Schön (1983) and the concept of inquiry as stance defined by Cochran-Smith \& Lytle (1993, 2009). In this section, I provide background on each concept, and then provide an understanding of how, in combination, these two concepts help us understand the mechanisms inherent in classroom research that lead to improved teaching and learning.

\section{The Reflective Practitioner}

This section examines Schön's concept of the reflective practitioner, and its central role in providing a rationale for classroom research. Reflection has long been viewed as important in 
providing the impetus for beginning classroom research and the primary tool for generating the findings of a study in a way which serves to maximize student learning (Jaworski, 2003). Given the nature of classroom research as a dilemma-driven endeavor, teacher-researchers are encouraged to reflect at each step during the research process. This systematic reflection is critical to engaging in classroom research that provokes action. Schön refers to those who engage in and actualize reflection as reflective practitioners.

At the conclusion of The Reflective Practitioner, Schön writes that "in a school supportive of reflective teaching, teachers would challenge the prevailing knowledge structure. Their on-the-spot experiments would affect not only the routines of teaching practice but the central values and principles of the institution" (1983, p. 335). Although The Reflective Practitioner was written to address practitioners in all professions, Schön's work has had a seminal influence on teacher education, especially on the classroom research movement. Schön's conception of the reflective practitioner is based on the assumption that there is a reciprocal relationship between reflection and action (Jaworski, 2003).

Almost a century ago, Dewey (1916) wrote that reflective experiences are distinguished from trial-and-error when a practitioner conducts, "a careful survey (examination, inspection, exploration, and analysis) of all attainable consideration which will define and clarify the problem at hand [and] a consistent elaboration of the tentative hypothesis to make it more precise and more consistent” (p. 103). Like Dewey, Schön theorizes that reflection leads to learning. In describing the ways in which this learning occurs, Schön $(1983,1987)$ differentiates between, reflection-in-action, reflection-on-action and reflection-for-action. Each of these types of reflection can impact teaching practice, including the practice of engaging in classroom research. 
Reflection-in-action could be described as thinking on your feet, as this process involves examining experiences and building new understandings to inform actions in a situation that is unfolding. Reflection-in-action relies on the concept of tacit knowledge as defined by Polanyi (1958). Polanyi's suggestion that we know more than we can tell is a central theme in guiding Schön's work (Grushka, McLeod, \& Reynolds, 2005). This reflection-in-action becomes an important part of action, as theory and practice are merged and utilized to guide both action and thought (Cochran-Smith \& Lytle, 1999; Marcos, Miguel, \& Tillema, 2009). In addition to the use of reflection as a problem-solving tool, as espoused by John Dewey and others, Schön also places emphasis on the role of self in reflection (Moss, Springer, \& Dehr, 2008). Through reflection-in-action, practitioners can begin to generate contextualized learning and span the boundaries between themselves and the academy, from where the knowledge which has traditionally been valued in teaching most often comes (Marcos et al., 2009).

Reflection-on-action occurs when teachers spend time exploring why they acted in particular ways, and how those actions influenced their teaching and their students, thus developing questions and ideas about practice. By reflecting-on-action, teachers begin to develop more of a learner-centered view of their classroom work, thereby engaging in professional learning to improve practice (Smith \& Sela, 2005). When teachers go a step further and are willing to reconstruct their experiences, an improved sense of self often results (Allard et al., 2007). This improved sense of self is cultivated through reflection experiences that encourage the conceptualization of new ways of knowing and doing. These reflections then become a foundation on which future teaching endeavors are built (Atay, 2008).

Reflection-for-action occurs when teachers consider how they have accomplished various teaching activities, and identify ways to accomplish similar tasks in the future. As a part of 
reflection-for-action, teachers consider their own practice, and how this practice impacts their students' learning experiences (Marcos, Sánchez, \& Tillema, 2008). When done properly, such critiques of practice are conducted with the end goal of achieving praxis, rather than making judgments (Rust \& Meyers, 2006). Here too, reflection allows teachers to combine theoretical knowledge developed through formal educational experiences with the understandings of practice developed through their lived experiences (Pilkington, 2009).

Encouraging teachers to engaging in each of Schön's three types of reflection has become a common theme in teacher education, especially in experiences designed to cultivate teacherresearchers (Marcos, Sánchez, \& Tillema, 2008). Schön's work illuminates the role that reflection can play in changing teachers' practice and in developing new theories which can be shared with others (Vogrinc \& Zuljan, 2009). Schön's work can also bolster arguments in favor of more closely connecting the work done by practitioners and researchers (Burant, Gray, Ndaw, McKinney-Keys, \& Allen, 2007; Vogrinc \& Zuljan, 2009). As Schön concludes:

The dilemma of rigor or relevance may be dissolved if we can develop an epistemology of practice which places technical problem solving within a broader context of reflective inquiry, shows how reflection-in-action may be rigorous in its own right, and links the art of practice in uncertainty and uniqueness to the scientist's art of research (1983, p. 69). Through reflection, teachers begin to construct knowledge and thereby shift long-held assumptions about the role of practitioners in generating professional knowledge within the field of education (Burant et al., 2007).

The work of Schön is critical to understanding arguments for encouraging reflective practice in teaching. His theory also can serve as a foundation for developing the understandings necessary to cultivate reflective practice in preservice teachers. The idea of action research 
(including classroom research) is minimally addressed in Schön's work. Instead, other scholars have developed theories using Schön's ideas as a rationale for cultivating teacher-researchers.

\section{Inquiry Stance}

Out of a desire to help move the classroom research movement forward, Cochran-Smith and Lytle consider those teachers who are able to systematically study their practice, contribute to their own learning and the learning of others, and address inequities faced by many children as having an inquiry stance. Although inquiry stance is an abstract idea, conceptual literature on classroom research emphasizes its importance.

The work of Cochran-Smith and Lytle explores the potential benefits of having teachers who systematically inquire into, and have an inquiry stance towards their practice. CochranSmith and Lytle (1993) originally defined inquiry as stance, "as a grounded theory of action that positions the role of practitioners and practitioner knowledge as central to the goal of transforming teaching, learning, leading and schooling” (p. 119). They later expanded on this definition by adding that an inquiry stance is:

A worldview and a habit of mind - a way of knowing and being in the world of educational practice that carries across educational contexts and various points in one's professional career and that links individuals to larger groups and social movements intended to challenge the inequities perpetuated by the educational status quo (2009, p. $5)$.

These definitions make it difficult to determine the specific perspectives necessary for teachers to actualize an inquiry stance, but the work of other scholars suggests that the education community benefits when teachers have an inquiry stance. 
The original definition of inquiry stance provided by Cochran-Smith and Lytle emphasizes the importance of teacher knowledge. Cochran-Smith and Lytle $(1993,1999,2009)$ argue that the cultivation of an inquiry stance towards teaching, through the process of classroom research, can serve as a powerful form of professional development. Hahs-Vaughn and Yanowitz's (2009) research on teachers who engaged in classroom research supports the link between an inquiry stance and contextualized professional learning. The earliest field work by Cochran-Smith and Lytle, which focused on teachers' attempts to improve practice in literacy and writing, has enjoyed a long track record of success in helping teachers develop this local knowledge (Lytle et al., 2009). Similar narratives have led some accreditation bodies and government agencies to accept classroom research as a viable learning tool (Hahs-Vaughn \& Yanowitz, 2009). Despite these successes, the learning reported in most studies on classroom research is often not disseminated in ways that might help convince policymakers, researchers, and accreditors of the value of teacher-constructed knowledge.

There has been significant discussion in the literature as to how greater sharing of the work of teacher-researchers might be accomplished. Much of this discussion is based on the belief that classroom research has the potential to challenge the hegemony of the university, and transform what is known about teaching and learning (Baumfield \& Butterworth, 2007). This hegemony, described by Cochran-Smith \& Lytle (1993) as outside-in knowledge, is precisely the type of knowledge which teacher-researchers could be expected to critique through their own classroom work (Brown \& Macatangay, 2002). In fact, many of those who have written about their own experiences working with teacher-researchers have expressed a desire to see teachers as greater contributors to conversations on teaching and learning (Haigh \& Dixon, 2007). 
Further, many believe these conversations can take place in policy-making contexts at local, state and national levels (Brock, Helman, \& Patchen, 2005; Smith, 2011).

Despite the belief that teacher research has the potential to impact practitioners and academics, studies indicate that the literature on classroom research is primarily disseminated through the work of those in academia, even when such research is based on teacher-driven data collection and analysis (Rust \& Meyers, 2006; Sweeney, 2003). As such, Cochran-Smith and Lytle's (2009) assertion that teachers with an inquiry stance can produce knowledge that can transform the profession is being simultaneous supported and questioned. Some postulate that the local knowledge produced by teacher-researchers is too dependent on context to encourage dissemination of such scholarship outside the walls of the school within which it was produced (Rosiek \& Atkinson, 2005). To help prevent the perpetual marginalization of teacher-constructed knowledge, Zeichner (2007) calls for teacher research to be synthesized in an effort to help its integration into the knowledge base. The work of other scholars has begun to mirror Zeichner's suggestions, as those adept at writing for academic audiences construct cases which allow the work of teacher-researchers to be shared with larger audiences (Allard et al, 2007; Rust \& Meyers, 2006). While there is continued debate as to the global value of knowledge produced by teacher-researchers, if classroom research is to contribute to the elevation of the teaching profession, teachers need to be provided with both the foundational knowledge and continued support necessary to conduct scholarship that is meaningful in global contexts (Kamler \& Comber, 2008).

Perhaps understanding the need for greater emphasis on the global knowledge produced by teachers, in their revised definition, Cochran-Smith and Lytle (2009) refer to an inquiry stance as a, "worldview, a habit of mind, [and] a way of knowing and being in the world of education." 
(p. 5). Smith and Sela (2005) suggest that such a worldview can allow teachers to view learning to teach as a life-long process. Shifting the foundational role of the teacher from that of a technician to that of a reflective practitioner with an inquiry stance, can serve to allow for greater understanding of real-world problems of practice in everyday contexts. Zeichner (2007) feels that this commitment to life-long learning is one way in which practitioners might overcome the difficult challenges they face as the regulation of the teaching profession continues to increase, echoing the need for teachers to challenge the status quo.

Cochran-Smith and Lytle again emphasize the global nature of teacher knowledge suggesting that an inquiry stance carries across contexts and connects individuals with groups. With one of the original goals of classroom research being the elevation of the teaching profession to actualize the ability to address problems of practice in teaching contexts, it becomes critical that teacher research facilitates the development both local and global knowledge. The construction of global knowledge is viewed by some as a way to prevent marginalization of the teaching profession, and to facilitate dissemination of findings from those studies whose subjects are often children in real-world learning contexts (Foreman-Peck \& Murray, 2008). Despite the sometimes divergent research traditions which contribute to various types of classroom research, the ability of these scholarly endeavors to fuse theoretical and practical knowledge make them critical to the professional learning of practitioners (Lytle et al., 2009; Smith \& Sela, 2005; Yendol-Hoppey \& Dana, 2010). The research process allows teachers to not only know more about their practice, but through the reflection, which guides each step of the inquiry cycle, teachers also learn more about themselves as professionals (Brock et al., 2005). Thus, whether eventual learning is local or global, such learning still serves as an essential form 
of professional development, especially when such learning occurs in collaborative settings (Cochran-Smith \& Lytle, 1999; Haigh \& Dixon, 2007, Hussein, 2007).

Finally, in redefining inquiry stance, Cochran-Smith and Lytle emphasize issues of social justice. They also write that classroom research is a method by which teachers can gain practical clarity on important personal, political, and professional issues, as well as those social justice issues which perpetuate inequality in the American system of education (Chubbuck, 2010; Cochran-Smith \& Lytle, 1993, 2009). Orland-Barak (2009) echoes the importance of classroom research as a tool which allows teachers to critique the prevailing social and political attitudes towards education, adding that by doing so, teachers are able to engage in substantive educational reform. This reform, along with the explicit discussion of inquiry stance as a worldview, helps to emphasize the need for greater recognition of teacher-constructed knowledge.

The concept of inquiry stance as defined by Cochran-Smith and Lytle is viewed throughout the literature as critical to the teacher research movement. Teachers who, through their research experiences, are able to develop an inquiry stance towards their teaching, are viewed by many scholars to be the same teachers who will elevate the teaching profession, contribute to policy-making conversations, and address the inequalities faced by many children. For teachers to actualize this stance, they must be willing to systematically study their practice, contribute global, as well as local knowledge, and become adept at reflecting on their students learning needs, as well as their own learning needs as teaching professionals.

\section{Integrating the Concepts of Reflective Practitioner and Inquiry as Stance}

This section examines the relationship between reflective practice and inquiry stance. 
For teacher-researchers who demonstrate an inquiry stance towards their teaching, reflection is a critical part of the classroom research process. As such, teachers who are reflective practitioners, as defined by Schön, are positioned to develop an inquiry stance towards their teaching as defined by Cochran-Smith and Lytle.

Reflection is a necessary part of the classroom research process. It must occur as teachers observe, analyze, and interpret information in an effort to better understand their own practice (Rogers et al., 2007). And while reflection is often viewed as a linear process, classroom research makes use of reflection at each step in a cyclical process (Marcos et al., 2009). Further, formalizing one's reflection, and the processes which guide this reflection, is viewed as essential to the process of classroom research (Potter, Badiali, \& Hammond, 2000; Rogers et al., 2007). In this way, understanding how to reflect on one's practice is seen as a prerequisite to engaging in classroom research. Given the role of reflection in classroom research, becoming a reflective practitioner can be seen as a prerequisite to developing an inquiry stance. Borg (2009) indicates that an inquiry stance allows teachers to develop local and global knowledge through the systematic study of practice, thus building on the concept of reflective practice. In originally defining inquiry as stance, Cochran-Smith \& Lytle (1993) referred to, "a grounded theory of action," (p. 119), a term borrowed from the work of Schön (Cochran-Smith \& Lytle, 2009). Thus, those who work to cultivate an inquiry stance in teaching professionals often begin by facilitating the process of reflective practice.

The common theories used in much of the literature on teacher research suggest that reflective practice can lead to a professional approach to teaching referred to as an inquiry stance. To actualize this stance, teachers must not only be reflective practitioners, but must also understand the practices which guide classroom research and the ways in which these practices 
are integrated with other teaching practices. In the next section, I will describe the literature on those research-based practices which guide classroom research.

\section{Practices Aligned with the Guiding Theories of Classroom Research}

Classroom research makes use of practices that guide traditional research and practices used by teachers in their daily work. This section examines the ways in which reflecting on practices used by teachers in their daily work can lead them to wonderings, how examining literature can transform wonderings into research questions, and how engaging in data collection and analysis can result in findings that lead to professional learning.

\section{Reflecting on Practice: From Dilemmas to Wonderings}

Prior to developing research questions, teachers can make use of reflection to recognize dilemmas, and then use these dilemmas to provoke wonderings. These wonderings can then lead to background research which can help transform wonderings into research questions. As a part of the process of moving from dilemma to formal research question, teachers consider the nature of the dilemma and then reflect on the dilemma to construct informal wonderings that can guide further study. This section defines dilemma and wondering, discusses the nature of dilemmas, how one reflects on these dilemmas to construct initial wonderings, and how this reflection can be encouraged by those seeking to support teachers in the development of their own theories of practice.

Prior to designing a classroom research activity, it is important to consider the underlying purpose of the research. One way for a teacher to frame this purpose is by making clear the dilemma which has provoked a need for further study. The dilemmas that guide classroom research activities arise from a teacher's perceived need to explore viable alternatives to existing practice. Dana and Yendol-Hoppey (2009) refer to these perceptions as "felt difficulties" (p.20). 
Wonderings are questions which emerge as teachers reflect on dilemmas, the complexity of the classroom and their own passions as a teacher (Dana \& Yendol-Hoppey, 2009). These wonderings lead to the research questions that eventually emerge.

The nature of the dilemmas which allow potential wonderings to emerge may be the product of a specific initiative, the collaborative interests of a professional learning community or critical friends group, or may come as a result of examining data culled from accountability reports. As a result of examining existing practice, the nature of the wonderings that teachers' craft allow classroom research to be a part of, rather than apart from the everyday work of a teacher in the classroom (Dana \& Yendol-Hoppey, 2008; Hayes \& Smith, 2011). Reflection which can help generate wonderings may also come as teachers begin to challenge their existing notions of practice (Burant et al., 2007). To do so, teachers devote time to deep and detailed analysis of the difficulties which arise in their classrooms (Cardno, 2006, Grushka et al., 2005).

In moving from dilemma to wondering, reflection can help teachers to understand the cause of a dilemma, and can also support the process of considering ways to address the dilemma in practice. Teacher reflection on the dilemmas that emerge from everyday teaching is essential to identifying a question (Brown \& Macatangay, 2002; Kraft, 2002). One way of promoting reflection is to help teachers become critical of their own practice by reflecting on the impact of practice on their students' learning. Chubbick (2010) suggests that preservice teachers need to also reflect on student difficulties with attention to both the individual child, and to the structures which contribute to that child's difficulties. Kesson, Traugh and Perez III (2006) followed one urban teacher education program that used an inquiry-oriented process called descriptive review. Their study found that when preservice teachers were able to "give themselves over" to inquiry by placing greater emphasis on understanding students rather than testing strategies, the 
perspectives necessary to understand those characteristics which contribute to children's experiences inside the classroom could be leveraged to encourage deeper learning (p. 1879). Those who facilitate teacher research often provoke this sort of substantive reflection by shifting the teacher's gaze towards the student.

Encouraging reflection on dilemmas is an important activity for those who facilitate classroom research. As reflection is a key component of many teaching practices, the process of purposeful reflection should be taught early on in teacher education, and reinforced through professional development activities (Ax, Ponte, Brouwer, 2008; Grushka et al., 2005). For those who are just learning to engage in purposeful reflection, initial experiences should include significant scaffolding designed to allow teachers to see the advantages of reflection, and to cultivate the mentoring relationships which are often crucial in encouraging future (and more indepth) reflective activities (Poetter et al. 2000). For those working with preservice teachers, integrating reflection into multiple learning activities allows preservice teachers to see the links that exist between reflection and action and between research and practice (Ax et al., 2008). If through reflection teachers better understand the complexities of the classroom, they can begin to see the nuances in their own theories of professional practice. Through understanding their own theories of practice, teachers are better able to diagnose problems which arise in the classroom, and can become more cognizant of the ways in which they can learn to solve these problems (Davis, Kiely, \& Askham, 2009; Sweeney, 2003). It is this ability to use reflection to both recognize problems, and the practices which cause these problems that allows teachers to transform the dilemmas they uncover into wonderings. Once wonderings are developed, the process of constructing the research questions that guide classroom research can begin. 


\section{Examining Existing Literature - Moving from Wonderings to Research Questions}

For teachers, reflection can help turn dilemmas into wonderings. However, to generate research questions, potential solutions to dilemmas are also needed. While many research questions may include solutions that come from preservice or inservice experiences or from suggestions provided by mentors and colleagues, teacher-researchers seeking to improve practice can also examine existing research related to their wonderings. This section considers how teachers can learn to use the literature as a way to develop research questions based on their dilemmas.

Literature that critiques classroom research often mentions the perceived inability or unwillingness of teachers to make use of existing research in the design of their own studies (Borg, 2009). In some cases this may be because teachers view research as something outsiders do, and thus do not make the connection between the traditional forms of scholarship with which they are familiar, and the classroom research in which they engage (Clayton et al., 2008). Additionally, institutional supports needed to facilitate a thorough review of the literature, such as time, may be lacking (Hahs-Vaughn \& Yanowitz, 2009, Thompson, 2007).

Despite the difficulties teachers often face, making use of existing research is an important part of the classroom research process. It is often this research that allows teachers to develop research questions which are appropriate for their context (Kirkwood \& Christie, 2006). Bartlett and Burton (2006) found that when inexperienced teacher-researchers are able to collaborate with more experienced peers, those who had experience could emphasize the role existing research can play in crafting quality classroom research. Such interactions can help to minimize the apprehension many teachers feel when engaging in background research (Watkins, 2006). Mentoring by university faculty and other academics can serve as another important form 
of support for teachers who have little experience examining existing research (Kosunen \& Mikkola, 2002). Hall (2009) suggests that teachers should be provided with as much autonomy as necessary to make their own choices and that teachers can benefit by discovering their own research questions. However, constructing research questions which are rooted in the literature can be one of the most difficult tasks faced by teacher-researchers, (Burant et al., 2007, Haigh \& Dixon, 2007, Clayton et al., 2008; Postholm, 2009). Clayton et al. (2008), in reflecting on their experiences facilitating teacher research, make explicit the need for an experienced researcher to guide teachers as they develop their research questions. Too often the studies carried out by teachers are not driven by recognized theories, epistemologies, or methodologies, and in these cases it is easier for others to dismiss eventual findings (Baumann \& Duffy, 2001). Atay (2008) suggests that by engaging in classroom research teachers should be empowered to make better use of more traditional forms of research.

The ability to synthesize research is an important step in the classroom research process. By understanding how to make use of existing research, teacher-researchers are able to consider new ideas for their own practice, thereby transforming the wonderings which have emerged from their own dilemmas into quality research questions.

\section{Collecting and Analyzing Data - From Questions to Professional Learning}

Once research questions have been constructed, the next step in the classroom research process is to implement the new practices that are being studied. In addition, if classroom research is to lead to findings which can potentially address dilemmas, not only does the practice being studied need to be implemented properly, but there must also be a suitable methodology used to examine the effectiveness of the practice in the teacher's classroom. This section 
examines the importance of making use of an appropriate methodology, and the ways in which executing this methodology can lead to an improved understanding of practice.

As with all research, the quality of eventual findings is highly dependent on the methodological choices made by the researcher to guide data collection and analysis. Without an understanding of the depth and complexity of the methodologies that guide the research process, frustration can dissuade teachers from making use of classroom research as a viable tool to improve their practice and their students learning (Galletta \& Jones, 2010). By learning the methodologies necessary to engage in the study of their own practice, teachers can begin to move beyond "logistical and managerial" tasks, and can instead focus more intently on tasks which explicitly consider "student learning outcomes" (Dawson, 2006, p.266). In some cases, this may lead to an improved ability to make data-based decisions (Bradley-Levine, Smith \& Carr, 2009). In other cases, the advantage of engagement with systematic data collection may improve a teacher's overall ability to properly organize information such as student performance records (Brookhart, et al., 2010). This suggests that the skills necessary to properly conduct classroom research are also transferable to other teaching tasks.

Given the usefulness of methodological skills for other teaching purposes, by engaging in properly developed classroom research studies, teachers are able to better problematize their practice and the learning of their students. The ability to construct new professional knowledge that is contextually relevant is described by Orland-Barak (1991, p.112) as a "paradigm of change." This paradigm of change is manifested by a willingness to engage in the "practice of variety" (p. 126). These two concepts provide a strong rationale for the benefits of engaging in classroom research. By examining the classroom research of practicing teachers, Capobianco \& Feldman (2006) illuminate the need for greater development of research skills in teacher 
education programs. By learning how to systematically collect and analyze data, preservice teachers are able to consider pedagogies they are being taught in university coursework and then examine the viability of these pedagogies in field placements (Keyes, 2000).

By putting what they learn into practice, teachers are often able to better connect with their students. McGee and Lawrence (2009) indicate that classroom research can also improve the ability of practicing teachers to situate learning into practice. Through a series of case studies culled from classroom research completed during a graduate course, Rogers et.al (2007) found that classroom research led to improved teacher-student relationships. One case illustrated how a teacher was able to improve relationships with students by providing opportunities for student voice before making important decisions that might impact student learning. These kinds of relationships can be fostered when teacher-researchers realize the importance of better addressing the needs of individual students, and are willing to act on these realizations (BradleyLevine et al., 2009). Sweeney (2003) spent several months exploring the changing relationships between a chemistry teacher engaged in classroom research and his students. The transformation in these relationships was evident in classroom conversations as the teacher was able to reflect on his practice, realize the difficulties students faced in understanding difficult concepts, then develop new ways to communicate these concepts with his students. By understanding the methodological choices which must be made while engaging in classroom research, and by practicing data collection and analysis, teachers can become more adept at both trying new practices in their classrooms, and considering the strengths and weaknesses of those practices which they have been directed to implement as part of school-wide initiatives.

By reflecting on existing practices and engaging in systematic research on new practices, teachers can assume an important role in enhancing student learning. Zeichner and Liston (1996) 
note that teachers who can both reflect on and research their own practice are more suited to be responsive to student needs. Further, by learning how to engage in classroom research, teachers become more able to consider viable solutions to real-world problems (James, 2006; Sweeney, 2003). Through reflection on dilemmas, the use of existing scholarship, and an understanding of the methodological skills necessary to conduct more formal inquiries, the process of classroom research can lead to many positive outcomes (Keyes, 2000).

\section{The Outcomes of Classroom Research}

The literature on classroom research suggests a myriad of outcomes for those teachers who systematically study their own practice. While there is only limited research which points to the types of outcomes often associated with traditional forms of research (i.e., measurable student learning gains), more commonplace are outcomes which are intrinsic to the teacherresearchers who engage in classroom research. It is postulated that these outcomes have the potential to lead to improved professional practice, which can in turn lead to the types of measureable outcomes coveted by policymakers (Prestage et al., 2002). This section explores the benefit of contextualized professional learning through classroom research and the ways in which this learning can potentially contribute to the learning of others.

\section{Contextualized Professional Learning}

As with any form of research, classroom research that is properly conducted has the potential to lead to new professional knowledge. The knowledge constructed through classroom research has the added benefit of being highly contextualized, and can also lead to increased selfefficacy and a desire to pursue further avenues for professional learning. This section considers the role of classroom research in constructing new knowledge, and the ways in which this learning can provoke teachers to place greater value on the knowledge they construct. 
Many teachers often question the relevance of their preservice and inservice learning experiences. Unlike traditional courses and inservice experiences, classroom research is viewed by many as an authentic and job-embedded form of professional development (Christenson, 2004; Thompson, 2007). In many cases, funded projects provoke classroom research that leads to professional learning. Many teachers who engage in classroom research center their work on the various curricula they are asked to implement. Through investigating programs designed to encourage practices such as formative assessment (Haigh \& Dixon, 2007), literacy interventions (Corden, 2002) and writing instruction (Moss et al., 2008), teachers have been able to better understand the ways in which these programs can best be implemented in the classroom. In reporting on their work with seven teachers in a discussion group formed to examine curricular initiatives, Bartlett and Burton (2006) note teachers eventually were able "to be more critical of what was presented as an officially sanctioned approach." The authors then suggest that this allowed the teachers to "be more confident in how they developed their classroom practice" (p.402). In this way classroom research can illuminate the practical expertise of teachers which is so often lacking when research-based initiatives are scaled-up after demonstrating small-scale success (Desimone, 2002; Ruthven, 2005). While classroom research can be used to examine the often prescriptive teaching practices implemented in response to external funding, in some cases classroom research is the practice which has been prescribed through such funding.

Given the necessity of writing program reports when receiving funding, it is not surprising that many of the articles which have been published about classroom research are narratives of funded teacher research programs. Often, funded programs designed to bolster the professional learning of teachers prescribe classroom research experiences (Christenson, 2004; 
Thompson, 2007). Especially prevalent outside of the United States, government grants have been used to provide resources to collaborative teacher research endeavors. Such projects are especially commonplace in the United Kingdom, as the British classroom research movement appears to be responsible for much of the knowledge base which provides evidence of the professional learning that occurs through teacher research. Studies from divergent locations such as New Zealand (Cardno, 2006), Finland (Kosunen \& Mikkola, 2002), Turkey (Atay, 2008) and Australia (Grushka et al, 2005) also confirm the positive effect classroom research has on teachers. Whether provoked by practices which are the result of external forces, or by an individual teacher's interest in improving their own practices, classroom research can help teachers value the learning that occurs through studying practice.

Once teachers understand the purposes and processes of classroom research, they can begin to change how they view themselves as professionals. Change, in this sense, is not confined to explicit learning around classroom practice. Significant evidence exists to suggest that teacher-researchers often demonstrate high levels of self-efficacy (Brookhart et al., 2010). These shifts, which can be gleaned from analysis of artifacts such as research diaries, suggest that the research process can lead to greater enthusiasm for teaching (Atay, 2008; Brown \& Macatangay, 2002). Such enthusiasm can lead to greater confidence as teachers recognize their own expertise as professionals (James, 2006). Through this sense of empowerment, teachers have greater confidence in their abilities to carry out professional duties (Bradley-Levine et al., 2009).

In the process of improving self-efficacy, classroom research has the potential to also provoke teachers to reenter the academy and pursue advanced degrees that more heavily emphasize research. Some of the doctoral students interviewed by Pilkington (2009) indicated 
that, in addition to wanting another degree, they were drawn to an inquiry-driven program because of the benefits they saw to their professional learning and their efficacy. Murray (2010) goes a step further in suggesting that for doctoral students with a background in practice, research on their university teaching can provide the impetus for a sound dissertation that leverages an advanced understanding of practice to support a less sophisticated understanding of research. This is not to suggest however, that there should not be a strict set of quality indicators that are used to help guide both the creation and evaluation of classroom research. Instead, the notion of action research (whether in a classroom or otherwise) as a viable form a scholarship is one that should become more pervasive in university settings (Avis, 2003). This may be especially true for research done in classroom settings, as both traditional forms of research and classroom research can contribute to the pedagogical content knowledge of researchers (Paulsen, 2001).

Given the contextualized nature of the learning which occurs through classroom research, many teacher-researchers begin to see the importance of constructing new knowledge. This knowledge may be designed to question practices which are teacher-designed, or those that are the result of mandates. Further, an appreciation for knowledge construction may change the way a teachers sees themselves professionally. This greater sense of professionalism may lead to further study, and can also provoke teachers to begin to seek out ways to share their work with others.

\section{Making an Impact outside the Classroom}

While the literature provides us with many concrete examples of how engaging in classroom research can have a positive impact on the professional learning of teacherresearchers, little scholarship exists that indicates how classroom research can impact the 
professional learning of others. However, evidence does suggest that when quality classroom research is shared with others, the potential exists for such work to influence the knowledge base in teaching, as well as the policies which guide practice in modern schools. This section examines the ways in which teachers can share the findings of their research, the impact this sharing can have on the knowledge base for teaching and the need for greater attention to quality if classroom research is to be considered a valuable form of scholarship.

The work of practitioners, especially those working in the public sector, is underrepresented in the literature. A study that examined articles in four of the most well respected school psychology journals found that $90 \%$ of the listed authors had university affiliations, despite data which suggests that academics make up only $15 \%$ of the professionals working in the field (Carroll, Skinner, McCleary, von Mizener, \& Bliss, 2009). Whether through a conference presentation, journal article, or other common mode of research dissemination, or through sharing structures more aligned with traditional teacher professional development, quality teacher research needs to make its way beyond the walls of the classroom in which the work was done. Bartlett and Burton (2006) underscore the importance of teachers sharing their work by suggesting that if the inquiry of a teacher is to be considered research, it must be disseminated in some meaningful way.

In describing their experiences with the Teachers Network Leadership Institute, one of the more well established organizations centered around classroom research, Rust and Meyers (2006) suggest that sharing the findings derived from one's work is perhaps more beneficial than any other step in the research cycle. Hall (2009) found that through sharing, teachers really begin to see themselves as both creators and consumers of knowledge, rather than just the latter. Further, by sharing their work, teachers also become more inclined to learn about the work of 
others, which can also serve as a strong form of professional development (Clayton et al., 2008). Finally, classroom research can be used to address policy directives, including those which are a product of standards-based learning reform.

Classroom research is one way to consider policy directives and provide feedback to policy-makers. In Philadelphia, for example, teachers have used classroom research for over 20 years to help accomplish various educational and political goals, depending on the political climate (Lytle et al., 2009). Classroom research can be used to share practices aimed at meeting higher standards, and can also guide the creation of new educational theory (Foreman-Peck \& Murray, 2008). Such conceptions appear to be pervasive in various places where education policy mirrors the standards-based reform common in the United States. Scholarship advocating for the use of classroom research to directly guide policy development in Ethiopia (Hussein, 2007), Chile (Montecinos, 2009), and South Africa (Robinson, 2009) has been conceptualized. Further, classroom research can allow global practices to have greater local and situational generalizability for teachers who implement practice (Elliott, 2007; Ruthven, 2005; Simons, Kushner, Jones, \& James, 2003).

Unfortunately, within each narrative that outlines or describes the potential for classroom research to influence the larger knowledge base and/or policymaking, there is also a discussion about the perceived, and sometimes real, weaknesses of practitioner-driven scholarship (Avis, 2003; Foreman-Peck \& Murray, 2008; Murray, 2010; Paulsen, 2001). As such, those who seek to elevate the perceived value of classroom research must also seek to conduct, facilitate or support work that is of high quality.

Although discussions centering on the perceived poor quality of classroom research are frequently focused on the lack of methodological skills possessed by most teachers, Elliot (2007) 
suggests placing greater focus on "quality-as-experienced" rather than "quality-as-measured" (p.230). Capobianco and Feldman (2006) suggest that constructing a context that can facilitate classroom research is the first step in ensuring quality experiences for teachers. Collaboration is another factor in building quality classroom research experiences (Groundwater-Smith \& Mockler, 2007). This is unsurprising as almost all classroom research-related studies focus on a project which was collaborative in nature. Such collaborative structures should be rooted in both practice-oriented and epistemic-oriented interactions, and should focus on allowing for transparent conversation to occur (Capobianco \& Feldman, 2006; Groundwater-Smith \& Mockler, 2007). Zeichner (2007) believes that if classroom research were to become part of larger research initiatives, these initiatives could simultaneously leverage the intrinsic benefits of classroom research and the methodological strengths of traditional forms of research, thereby creating a space for classroom research in the larger academic community. There seems to be a growing number of scholars who assert that quality classroom research can serve to elevate the status of the teaching profession, however there is a need to devote more time to the study of those indicators that can be used to judge the quality of classroom research projects (Schmertzing, 2007; Smith, 2011).

The findings of classroom research, when the result of a high quality research designs, can benefit many in the education community. Even when teachers do not share their work with others, classroom research has the potential to provide contextualized learning and improve the self-efficacy of those who are willing to address dilemmas in a systematic way. As such, the practice of classroom research is becoming a common part of the learning experiences for inservice and preservice teachers. However, those who provide these learning experiences must be aware of the key structures which can facilitate or inhibit classroom research. 


\section{Facilitators and Barriers to Classroom Research}

In analyzing the literature, several structures emerge that can either facilitate or inhibit meaningful learning through engaging in classroom research, and thus must be provided or avoided by those who facilitate classroom research. First, opportunities for meaningful collaboration need to be provided. Second, sufficient time needs to be available so teacherresearchers can construct and fully explore their research questions. Finally, those who facilitate classroom research must help to address the common tensions inherent in most educational contexts. This section considers these important structures and how they can be developed in a way that supports the classroom research process.

\section{Collaboration}

As with most scholarship in education, much of what is published about classroom research is written by those in higher education who work with teacher-researchers. In many cases, these university researchers have worked with teachers through school-university partnership work. This section considers collaboration by using Jaworski's (2003) framework for teacher-research partnerships. Jaworski outlines four dimensions of teacher-research collaboration: (1) inside/outside, (2) individual/community, (3) knowledge/learning, and (4) inquiry/reflection, each of which can impact the work of teacher-researchers and those who support them.

The first dimension of collaboration suggested by Jaworski, inside/outside, suggests that members of the partnership must have a clear understanding of their role. Where partnerships between teachers and researchers have been successful, there has been an open exchange of ideas (Baumfield \& Butterworth, 2007). These exchanges are such that interactions are collegial, with each participant willing to listen, but also willing to challenge the work of research peers 
(Gewirtz, Shapiro, Maguire, Mahoney, \& Cribb, 2009). Those who come from the outside can also bring additional resources to bear on the partnership, but in doing so, must be careful not to place themselves at the top of a hierarchy in the partnership (Kamler \& Comber, 2008).

The second dimension of Jaworski's model for collaboration, individual/community, emphasizes the nature of collaboration. In some cases, collaborative teacher-research involves a group of teachers coming together to work on a single project, and in other cases the purpose of the group is to collectively support the work of individual teacher-researchers (Jaworski, 2003). In either case, these group dynamics allow the assumptions and beliefs of each individual to be considered and challenged (Allard et al., 2007). These discussions can take place beyond the group, as even in collaborative inquiry, much of the work done will be carried out alone by teachers within their classrooms (Cardno, 2006).

The third dimension articulated by Jaworski, knowledge/learning, emphasizes the outcomes of collaboration. Through collaborative research efforts, there is the potential for each member of the team to learn from the others, and for all members of the team to learn together (Cardno, 2006). These experiences allow for expertise to be built across the group as the learning of each individual, when shared with peers, becomes new knowledge for others (James, 2006). Such experiences can lead simultaneously to the development of an inquiry stance, and to the development of new teaching practices (Postholm, 2009).

The final dimension suggested by Jaworski, inquiry/reflection, recognizes that the conditions needed to formalize reflection and to participate in inquiry are difficult to achieve for a teacher working alone. Collaboration can provide these conditions, and support efforts to reflect and study practice within the context of accountability (Kraft, 2002). However, the success of the individual, even when supported by a collaborative environment, is still ultimately 
influenced by his or her own classroom practice (Jones \& Tanner, 2002). To maximize the potential for effective classroom research supported by collaboration, McLaughlin and BlackHawkins (2007) recommend that such partnerships have "clarity of purpose, invigorating relationships, effective and flexible communication, dissemination, commitment of leadership, and resources (time and money)" (p.336).

The framework outlined by Jaworski makes clear that there are various forms of collaboration which can guide the classroom research process. This framework also underscores the need for those who facilitate classroom research to understand that collaboration has the ability to provide both the pressure and support necessary to encourage teacher-researchers. This collaboration can also help create spaces for sharing, and can maximize the learning that occurs when sufficient time is devoted to classroom research.

\section{Time}

Time is consistently reported as both a facilitator and barrier to teachers engaging in the study of their own practice. Given that time is a scarce resource for most classroom teachers, those who facilitate classroom research should carefully consider how and when teachers can make time for their research endeavors. This section briefly considers the importance of ensuring that teacher-researchers have time to engage in their work.

Research suggests that it is necessary for teachers to have time at each step of the inquiry cycle. This includes having significant time for deep reflection and analysis of the problems that guide classroom research (Cardno, 2006). Hahs-Vaughn and Yanowitz (2009) found that time, along with mentoring, were the only two supports that could significantly predict which teachers were most likely to engage in classroom research. Hall (2009) asserts that it is in fact the amount 
of time available that is most likely to influence teachers' choices as to when they might engage in classroom research.

Because time is such a critical factor in determining the success of classroom research activities, the current pressures faced by teachers are especially problematic. The pervasiveness of mandated activities that often lead teachers to spend time worrying about their own performance often leaves these teachers with insufficient time to seek contextually relevant ways to improve performance (Clayton et al., 2008). According to Orland-Barak (2009), even when teachers are encouraged or required to engage in classroom research, there is seldom enough time provided for such research to be conducted in a way that will produce meaningful learning. While such initiatives may lead to some changes in practice, without the time needed to engage in meaningful data collection and analysis, teachers are unlikely to understand the links between their work and its potential impact on their students' learning (Thompson, 2007). McGee and Lawrence (2009) emphasize the importance of building structures that support classroom research's potential to produce meaningful products.

As with any professional endeavor, time is a critical factor. Research suggests that limited time often adversely impacts the effectiveness of classroom research. For those who facilitate such research, it is important to understand that time is one of the institutional tensions that can influence the success or failure of a classroom research initiative.

\section{Working through Tensions in the Classroom Research Process}

In addition to a need for collaboration and sufficient time, it is important for those who facilitate classroom research to understand that the institutional barriers that may emerge as tensions and inhibit the work of teacher-researchers. As with many other practices that are popular amongst teacher educators, the theories behind classroom research often conflict with 
the practical expectations school administrators have for teachers. Operating under the assumption that teachers should be change agents, Price and Valli (2005) noted that teacher educators need to help preservice teachers reconcile their unique purposes for wanting to provoke change with the tensions that can exist for all teacher-researchers, but that are especially problematic for preservice teachers. Those who help teachers, especially preservice teachers, develop the skills and abilities needed to successfully study their practice need to understand the tensions which often arise as preservice teacher-researchers design, and later implement, their studies. Five tensions are addressed by Price and Valli's (2005) work with preservice teachers: (1) individual/institution, (2) action/understanding, (3) support/challenge, (4) passion/reason, and (5) regulation/emancipation. This section considers the impact of these tensions on teacherresearchers, especially for those who are engaged in classroom research as part of their preservice experiences.

The first tension discussed by Price and Valli is that which exists between the individual researcher and the institution that provides the context for their research. When there is institutional support for classroom research, teachers are more apt to see their work as part of a larger culture of change within the school. Poetter et al. (2000) found that preservice teacher research conducted within a supportive institutional context allowed for developing teacherresearchers to find supportive mentors within their classrooms. These mentor teachers were willing to engage in some of the more difficult research activities in an effort to help the preservice teachers they were mentoring. This potential tension highlights the need for those who facilitate teacher research to be sure preservice teachers are placed in contexts where classroom research is supported. 
The next tension noted by Price and Valli exists between action and understanding. Often teacher educators fail to help their students see a continual link between action and understanding. Dawson (2006) noted that for her students, engaging in inquiry led to an improved ability to reflect, but did not necessarily lead to the implementation of new (and better) practices. Lieberman and Miller (2001) suggest that those facilitating the research of preservice teachers can address this tension by encouraging their students to remain in the inquiry cycle continuously. When facilitating classroom research, it is necessary to constantly emphasize the link between what the teacher-researcher is doing, and what is being learned through this action.

Support versus challenge is the third tension Price and Valli found in their work. While many discuss the ways in which classroom research can help teachers feel the empowerment that comes with autonomy, this autonomy can be a double-edged sword (Hall, 2009). Scaffolding, especially during the development of a study, is one of the critical functions of those who facilitate and mentor the classroom research of others (Grushka et al., 2005; Kamler \& Comber, 2008). This support is especially important as teachers strike a balance between their interests as teacher-researchers and the climate of their research context. Even when teachers are prepared to engage in systematic study, additional supports are necessary to allow for classroom research to be conducted within the reality of an increasingly standards-based system of education (Kraft, 2002). Because so much of the work done to help teachers develop research skills is funded through government sources (including at public universities), teacher-researchers must be taught to consider the student outcomes which are products of government programs (Prestage et al., 2003). In guiding the work of teacher-researchers, Dana and Yendol-Hoppey (2009) propose a litmus test for constructing and refining research questions. The last question of this litmus test 
simply asks: "Is it doable?" (p.64). This question helps bring into focus the tensions that often exist between a teacher-researcher's passions and what is practical for them to study.

The fourth tension identified by Price and Valli, is the one that exists between passion and reason. Another of the questions in Dana and Yendol-Hoppey's litmus test asks, "Is [your research question] something you are passionate about?" (2008, p.71). While all researchers generally engage in studies around issues of interest to them, Haigh and Dixon (2007) note that many teachers are not initially interested in considering ways to improve their own practice through classroom research. Often, the framing of classroom research mirrors what Luckcock (2007, p.127) calls "appreciative inquiry." In appreciative inquiry, the reflective process leads to levels of internal understanding that can be described as "the soul of teaching" (p.129). However, if inquiry is seen only as a tool for improving one's own efficacy, it is unlikely that those who suggest that more time be provided for classroom research, will see the implementation of structures necessary to resource this time (Cardno, 2006; Clayton et al., 2008).

The final tension illuminated by the work of Price and Valli, is that which exists between regulation and emancipation. As so much of the foundational work on researching one's practice is rooted in notions of emancipation, it is critical that teacher-researchers not be afraid to take on subjects that may prove controversial (Stenhouse, 1975, 1981). However, and especially for preservice teachers, it is important to frame research in ways that are sustainable within a given context (Cochran-Smith \& Lytle, 2009). However, this does not mean that those dispositions that may serve to later facilitate emancipatory inquiry cannot be considered as part of teacher education programs (Chubbuck, 2010). This tension is most often (as is the case with the work of Price and Valli) seen as a barrier, indicating that perhaps the traditional relationships that support 
preservice teacher research are not strong enough to mitigate potential conflicts between regulation and practices which are inherently emancipatory.

The theoretical purposes which are often used as rationales for helping teachers learn to engage in classroom research can sometimes conflict with the real-world context in which most classroom research occurs. As such, those who facilitate classroom research must understand the institutional contexts of the teacher-researchers with whom they work. Providing support based on these contexts, along with providing ample time and space for collaboration, is an important part of supporting teachers who are engaging in classroom research, especially when working with preservice teachers.

\section{Facilitating Classroom Research in Preservice Teacher Education}

Most studies on facilitating classroom research are based on the experiences of those who work with practicing teachers. While many of the same ideas for facilitating classroom research that are used with practicing teachers can be applied to preservice teachers, there are additional considerations for those working with preservice teachers. Ax et al. (2008) emphasize the importance of integrating the process of classroom research into teacher education experiences. Using their experiences as teacher educators, as well as their research on the teacher research experiences of students in three programs, they conclude that facilitators of classroom research for preservice teachers should: (1) make connections to traditional knowledge, (2) emphasize K12 students' learning, (3) recognize prior research experiences, and (4) integrate research with other teaching practices. This section makes use of these four conclusions to consider how those who facilitate classroom research experiences for preservice teachers might address the needs of their students. 
The first conclusion from Ax et al.'s work is that there must be a connection between knowledge generated through classroom research, and traditional forms of knowledge. This assertion is well supported by consistent findings which indicate that practicing teachers demonstrate an inability to make use of existing research when trying to address their own practice and their students' learning (Borg, 2009; Kirkwood \& Christie, 2006). Given the everincreasing pressure on teachers to show student learning gains, it is important that classroom research be seen as one tool to provide such evidence. However, Prestage et al. (2002) indicate it also important that practices examined during the inquiry process are rooted in existing research. While the purpose of a given study may be to examine the extent to which one solution is viable in the researcher's own context, James (2006) cautions that traditional ways of uncovering potential solutions must not be replaced by a system whereby preservice teachers pull ideas out of thin air and use classroom research to see if they work.

The second conclusion drawn by Ax et al. is that preservice teachers must be encouraged to consider their students' learning. Preservice teachers tend to view the findings that arise from their research in terms of their own learning, while ignoring the extent to which their students may have benefited. Through development of an inquiry stance, a teacher's approach to his or her professional roles will lead to indirect benefits for students (Prestage et al., 2003). However, classroom research still generates findings, and these findings should be considered in terms of the benefit to the preservice researcher's students. Brookhart et al. (2010) echo these findings, calling an increased focus on how a given classroom research study impacts those students who were the focus of the preservice teacher's research.

The third conclusion of Ax et al. (2008) emphasizes the need to consider the prior experiences of preservice teachers when teaching the various skills that guide classroom 
research. Programs that work with groups of preservice teachers often do not consider the prior experiences of the individuals who make up the group. This could perhaps be one of the reasons why some programs designed to both teach classroom research and improve other teaching practices, are only able to accomplish the first goal (Dawson \& Dana, 2007). If the limitations of students' prior experiences with research are not diagnosed in advance, moving beyond the structure of classroom research and focusing on the other classroom practices that the research process can help to develop may prove difficult (Bradley-Levine et al., 2009; Brock et al., 2005).

The final conclusion that arises out of the work of Ax et al. (2008), as well as the finding which is perhaps best supported by other research, is the need for greater integration between research activities and other teacher preparation pedagogical learning experiences. Allowing the process of research and reflection to be a part of early professional learning experiences can provide the necessary foundational knowledge needed to help preservice teachers see the value of engaging in classroom research (Grushka et al., 2005). Further, incorporating research experiences into field placements can allow for the dual roles of mentoring inquiry and supervising teaching to be integrated (Poetter et al. 2000). Finally, by stretching out the learning that is necessary to successfully engage in classroom research, the various attributes of quality research can be taught in chunks that are more manageable for students (Hayes, Smith, \& Curtis, 2010).

Given the complexities that arise at each step of the classroom research process, as well as the likelihood that preservice teachers will find it more difficult to find their way through such complexities, those who work to develop the skills of preservice teacher-researchers must provide systematic and sustained mentoring to their students. This mentoring can be guided by the literature on classroom research, but should also consider specific needs of preservice 
teachers like those pointed out by Ax et al. Providing high quality mentoring can allow new teachers to begin their careers prepared to use of classroom research as a part of their daily teaching routine.

\section{Conclusion: The Impact of Classroom Research on the Development of Preservice Teachers}

The existing literature on classroom research suggests that there is tremendous potential for a system of education in which teachers both construct and consume knowledge. However, missing from the empirical literature is an understanding of the ways in which preservice teachers engaging in classroom research begin to develop those perspectives that allow reflection and action to become a part of their daily work as teachers. Further investigations of preservice teachers' research experiences are needed These studies need to consider both the ability of novice teachers to engage in classroom research and the ways in which both thinking about research and doing research impacts preservice teachers' understandings of what it means to have an inquiry stance. In the final section of this chapter, I consider the relationship between preservice teacher classroom research and teaching practice, drawn from previous research I have conducted and reviewed, to begin addressing gaps in the literature on preservice teacher classroom research. After summarizing this work, I frame my current study by providing research questions designed to address the impact of classroom research on preservice teachers' development of those perspectives which might eventually lead to an inquiry stance.

\section{Rethinking the Relationship between Classroom Research and Practice}

Much of the scholarship on classroom research focuses on the development of teachers who value themselves as professionals, and are able to make informed decisions with respect to teaching practice. In most cases, scholars and practitioners who have both developed and 
examined theories that underpin classroom research, emphasize the importance of reflection as a critical factor in designing and implementing quality classroom research. This emphasis suggests that those teachers, who become the reflective practitioners defined by Schön (1983), can make use of classroom research, and develop perspectives that suggest an inquiry stance as defined by Cochran-Smith and Lytle (1993; 2009).

If preservice teachers are to become reflective practitioners and eventually possess an inquiry stance, they must first begin to see classroom research as a practice that allows them to systematically investigate other teaching practices. Through understanding classroom research as a practice that can improve other practices, preservice teachers may be able to develop perspectives towards inquiry leading to an inquiry stance. My understanding of perspectives towards inquiry is influenced by the concepts discussed in this literature review and presented in Table 2.1.

Table 2.1 Concepts that contribute to the development of perspectives towards inquiry

\begin{tabular}{lc}
\hline Concept & Citation \\
\hline Engages in reflective practice & Schön (1983) \\
Uses real-world dilemmas to frame wonderings & Dana and Yendol-Hoppey (2009) \\
Uses existing research to frame research questions & Kirkwood and Christie (2006) \\
Uses classroom research to address research & Cochran-Smith \& Lytle (1993) \\
questions & Galetta and Jones (2010) \\
Uses a well thought out methodology to guide & Prestage et al. (2003) \\
research & Brookhart et al. (2010) \\
Uses data to consider student learning & Rust and Myers (2006) \\
Makes classroom research public & Glanz (1999) \\
Recognizes the cyclical nature of inquiry & Cochran-Smith and Lytle (1993; 2009) \\
Over time, develops an inquiry stance &
\end{tabular}


Only when a teacher understands the purpose of classroom research, and is able to make use of classroom research as a practice, will the reflection and action needed to actualize Cochran-Smith and Lytle's concept of an inquiry stance occur. Thus, if the purpose of making classroom research a part of preservice teacher education is to cultivate a "worldview" and "habit of mind" (Cochran-Smith \& Lytle, 2009, p. 5) whereby reflection and action lead to systemic change in the classroom, further examination is needed that focuses on the development of perspectives and practices that can guide and sustain classroom research.

\section{Preservice Teachers' Reflection through Classroom Research: A Prelude}

The need to consider how preservice teachers develop perspectives towards inquiry through classroom research experiences has been one of my own wonderings. Two years ago, I engaged in a study of preservice teachers' ability to reflect on their classroom research experiences (Smith, Yendol-Hoppey, Milam, 2010). After completing required classroom research experiences, students with whom we worked were asked to reflect on the processes and products of their work. These narratives, written by a cohort of 102 students, were analyzed. The goal of this analysis was to characterize the nature of reflection provoked by engaging in classroom research. This study yielded several assertions: (1) reflectivity was demonstrated at a variety of critical junctures, (2) this reflection led to a variety of shifts in teacher practice, (3) the level of development of an inquiry stance varied, and this variation led to variation in the overall teaching performance of the students. Many of the students indicated that they had greater levels of confidence in their own ability to consider problems of practice, the solutions to such problems, and the ways in which they might critically reflect on changes made as a result of these problems. Further, students indicated that they used reflection throughout the classroom 
research process to help consider the impact that their own work was having on them and their students.

While the findings of this study were encouraging, limitations were also recognized. One limitation was the time when the reflection narratives were constructed. Students had just submitted their final report, and many expressed unhappiness at being asked to complete yet another product related to their research. Further, the narratives analyzed represented student reflection on the process of engaging in classroom research, yet the experiences in place at the time did not align with the theories described earlier in this chapter. As such, students did not have time to engage in substantive reflection, nor the theoretical background to situate their experiences. These limitations served as an important form of evidence to provoke changes to the way students learned about and engaged in classroom research. The findings of this previous investigation, supported by the synthesis of research which appears in this chapter, guided construction of the research questions for this study. Further, the limitations of my previous study, the changes made as a result of that study, and the gaps in the literature on classroom research, provided the purpose for the study outlined in the next chapter.

\section{Guiding Questions for this Study}

Recognizing the gaps in the existing literature, the findings of my previous study, and the necessary development needed for preservice teachers to begin to see classroom research as an important everyday practice, I sought to consider how our students' developed as they learned about, and engaged in, classroom research. To better understand if my students were developing perspectives which could eventually lead to an inquiry stance, I studied the inquiry-related products produced by my students. In doing so, I hoped to find answers to the following questions: 
1. How do preservice teachers' perspectives towards inquiry develop through the process of engaging in classroom research?

2. How do preservice teachers manifest perspectives towards inquiry in practice as they engage in classroom research?

3. What barriers and facilitators impact the development of teachers' perspectives towards inquiry?

The following chapter outlines the methods that guided the study of these research questions. These methods were developed in an effort to generate findings that could further contribute to what is known about the ways in which preservice teachers develop through learning about, and engaging in, classroom research. 


\section{Chapter 3: Methods and Design}

Recognizing the strengths and weaknesses of the existing literature, the findings of my previous study (Smith et. al, 2010), and the necessary development needed for preservice teachers to begin to see classroom research as an important everyday practice, I sought to consider ways in which I might trace how our students developed as they learned about and engaged in classroom research. To these ends, the purpose of this study was to determine the extent to which preservice teachers explicitly and implicitly demonstrated the development of perspectives which could provide the foundation for an inquiry stance, as well as the experiences which contribute to this development. As a result, the research questions guiding this study included:

1. How do preservice teachers' perspectives towards inquiry develop through the process of engaging in classroom research?

2. How do preservice teachers manifest perspectives towards inquiry in practice as they engage in classroom research?

3. What barriers and facilitators impact the development of teachers' perspectives towards inquiry?

To better understand if our students were developing perspectives which could eventually lead them to an inquiry stance, I endeavored to study the inquiry-related products produced by our former students. Through analysis of artifacts produced by one program cohort, I investigated how our students developed perspectives towards inquiry and manifested these perspectives in practice. I also considered the barriers and facilitators to the development of these perspectives and practices. 
I begin this chapter with an outline of the paradigm, theoretical perspective, and epistemology that guided this study. Next, I describe the teacher education program that served as the context for this study, as well as the classroom research experiences that we developed. I then describe the students who served as participants and the products they produced as part of the inquiry strand of their program. I then describe the methods used to collect and analyze the student-constructed products that served as data in the study. I also include a discussion of my relationship to the participants and the extent to which this relationship may or may not have influenced the students' learning processes. Finally, I address the credibility and trustworthiness of this study.

\section{Paradigm, Theoretical Perspective, and Epistemology}

This study is guided by an interpretivist paradigm. In contrast to positivist traditions, Crotty (1998) describes the interpretivist paradigm as one which "looks for culturally derived and historically situated interpretations of the social life-world" (p.67). In his foundational work which helped to develop interpretivist frameworks, Weber (1949) suggested that in the social sciences, inquiry is concerned with understanding a phenomenon rather than explanation. This understanding requires the researcher to move beyond description, and further interpret the phenomenon that they are examining.

As a researcher, I engaged in this study with the understanding that no matter the methodology used, it would be necessary to interpret rather than simply describe the texts used as data. This would be necessary to tease out what Erickson (1986) referred to as the "immediate and local meaning of social actions for the actors involved in them" (p. 129). Further, my understanding of teaching mirrors that described by Borko, Whitcomb and Byrnes (2008), who, in rationalizing the need for interpretivist research on teaching, describe teaching as "a complex 
intellectual endeavor that unfolds in an equally complex socio-cultural context" (p. 1025). Given the presence of these complexities in the activities that generated the data used in this study, as well as in the contexts in which these activities were conducted, the interpretivist paradigm served to guide construction of an appropriate methodology.

While the interpretivist paradigm can serve to situate this study, Crotty (1998) emphasizes the need for methodologies to be framed by both a theoretical perspective that serves as a philosophical stand, and an epistemology that provides context as to the researcher's way of knowing. Koro-Ljungberg, Smith, Yendol-Hoppey and Hayes (2009) illuminate some of the "sloppiness" which often exists in the methodological descriptions of qualitative studies, attributing this lack of clarity to disjointedness between theoretical perspectives and epistemologies (p. 691).

My research made use of constructivism as a theoretical perspective. Constructivism, like other interpretivist frameworks, recognizes that social sciences and natural sciences must be examined differently (Guba \& Lincoln, 1990). Constructivist perspectives make room for the various ways in which individuals construct their own reality (Patton, 2002). Crotty (1998) asserts that "each one's way of making sense of the world is as valid and worthy of respect as any other, thereby tending to scotch any hint of the critical spirit." (p. 58). Because I believed it necessary to emphasize the ways in which individual students understood their own experiences, and to attend to the ways in which individual contexts influenced these understandings, constructivism provided the theoretical basis for the methods used to collect and analyze my data. 
This study is further informed by a constructionist epistemology. Constructionism emphasizes the importance of context to the research process (Patton, 2002). Crotty (1998) expands on this importance, describing constructionism as:

The view that all knowledge, and therefore all meaningful reality as such, is contingent upon human practices, being constructed in and out of interaction between human beings and their work, and developed and transmitted within an essentially social context (p. 42). In making use of constructionism as an epistemology, I recognized that the ways in which the participants interpreted their experiences would influence the ways in which they constructed their narratives. Further, the ways in which I interpreted these narratives would influence the ways in which I constructed my own narrative. As such, in engaging in this study, I operated under the belief that I was studying multiple constructed realities holistically (Lincoln \& Guba, 1985). It was this belief that guided the methodological choices I made throughout the study.

\section{Context}

This study occurred within a five-year teacher education program at a land grant institution. The program admits students prior to their third year of study and successful completion results in a bachelor's degree and a master's degree. The program utilizes a cohort model. Students are admitted to the program only once per year, and courses and field placements for a given cohort are offered during only one semester. Students who drop a course or who do not meet the matriculation requirements must wait a year before re-entering the program. This cohort model allows for experiences to be tailored to each group of students in a given semester, and also allows for a consistent delivery across the cohort.

The program admits students seeking certification in either elementary or secondary education, and provides all necessary coursework and field experiences for certification in the 
state in which the university is located (See Appendix B). In addition to traditional coursework, students complete in excess of 1000 hours of clinical experiences ranging from short volunteer placements completed prior to admission, to field placements of varying length, including a traditional full-time internship during the first semester of students' third year in the program. While traditional course offerings allow for the development of students' dispositions, skills and abilities in various methods and pedagogies, the program also addresses other learning domains through strands. These strands are addressed through practicum seminars which allow for discussion of key concepts and ideas, along with experiences and activities designed to be embedded in field placements.

Of particular importance to this study is the program's Inquiry Strand. The inquiry strand is designed to develop an understanding of systematic study of teaching practice. In this strand, students participate in on-campus seminars, design and develop classroom research studies of varying length and scope, and collect, analyze and report on data related to the research questions that guide their studies. The seminars and related activities, which increase in depth and complexity over time, allow students to problematize their teaching and their students' learning, as well as to explore potentials ways to address the felt difficulties they faced in their field placements. Students develop and conduct the research for their final classroom research project, as well as write their report, during the same semester as their full-time internship experience. Further, small group seminars preceding this semester address the processes and reasons for conducting classroom research and include the construction of small-scale inquiry projects, aligned with other components of the related field placements. Finally, a single university supervisor is responsible for the supervision of students' work related to the inquiry 
strand, and also serves as a facilitator for the seminars and practicum experiences which guide this work.

It should be noted that the inquiry strand had recently undergone extensive changes and that the group of students in this study comprised the first cohort to matriculate through the redesigned strand. In the first year, most of the changes were theorized and for the first time seminars were conducted with students in their first year (third year as college students) in the program (the participants in this study). Figure 3.1 is the slide we used when presenting these changes to faculty. In year two, the students now in year four of their undergraduate studies (the participants in this study) were exposed to key components of classroom research in a hybrid of small (10-12) and large (50-60) group seminars. While students were assigned a facilitator for small group seminars, all products they produced were assessed by two people (Dr. Rutherford and me). Finally, during the semester in which the participants in this study were completing their full-time internship, and completing their final classroom research study, they were each assigned to a small group facilitator. This facilitator was responsible for conducting bi-weekly seminars, supporting student classroom research, and assessing and evaluating student products. There were six such facilitators, each working with approximately 20 students. Dr. Rutherford and I each served as small group facilitators, and four other doctoral students also served in this role.

For the cohort of students whose work served as data for this study, the above system was implemented while they were in their first year of the program. As such, we only met with them a few times during that year. We asked these students to collect data on a lesson they had taught, and to consider wonderings which emerged from this data. Beginning with their second year in the program, the students in this cohort were organized into small groups. Elementary and 
secondary majors were separated, but otherwise the specializations within a given group were heterogeneous.

Over the course of this year (2009-10), students attended seven seminars in which topics such as constructing research questions, searching the literature, planning, data collection and analysis, and sharing findings were discussed. Readings were assigned and students completed admission and exit tickets designed to integrate readings and seminar discussions with students' practicum experiences. Students attended seven seminars during the fall of their final year in the program. These seminars were constructed almost exclusively in small groups of around 20 students (there was a whole cohort introduction and part of a seminar on data analysis was

Figure 3.1. Presentation slide used to demonstrate stance development in the inquiry strand

\section{Developing an Inquiry Stance}

\begin{tabular}{|l|l|l|l|}
\hline Tutor Wonderings & $\begin{array}{l}\text { Participant } \\
\text { Inquiry 1 }\end{array}$ & $\begin{array}{l}\text { Participant } \\
\text { Inquiry 2 }\end{array}$ & Intern Inquiry \\
\hline $\begin{array}{l}\text { Focus on } \\
\text { identifying } \\
\text { passions and } \\
\text { developing } \\
\text { those into } \\
\text { fruitful areas } \\
\text { for further } \\
\text { inquiry }\end{array}$ & $\begin{array}{l}\text { Focus on learning to inquire by } \\
\text { doing inquiry in current } \\
\text { classrooms. Connect inquiries } \\
\text { to felt difficulties and course } \\
\text { assignments. Collaborate } \\
\text { closely with host teachers and } \\
\text { liaisons. }\end{array}$ & $\begin{array}{c}\text { Develop focus base } \\
\text { on classroom and } \\
\text { building level } \\
\text { needs in close } \\
\text { collaboration with } \\
\text { host teachers and } \\
\text { liaisons. }\end{array}$ \\
\hline
\end{tabular}

Final Report

Describe all wonderings / inquiries with focused reflection on their development as teachers utilizing an inquiry stance. 
conducted in a large group setting) primarily designed to support students as they conducted their final classroom research study. Students received feedback as they went through the steps which had served as topics for the previous year's seminars. The details of the activities which were supported by these seminars are described in the next section. In addition to learning the processes of conducting classroom research, significant time was spent on considering the importance of classroom research as a viable practice. These discussions helped to develop the concept of inquiry stance as defined by Cochran-Smith and Lytle, and framed the syllabus that guided all of the experiences in the inquiry strand (See Appendix C).

An important factor related to the context of the program is its affiliation with a Professional Development School (PDS) network. Each student in the program is placed at one of 30 PDS which make up the partnership. Teitel (2003) defines PDS as "innovative types of school-university partnerships designed to ... bring about the simultaneous renewal of schools and teacher education programs" (p. 2). While there are many components of PDS partnerships, of greatest importance to this study is a focus on classroom research, which is often referred to simply as inquiry in the PDS literature.

Basile and Sands (2009) consider classroom research a critical form of human capital which PDS can help to build. In constructing standards for PDS Partnerships, the National Council for Accreditation of Teacher Education (NCATE, 2001) emphasizes inquiry as a way to: (1) identify and meet student learning needs, (2) affect the learning of teacher education candidates, and (3) determine the professional development agenda of partner schools. The importance of classroom research to the mission of PDS partnerships is also emphasized by the National Association of Professional Development Schools (NAPDS, 2008) in the nine essentials which they provide as a framework for defining PDS. This document states that PDS 
partnerships must "engage in and publically share the results of deliberate investigations of practice by respective participants" (p. 6). Among these participants are preservice teachers placed in PDS as part of their university preparation program. These frameworks guided the program which served as the context for this study as well as the design of the inquiry strand, and as such, engagement in classroom research was a critical practice for students in the program to both learn about and engage in.

\section{Selection of Data Sources}

One of the more challenging aspects of designing this study was deciding which products to utilize as data sources. Each of the 110 students in the cohort completed multiple products of varying length and purpose. These included admission and exit tickets (see Appendix D) assigned before/after seminars, two small scale classroom research activities completed during students second year in the program (See Appendix E), an internship inquiry (classroom research project completed while in the full-time internship) (See Appendices F, G, \& H for the description, template and rubric used for this activity), the research briefs which guided each inquiry project (See Appendix I) and an inquiry synthesis essay assigned during the students' last semester in the program (See Appendix A). In addition, students were asked to provide feedback on their experiences throughout the program, and participated in an audio-taped debriefing at the beginning of their final semester of the program.

To facilitate the process of determining which student products to utilize, prior to beginning this study, I asked each small group facilitator to provide the names of two students: one who they believed understood the overarching purpose of inquiry, and one who seemed to struggle with the purpose of inquiry. I took the names, along with two students I selected from my small group, and began to examine all of the products they developed across the three years 
they had been in the program. Using open coding, I began to look at various products for each of the students $(\mathrm{n}=12)$ in this exploratory sample. As I began this process, I quickly realized that there was very little consistency across the group. I noticed that in many cases, products were illsuited to making inferences around a student's understanding of the purposes of inquiry. Through this analysis, I began to discover that formal products, rather than seminar-related activities or admission/exit tickets, provoked students to produce narratives which could allow for analysis of their progress in developing perspectives towards inquiry. I further realized that even in these more formal products, specific portions of the narrative were more suited to analysis for this study than others.

The most helpful data for exploring my research questions was provided by the inquiry synthesis essays. In the semester following their full-time internship, students enrolled in a course called The Teacher as Leader (See Appendix $\mathrm{J}$ for the syllabus). One of the activities in this course asked students to construct a 2000-3000 word essay around their experiences in the inquiry strand of the program. The students were asked to consider what they learned about inquiry through classroom research, their teaching and their students, how inquiry had impacted their teaching practice, and how they planned to use inquiry in the future. Further, students were asked to talk about how engaging in inquiry had proved difficult for them. In doing so, students were asked to make specific reference to their various inquiry products, as well as to specific experiences that had guided their understanding and use of inquiry.

The inquiry synthesis essay was described on the syllabus for The Teacher as Leader, and students had three months to construct their essays. Although their instructor for the leadership course may have been different than their small group facilitator, this activity was submitted to the small group facilitator for assessment. This activity was assessed holistically, 
and an emphasis was placed on providing supporting evidence for responses to each of the essay's six prompts (See Appendix A).

Through this exploratory analysis, designed to provide focus to my study, I determined that the research design would benefit from examining a specific product for the cohort as a whole, rather than examining all of the products for a smaller number of students. Within this structure, the synthesis essays seemed to have the best potential to provide answers for my research questions. This approach would allow me to better understand the extent to which preservice teachers' develop perspectives toward inquiry through the process of engaging in classroom research; how these perspectives towards inquiry were manifested as preservice teachers engaged in classroom research; and what the barriers and facilitators were to the development of perspectives toward inquiry.

\section{Participant Selection}

The participants in this study were students in a five-year teacher education program. These students, representing one cohort of the program, included 110 preservice teachers. The group began in the program the same year that I began working with the inquiry strand. These students were initially exposed to classroom research as part of a single seminar during their first year in the program. During their second year in the program, they attended seven seminars related to the inquiry strand, and completed an inquiry-related activity during each semester which was embedded in their field placements. During their final year in the program, these students, while enrolled in their full time teaching experience, designed a classroom research study, implemented their study, and constructed a report for their study. During their final semester in the program, students presented their work at a university-sponsored conference and 
at their placement school. Students were also asked to reflect across their program experiences and construct an essay synthesizing their experiences related to the inquiry strand.

Of the 110 students in the program cohort, 83 students agreed to participate in the study. Prior to the end of their final semester, I provided each student with an informed consent document (See Appendix K \& L for the cover letter and informed consent document). These documents were collected by a colleague, placed in sealed envelopes, and were not opened until after the students had graduated. I took this step to ensure students did not feel compelled to participate if they were uncomfortable. While all students had completed the synthesis essay, seven students explicitly declined to participate, and an additional 21 did not return the informed consent document. Of the 83 students who provided informed consent, 60 were female, and 23 were male. Eighty-two of the students were Caucasian and one of the students was AfricanAmerican. There was a fairly even distribution between elementary education majors (43) and secondary education majors (40). All of the students graduated with their Master of Arts Degree in May of 2011.

\section{Data Collection}

The inquiry synthesis essays used as data in this study were naturally occurring artifacts of our students' coursework. All documents were submitted electronically, and copies were retained. The essays that I examined had been assessed holistically and feedback had been provided by one of the small group facilitators. So as not to be influenced by this feedback, I examined clean copies of students' work removing all names and instructor feedback. I then saved each document, changing the file names to a random number that allowed me to organize data for analysis, while maintaining students' anonymity. 


\section{Data Analysis}

In this study, I sought to understand the ways in which students developed perspectives towards inquiry through their engagement in classroom research. I examined students' written products, which served as narratives for my study. Reissman (1993), in writing about narrative analysis, notes that while researchers do not always agree as to the definition of a narrative, they are, in general terms, stories which follow some logical sequence. Further, narratives may be stories told in traditional written form, or expressed in other verbal and non-verbal forms (Patton, 2002).

Labov (1972) identifies six elements present in narratives: (1) an abstract which summarizes the narrative; (2) text which provides the orientation of the narrative (i.e. time, place, etc.); (3) text which provides the complicating action; (4) text which serves as an evaluation of the complicating action; (5) a resolution which provides the narrative's outcome; and (6) the coda which often ties the narrative to the present. Through examination of each element in a narrative, the ways in which participants organize their own experiences, including the social interactions which guide these experiences becomes visible (Gall, Gall \& Borg, 2007). Given my research questions and the story-like nature of the inquiry synthesis essay, narrative analysis emerged as an appropriate analysis tool for this study.

Grbich (2007) identifies two distinct types of narrative analysis, socio-linguistic and socio-cultural. Socio-linguistic analyses focus on the ways in which meaning is communicated through the structure of a narrative, and as such, are more likely to make explicit use of the elements described by Labov. Socio-cultural analyses examine the broader frameworks that are used to make sense of particular incidents in peoples' lives. In this study, I made use of sociallinguistic narrative analysis to examine the multiple stories embedded in each written text. In 
doing so, I examined both the content of the story, and the story's context to consider how a student made sense of his/her own experiences with classroom research (Grbich, 2007). This process allowed me to compare the stories of different students, in different contexts, and across different experiences, in an effort to better understand the different ways students organized and characterized their experiences (Patton, 2002). Through this type of analysis, I sought to see variation in the ways in which students constructed their narratives, and through this variation, understand in what ways preservice teachers develop perspectives toward inquiry through the process of engaging in classroom research; how these perspectives towards inquiry manifest themselves as preservice teachers engage in classroom research; and what barriers and facilitators exist to the cultivation of perspectives toward inquiry.

\section{Coding of Documents}

In examining the inquiry synthesis essays, I searched for evidence of systematic and intentional study of teaching practice by searching for text which explained either the ways students understood classroom research, or the ways in which they used classroom research. Additionally, I identified examples of text which could be considered evidence of understanding or misunderstanding the perspectives that underpin classroom research. I also searched for the ways in which participants' classroom research impacted, or was impacted by other teaching practices. Finally, I identified any conditions reported in the narratives that served as barriers or facilitators to learning about or engaging in classroom research.

In making use of narrative analysis, I focused on text which represented each of the six narrative elements defined by Labov. Abstract elements were used to frame the underlying theme of each essay. Elements contributing to orientation were used to frame students' perceptions of their contexts, including text which described their clinical placements. Text which provided 
complicating action was examined to key experiences which shaped students' understanding of classroom research and its purposes. Evaluative elements were used to consider the ways in which students responded to complicating action. These responses included shifts in understandings about classroom research, teaching, and teaching practice. Elements which provided resolution of complicating action were examined as well. While evaluative elements served to guide shifts in understanding, resolutions were used to consider shifts in practice. Shifts in beliefs, including those which underpinned shifts in practice were considered as coda in each essay, as these shifts represented students' attempts to situate their learning in the present.

To begin, open coding was used to classify each piece of text. Throughout the analysis of these artifacts, codes were adjusted, collapsed, and/or expanded as necessary. I also engaged in memoing (See Appendix M), writing a brief summary of each essay I analyzed. As I coded, I began to look for themes which emerged across my list of codes.

After using open coding and memoing to examine artifacts, discrepancies emerged between the level of sophistication of some students' perspectives towards inquiry, and their ability to manifest these perspectives in practice. These discrepancies became important to me as I continued to look at data so I began to consider how I might recognize this phenomenon in my coding. After examining 42 documents, I arranged my emerging codes, using the six narrative elements from Labov's (1977) framework (See Appendix N).

In my second round of coding, I examined each of the 83 essays in my data set. I made use of the codes I had constructed and classified under one of the six narrative elements from Labov's framework. I also continued to memo after analyzing each essay, summarizing the narrative, noting specific evidence provided which might help me illustrate findings. 


\section{From Codes to Elements: The Process of Making Meaning}

After completing the coding of these 83 documents, I examined the consistency across text related to each code. This process suggested that I had consistently coded students' essays during my second round of coding. I then examined the narrative element I had placed each code in, examining the consistency across codes related to each element. Through this process, I quickly realized that codes within a given narrative element often represented divergent perspectives and practices. Given that individual codes tended to describe consistent ideas across students, while codes within the same narrative element described different ideas, I began to see the emergence of multiple kinds of narratives embedded in students' essays.

In addition to students' inquiry synthesis essays, which I began to call Life-Long Narratives, students often developed Inquiry Narratives and Classroom Research Narratives. While a student's Life-Long Narrative told a story that detailed multiple dilemmas faced by a preservice teacher, and included the ways in which the preservice teachers addressed these dilemmas, the other narratives focused on a specific dilemma. Inquiry Narratives told the story of a specific instance of how a student used reflection and action to solve a classroom dilemma, and Classroom Research Narratives told the story of a specific instance of classroom research where a student integrated teaching and research, using systematic and intentional data collection and analysis to generate meaningful findings. In some cases, a single dilemma led to the construction of both an Inquiry Narrative and a Classroom Research Narrative. 
Table 3.1: Organization of codes by narrative type and narrative element

\begin{tabular}{|c|c|c|c|}
\hline Codes & $\begin{array}{l}\text { Life-Long } \\
\text { Narrative } \\
\end{array}$ & Inquiry Narrative & $\begin{array}{c}\text { Classroom } \\
\text { Research Narrative }\end{array}$ \\
\hline Previous Understanding of Inquiry & Abstract & & \\
\hline Initial Understanding of Inquiry & Abstract & & \\
\hline Wonderings & $\begin{array}{c}\text { Complicating } \\
\text { Action }\end{array}$ & Abstract & \\
\hline Test Changes in Practice & Evaluation & Abstract & \\
\hline Practices for Inquiry & Evaluation & $\begin{array}{c}\text { Complicating } \\
\text { Action }\end{array}$ & \\
\hline Use of Literature & Evaluation & $\begin{array}{l}\text { Complicating } \\
\text { Action }\end{array}$ & \\
\hline Research Questions & Evaluation & $\begin{array}{l}\text { Complicating } \\
\text { Action }\end{array}$ & Abstract \\
\hline Conflict Teaching-Research & Evaluation & Evaluation & $\begin{array}{c}\text { Complicating } \\
\text { Action }\end{array}$ \\
\hline Data Collection & Evaluation & Evaluation & Evaluation \\
\hline Data Analysis & Evaluation & Evaluation & Evaluation \\
\hline Learning about Students & Resolution & Resolution & Resolution \\
\hline Learning from Students & Resolution & Resolution & Resolution \\
\hline Student Learning & Resolution & Resolution & Resolution \\
\hline Variation in Data & Resolution & Resolution & Resolution \\
\hline Unexpected Findings & Resolution & Resolution & Resolution \\
\hline Impact of Inquiry on Teaching & Resolution & Coda & Resolution \\
\hline Student-Teacher Relationships & Resolution & Coda & Resolution \\
\hline Becoming a Teacher-Researcher & Resolution & Coda & Resolution \\
\hline Use of Actual Data & Resolution & Coda & Resolution \\
\hline Open Ended Process & Resolution & Coda & \\
\hline Best Practice & Resolution & Coda & \\
\hline Reflective Practice & Resolution & Coda & \\
\hline Outcomes from Inquiry & Resolution & Coda & \\
\hline Collaboration in Future & Resolution & Coda & \\
\hline Sharing Findings & Resolution & Coda & \\
\hline Data-based Instruction & Resolution & Coda & \\
\hline Emergent Wonderings & Resolution & Coda & \\
\hline Professionalism & Resolution & Coda & \\
\hline Teaching Inquiry to Others & Resolution & Coda & \\
\hline Inquiry Conference & Resolution & Coda & \\
\hline Other Places/Times & Resolution & Coda & \\
\hline Current Understanding of Research & Coda & Coda & \\
\hline Future Practice & Coda & Coda & \\
\hline
\end{tabular}


By working back and forth between codes that highlighted similar experiences, I was able to organize codes by narrative element and in relationship to the three narratives that emerged. Table 3.1 demonstrates this distribution of codes across these narratives and the narrative elements embedded in each narrative. These three narratives allowed me to interpret the data I analyzed, in ways that aligned with my research questions.

\section{Returning to Codes from the Elements}

After I arranged my codes by narrative and narrative element I was able to relate my data to my research questions. However, to consider my third research question, "What are the barriers and facilitators to the cultivation of perspectives towards inquiry?" it was necessary to work outside the framework of the narrative elements.

To consider the ways in which context, as well as experiences embedded in these contexts, served as barriers or facilitators to students' development of sophisticated perspectives towards inquiry, coding of orientation elements was especially important. In my second round of coding, orientation was used to frame the contexts in which students learned about teaching practice, as well as those contexts in which students actualized their learning. By considering the ways in which students described these contexts, I was able to consider how individual students were influenced by the settings in which they learned. I then considered other factors which seemed to influence students' perspectives towards inquiry. Table 3.2 describes these factors and the codes they aligned with.

Looking at codes rather than narrative elements, and focusing especially on elements of orientation allowed me to also consider the structures that related to development of students' perspectives towards inquiry. By working outside of the narrative elements, I was able to consider barriers and facilitators for all students, regardless of the sophistication of an individual 
student's perspectives. Then, I was also able to consider the ways in which students worked through the barriers they faced. This allowed me to consider answers to my third research question, as I uncovered evidence of the barriers and facilitators to students' development of perspectives towards inquiry.

Table 3.2: Codes used to consider evidence of barriers and facilitators.

\begin{tabular}{lll}
\hline \multicolumn{1}{c}{ Code } & \multicolumn{1}{c}{ Barrier } & \multicolumn{1}{c}{ Facilitator } \\
\hline Writing Report & Context & \\
Issues with Learning Inquiry & Context & \\
Conflict Teaching-Research & Methodology & \\
Difficulty w/ Data Analysis & Methodology & \\
Intimidated by Research & Methodology & \\
Time (During Projects) & Time & \\
Time (Impact on Future) & Time & \\
Difficulty with Wonderings & Wonderings & Context \\
Learning from Facilitator & & Context \\
Learning from Peers & & Context \\
Learning from Mentors & & Context \\
Personal Connections & & Reflection \\
Reflective Practice & & \\
\hline
\end{tabular}

\section{Role of the Researcher}

In assessing the quality of this study, it is important to understand how my role was intertwined with the participants and data, not only as a researcher, but also as a facilitator of participants' learning, critical friend during their experiences, and evaluator of their products. The participants in this study met only with Dr. Rutherford and me during their first year in the program. During their second year in the program, Dr. Rutherford and I facilitated the large group seminars and the two of us provided feedback on all student products. In addition, each student was assigned a small group facilitator. As such, some students worked with Dr. Rutherford or me in these small group seminars, and others did not. During their final year, the students were assigned to one of six small groups. Dr. Rutherford and I primarily worked with 
the same students as we had in the previous year, and other students were assigned to one of the four remaining facilitators - two of whom had served in that role the previous year. One of the remaining facilitators was a former principal, familiar with classroom research, and the other was a former graduate of the program. In addition to this instructional role, I was also involved in the reconstruction of the inquiry strand of the program. I served as a facilitator of seminars, both in small groups and in large. I provided feedback to students throughout the process, and in many cases, it was my evaluation of products that eventually provided the formal grading for students in the strand.

Given that my role extended far beyond that of researcher, it is important to consider how I may have influenced the production of products which served as data in this study, and how I might look at this data given my relationships with the students who produced it. Through this consideration, I do not suggest that my bias was eliminated, nor do I suggest that my bias taints the findings of my analysis. Instead, I venture to illuminate the ways in which my dual role as facilitator and researcher impact this study.

Many of the products which I ultimately utilized for my analysis had already been evaluated by me. As it relates to the design of experiences and products, I recognize that I will always examine student work using the same philosophy and values for research which guide my teaching. As such, my conceptions of classroom research, inquiry as stance, and the role of inquiry and teaching, which I have outlined in chapter 2, influence both my teaching and my research. Even if I selected a group of preservice students I had never met or worked with before as participants, I would still apply the same perspectives as I did with my current sample. Further, even if I had no interest in conducting this study, I would still have made the same decisions in the ways in which I facilitated my students' learning. Thus, while my dual role as 
teacher and researcher was critical to consider as a factor in my data analysis, this study is not designed to examine students within the context of my teaching. Instead, my students served as participants whose work was considered as data in an effort to address the research questions that guided this study.

An additional limitation is that while discovering evidence of students' development of perspectives which could lead to an inquiry stance was the primary goal of this study, it was not the primary goal in the formal assessment of the essays used as data. In some ways, I hoped this could serve as an advantage because there was not pressure for students to make use of the words or phrases which might suggest a more sophisticated understanding of the ways in which classroom research could guide practice. As such, I believe there is a greater likelihood that the text used by students to illustrate their own understanding and development was authentic. However, because of the rigor of producing the products which guided the inquiry strand of the program, there is the risk that students constructed narratives which, because of their own focus on the necessary (and graded) processes of inquiry, did not provide the necessary level of detail for me to effectively determine the extent to which students developed perspectives towards inquiry, or the ways in which these perspectives were manifested in practice through classroom research. Given this limitation, it is important that the findings of this work not be seen in terms of how many students demonstrated various levels of development, but instead what characteristics of individual narratives pointed to this development.

\section{Trustworthiness}

Although my roles as strand designer, facilitator and researcher may be viewed as a limitation of this study, I have attended to a variety of issues of trustworthiness and credibility in the design. While positivists generally subscribe to concrete definitions of reliability and validity 
to determine the trustworthiness of a study, the traditions of narrative analysis allow for the use of consensual validation, whereby a study is trustworthy when its author is willing to construct findings and allow these findings to be examined by other researchers (Lieblich et al., 1998). The reliability of one's work is then judged as others examine the extent to which careful procedures were used. Through delineation of these procedures, others are able to contextualize the findings of a study, and then are able to determine the extent to which they can make use of the findings.

The above description of methodology is designed to provide a clear description of, and rationale for, the use of each set of procedures which guided this study. The short exploratory study described earlier was conducted to allow appropriate data sources to be selected. The use of the inquiry synthesis essays, representative of each student's experiences across the entirety of the inquiry strand of the program, were used to capture data which could address the ways in which these students (and presumably others) might develop (or fail to develop) sophisticated perspectives towards inquiry - the kinds of perspectives that could allow for teaching that realizes the idea of an inquiry stance as defined by Cochran-Smith and Lytle (1993, 2009). The method of analysis selected allowed for examination of narratives which asked students to trace their development through multiple examples. The examples within each text could then be considered together in an effort to provide the more holistic analysis which is prescribed by Lieblich et al. (1998).

As with reliability, it is not necessary to meet an explicit set of criteria in determining the validity of a narrative analysis. Instead, Riessman (1993) suggests that four factors can, in totality, allow for one to determine the value of such an analysis. First among these is persuasiveness, whereby authors bolster the claims made through their analysis by providing significant evidence, including counter evidence. The construction of the findings in this study, 
supported by multiple examples from within narratives that provide a deeper understanding of each finding, serve as evidentiary support for claims which are made.

Riessman also makes use of coherence as a way to ascribe value to a narrative analysis. In doing so, three levels of coherence, global, local, and thermal, as described by Agar and Hobbs (1982) are presented. Global coherence is defined as a way for authors to justify their writing. Local coherence is what the author is trying to effect by writing a narrative, and thermal coherence represents the important themes which are uncovered in the narrative. Agar and Hobbs postulate that more value can be placed on those narratives which seem to have agreement across the three levels. My examination of student work examined the perspectives which guided decisions students made in the classroom research process, as well as the decisions made as a result of this process. These perspectives were supported by student-constructed examples which shed light on these students' own lived experiences. Given this, the coherence of the analysis, at the very least, does not serve to detract from the overall value of this study.

Value in a narrative analysis can also be judged by considering the extent to which the findings have pragmatic value. Riessman defines this pragmatic value as the extent to which the study will be used to guide other studies. The development of research questions to guide this study was based largely on gaps within the literature. Therefore, the findings generated and discussed should prove valuable to those who are interested in studying the ways in which classroom research can serve to help develop perspectives that can lead to an inquiry stance.

The final concept which Riessman suggests as a determinant of value is correspondence, also called member checking (Guba and Lincoln, 1985). Member checking was not practical given that my study began after the students in my sample had left the program. Further, many of these former students are now practicing teachers, and Blackman (1992) notes that it can become 
difficult for those who construct a narrative to judge their earlier work, once they have developed different understandings of the themes which guided development of such work. As such, I decided not to utilize member-checking in this study, understanding that I was still attending to three of the four factors that Reissman suggests bring value to narrative analysis.

In this chapter I have outlined the methods that allowed me to trace how my students' developed perspectives towards inquiry as they learned about, and engaged in, classroom research. The next seven chapters will be devoted to the findings of my study. In Chapter 4, I will provide a description of the three narratives that frame my findings. In Chapter 5 and Chapter 6, I will focus on each of my first two research questions by looking at the ways in which some students were able to develop sophisticated perspectives towards inquiry and manifest these perspectives in practice. In Chapter 7, I will provide evidence of the ways in which some students demonstrated a lack of sophistication in their perspectives towards inquiry or in their ability to manifest perspectives into practice. In Chapter 8 , I will look at the work of one student (who I call Brian) as an example of how it is possible to both demonstrate sophisticated perspectives towards inquiry and manifest these perspectives in practice. In Chapter 9, I will examine the barriers and facilitators that impacted students' development of perspectives towards inquiry. In these chapters, I will make use of Labov's narrative elements to demonstrate how many students constructed multiple narratives that help demonstrate the ways in which their perspectives developed or were manifested in practice. Finally, in Chapter 10, I will synthesis my findings, demonstrated the interconnectedness of my research questions. 


\section{Chapter 4: The Rise of Three Narratives - Developing Perspectives towards Inquiry}

In the previous chapters, I have outlined the purpose of my study, the literature that provides the theory that underpins my methodology and the framework for my research questions, and a description of the methods used in my study. In this chapter, I begin to consider the findings generated from my analysis by outlining a framework, comprised of three narratives, which can be used to view the inquiry synthesis essays that provided the data for my study. As noted previously, each of these essays represents the narrative of one student's journey, as the student learned about and engaged in classroom research. The framework described attends to both the complexity of these narratives and the research questions that framed my study.

\section{One Essay, Multiple Narratives}

In examining my data, I used narrative analysis as a way consider evidence of the development of perspectives towards inquiry, manifestations of these perspectives in practice, and barriers and facilitators that impacted the development of participants' perspectives. The coding process outlined in chapter 3 led me to identify three different kinds of narratives. Further, I found that narratives were related in specific ways. In an effort to clarify the narratives and their relationship to one another, in this section I define each of the three narratives. In doing so, I align each narrative with my research questions and my analysis. I define the elements present in each narrative. Finally, I provide an overview of the ways in which the narratives are connected thereby providing the necessary context for making sense of the findings presented in chapter 5 through chapter 9 .

\section{The Life-Long Narrative}

While the Inquiry Synthesis Essays clearly emphasized the development of individual students' perspectives towards inquiry, a lot of what students wrote about had implications not 
just for thinking about classroom research, but also for thinking about teaching in general. In this way, students were constructing a narrative about the beginnings of their teaching career. Whether teachers engage in classroom research or not, they will routinely face dilemmas that have the potential to lead to classroom research. Therefore, we could expect all teachers, from preservice teachers to recently retired veterans, to possess a Life-Long Narrative that details ways in which they addressed the dilemmas they faced as educators. Thus, the essays I examined can be seen as the very first chapter of our preservice teachers' Life-Long Narratives, comprised of experiences drawn from their three years in the program.

While the actual ways in which students constructed their narratives were divergent and perhaps influenced by the prompts they were provided, almost all students considered the development of their understanding of classroom research across their three years in the program. While some students focused on only one or two specific classroom research experiences, others focused on many experiences. By using Labov's (1972) narrative framework, I could identify how each of the framework's six elements was present in the Life-Long Narratives constructed by our students. Through this analysis, I defined what each element might look like for a preservice teacher-researcher.

In almost every essay, students' described their initial understandings of inquiry. These descriptions can be seen as the abstract of the students' Life-Long Narratives. At the end of each narrative, students generally discussed the evolution of their understanding of inquiry, in light of their classroom research experiences. These discussions serve as the coda for the students' LifeLong Narratives. Because both the abstract and coda of a Life-Long Narrative are influenced by the author's understanding of inquiry at the time they constructed the narrative, each essay 
generally had one abstract and one coda. The other elements of Labov's framework generally appeared in multiple places in each essay I analyzed.

While there was great variation in the number of experiences (i.e. Tutor placement or Internship) shared by individual students, as well as the scope of individual discussions about these experiences, students generally provided evidence of when these experiences occurred. This evidence can be seen as orientation in each student's Life-Long Narrative. For each experience described, there is generally some kind of dilemma provided. Given this, each experience can be seen as having some form of complicating action. In most cases, students also described the process whereby they tried to reconcile dilemmas. These descriptions served as evaluation in the Life-Long Narrative of students. Finally, students talked about the outcomes of their evaluations, focusing on what they learned through these experiences and providing the resolution in their narratives. Figure 4.1 provides a summary of the elements of a Life-Long Narrative.

After I finished my second round of coding, and began to look back at individual narratives, I noticed that in almost all cases, the elements orientation, complicating action, evaluation and resolution often appeared in multiple places in a single essay, and I began to wonder what this said about the nature of each student's Life-Long Narrative. After looking at the ways in which various narrative elements appeared in essays, I began to consider that perhaps there were multiple narratives embedded in each Life-Long Narrative. Through interpreting my coded data, I identified two additional types of narratives that existed in many of the essays I examined: the Inquiry Narrative and the Classroom Research Narrative. In the following sections, I will define each of these narratives, and briefly explain why each is central to aligning my findings with my research questions. 
Figure 4.1. Narrative Elements of a Teacher-Researcher's Life-Long Narrative Life-Long Narrative of a Teacher-Researcher

- Abstract: Scope of understanding inquiry across career.

- Orientation: Complex and changing classroom.

- Complicating Action: Various difficulties and dilemmas.

- Evaluation: Use of INQUIRY to address difficulties and dilemmas.

- Resolution: Outcomes from INQUIRY

- Coda: Life-long impact of being a teacherresearcher on self, students, colleagues and community.

\section{The Inquiry Narrative}

In defining a Life-Long Narrative, I noted that some dilemmas generally served as complicating action, and that the evaluation and resolution of these dilemmas then followed. In returning to my research questions, I wanted to consider how the process of addressing dilemmas provided evidence of students' development of perspectives towards inquiry. For those students who demonstrated sophisticated perspectives towards inquiry, reflection and action were central to the process of overcoming the dilemmas they faced. I began to realize that these students were constructing a different kind of narrative as they told the story of how they attempted to overcome the dilemmas they faced. I refer to these narratives as Inquiry Narratives. In this section, I define Inquiry Narrative and provide a description of the elements of this narrative. 
I define an Inquiry Narrative as the story of how a teacher reflected on a dilemma and then took action including changes in practice and data collection and analysis on this practice in an effort to resolve the dilemma. The work done by teachers who are able to frame these narratives aligns closely with the notion of the reflective practitioner as defined by Schön. Like a Life-Long Narrative, an Inquiry Narrative demonstrates each of the elements of Labov's narrative framework. However, in an Inquiry Narrative, the construction of these elements takes a different form. In the Life-Long Narrative, dilemmas serve as complicating action (e.g. a group of students being unable to complete long division problems). Once a teacher endeavors to use reflection and action as a way to evaluate and resolve their dilemma, this dilemma becomes a wondering, and the teacher then begins to construct an Inquiry Narrative, with the dilemma serving as an abstract for this new narrative (e.g. how can I help my struggling students do longdivision?). The orientation of an Inquiry Narrative is the context in which a dilemma arises that provokes a teacher to begin the inquiry process (e.g. a fourth grade classroom). When, through the literature and other resources teachers are able to turn their wonderings into a research questions, they construct problems which serve as the complicating actions of their narratives (e.g. How will using peer coaching strategies affect my students' ability to do long division?). The actual process of collecting and analyzing data serves as evaluation in the narrative (e.g. trying peer coaching and then looking at students' performance on their quizzes), and the findings serve as resolution of the Inquiry Narrative (e.g. peer coaching seemed to help struggling students being coached, but not the students who were coaching). The coda of the Inquiry Narrative includes the ways in which the process of reflecting on and acting to resolve a dilemma has impacted teacher practice and student learning (e.g. I will make sure that only students who have mastered a concept are asked to peer coach their struggling colleagues). 
Descriptions of how working through a dilemma has enabled a teacher to consider the larger importance of inquiry can also serve as part of the coda, as can descriptions of the ways in which this process has impacted the teacher's school, colleagues and community (e.g. I would now like to collected observation data to understand how students interact during coaching session, especially since my grade-level team was so impressed with my findings). Figure 4.2 summarizes the elements of the Inquiry Narrative.

The ability to develop an Inquiry Narrative suggests that a preservice teacher was able to engage in reflection and action as they sought to evaluate and resolve a dilemma. While constructing this narrative requires teachers to implement new practice, collect and analyze data, and consider how the findings of their analysis can guide their future practice, an Inquiry Narrative does not prescribe the level of methodological depth necessary for classroom research.

Figure 4.2. Narrative Elements of a Teacher-Researcher's Inquiry Narrative Inquiry Narrative

- Abstract: Understanding of inquiry

- Orientation: Context of inquiry.

- Complicating Action: Research question arising from a wondering considered in light of existing research.

- Evaluation: New practice implemented. Data collected and analyzed.

- Resolution: Findings from data analysis.

- Coda: Impact of findings on teacher practice, student learning, understanding of inquiry, colleagues and community. 
When our teachers were provoked to provide this depth, they also constructed the Classroom Research Narratives outlined in the next section.

\section{The Classroom Research Narrative}

In the previous section, I outlined how teachers with sophisticated perspectives towards inquiry make use of reflection and action to address classroom dilemmas and construct an Inquiry Narrative that is embedded in their Life-Long Narrative. However, in this study, I make purposeful use of the phrase classroom research rather than inquiry. In doing so I recognize that while reflection and action are critical to the work of teachers who are reflective practitioners, systematic and intentional data collection and analysis, designed to align with the practice being study, is also critical to the work of a teacher-researcher. For students able to integrate their teaching and research, systematically collecting and analyzing meaningful data as part of the process of resolving their dilemmas, I noted that a Classroom Research Narrative was also being constructed within the Life-Long Narrative of these students. In this section, I define the Classroom Research Narrative and provide a description of the elements of this narrative.

A Classroom Research Narrative is the story of a specific instance of classroom research that uses systematic and intentional data collection and analysis to generate meaningful findings. The work engaged in by teachers able to construct these narratives aligns with the definition of classroom research, emphasizing the "systematic and intentional study" called for by CochranSmith and Lytle (1993, p. 5). When a teacher endeavors to make use of systematic and intentional data collection and analysis as a way to resolve a dilemma, they begin to construct a Classroom Research Narrative. The research question that serves as the complicating action in an Inquiry Narrative then becomes the abstract of a Classroom Research Narrative (e.g. How will using peer coaching strategies affect my students' ability to do long division?). 
In addition to an abstract, a Classroom Research Narrative has each of the other five narrative elements of the Labov framework. The orientation of this narrative is that context in which new practices are implemented and studied (e.g. fourth grade). The complicating action is provided by the complexity of properly attending to teaching and researching simultaneously (e.g. planning for lessons that include peer coaching, and allowing for the collection of observation data during the peer coaching session). When this data collection is properly carried out and aligned with a meaningful analysis, the teacher is able to provide evaluation for their Classroom Research Narrative (e.g. coding observations, looking at individual steps students follow during their quizzes, considering the ways the steps are taught by peer coaches and the ways they are enacted during quizzes). The results of this analysis, when focused on student learning and teacher practice serve as resolution of the Classroom Research Narrative, as does any additional learning about or from students which occurs as a result of systematic data collection and analysis (e.g. peer coaching helped the struggling students, and they tended to follow the steps they were taught. Peer coaches did an excellent job not getting frustrated, and continued to coach their classmates even outside of formal coaching activates). The coda of a Classroom Research Narrative is the author's assessment of the overall quality of the research (this assessment is interpersonal in nature). Figure 4.3 provides a summary of the elements of the Classroom Research Narrative.

In asking the question, "How do preservice teachers' perspectives towards inquiry develop through the process of engaging in classroom research?" I hoped to find evidence of sophisticated perspectives towards inquiry as defined in the literature (see Table 2.1). My analysis provided evidence that some students were able to demonstrate sophistication in some of the elements necessary to construct a Classroom Research Narrative, and some demonstrated 
sophistication in all areas. My analysis suggests that these students have developed the perspectives necessary to provoke them to make use of systematic and intentional classroom research to address the dilemmas they face.

Figure 4.3. Narrative Elements of a Teacher-Researcher's Classroom Research Narrative

\section{Classroom Research Narrative}

- Abstract: Research question.

- Orientation: The research context.

- Complicating Action: Engaging in meaningful teaching and research activities simultaneously.

- Evaluation: Meaningful data analysis.

- Resolution: Impact of findings on teacher practice and student learning.

- Coda: Quality of the research.

In asking the question, "How do preservice teachers manifest perspectives towards inquiry in practice as they engage in classroom research?" I hoped to find evidence of classroom research that involved systematic and intentional data collection and analysis. My analysis suggested that some students were able to demonstrate sophistication in some of the elements of the Classroom Research Narrative. Other students were able to demonstrate sophistication in all of the elements of the Classroom Research Narrative, thereby demonstrating an ability to engage 
in systematic and intentional study as a way to examine their own practice, and an ability to use data to determine the impact of their practice on their students' learning. In the next section, I demonstrate how my analysis indicated that these skills might be integrated into a Life-Long Narrative and be guided by an Inquiry Narrative.

\section{Integrating the Three Narratives}

The essays of each student in my study can be considered a Life-Long Narrative, however, only a handful of students demonstrated an ability to embed both Inquiry Narratives and Classroom Research Narratives into the Life-Long Narratives they constructed. In some cases, students did not write about some of the elements of an Inquiry Narrative or Classroom Research Narrative which could allow me to consider the students' overall ability to construct both narratives. In other cases, students addressed the elements of each kind of narrative, but in doing so provided evidence that they lacked the perspectives or practices necessary to construct an Inquiry Narrative and a Classroom Researcher Narrative. In this section, I consider how the three narratives connect, thereby allowing for my findings to point to ways in which this connection might be made, and ways in which it might be disrupted. Understanding this connection is important because the interrelatedness of each of the narratives helps us to understand the necessary connections between perspectives and practices that preservice teachers must make, if they are to become teacher-researchers.

In defining the Life-Long Narrative, I defined dilemmas as complicating action, the process of trying to reconcile dilemmas as evaluation and the learning that occurs when trying to reconcile a dilemma as resolution. Given this format, when the process of trying to reconcile a dilemma leads to inquiry, the Inquiry Narrative becomes the evaluation of that part of the LifeLong Narrative. Further, because the resolution (and perhaps the coda) of the Inquiry Narrative 
involves making use of the learning that occurs through reflection and action, the resolution of the Inquiry Narrative becomes the resolution for that part of the Life-Long Narrative as well. This interrelationship is illustrated in Figure 4.4. Thus, the process of engaging in inquiry is one way to evaluate and resolve complicating actions faced in a career. Because there will be many dilemmas over a career (in fact even in our preservice teachers' essays there are often multiple dilemmas), a finished Life-Long Narrative would be expected to have many, many Inquiry Narratives, if the author of the Life-Long Narrative was indeed a reflective practitioner.

Figure 4.4. Relationship between Life-Long Narrative and Inquiry Narrative

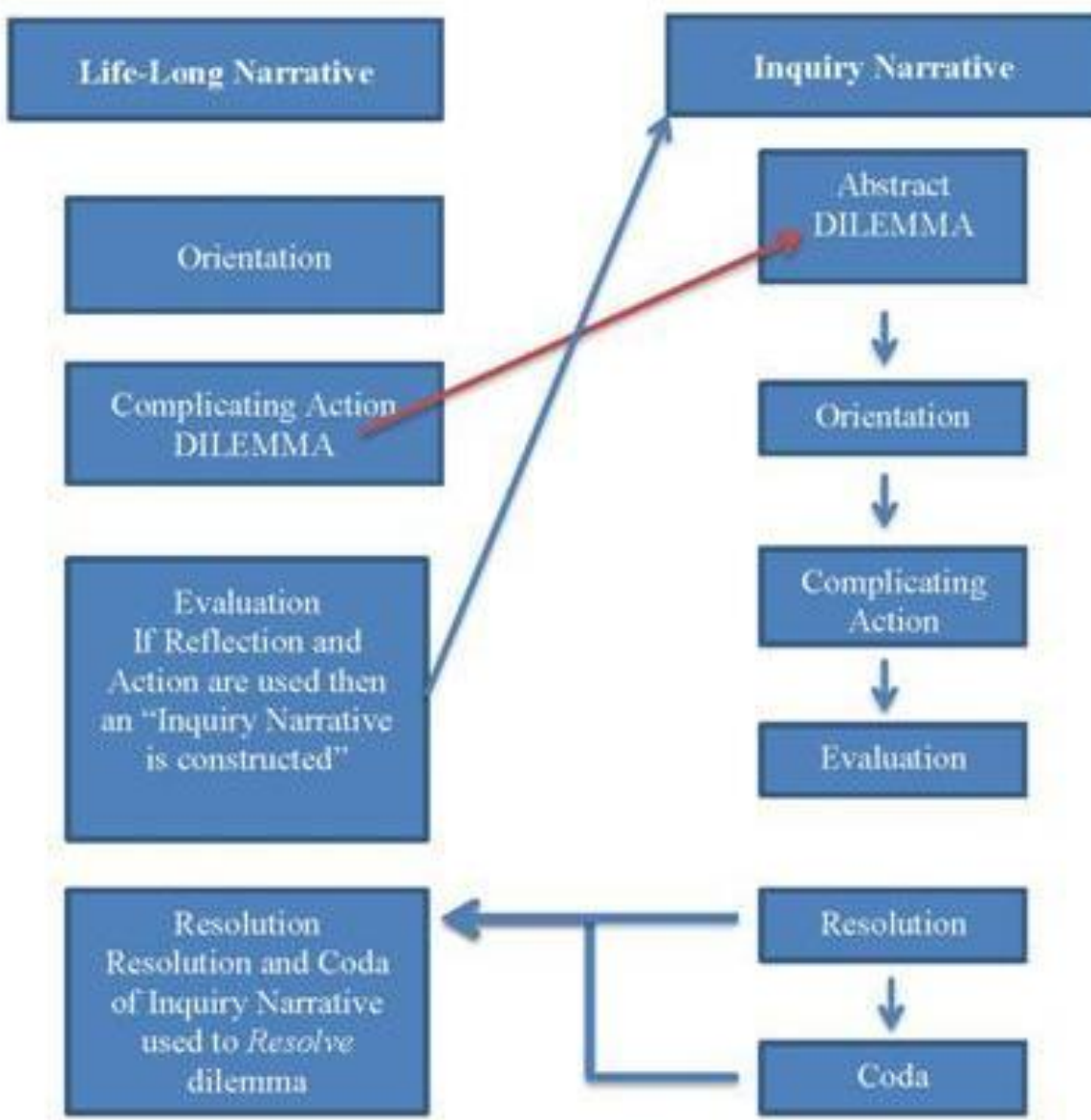


In defining the Inquiry Narrative, I defined research questions as complicating action, the actual process of collecting and analyzing data as the evaluation of the narrative, and the findings, as well as the way these findings serve to impact future practice as resolution of the narrative. Given this format, when the process of inquiring into a dilemma leads to classroom research, a Classroom Research Narrative is constructed to evaluate the research question that serves as the complicating action of the Inquiry Narrative. Further, because the resolution of the Classroom Research Narrative is the learning that occurs as a result of systematic data collection and analysis, this becomes the resolution of the Inquiry Narrative as well. Therefore, for each Inquiry Narrative constructed, a single Classroom Research Narrative can also be constructed (See Figure 4.5).

The Life-Long Narrative of a teacher will include dilemmas as complicating action. If the teacher has sophisticated perspectives towards inquiry, these dilemmas can be evaluated and resolved through reflection and action. If the teacher is able to engage in the practices necessary to act on their reflection, an Inquiry Narrative will be constructed. Further, if the teacher is able to manifest their perspectives towards inquiry in practice by using classroom research to integrate teaching and research, and systematically study the research questions that serve as complicating action in the Inquiry Narrative, then a Classroom Research Narrative will also be constructed. In these cases, the three narratives come together as demonstrated in Figure 4.6. My data suggests that few of our students demonstrated an ability to construct all three narratives. These findings, which are supported by evidence from students' inquiry synthesis essays, are presented in the next five chapters. 
Figure 4.5. Relationship between Inquiry Narrative and Classroom Research Narrative

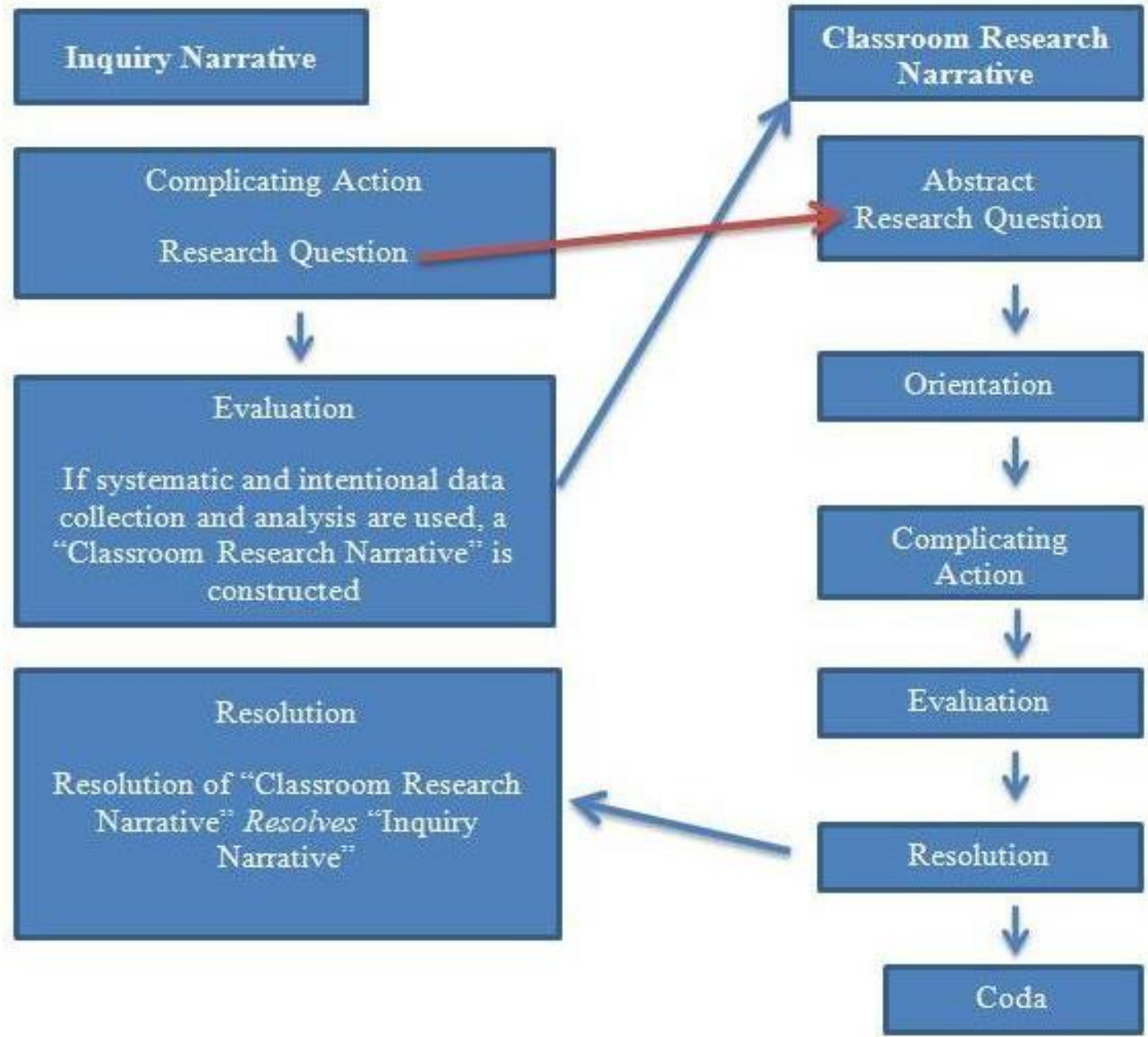


Figure 4.6. Integration of Life-Long Narrative, Inquiry Narrative and Classroom Research Narrative

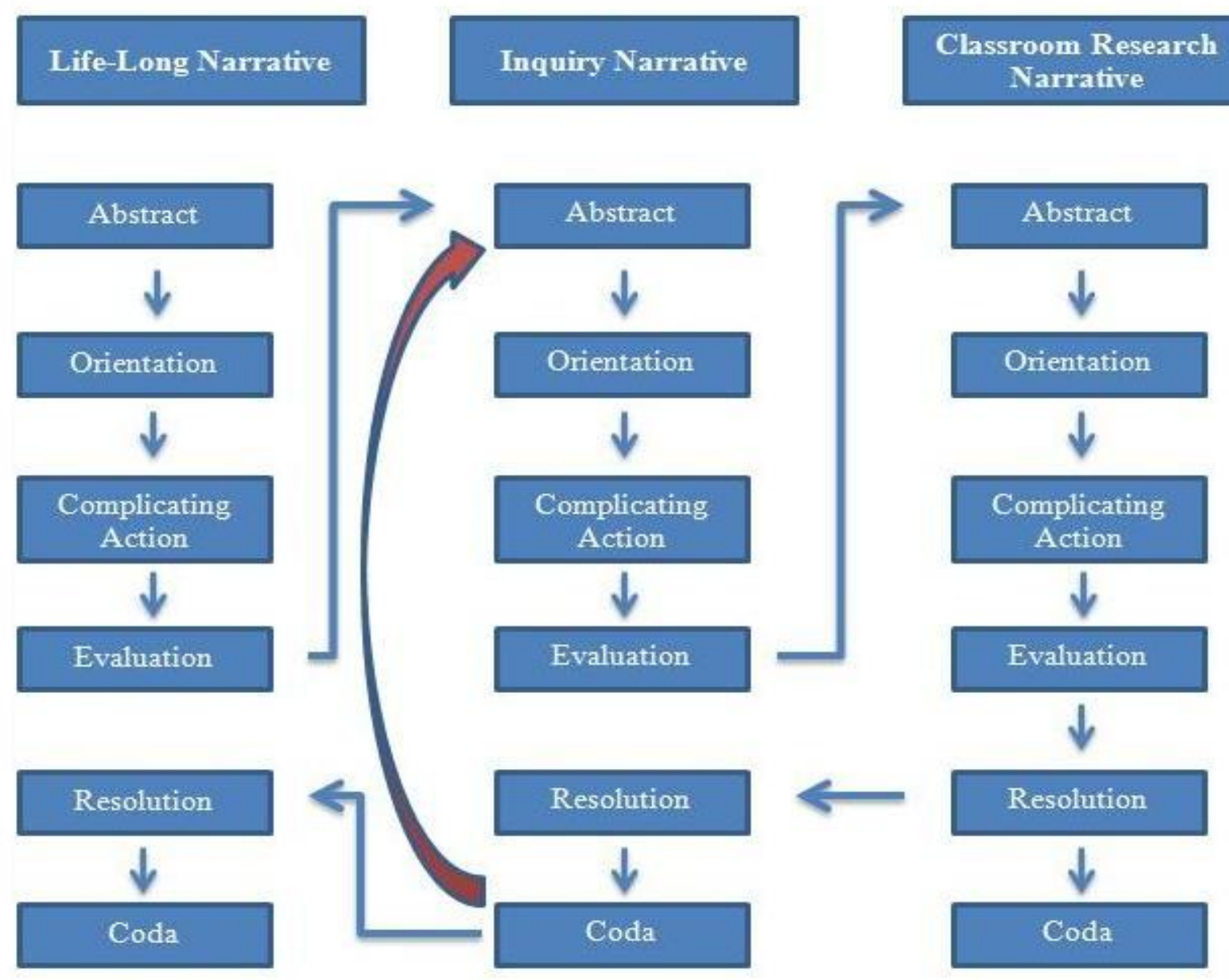




\section{Chapter 5: Developing the Inquiry Narrative}

In constructing the research questions that guided this study, I asked, "How do preservice teachers' perspectives towards inquiry develop through the process of engaging in classroom research?" I hoped to consider how preservice teachers might suggest that classroom research would indeed become a part of their future practice. I also asked, "How do preservice teachers manifest perspectives towards inquiry in practice as they engage in classroom research?" In doing so, I hoped to consider if preservice teachers were able to demonstrate an ability to actualize those practices that would allow them to engage in systematic and intentional classroom research. After I completed my coding, I considered the relationship between my data analysis and my research questions. In doing so, I began to see the development of a specific type of narrative, which I named an Inquiry Narrative, embedded in students' essays. In this chapter I will briefly explain how the data I analyzed was interpreted to allow formation of an Inquiry Narrative. Next, I develop the elements of this narrative, making extensive use of coded examples to support the inclusion of each element.

In my coding of data, I looked for evidence of the development of those perspectives toward inquiry that suggested the potential for classroom research to become a part of students' overall approach to being a teacher. Making use of my initial codes, along with the literature reviewed in chapter 2 (See Table 2.1), I identified elements that suggested both the presence of practices necessary to engage in the reflection and action required to make use of inquiry, and the development of perspectives towards inquiry necessary to provoke a teacher-researcher to use these practices. After reviewing my analysis, I realized that these elements, taken together, allowed for the formation of an Inquiry Narrative, with each of the elements I had identified corresponding to an element in Labov's (1972) framework. These elements, identified in Table 
5.1, were: (1) crafting wonderings which are based on real-world dilemmas (abstract), (2) using the literature and other resources to turn wonderings into research questions (complicating action), (3) collecting and analyzing meaningful data (evaluation), (4) considering findings as a way to promote contextualized professional learning (resolution), and (5) extending the impact of classroom research beyond the classroom ( coda).

Table 5.1: Practices and perspectives of the Inquiry Narrative

\begin{tabular}{|c|c|c|}
\hline Practice or Perspective & & Related Narrative Element \\
\hline Reflect on Practice & Perspective & Required for all Narrative Elements \\
\hline Act on Reflection & Perspective & Develop Inquiry Narrative \\
\hline Dilemma becomes Wondering & & Abstract of Inquiry Narrative \\
\hline Context for Inquiry & & Orientation of Inquiry Narrative \\
\hline Developing Research Questions & Practice & Complicating Action of Inquiry Narrative \\
\hline Data Collection and Analysis & Practice & Evaluation of Inquiry Narrative \\
\hline Considering Findings & Practice & Resolution of Inquiry Narrative \\
\hline Sharing Learning & Practice & Coda of Inquiry Narrative \\
\hline Reentering the Inquiry Cycle & Perspective & Develop a new Inquiry Narrative \\
\hline
\end{tabular}

The element of orientation, which serves to identify the context in which an Inquiry Narrative is formed, was also generally described by the students, however, this element does not provide evidence of perspectives towards inquiry, but rather describes the setting in which evidence generated by students was provided. For the remainder of this chapter, I examine each of the elements of the Inquiry Narrative.

\section{Crafting Wonderings as the Abstract of the Inquiry Narrative}

As part of the process of each classroom research experience embedded in the inquiry strand of the program, students were asked to begin with a wondering. We asked students to consider their own needs with respect to improving professional practice, the learning needs of 
their students, and their own passions as preservice teachers. We encouraged students to craft wonderings based on the junction of these three ideas. Authors of the most sophisticated essays were able to construct an abstract for their Inquiry Narrative by pointing to dilemmas embedded in their wondering that framed both a specific student learning need and an area of professional practice that could be improved as a way to address the needs of students. Further, these preservice teachers also considered their own passions as educators to help frame their wonderings. In writing their essays, most students addressed the process by which they developed their wonderings. One student who considered student learning needs, his own professional practice and his passion shared:

As I said before I changed my final Action Research project three times from the original "wondering" but I believe it was for the better. Having done this helped me focus in on exactly what I wanted to research. I felt as if it was tough trying to find something that I was actually adamant about so early on in the process before the final product was due. Also, not being in my classroom each and every day like I was during my Intern year was tough because I didn't have the same interactions with the students and wasn't able to gather as much as or the type of data that I wanted to. I now realize the value that was associated with changing my ideas so much because in the end I was able to actually accomplish something that I was passionate about and something that I was interested in. I was lucky though because from the start it didn't seem like it would turn out the way that it did.

In this example, the student demonstrates that while it was initially difficult to see problems that could lead to inquiry, once a problem was found that aligned with his interests he was able to engage in research that led to the construction of meaningful knowledge. 
For other students, the process of finding a wondering was borne out of dilemmas that are pervasive in their specialization. A preservice mathematics teacher wrote:

Students tell me all the time about how they hate math because there are confused and frustrated by all of the rules and theories. This is because they never fully understood the math concepts when they were originally taught to the student. Because of this, I wanted to put my focus on foundational math concepts, since math is a subject that builds off of itself.

In this case, the author's own beliefs about the importance of mathematics, combined with her ability to see the frustrations of her students, allowed for her to focus her inquiry on foundational math concepts.

While the previous two examples were a part of students' discussion about their internship inquiry, some students exhibited sophistication during the development of their miniinquiry (See Appendix E), conducted the previous semester. In talking about finding a wondering for her mini-inquiry, one student commented:

When I first started inquiry I was in a $2^{\text {nd }}$ grade classroom [During the practicum]. This general education classroom was full of students that ranged from gifted to special needs. We even had a non-verbal student in the classroom. This made whole group instruction very interesting. When we would have discussions you would find so many students were sitting there unresponsive, or scared to speak, while others were dominating the entire conversation. This was how I developed my wondering for my mini-inquiry project. I wanted to see what strategies I could use to help get students who were nervous about voicing their opinions involved in class discussions. 
In this comment, the student demonstrates her ability to recognize a clear dilemma (getting students involved in class discussions) through observation, and then commits to using inquiry as a way to address this dilemma.

The essays of a few students suggested that the ability to find a wondering developed early on in the program. One student talked about the lesson inquiry (see Appendix D) she conducted in her first year in the program:

During that tutor year, I spent time in a collaborative mathematics classroom both semesters. Through these experiences, I developed my first wondering. I thought, "Why are some students not involved in the lessons and just sitting in the class passively?" At this time, I was not used to the key terms "student engagement" and "differentiated instruction." I spent most of this time as an observer and a one-on-one tutor, and the fact that one or two students were not interacting in the class bothered me. Each time I was at [placement school] I tried to delve deeper into this issue that I was seeing. I tried to find the reasons for the lack of participation on the part of one or two students.

While this example does not continue to describe some process of sophisticated data collection, this student's comment does suggest that she quickly understood the benefit to both seeing a dilemma, and trying to figure out what might be causing the dilemma.

In these examples, each student ends up with a wondering that is rooted in a dilemma. These wonderings were generated across multiple experiences, at multiple points in the program, and were generated as a result of various circumstances. In one case, we see a teacher's passions and interests helping to generate a wondering. In another case, the ability to see students' frustration serves as a dilemma. And in the case of the last two examples, frustration over a lack of student engagement serves to help generate wonderings. 
This data suggests that some students may have to initially search for the dilemmas that serve as complicating action in a teacher's Life-Long Narrative, while for others, dilemmas emerge naturally. Once a dilemma emerges, if teachers realize that they want to make use of reflection and action as a way to evaluate and resolve a dilemma, then creation of an Inquiry Narrative begins. When this happens, the dilemma becomes a wondering that serves as the abstract for the Inquiry Narrative and the context that gives rise to the dilemma serves as the orientation for this new narrative.

\section{Constructing Research Questions as the Complicating Action of the Inquiry Narrative}

While wonderings are important to the development of meaningful inquiry, they are insufficient to guide the examination of new practice. Wonderings ask how something could be better, but do not include a potential solution. Thus, wonderings need to be converted into research questions that include a potential solution to a dilemma that can be studied. In facilitating the learning of our students, we emphasized the need to consider what is already known about the areas of teacher practice and student learning related to a wondering. To do this, we emphasized the need to use the literature and the need to discuss potential practices with mentors and peers.

The inquiry synthesis essays provided evidence of the different ways in which students crafted research questions. In writing about their experiences, some students did not differentiate between wonderings and research questions, while others implied that there was a difference, but did not talk about the process they used to go from wondering to research question. There were some students, however, who were able to talk about how they moved from wondering to research question by using the literature and other resources. These students were best able to 
frame the kind of research questions that can serve as complicating action in an Inquiry Narrative.

Several students talked about how they made explicit use of literature to guide the creation of research questions. One student said:

In spring of 2010, I conducted a mini-inquiry about a cooperative learning strategy, the "Jigsaw Method" (Aronson, 1978), in a fifth grade classroom. My motivation for this project stemmed from my desire to vary my instructional methods while teaching Social Studies. I noticed a general lack of motivation amongst my students and wondered if anything could be done to increase their interest in the material. In addition, my mentor teacher observed a trend of mediocrity in students' performance in her class. Together, we decided that we would implement a strategy that allowed students to interact more with the text and socialize with peers. The "Jigsaw Method" was selected because of its collaborative nature and research support.

In this example, the student first makes explicit reference to a dilemma (lack of motivation), a wondering (varying instructional strategies to impact student interest), and an orientation (social students instruction in a fifth grade classroom during year 4). Then, she uses the literature to identify a strategy (Jigsaw Method) which can be researched. Although the student did not actually state her research question, all the elements necessary for a quality research question are explicit.

In some cases, student references to using the literature were less specific, but still pointed to an understanding of why examining existing research is important. For example, one student said, "After looking into some research on the subject, I found that students need more time than the typical class period allows to process the information [they are] taught." While this 
excerpt does not provide evidence that the literature referenced led to a specific research question, at the very least, it seems likely that existing research guided research question development.

In addition to the literature, some students used the ideas provided by their mentor teachers, course instructors, or facilitators when developing research questions. Some students found mentor teachers invaluable to the process of developing research questions. One student commented:

My participant inquiry was focused on a style of teaching I had seen modeled in my fall placement. In that placement, my mentor teacher would teach most of the lesson, but for each chapter, groups of students would present a selection to the rest of the class. It seemed to be a welcome change from the norm, as well as an opportunity for the students to learn by teaching others. I took this concept from that 10th grade classroom to my 8 th grade middle school placement when I began my mini-inquiry.

In this example, the student was able to observe and see value in the practice of her mentor teacher. The mentor teacher's practice then became a way for the student to address the needs of a different group of children.

Another student suggested that his course experiences helped him develop research questions:

My research idea came from a wondering that I developed while I was taking reading across the content areas. In that class I learned that literacy does not just mean that the students can read. Literacy is also something that needs to be taught in each content area so that the students can become literate in the subject. This was a new idea for me, and I wanted to try reading activities in my math class 
In this example, the student considered a practice he had learned in a university course, and then decided to consider how effective the practice might be in a subsequent classroom placement. The role of the small group facilitator also proved helpful to some students as demonstrated by a preservice teacher who wrote:

First, in a debriefing with [field supervisor] after she observed my class playing this game, she asked me if I was doing anything to address the students that did not seem to be engaging with the game, and also if I thought the students were really getting anything from it. Second, in a small-group meeting on inquiry, [small group facilitator] mentioned, when we were discussing wonderings, that when he had been a classroom teacher, he had often used review games without ever testing their merit. Both of these conversations led me to want to test the merit of my old standby, and to see if it really did my students any good.

For this student, feedback from both her field supervisor and her small group facilitator helped her to transform a wondering into a research question.

In each of these examples, a student considered a practice that had been modeled by another educator. While these students may not have known whether or not the practices they utilized were research-based, they felt strongly about the practices, and wanted to further examine these practices' potential to have a positive impact in their classroom. In sum, these examples suggest that the author has an understanding of how the literature and other resources, like mentor teachers, can help in the development of research questions that are suitable to guide inquiry. When students are able to use the literature and other resources to come up with a meaningful practice they have moved from a wondering based on a dilemma to a research 
question. The dilemma then becomes a problem to solve and these problems then serve as the complicating action for an Inquiry Narrative.

\section{Collecting and Analyzing Data as the Evaluation of the Inquiry Narrative}

Throughout their three years in the program, students were asked to engage in a series of

classroom research activities, each requiring students to collect and analyze data. We emphasized the importance of collecting data which, when analyzed, would generate findings to help students discover answers to their research questions. We also emphasized the importance of both qualitative and quantitative data analyses techniques.

While all students collected and analyzed data, some students focused on data they felt would be easiest to collect and analyze. Others thought more carefully about their choices. Perhaps most importantly, the richest narratives outlined the process of collecting and analyzing data, and were also critical of the choices made. These students gave significant attention to the evaluation of their Inquiry Narratives.

Those students who demonstrated the importance of making data collection and analysis choices often talked not only about the choices they made, but also why they made these choices. One student demonstrated an understanding of making systematic choices when she said:

I journaled and recorded my thoughts every day of my large-scale inquiry project. I would write down how the students were behaving, what type of problem was being answered, the class dynamics, and any external factors that were affecting the students' behavior (snow storm, fire drill, power outage). This journal was especially helpful to me as I was analyzing my data because I could look for abnormalities in my data and refer back to my journal to see if I could find some explanation for inconsistencies in my 
results. I also was able to draw a lot of qualitative conclusions from evaluating my journal. These conclusions proved to be some of the most insightful and informative. In this example, the author demonstrates her openness to qualitative data, and persistence in using journaling as a way to chronicle her work. Because of this openness and persistence, the author suggests that she was able to better understand her other data sources, and through analysis, make strong conclusions related to her inquiry.

Another student illustrated that his past experiences helped him to understand the need for thinking about the choices he made with respect to data collection and analysis. He said: This mini inquiry project helped prepare me for my internship inquiry project. The inquiry project is more in depth and has a much longer timeline. With a longer timeline, I was able to collect more data and make more observations. Writing a mini inquiry paper allowed me to understand the process and how to analyze my data. Learning how to write my process, findings, and conclusion gave me time to reflect on my process. In this excerpt, the student makes no reference to actual data collected. However, he demonstrates an evolution in understanding why it is important to think about what data will be collected, how it will be collected (referred to as "my process"), and how best to analyze data. Also important is the student's mention of reflecting on data collection decisions suggesting that he sees the value of both action and reflection.

For some students, the process of selecting data sources and analysis methods did not go smoothly, but they were able to understand why they had trouble. This suggested that they would be more successful in the future. One student commented: 
My final data showed my students did better on this chapter than they had on the last, but in my mind, my findings were far less than definitive. I was left questioning whether the difference in their performance was due to the style of delivery or the style of assessment. This student's comment is important because rather than letting the data speak for itself, she was able to look at the interaction between her practice and the resulting changes.

Another student identified problems related to her data collection:

For my action research I used spelling assessment scores and word recognition checklists averages to evaluate the effectiveness of word-sorts on the spelling achievement of students with special needs. As I began implementing word-sorts into my daily instruction and collecting data based on test scores and checklists, the time for collecting surveys from my students and personal daily reflections on my teaching seemed to quickly slip away from me. Furthermore, as my inquiry progressed, I had a hard time finding a place for qualitative data to fit into my study. I understand the benefits of data collected in the form of language; however, it has proven difficult for me to incorporate qualitative data into my formal inquiries on more than one occasion. I look forward to being able to make better use of qualitative data as I continue to look at teaching through inquiring eyes.

While this quote suggests that the data collected and analyzed may or may not have been appropriate for the student's inquiry, her ability to critique the process of data collection, combined with her willingness to work at the process of qualitative data analysis suggests that she values the role data plays in inquiry.

Understanding the difficulty of making appropriate choices related to data collection and analysis, I considered not only those students who made good choices, but those students who, 
even when they did not make the best choices, were able to think critically about why their choices were problematic. These examples illustrate the various ways that students demonstrated a sophisticated understanding of the role of data collection and analysis in the classroom research process. Whether the data collection and analysis is part of a robust research methodology, or is accomplished in more informal ways, for teachers with the ability to recognize that there are various kinds of data that can be used for different purposes, the process of collecting and analyzing this data serves as evaluation in their Inquiry Narratives.

\section{Using Findings as the Resolution of the Inquiry Narrative}

Perhaps the greatest motivation we had for making changes to the Inquiry Strand of the program (outlined in chapter 3) was our concern that the previous model did not place enough emphasis on developing perspectives that could allow preservice teachers to see the value of classroom research as a part of their regular classroom practice. As such, in this redesign we emphasized classroom research as a cyclical process rather than a liner one. We developed activities so that students were afforded multiple opportunities to consider what they learned through classroom research and how this learning would impact their future teaching.

Given our emphasis on learning and future practice, as well as the nature of the data for my study, it is little surprise that most students spent time talking about what they learned. In some cases, this learning was framed mostly in terms of findings related to individual classroom research activities, especially the internship inquiry. For other students, however, there was a focus on how the findings they generated would impact both future teaching and future inquiry experiences. Students' whose narratives talked about future inquiry and teaching endeavors demonstrated development of an understanding of the cyclical nature of inquiry, and an ability to 
think about how they would use what they had learned in their own classrooms. These students provided strong resolutions to their Inquiry Narratives.

Most prominent were discussions of how the findings from a classroom research activity would impact future teaching. These discussions generally talked about new practices the preservice teacher would adopt. For example, one student said:

Student achievement was also positively affected by the methods I used in my research. It was interesting to see that this study related back to the wondering I developed almost two years prior. I was concerned with student engagement and motivation, and this study found a possible teaching method to address this wondering. I learned a lot about making math meaningful and relevant to the students by conducting this mini-inquiry.

In this example, the student has clearly added a new practice to his teaching repertoire. Data was used to help the student determine the value of the practice he considered, and this practice helped him to reconcile a dilemma that had led to multiple wonderings.

Another student demonstrated how findings could be considered in-depth as a way to guide future practice by writing:

My findings and conclusions from my inquiry project helped me reflect on my future practice. I found that students test grades all increased when vocabulary was emphasized. The low achieving student grades increased more than the middle and high achieving students. Quiz grades also increase when vocabulary was implemented into the classroom. Again, the low achieving students increased more than the middle and high achieving students. I kept a daily journal where I took note on student participation and engagement. I found that students were distracted, unmotivated, and participated little $28 \%$ of the time, students were engaged with vocabulary strategies $41 \%$ of the time, 
and engaged in lessons without vocabulary $31 \%$ of the time. I found that using different vocabularies helped student engagement. I gave a survey at the end of my student to ask the students their opinion. Students also found that vocabulary strategies were interesting and helpful.

In this case, the author not only found the vocabulary strategies she examined to be effective, she also considered sub-groups for which the strategies were especially effective. Further, she used student perception data (surveys) to determine that her assessment data aligned with the feelings of her students. This set of findings demonstrates how inquiry allowed the student to be specific as to the ways in which she would use the practice she studied in the future.

In some cases, classroom research allowed students to see that their existing practice needed to be modified. For example, one preservice teacher wrote:

Because I assumed this "best practice" would be effective with all my learners, it was disappointing to see such wide variability in student performance. As an outcome of this situation, I learned how my students respond differently to a single teaching strategy and how I might differentiate a learning strategy to meet the needs of all my students. While there is not an explicit mention of actual findings here, the student's ability to consider variation in findings allowed him to learn something about his teaching practice. It is difficult to say whether this student will make use of the strategy researched, but it is clear that he learned the importance of differentiating instruction.

In other cases, classroom research led students to realize that they no longer felt confident in the validity of some practices. One student said:

I learned that I used direct instruction too much in my classes. After reflecting on my daily journals that I used in my inquiry project, I saw that students were becoming 
disinterested on the days that I would use direct instruction. After using different strategies and activities, I saw that student engagement rose.

In this excerpt, we again do not have evidence that a specific practice will be implemented.

Instead, we see how reflection allowed the author to better understand how students responded to his teaching practice. Whether the "different strategies" are utilized specifically, the learning here seems to be that when possible, it is a good idea to try and steer away from direct instruction.

In these examples, students discussed the way in which classroom research impacted their future practice. Because there were multiple classroom research experiences embedded in the inquiry strand of the program, some narratives talked about the way early classroom research experiences impacted teaching in later placements, providing evidence of the cyclical nature of inquiry. One such example of this change comes from a narrative whose author wrote:

During my participant year inquiry, I did not know my students very well because I spent most of their time in the classroom, outside of the classroom since I had classes to attend. When I first entered the classroom, I had ideas of what the students were like which turned out to be different than the truth. Being able to work with the students in a small group basis helped me get to know the students' mathematical knowledge a little better because I got to hear from them one on one.

This preservice teacher went on to say:

During my internship, I waited at least one month before starting my inquiry. Just being in the classroom all day, every day, made it a lot easier to get to know [my] students, because you spend every minute of the school day with them. This made my action 
research much more valuable to me because I was working to improve something that was lacking in my students' education.

In this excerpt the student was able to take what he had learned in early experiences and apply this learning to later experiences. Though only implied, the student seems to feel that his prior research experiences were rushed. This realization allowed the student to make time for wonderings to emerge during the longer internship experiences, thereby increasing the value of the research he conducted.

In another narrative, the author also illustrated the connection across experiences by first saying:

During my mini inquiry, I focused on one student. This student had a very hard time controlling himself in class. He was constantly disturbing his peers and interrupting the teacher. While working with him, I found a lot of information about some of the reasons why he was unruly. For insistence, it was just him and his mother and she worked a whole lot. He did not have any friends because of his "bullying” nature. While I know there are no excuses for such behavior, it gave me an understanding of why. Without conducting the mini inquiry with him, I feel I may have done as my mentor did and "wrote him off." She did her best to ignore him and when that did not work he was sent to the office. Due to the mini inquiry, it strengthened the fact that I NEED to know my students. I need to listen to my students.

Later in her essay, the author returned to this initial learning by commenting:

In particular, the inquiry projects I have done have allowed me to see students on a different level i.e. "Brandon." This is something I may not have developed until much further into my career. I feel I have grown in the way I teach, due to the immediate 
feedback I was receiving on the exit tickets. I was realizing what worked and what did not. I figured out right away the students who needed extra assistance.

While the prior set of excerpts suggest an impact of early experiences on the ways in which the author looked at her practice, these excerpts demonstrate how early classroom research experiences impacted subsequent teaching. In this case, the author's data allowed her to see her students differently, and this experience had an immediate impact on her teaching.

While impact on future practice was central to many students' discussions about their classroom research experiences, often those students who exhibited sophisticated perspectives towards inquiry also discussed the ways in which their findings might guide future research. One student talked about future research by saying, "My two inquiry projects that I already conducted have sparked new ideas for extensions with these topics. The more I conducted inquiry, the more I realized how important it was and how many more things I had 'wonderings' about." In this example, the author has begun to understand the value of reflecting on practice, and has already begun the process of constructing new wonderings.

Another student felt that:

Seeing the effect that my teaching has had on students has been so exciting, and makes me look forward to the future. In fact, one of my graduate courses this semester has sparked an inquiry that I plan to conduct even in my first year as a teacher.

In this example, the wondering did not come from a specific classroom research experience, it came from a course. However, by having gained experience studying practice, this student was able to reflect on what she was learning in a course, and consider how she might investigate the effectiveness of this new practice in a different context. 
The stranded nature of students' classroom research experiences allowed some to learn from early experiences thereby improving the quality of subsequent research activities. One student said:

I conducted a lesson-based inquiry and at first deemed it unsuccessful. After a discussion with my small group facilitator, I realized that just because you do not see positive results, your inquiry is not unsuccessful. However, I did not let this experience cloud my views on inquiry. I was still very intrigued by the idea and knew that I would have to better understand the process of inquiry before I could become an effective educator. In this case, an early experience allowed the author to see that she needed to better understand inquiry as a cyclical process before she could draw meaningful conclusions about practices that she investigated. This excerpt also suggests that she was able to critique the findings from one experience without passing judgment on inquiry as a viable way to address dilemmas.

Another student was more blunt, writing:

My Tutor mini-inquiry bombed drastically. I did not answer my questions in the least; however, this did lead to my need to find the answer. This is when I started getting to accept that inquiry is not just a straight path to find an answer but, rather, a continuous journey that always spurs new thoughts and questions This excerpt demonstrates that the student understands how findings from one study, whether positive or negative, can allow for new questions to emerge, thereby demonstrating an understanding of inquiry as a cyclical process, rather than an "answer."

These examples indicated that the authors learned something about their teaching or about research that would impact their future practice. The examples also suggested that these students' early experiences engaging in classroom research had an impact on their teaching 
and/or research in subsequent experiences, thereby suggesting a sophisticated understanding of the cyclical nature of inquiry. In some cases, positive outcomes led to new practices and new questions. In other cases, negative outcomes led to eliminating practices and asking new questions. In a few examples, the focus was less on outcomes, and more on the actual process of asking questions and finding answers. These examples suggest that when teachers are able to use the process of investigating their practice as a way to improve their teaching, or when the consistent use of reflection and action helps students to value and better understand the cyclical process of inquiry, these changes in teaching and research practice can serve as resolutions in an Inquiry Narrative.

\section{Going beyond the Classroom: The Coda of the Inquiry Narrative}

One of the final experiences for our students prior to graduation is their participation in a conference. Students present their work to peers, faculty, and other guests, and attend sessions where they hear about the work done by others. While this experience aligns with conceptual literature on classroom research that suggests teachers should share their work with others, the conference is also a mandatory experience. During strand seminars, we also tried to provoke students to consider other ways in which classroom research could become a tool for making changes beyond the walls of the individual classroom.

In looking for evidence of sophisticated perspectives towards inquiry, I searched for examples of how students planned to make use of classroom research in other ways besides collecting and analyzing data from their own classrooms. Some students did not articulate any plans for extending the scope of classroom research. Others talked about sharing their work with others or collaborating with colleagues to conduct larger-scale inquiries. Further, some students talked about helping others to understand the value of classroom research, while others talked 
about using the findings from future research endeavors to impact policy at the school level and beyond. Those students who were able to consider their learning about classroom research and the implications this learning could have beyond their own classroom were able to provide a coda for their Inquiry Narrative.

For those students that wrote about their desire to move classroom research beyond the walls of their classroom, many spoke about sharing their work with colleagues. One student said: Teachers are the only ones who see their students every day in the classroom setting. All other research is done by professionals who do not know the students and have limited access to schools. I now see the need for progressive movement of teachers to create their own inquiries. They can better understand their students and share the data with administrators and the community who rarely have a window into the everyday classroom.

In this example, the author sees classroom research as a way to provoke change at the school and community level. In specifically mentioning traditional forms of education research, the author also suggests that teachers are best positioned to provide evidence that practices are contextually appropriate.

Other students talked about collaborating with colleagues to design and implement research on a larger scale. One student considered this process by writing, "I hope to carry with me the skills and knowledge that I have gained about conducting inquiry and utilize them in my classroom, while at the same time encouraging my colleagues to do the same." This comment indicates that the author values not only her own work, but also the work done by others, while also pointing to an interest in collaborative research that extends beyond the individual classroom. 
Some students indicated a desire to share their learning with future colleagues, suggesting that they would like to coach others engaging in classroom research. The author of one essay explained that:

It is my intention to enlighten others about the value of inquiry and also take on the role as a facilitator for those who are in need of further clarification or assistance. I wish to inform my fellow faculty members about how this particular method can indeed enhance the capacity of educators as reflective practitioners and researchers.

This student not only suggests a willingness to engage in collaborative research, but also a willingness to help colleagues understand the importance of using reflection and action to solve dilemmas.

Other students talked about making an impact on policy. In some cases this was seen as a way to actualize findings of classroom research. For instance, one student said:

On a formal note, I learned that one way for teachers to be heard and listened to by administration and larger policy makers, is for them to have research to back up their statements. Inquiry is helpful in this sense, in that a teacher can conduct a project about something they are concerned about and show meaningful classroom data to back up their opinions.

In this excerpt, the author demonstrates the need for data when advocating for changes in policy, further recognizing that by engaging in classroom research, teachers can help those in positions of power make data-based decisions.

Another student expanded on this idea and emphasized the need for school leaders to make sure that there was space for classroom research as a form of professional development. She noted: 
Teacher inquiry is important in educational reform but there needs to be regulation in the ways we convey our findings. I also believe the teaching profession would be better respected if we can produce more frequent and formal writing. It is hard for the public to take our word into account without formal findings of what we see in the classroom. There can be no question about your practice if you have a formal way of proving a systems works in your classroom.

In writing about the need for administrators to support the work of teachers, the author considered how classroom research can benefit the teaching profession as a whole, especially when findings are formalized and shared.

In each of these examples, students were able to demonstrate a sophisticated understanding of how classroom research can become an invaluable practice that promotes the teaching profession. Whether through collaboration, sharing, coaching, or advocacy, students who took time to talk about the ways in which they hoped to move classroom research beyond the walls of their individual classroom demonstrated an understanding of the kinds of outcomes the literature suggests are critical to making classroom research a part of teachers' everyday practice. When teachers are able to see that their research has the potential to impact not only their classroom, their teaching, and their students, but also the potential to impact colleagues, communities and the teaching profession, there is evidence that these teachers are positioned to help develop a culture of inquiry at their schools. As such, when classroom research experiences help to develop sophisticated perspectives towards inquiry that include an understanding of how the work of one teacher can extend beyond the classroom, these understandings serve as the coda for the teacher's Inquiry Narrative. 
Each of the five elements described above are developed in the literature on classroom research and are aligned with the notion of a reflective practitioner as defined by Schön (1983). Preservice teachers who are able to: craft wonderings, construct research questions, collect and analyze data, make use of findings, and extend their learning beyond the classroom, demonstrate an ability to make use of reflection and action as a way to evaluate and resolve the classroom dilemmas they face. When preservice teachers also demonstrate the perspectives necessary to suggest that dilemmas will provoke them to make use of reflection and action, they provide evidence that they are willing to make use of the practices needed to evaluate and resolve a dilemma through inquiry. Table 5.2 summarizes the practices that allow for creation of the Inquiry Narrative. As students constructed their synthesis essays at program's end, many of them were able to articulate their own perspectives towards inquiry by discussing these elements. The students whose perspectives demonstrated the most sophistication provided evidence of having thought about and used each of these elements during a given classroom research experience, thereby embedding a complete Inquiry Narrative in their Life-Long Narrative. Table 5.2: Supporting practices in the Inquiry Narrative

\begin{tabular}{|c|c|c|}
\hline Narrative Element & Practice & Supporting Practices \\
\hline Abstract & Find a Wondering & $\begin{array}{l}\text { Look at the intersection of teacher } \\
\text { practice, student learning and passion. }\end{array}$ \\
\hline Complicating Action & Construct a Research Question & $\begin{array}{l}\text { Use the literature to identify practices; } \\
\text { Take practices learned through courses } \\
\text { and field experiences. }\end{array}$ \\
\hline Evaluation & Data Collection and Analysis & $\begin{array}{l}\text { Use multiple forms of data; } \\
\text { Be critical of data choices and learn } \\
\text { from mistakes. }\end{array}$ \\
\hline Resolution & Consider Findings & $\begin{array}{l}\text { Consider how findings impact practice; } \\
\text { Consider how findings impact inquiry. }\end{array}$ \\
\hline Coda & Share Learning & $\begin{array}{l}\text { Share with peers and colleagues; } \\
\text { Help others to inquire into practice. }\end{array}$ \\
\hline
\end{tabular}


While the ability to construct an Inquiry Narrative allows a teacher-researcher to move towards the development of an inquiry stance as described by Cochran-Smith and Lytle (2009), the elements of the Inquiry Narrative emphasize the reflective nature of inquiry over the systematic and intentional study necessary for classroom research. For many students, a willingness to engage in reflection and action to resolve a dilemma, did not always translate into systematic and intentional classroom research. When students were able to demonstrate an understanding of the importance of using classroom research to resolve dilemmas, and were able to simultaneously implement the teaching and research practices necessary to systematically and intentionally study their practice, these students were able to construct the Classroom Research Narratives described in chapter 6. 


\section{Chapter 6: Developing the Classroom Research Narrative}

In constructing my study, I asked, "How do preservice teachers' perspectives towards inquiry develop through the process of engaging in classroom research?" I also asked, "How do preservice teachers manifest perspectives towards inquiry in practice as they engage in classroom research?" In constructing a Life-Long Narrative we would expect a teacher-researcher to construct multiple Inquiry Narratives, each demonstrating an ability to engage in the practices necessary to use reflection and action as a way to evaluate and resolve a dilemma. Making use of these practices would suggest sophisticated perspectives towards inquiry, and could, over time, support the development of what Cochran-Smith and Lytle refer to as an inquiry stance.

In their definition of inquiry stance, Cochran-Smith and Lytle use the words "intentional" and "systematic" in describing the process by which teachers should study their practice. This is important, because while the process of using reflection and action to address dilemmas and construct an Inquiry Narrative can be both systematic and intentional, there is room for great variability with respect to the ways in which data is collected and analyzed. This mirrors the experiences that make up the Inquiry Strand of our program, with early experiences designed to demonstrate the process of inquiry, while minimizing the extent to which new practices need to be implemented, as well as the depth and breadth of data collection and analysis, and later experiences which call for a greater focus on implementing and studying new practice. In these later experiences, the most sophisticated students were able to demonstrate evidence of student learning. As with any pedagogy, for classroom research to be viewed as an important practice there needs to be evidence that engaging in classroom research provides evidence of student learning. While I believe strongly that those teachers who understand and use the elements of inquiry developed in the literature and described in chapter 5 as being part of an Inquiry 
Narrative have a greater potential to impact student learning, also important to consider is how engaging in classroom research impacts teaching practice.

In this chapter, I identify evidence of classroom research having an impact on student learning and teaching practice. In doing so, I differentiate between the implications for future practice discussed in the previous chapter, focusing instead on how, through classroom research, our students made changes to the ways in which they teach and naturally integrate learned research skills into their teaching. Further, I include examples whereby preservice teachers provide specific evidence of how classroom research impacted their students. Finally, I consider the ways in which some preservice teachers were able to articulate how classroom research allowed them to learn about their students, learn from their students, and develop better relationships with their students. Through this evidence, I begin to consider the ways in which the learning that occurs through classroom research is manifested in the practice of preservice teachers, and consider how those students who are able to demonstrate impact through their work are able to construct a Classroom Research Narrative.

The Classroom Research Narrative is constructed when a teacher, who is engaging in inquiry, makes use of a sophisticated methodology that integrates teaching and research. As mentioned previously, the evaluation of an Inquiry Narrative is the process of collecting and analyzing data, and the findings generated as a result of this analysis provide the resolution of an Inquiry Narrative. If this data collection and analysis is part of systematic and intentional classroom research, then a teacher-researcher also is able to generate a Classroom Research Narrative. When this happens, the research question that served as the complicating action of an Inquiry Narrative becomes the abstract for the Classroom Research Narrative, and the orientation of the Classroom Research Narrative becomes the context in which new practices are 
implemented and evaluated using meaningful data. In these cases, the process of simultaneously engaging in teaching and research becomes the complicating action of the Classroom Research Narrative. The findings generated through analysis and interpretation of collected data become the narrative's evaluation, and the teacher's considerations of how findings impact teacher practice and student learning provide resolution of the Classroom Research Narrative. Finally, the coda of the Classroom Research Narrative is provided by the teacher-researcher's assessment of the quality of his or her research. Table 6.1 summarizes the practices and perspectives necessary to construct a Classroom Research Narrative. The next three sections develop the elements of complicating action, evaluation and resolution in the Classroom Research Narrative. Table 6.1: Practices and perspectives of the Classroom Research Narrative

\begin{tabular}{|c|c|c|}
\hline Practice or Perspective & & Related Narrative Element \\
\hline Reflect on Practice & Perspective & Required for all Narrative Elements \\
\hline Engage in Classroom Research & Perspective & Develop Classroom Research Narrative \\
\hline Research Question & & Abstract of Classroom Research Narrative \\
\hline Context for Classroom Research & & Orientation of Inquiry Narrative \\
\hline Integrate Teaching and Research & Practice & $\begin{array}{l}\text { Complicating Action of Classroom } \\
\text { Research Narrative }\end{array}$ \\
\hline Meaningful Data Analysis & Practice & Evaluation of Classroom Research Narrative \\
\hline Impact of Findings & Practice & Resolution of Classroom Research Narrative \\
\hline Assessment of Research Quality & & Coda of Classroom Research Narrative \\
\hline
\end{tabular}

\section{Teaching Practice: From Complicating Action to Evaluation in the Classroom Research}

\section{Narrative}

In working with preservice teachers, we encouraged students to give considerable thought to the practices they might investigate as part of each classroom research experience. We suggested that in some cases the genesis for research questions may be an attempt to consider the usefulness of an existing teaching practice, or that perhaps by considering student learning needs, 
alongside potential ways to improve teaching, new practices may emerge which could then be examined through classroom research. In either case, we emphasized the need for classroom research to be "a part of" rather than "apart from" the daily routine of teaching.

In examining the narratives constructed by students, I discovered that those students who seemed most able to demonstrate meaningful learning related to their own practice, were able to consider the impact of their research activities on their teaching and then examine their practices in ways which allowed more integration of teaching and research activities. In some cases, our students chose to examine practices they were already familiar with, had already been using as part of their own teaching, or had seen used by their mentors and other practicing teachers. In each case, students whose narratives indicated a sophisticated understanding of how classroom research impacts teacher practice were able to talk about their research in a way that was connected to the practices the research was originally designed to examine. For example, one student talked about a need to examine a practice she had assumed was effective, saying:

I have taken the broad idea of inquiry and instead of trying to design a ground-breaking study; I looked simply at a strategy already in place. I always want to use the best methods and techniques in my class but sometimes current strategies just need to be tweaked in order to really benefit the students.

After looking at this practice, the student was able to assess the value of the practice in light of her findings:

Some students obviously mastered the content while others fell further behind. I also noticed that some students had already mastered the content before the skills review. In this case, these students should have been offered a more challenging assignment. After 
my Skills Review project, I also realized that one strategy may not fit all subject areas or specific content topics.

In these excerpts, the author is clear that she wanted to consider the effectiveness of a practice she was already using (Skills Review). Her study allowed her to draw conclusions about student learning that were aligned with the practice she investigated, and in this case she was able to see that the reviews were effective for some students, but not challenging enough for other students.

For some students, having multiple classroom research experiences allowed for a deeper investigation into a single practice. One student chose to build on a practice she had already begun to examine, noting:

Before I even began my research in my internship last semester, I conducted a survey the previous year with students in the same grade I would be working with. I asked for their opinions on reading choice, for their experiences with reading in general. From that data I was able to see if my original action research idea to study reading choice would be a good fit for those students. I talked to my future host teacher and my inquiry professors and all agreed that reading choice would be an interesting topic to study.

Because later classroom research experiences were more involved, the student was able to better understand the viability of the practice through a more extensive investigation, commenting:

As I went on with my research I realized that the two different classes I was working with were quite different and had different needs. I learned from my students that the fast pace of the literature circles was a little too difficult for my Transition Team, who operate slightly behind on-level students. I made changes in how their literature circles would be run and tried to reorganize their class. 
In this set of comments, teacher research and the use of data to inform practice is emerging as a part of teaching practice. The author used data even before she began her internship. This data allowed her to prepare the teaching and learning structures in advance. She goes on to say that by looking closely at data early in her implementation, she was able to adjust her instruction as necessary, in an effort to maximize the impact of her reading choice activities on her students' learning.

For many students, the practices they investigated were those that emerged through new experiences during their time in the program. One explained:

I knew that there was a vast amount of research regarding ability pairing and wanted to know which pairing method would be the most beneficial to my students in terms of collaboration, motivation, and promoting reading fluency. We chose to focus on three pairing methods: similar-ability, mixed ability, and student choice.

Her findings helped to more deeply consider the effectiveness of the practice. This is evidenced by her narrative when she wrote:

Perhaps the most shocking data revealed that students reported the most negative feedback regarding pairing with a peer of their choice. Not only did I find these pairs to be unproductive, but undesirable. This was very telling in terms of the social norms of young children. I began to realize that first grade friendships were rather unstable and changed frequently. Self-selected partners became much more undesirable to work with after more than a week had passed since making their selections.

In this set of excerpts, the author considered the research on ability pairing and then selected a series of pairing strategies to implement. The products of her learning suggest that self-selected grouping was not only of little academic value, but also that students did not enjoy the structure. 
Later in her comments, this student is able to draw meaningful conclusions, rooted in her analysis, as to the reason for this outcome.

While there was variation in the rationale for investigating a given practice, those students who seemed to understand how engaging in classroom research helped them to better understand a given practice, had success collecting data that was fully integrated with their teaching. One student demonstrated how she enhanced existing teaching structures to accommodate data collection and analysis needs, commenting, "I recorded the number of students who answered the question and the number who got the question right, and was therefore able to figure out the percent accuracies for each day." Although this analysis structure is straightforward, the student demonstrates how existing data (the author is referring to a homework assignment) was collected and organized in a different way (by question) to suit the needs of her study. Another student considered the relationship between teaching and data throughout her study, commenting:

The data that I collected from my study provided me with great insight in to the effect writing had on students' classroom experiences. Throughout the research process I gathered up student grades and student writing samples, and I kept a teacher journal. Also, an attitude survey was given in the middle of the study to determine students' feelings towards writing about math.

In this quote, we see that naturally occurring data was collected through classroom activities (grades and writing samples), research activities (attitude survey) and teacher activities (journal), thus allowing the student to triangulate findings and generate new learning outcomes.

In each of these examples, students demonstrated an understanding of how the findings of their classroom research activities allowed them to consider a practice they had been using, or 
had seen others using. Those who felt they now had a clear understanding as to a practice's effectiveness also demonstrated that they had made a concerted effort to conduct their research in ways that did not impact their ability to implement the practice they were examining. The process of implementing new strategies to impact student learning, along with collecting meaningful data on these strategies serves as the complicating action of the Classroom Research Narrative. When teachers are able to work through the process of simultaneously engaging in teaching and research activities well enough to generate meaningful findings related to teacher practice and student learning, they are able to evaluate the complicating action in their Classroom Research Narrative.

\section{Student Learning as Evaluation of the Classroom Research Narrative}

Throughout their time in the program, the students we worked with were constantly asked to consider student learning as a critical part of any classroom research activity. As such, we emphasized the importance of not only collecting meaningful data and using appropriate data analysis techniques, but also thinking critically about the findings generated.

While most preservice teachers were able to think about each classroom research activity in terms of how successful they felt the practice they implemented was, those who demonstrated a strong understanding of classroom research as a way to affect student learning, were able to talk about their findings in terms of impact on student learning. In examining this characteristic of students' narratives, I considered the ways in which students supported findings, whether or not these findings indicated that a practice was successful.

In some cases, students were able to use data to demonstrate the ways in which practices they examined had a positive impact on students. One student noted: 
My students' test and quiz scores all increased as a class after each new alternative assessment technique that was used. The students' surveys and informal interviews suggested that they didn't feel as pressured as they normally are when they have to memorize a plethora of knowledge from a specific chapter in a book then remember it all for a multiple choice test.

In this example, the student was able to see a positive impact through traditional classroom assessments, as well as through data designed to elicit direct feedback from his students. Further, informal interviews allowed him to understand why his students felt more comfortable with the alternative assessments.

In another example, a student commented:

This mini-inquiry helped me realize that positive reinforcement can have a huge effect on the atmosphere and occurrences in the classroom. My students reacted much more respectfully and with a better attitude when they were receiving positive reinforcement or feedback from me. Of course, there were still some students who remained unchanged and disinterested in class, but I was able to change some students' attitudes about math, and I learned a lot about classroom management.

In this comment, there is less of a focus on explicit student learning, and more of an emphasis on student "attitudes." This student was able to use data to determine change in student interest class-wide, and for individual students.

In other cases, students were disappointed with the impact of the practices they examined; however, these students were able to now see a practice as problematic by using realworld data. One student said: 
More importantly, I have learned that it is ok to fail. We can learn more from defeat than victory. My action research this semester produced inconclusive results. It's important not to be discouraged, but to take strength in the effort and the process.

In this quote, the student was disappointed with his findings. However, the process of collecting and analyzing data allowed him to learn about a strategy, even though the strategy proved ineffective.

For many students, their data led to mixed conclusions. One student illustrated this phenomenon by writing that:

When I first decided on a topic and established a question to guide my inquiry, I was naïve enough to think that my strategy would help my students become phenomenal note takers and would begin to ace all of their tests after I introduced the strategy. Well, I was half right. When the result of my inquiry began coming in, I did notice a definite increase in test scores from the baseline where the students outlined nothing. At first I was ecstatic but when the final piece of data from the test scores rolled in at the end of my inquiry, my thoughts were dashed because the test scores dropped. I was faced with the fact that while it appeared the outlining did help; it did not help as much as I previously thought.

In this excerpt, there is evidence that the student was analyzing her data throughout implementation of a note-taking strategy. By using baseline data and data from multiple summative assessments, she was able to see initial progress followed by a drop in performance. Although disappointed with the final outcome, the use of multiple data collection points allowed for the student to understand the long-term impact of her strategy. 
The process of classroom research, as illustrated in each of these examples, indicates that students demonstrated a sophisticated understanding of the use of data to draw conclusions about the viability of practice through its impact on student learning. While the impact of the practices discussed by the students may have been seen as supporting student learning, not supporting student learning, or partially supporting student learning, these students were able to make use of the data they collected to support their claims. For teachers able to analyze multiple forms of data in a meaningful way, analysis leads to findings that serve as the evaluation of their Classroom Research Narrative. Teachers that are able to generate meaningful findings are then able to make use of these findings in ways that provide a resolution to their Classroom Research Narratives.

\section{Teachers Understanding Students as Resolution of the Classroom Research Narrative}

As a part of each classroom research experience we provided for our students, we asked students to consider what they learned about their own practice and their students. However, we did not confine learning about students strictly to measureable outcomes. We also encouraged preservice teachers to consider how engaging in classroom research had helped them to better understand who they were teaching and how this understanding impacted their teaching.

In examining essays, I found that many narratives talked about ways in which classroom research had allowed for preservice teachers to better understand their students. In many cases, narratives talked about the ways in which authors had learned about their students through the data they collected. In other cases, preservice teachers actually considered how their data collection and analysis efforts allowed for them to learn from their students. For preservice teachers that constructed essays that demonstrated a strong understanding of how classroom 
research can impact practice, there was also evidence that classroom research allowed them to forge stronger relationships with their students.

Many narratives talked about how engaging in classroom research had provided an opportunity for authors to learn about their students. In one narrative, the author commented, "This work has shown me exactly how I can attract more and more students to the sciences and how to keep them actively engaged all while achieving mastery of the topic and subject content that is taught." In this example, the author was able to make use of his findings to better understand how the practice he implemented allowed for improved student interest, while still attending to student learning. In another narrative, the author said:

By conducting research during my mini-inquiry and final action research project, I was able to understand what backgrounds and experiences my students brought to the classroom that might influence how they learned from me. Conducting inquiry projects allows you to understand the demographics of your classroom. This includes the diversity of your students, their disabilities, and unique learning styles.

This preservice teacher was able to make use of multiple classroom research experiences to better understand his students. His quote suggests that classroom research had an impact on his ability to see the interaction between his teaching and his students' learning.

The author of another narrative noted:

While trying to provide students with the ability to control their own learning experiences, I found that they not only responded positively to the changes I made, but they took responsibility for their behavior and performance in my class. They started understanding that they were expected to perform to the best of their ability. Likewise, they showed me that all students are capable of positively responding to change and it is 
possible to alter students' attitudes toward learning when they are given the responsibility to learn on their own.

This excerpt is another example of how classroom research led one preservice teacher to better understand his students' skills and abilities. This quote also demonstrates that implementing new practices could also lead to a change in attitudes amongst students.

Our students also talked about learning about their practice from their own students. Often this occurred when the preservice teacher used surveys as a form of data collection. One student said:

During my secondary education, I was never asked what I wanted to learn or how I wanted to learn it. Therefore, I wanted to give my students a voice through freedom of choice and surveys to get their input on their education. I asked them how do they like to learn, and they answered with "technology." So during my Internship, I gave my students a choice in a project topic they would research on and the final project itself, which most consisted of videos and other technological creations, with the guidance of a class website. They had the freedom to do whatever they wanted, which they really enjoyed. I feel that this was such a valuable asset to learn because it is so useful.

In this example the student was able to provide choice as part of her classroom research. As a result, she was able to tailor new learning experiences to the interests of her students. This allowed her to make use of student feedback as part of her own learning process, and for her students to engage in meaningful learning.

In another example of learning from students, one preservice teacher wrote: During action research, I learned a lot from my students. Practices that I read in textbooks do not apply in certain classes, and I can see it in my students' performance. In 
my final inquiry project, I used student feedback as a data source. From the students, I learned that they are interested in having a voice in classroom projects. I chose the reading activities, but they had a lot of ideas for how they could be improved. I did not take what I learned from them as negative criticism, but rather constructive criticism. This example further illustrates the ways in which student feedback was viewed as a way to learn about the quality of a practice directly from students. This preservice teacher was able to take her students' feedback as "constructive criticism," and think about how to improve the strategies she implemented.

In still other cases, preservice teachers used observations to better understand their students. One preservice teacher commented, "The students were also very helpful when I asked them to complete something for my Action Research especially the informal interviews and surveys because they knew that their responses would directly affect what would be happening in the classroom." The intern quoted made clear to her students that she was researching her practice. By sharing her work with students, she was able to encourage them to actively participate in data collection, and thereby was able to improve her students' interest in how they were being taught, while also generating meaningful findings for her research.

Through their classroom research, some preservice teachers were able to notice ways in which their work impacted the relationships they had with their students. One preservice teacher said:

By getting the students' perspective on so many different issues, I am able to get a feel for my students, and enhance my rapport with them. I am able to find out what my students like and dislike. Also through surveys I was able to further determine student likes and dislikes 
In this excerpt, the preservice teacher was able to make use of surveys to better understand how his teaching impacted individual students. This demonstrates how data collection can allow for teachers to not only consider the academic impact of their practice, but also the impact of their teaching on students.

In another example, a student commented:

As I was inside of the classroom more, a relationship with my students was built. Once that relationship was built, inquiry helped strengthen the bond by allowing me to see how my students learned and how they liked to be taught.

In this excerpt, the author makes an explicit link between engaging in classroom research and bonding with students. This further illustrates the impact that classroom research can have on teacher-student relationships.

In each of these examples, students were able to make use of classroom research as a way to better understand their students. This understanding was less about their students' academic abilities, and more about how their students felt about school, learning, and the practices used by their teachers. In the most sophisticated essays, preservice teachers were able to use data collection and analysis to learn about their students, learn from their students, and then use this learning to positively impact their relationships with students. Teachers who are able to construct this learning through classroom research can then provide a resolution for their Classroom Research Narratives.

Having looked at our students' Inquiry Synthesis Essays in light of my research questions, my analysis suggests that some students were able to evaluate and resolve the research questions they constructed through systematic and intentional classroom research. These students were able to: (1) integrate their teaching and research, (2) generate findings focused on student 
learning and (3) learn about their students in ways that impacted practice, thereby developing a Classroom Research Narrative. Table 6.2 summarizes these practices and the practices that contribute to them.

Table 6.2: Supporting practices in the Classroom Research Narrative

\begin{tabular}{lll}
\hline Narrative Element & Practice & Supporting Practices \\
\hline Complicating Action & $\begin{array}{l}\text { Integrate Teaching and } \\
\text { Research }\end{array}$ & $\begin{array}{l}\text { Make research a part of teaching; } \\
\text { Consider impact of research on } \\
\text { teaching. }\end{array}$ \\
Evaluation & Meaningful Data Analysis & $\begin{array}{l}\text { Datalysis guided by research } \\
\text { questions; } \\
\text { Use experience to build on data } \\
\text { analysis skills }\end{array}$ \\
& Impact of Findings & $\begin{array}{l}\text { Use data to consider student learning; } \\
\text { Use data to consider teacher practice; } \\
\text { Consider learning about and from } \\
\text { students. }\end{array}$ \\
\hline
\end{tabular}

When students were able to use reflection and action to address a dilemma and were able to systematically and intentionally study their practice through classroom research, they were able to construct both an Inquiry Narrative and a Classroom Research Narrative, each of which contributed to their Life-Long Narrative. Preservice teacher who are able to construct all three narratives, demonstrate that they have sophisticated perspectives towards inquiry, and that they are able to manifest these perspectives in practice, including through the use of systematic and intentional classroom research. In the next chapter, I will look more closely at the many students for whom evidence of these perspectives and practices was missing. 


\section{Chapter 7: Considering Evidence of Inability to Construct Narratives}

In this chapter, I consider ways in which some students provided evidence that suggested either less sophisticated perspectives towards inquiry or less of an ability to provide evidence of how perspectives were manifested in practice. In doing so, I hope to share those parts of my analysis which allow a better understanding of the various ways in which some students, through their classroom research experiences, fail to develop as reflective practitioners, and ways in which some students demonstrate an inability to engage in systematic and intentional study of their practice.

In this chapter, I consider the ways in which various elements were missing from the essays I analyzed. First, I consider students whose essays either omitted key elements of the Inquiry Narrative, or whose essays provided counter-evidence of understanding these elements, thereby suggesting an inability to construct an Inquiry Narrative. Next, I consider ways in which many of the narratives I examined were missing elements that suggest an ability to construct Classroom Research Narratives. In some cases, an essay never addresses one or more elements of a narrative. In other cases, I was able to use coded text as evidence that an author did not understand an element. Where possible, I use this "counter-evidence" to demonstrate the misconceptions that some students had related to various elements of the two narratives. In providing these coded examples, I attempt to illuminate the various flaws that prevented students from constructing each kind of narrative.

\section{Evidence of Fracture in Inquiry Narratives}

In chapter 6, I considered evidence of how some students were able to construct a Classroom Research Narrative. Even with an ability to construct this narrative, a teacher would need to arrive at a point in which classroom research was necessary. For some of our students 
however, evidence of the reflection and action needed to provoke them to engage in classroom research was missing from their essays. For these students, all or part of the elements necessary to construct an Inquiry Narrative were absent. These students were either unable to demonstrate an ability to engage in the practices necessary to construct an Inquiry Narrative, or to demonstrate that they had developed perspectives towards inquiry that were sophisticated enough to suggest that inquiry would become a part of their teaching practice.

Worthy of noting is that many of the examples I used below are pulled from essays written by students who demonstrated an ability to engage in systematic and intentional classroom research. Given this, many of these students constructed narratives that demonstrated that their use of classroom research during preservice experiences had an impact on their teaching practice and their students' learning, but in doing so, did not provide evidence that these experiences led to the development of perspectives towards inquiry that allow for the development of Inquiry Narratives, and that might point to future use of classroom research.

\section{Wonderings without Dilemmas}

As mentioned previously, we emphasized the need for students to craft wonderings that were based on real-world dilemmas that arose in the classroom. We suggested that these wonderings might arise at the junction of preservice teachers' needs to both improve their own practice and impact their students' learning. Further, we suggested that wonderings should reflect preservice teachers' unique passions. In examining essays, students with less sophisticated perspectives towards inquiry often did not consider one or more of these ideas, thus making it difficult to see whether the classroom research of these students, no matter how well constructed, was undertaken with an actual dilemma in mind. 
In most cases, even when there was no mention of a student learning need or passion, preservice teachers considered their own practice. However, some students were not even able to focus on practice, as is the case with a student who wrote:

This first difficulty was finding guiding questions. I have not had much experience in the classroom therefore I do not have many meaningful questions to ask about my teaching styles or classroom environment. I believe inquiry would be more significant if I had more time to find guiding questions.

The author of this quote seems to suggest that finding a research question is a difficult and time consuming process. Whether he refers to an inability to make use of the literature and other resources to turn a dilemma into a research question, or simply an inability to find dilemmas, he leaves doubt as to how he will evaluate and resolve the complicating actions that arise as part of subsequent chapters of his Life-Long Narrative.

In other cases, it was a student learning need that was missing from wonderings. In the example below, there seems to be an interest in classroom management, yet there is no mention of a dilemma when the preservice teacher writes:

My first inquiry project was conducted in kindergarten and dealt with a classroom management technique to have the students learn about personal space. I read a story, did several activities, and brought in small hoops for them to sit in during carpet time for them to be able to see their 'personal space bubble.'

In developing the idea of an Inquiry Narrative, I have suggested that inquiry can serve to evaluate and resolve dilemmas. In this example, we see no evidence of an actual dilemma, thereby suggesting that this student may only have considered the process of inquiry because doing so was required. 
Very often, there was no mention of the preservice teacher's own passions, either explicitly or implicitly. Here a student seemed matter of fact in presenting her wondering:

I conducted my inquiry in a sixth grade reading classroom with twenty students. None of my students had any known special needs. I implemented literature circles in my class; they consisted of discussion, connection, and various other elements. I expected my students to be able to perform these skills at this age level, and taught them how to conduct the literature circles through direct instruction, modeling, and by having the students conduct "trial runs".

In this example, we see another instance where there is no discernible dilemma related to student learning. Further, the author of this excerpt provides no rationale as to why she chose to implement literature circles. Again, we might assume that the primary purpose of her work was to meet the needs of the assignment she was given.

In each of these examples, the process of finding a wondering was not clearly linked to a dilemma that came at the intersection of student learning, teacher practice and passion. In several cases, the underlying dilemma is not mentioned at all. Each of these examples suggest less sophisticated perspectives towards inquiry, and leave doubt as to their authors' interest in, or ability to, make use of reflection and action to evaluate and resolve the complicating actions that will arise during their careers as teachers.

\section{Underdeveloped Research Questions}

During program experiences, we made a clear distinction between a wondering and a research question. We explained that dilemmas around teacher practice and student learning, along with a teacher's passion, lead to wonderings. We then added that teacher-researchers need to consider what is already known about a given topic to turn their wondering into a meaningful 
research question. In examining student essays with less sophisticated perspectives towards inquiry, I found that often there was minimal evidence that the authors had used a systematic process to turn their wondering into a research question.

In many cases, students discussed their wonderings as if they were research questions. For instance, one student said, "I wanted to see where my students were at and see if I could prove my theory right. My theory was that students were relying too much on calculators and forgetting how to do their basic skills on their own." In this quote we see a dilemma that seems to come from the student's own views on calculator usage. While a teacher's beliefs about learning can often be the source for a dilemma, without any systematic process to consider existing research, "theories" like the one stated above are poorly suited to guide meaningful inquiry.

Another student, writing about her wondering, noted:

Through my final inquiry, conducted during my internship, I learned a great deal about the importance of assessing students' comprehension of a skill. My wondering focused on what variations could be used to teach $8^{\text {th }}$ grade English students how to recognize and identify writing and grammatical skills, as well as comprehend these skills at a level in which they were able to apply them to their own personal writing.

In this excerpt, the student clearly has a wondering (recognition of writing and grammar skills), and her inquiry seems to have generated some meaningful learning. However, because she never identifies the process whereby she selected the practices that guided her work, we have no way to determine if her resolution was properly aligned with her complicating action.

In some cases, students suggested some process whereby they turned wonderings into research questions, but this process seemed to lack any basis in the literature. For example, one 
student had a wondering based on a clear dilemma, but seemed to rely on her own opinions when she went from dilemma to implementation of a new strategy:

During my participant year in the program, I conducted a mini-inquiry project in which I wanted to see if reading with expression would increase fluency rates. At my PDS, and well as most other elementary school, younger students are constantly tested on their fluency rates. I had noticed that many of the students felt pressured to read a text as fast as they could, and were forgetting about comprehending what they were reading, and were quite monotone. Very few students actually read aloud with expression. During this study, students made characters from the books to read along with. Students had to construct the character, make up a voice for it, and read the story using that voice.

In this example, the student has a dilemma that serves as complicating action in her Life-Long Narrative (fluency). She also has constructed a research question that considered the role of expression in improving fluency rates. However, there is no evidence that the idea of expression as a way to improve fluency has any basis in the literature, thereby leaving us to wonder if the research question she constructed was an appropriate complicating action to evaluate and resolve.

Other students seemed to feel that classroom research was a way to test out various practices, rather than a way to look more closely at a carefully selected practice. For instance, one student commented:

My study was on implementing different learning styles, and how that can improve the learning of spelling words. I have always had an interest in different learning styles, and meeting the needs of all of my students. To do this successfully, I had to get to know my 
students. I had to experiment with different activities to see what helped them the best, and what did not help them at all.

While the idea of learning about students is a way to construct resolution in a Classroom Research Narrative, this student does not provide us with the research question that could serve as an abstract to her Classroom Research Narrative, thus no matter the quality of her data collection, analysis, and findings, we cannot tell if these findings are appropriate for the Inquiry Narrative her classroom research was expected to evaluate and resolve.

In each of these examples, students' essays failed to provide evidence that their authors had given thought to the process whereby a wondering became a research question. In some cases, students seemed to view wonderings and research questions as interchangeable. In other cases, students talked about moving from a wondering to a research question without providing a basis for how the process was accomplished. In other cases, there was no mention of a wondering at all. In all of these instances, my analysis indicated a lack of sophistication in this critical component of studying practice, and thus called into question the ability of these students to construct an Inquiry Narrative.

\section{Unsystematic Piling up of Data}

Through a series of classroom research experiences, we seek to emphasize the importance of systematic data collection and analysis to preservice teachers. In doing this, we encourage students to consider what data they collect, as well as how they analyze their data in light of their specific research questions. In some instances, however, I found evidence that data collection and analysis methods were not selected with research questions in mind. In these cases, students used whatever data was already available, often repeating their mistakes through 
multiple classroom research experiences. Further, these students also seemed to consider datarelated problems as beyond their control, rather than a product of poor decision-making.

In many cases, data sources were identified based on existing classroom activities and assessments. These activities and assessments were generally misaligned with preservice teachers' research questions. For example, one student seemed to want to arbitrarily simplify data collection noting, "Next, I had to determine the analysis of these data sources. I came up with the conclusion that I just needed to track participation and engagement as well as compare pre and post test scores." This quote suggests that no matter how adept he was at analyzing his data, it was unlikely that he would be able to generate findings that served as a meaningful resolution for his Inquiry Narrative. Another student seemed to go to the opposite extreme when she commented that:

After I figured out the strategy that I wanted to implement, I had to determine the data that I was going to collect. At the beginning, I was not sure what would be sufficient data to back up my inquiry. I started collected everything that I could, pre/post-quizzes, student work, test scores, and other in-class activities. During the data collection, I felt overwhelmed with all of the data that I was collecting because then I had to figure out how to analyze it.

The lack of thought as to what data might best help this student provide answers to her research questions led her to simply collect whatever data was available. This student did not demonstrate an ability to engage in the type of systematic and intentional study needed to construct a Classroom Research Narrative; nor provide evidence that she used reflection and action as is necessary to construct an Inquiry Narrative. 
Almost all students spoke about poor data-related decisions during early experiences. However, some students seemed to repeat those decisions in later experiences. For example, one student wrote:

Sometimes, it would feel so overwhelming to have such a vast amount of data in any given project. For example, in my direct versus indirect consequences inquiry, I had teacher notes, student interviews, documentation of on task and off task behavior and journals to read through and review. This seemed like a never ending amount of information to try to sort through to find the important aspects. My multiplication inquiry was similar. Having so many pre and post quizzes and surveys from an entire class of 25 was almost too much for me to handle.

As in the previous excerpt, we again see evidence that suggests an absence of the systematic and intentional study needed to construct a Classroom Research Narrative, and a lack of reflection to guide action in a way that allows for research questions to be evaluated and resolved through construction of an Inquiry Narrative. Given these same problems occur multiple times for the student, we must begin to wonder if this student, along with the student quoted in the previous excerpt, will be able to use reflection and action to solve the dilemmas they face during their careers.

For students who had data-related issues, I looked for evidence that these mistakes had served as a learning experience. However, often students saw these mistakes as beyond their control. Some blamed data-related problems on their students. One preservice teacher said: Another major issue I had was the size of the group I was able to study during my research. I found early that the amount of students that were in class on a daily basis and completed all of the necessary assignments was a very small fraction compared to the 
amount of total students in my classes. Since I had to drastically limit the size of my study, my results were inconclusive and biased toward students who were already performing well in my class.

As I have described previously, the difference between an Inquiry Narrative and a Classroom Research Narrative lies primarily in the extent to which a new practice is aligned with sophisticated data collection and analysis strategies used to generate robust findings. However, because all inquiry involves some level of data collection and analysis, when a student simply seeks to explain away the findings that come from data analysis, it seems less likely that they will make use of inquiry as a way to evaluate and resolve the dilemmas which serve as complicating action in a teacher's Life-Long Narrative.

In another example, a student again explained away his findings, this time using a routine issue, the weather, as an excuse, "I conducted a formal survey and analyzed some of the data. While I was invested in the participant inquiry, numerous amounts of snow days and cancellations prohibited the study from going further." While it is very possible that school cancelations prevented this student from generating the robust findings he was hoping for, his inability to consider those findings he did generate, suggests that he may continue to have difficulty finding the time and space necessary to collect and analyze enough data to make use of inquiry as a way to solve dilemmas.

In working with students throughout various classroom research experiences, I understand how difficult the process of data collection and analysis was for them to comprehend. While I expected to read about difficulties in this area, I also found evidence of students learning to be more careful when making data-related decisions. The examples above each point to students who did not make significant progress in their ability to align data collection and 
analysis with their research questions. These findings not only suggest an inability to construct a Classroom Research Narrative, but also suggest that for these students, the process of collecting and analyzing data is so challenging, it becomes questionable as to whether they will be willing or able to address dilemmas in a meaningful way. In these cases, we do not have evidence that, when dilemmas arise as complicating action in a Life-Long Narrative, an Inquiry Narrative will be constructed as a way to evaluate and resolve these dilemmas.

\section{Findings as an Endpoint}

In helping our students to understand classroom research, we placed significant emphasis on the ways in which teachers with an inquiry stance engage in cycles of reflection and action. Provoked by a process we saw as too product-focused, many of the revisions made to the Inquiry Strand were aimed at encouraging students to end each classroom research experience with new questions to consider. We encouraged students to take what they learned about their teaching and about research in early experiences, and apply this learning to later experiences. We also encouraged students to consider how their learning throughout the program would impact their future teaching and research activities. Yet, the essays of some students provided minimal evidence that classroom research experiences were going to have a tangible impact on future teaching or research.

In some cases, the ways in which essays discussed various experiences during the author's time in the program demonstrated little evidence that early experiences impacted later experiences. In some cases, students talked about the potential impact of their classroom research on students, but never suggested that they would implement the practices that had guided their research. In other cases, preservice teachers pointed to findings that suggested a practice was ineffective, but still felt that they would use the practice. One student wrote: 
I would recommend in the future integrating the art form every other week or every three weeks. It gave the students something fun and exciting to look forward to, but it had very little impact on the students actual test scores.

No matter the quality of this student's research questions, data collection and analysis, and findings, her conclusions suggest that she was willing to ignore outcomes in favor of what seems to be "fun." This kind of response suggests an inability to provide resolution to an Inquiry Narrative. For students that are willing to ignore findings, it becomes questionable as to whether they will be willing to continue to invest the time and effort necessary to generate findings.

Because one of the prompts of the synthesis essay activity asked how students would make future use of inquiry, almost all students suggested they would use inquiry in their future practice. However, many students did not discuss how they might continue to investigate new practices in a systematic way. One student said:

Ultimately I think every teacher uses inquiry whether they realize it or not. It can be as detailed as the work I completed in my internship or as simple as questing and trying to understand why one student is not reaching their potential. I will always want all of my students to be successful and therefore, will continue to use inquiry in my practice.

While this student seems to place some value on inquiry as a practice, by saying that "every teacher uses inquiry," and then suggesting how "simple" inquiry can be, we are left to wonder whether this student truly understands the importance of each step that goes into engaging in inquiry, even when this inquiry does not involve systematic and intentional data collection and analysis.

Another student provided an example that was even more contradictory, commenting: 
I believe inquiries that I conduct in my future classroom will model more of the smallscale inquiry as opposed to the large-scale inquiry due to the fact of time constraints and attitude towards reading professional articles and collecting and analyzing data. In this program, I have been provided with the support and time to work on the whole inquiry process, but when I am out there in the classroom on my own, I won't have an inquiry expert to consult and will probably be so busy that I don't even want to think about reading articles for information. I probably will either hear about or come up with a teaching method, want to see the effectiveness and gather a few data points for baseline, implement the method for a few times, and glance at the scores during and after the new method. I probably won't analyze them further, but I would look to see if the students' scores changed or not.

In this example, the student refers to "small-scale inquiries." However, when he is explicit about not having the time to review the literature, and then suggests that future data collection will not only be informal, but also will be focused less on classroom dilemmas and more on happenstance teaching methods, it seems unlikely that he will ever construct an Inquiry Narrative, and even less likely that he will construct a Classroom Research Narrative.

Each of these examples comes from narratives written by students who were unable to demonstrate understanding of the cyclical nature of inquiry. Whether during the program, or at its conclusion, there was a lack of clarity as to how these students would make use of either their understanding of practice, of research, or both. Further, while we encouraged students to allow the context of their classrooms to dictate wonderings and then research questions, we also encouraged students to take what they had learned in earlier experiences and then investigate these ideas in greater depth. Some students noted that they had interesting findings or that their 
early research had impacted them, but then never returned to these practices. In each of these instances, students did not demonstrate perspectives towards inquiry that were sophisticated enough to suggest that classroom research would become a part of future practice.

\section{Minimizing the Scope of Classroom Research}

As students progress through the program, each experience of the inquiry strand becomes more in-depth. In the mini-inquiry and the internship inquiry, we ask students to create written products and engage in extensive data collection and analysis which we hope will allow them to demonstrate an ability to construct what I have called Classroom Research Narratives. However, we also emphasize that inquiry can take many forms. As such, many students talked about different ways in which they might undertake inquiry experiences in the future. In some cases, students referred to the less formal experiences that would hopefully generate an Inquiry Narrative. In other cases, students talked about more formal experiences which would also generate a Classroom Research Narrative. However, some students talked about their future experiences in ways that suggest limited understandings of the necessary reflection and action required even for less formal inquiry, thereby suggesting that perhaps neither of these two narratives would be constructed. These students leave us to wonder if they would continue to use reflection to identify dilemmas, and if so, how they would evaluate and resolve these dilemmas.

Many students talk about inquiry in ways that suggested a disconnect between reflection and action. For example, one student said, “As I begin my teaching profession, I have many ideas on how I will incorporate inquiry into my future teaching. First, I would like to conduct and document frequent informal inquiries." While we accept that not every inquiry activity will involve robust data collection and analysis; this quote seems to suggest that a series of "informal 
inquiries" conducted "frequently" can be accomplished without attending to some of the processes of inquiry like using the literature to consider practices that might be appropriate.

Another student went even further by commenting, "I will not use inquiry the way that our teaching program had us use it, because let's just face it, that is way too in-depth and way too time consuming as a full time teacher to do." Given that we provided many experiences that asked for only minimal action, we must wonder what level of reflection and action will meet the time constraints of this student. Some students even suggested that classroom research might be replaced by some other technique. One student noted:

All in all inquiry was a good experience for me, and has taught me a lot about myself as an educator, my students, my practice and how something as little as inquiry can help us become a more effective teacher. I will continue to use inquiry in my future practice until I am presented with something that tells me that "xyz" is better than what I am currently doing.

While part of the inquiry strand of the program is focused on trying to find better ways of doing things, this student seems to think that the process of engaging in reflection and action as a way to evaluate and resolve dilemmas, is a practice that might be easily replaced, leading us to wonder if a practice so easily discarded might ever actually be used.

In each of these examples, the author suggests that they have only a surface understanding of inquiry. For students whose narratives did not make clear reference to potential future uses of classroom research, or who made reference only to inquiry of a limited scope, it is difficult to see development of perspectives towards inquiry that are sophisticated enough to suggest that classroom research will become a part of these students' teaching practice. As such, 
these examples also suggest that for these students, classroom research experiences did not seem to allow for a clear coda to be provided for their Inquiry Narratives.

In this section, I have provided examples in which students failed to provide evidence of one or more of the elements that make up an Inquiry Narrative, and thereby suggest less sophisticated perspectives towards inquiry. In many cases it is not possible to provide such evidence because students did not mention one or more elements. While these omissions could be the result of students choosing to focus on other things in their writing, such omissions could also mean that students were not considering each of the elements important to sustaining inquiry as a part of the day-to-day work of teachers who are reflective practitioners. In some cases, these same students provide robust evidence of the impact their classroom research had on students or their practice while they engaged in a given classroom research experience, but were unable to demonstrate that this research served as the resolution of a meaningful research question, or how their research would influence future practice. While these students may have developed some research practices, evidence suggests that they are lacking the practices and perspectives necessary to become teacher-researchers.

\section{Evidence of Fracture in the Classroom Research Narrative}

The previous section described how some students were lacking in their ability to provide evidence of an ability to construct an Inquiry Narrative. However, in chapter 5, I provided evidence that many students were able to develop the elements of an Inquiry Narrative. For many of our students, whether or not they were able to articulate sophisticated perspectives towards inquiry, their ability to provide actual examples of how these perspectives were manifested through systematic and intentional classroom research was lacking. Even in instances where 
narratives had suggested sophisticated perspectives towards inquiry, some preservice teachers did not discuss how these perspectives had a direct impact on their teaching or students.

In this section, I consider the elements described in chapter 6 as comprising a Classroom Research Narrative. I examine ways in which many students fell short in demonstrating an understanding of these elements, thereby leaving doubt as to these students' future ability to make use of classroom research in ways that could make a significant impact on their teaching practice and/or their students learning. It should be noted that many of the examples I use below are from essays written by students who demonstrated the practices and perspectives necessary to develop an Inquiry Narrative. However, these students were unable to indicate that they would be able to make use of classroom research as a way to evaluate and resolve the research questions that serve as complicating action in these narratives.

\section{Missing Teacher Practice Elements}

As mentioned previously, we emphasized the need for thinking critically about those practices that would be examined during classroom research experiences. We further discussed the need for students to talk about what they learned about the practices they investigated. Finally, we encouraged students to be teacher-researchers, rather than part-time teachers and part-time researchers. My analysis suggested that often students did not attend to their practice in these ways as they engaged in classroom research.

In examining their essays, often students failed to provide evidence that their understanding of classroom research was developed enough to help guide the selection of the practices that served as the basis for classroom research experiences. In many cases, essays made no mention of how a given practice became the focus of research. In these examples, students often addressed their "topics" simply by saying things like, "In the second year, I had a different 
group of students so I had to change my question again to meet the needs of my classroom at the time, this again seemed like it was just another assignment." This quote suggests that the student approached his work as a researcher, rather than a teacher-researcher, and thus did not provide evidence of his ability to provide the complicating action necessary for a Classroom Research Narrative. Even when students talked in greater detail about the topics they investigated, the genesis of topics often was not clear. For example, one student wrote:

When I started to think about my inquiry project, I was trying to decide what area that my students could gain the most benefit in. I considered a variety of different strategies, such as having my students write mathematical concepts to help with their understanding, or focusing on fractions. But I decided that so many students struggle with math classes because they do not have the foundational skills necessary to move on. Realistically, I cannot spend my time figuring out what these missing skills are and then focusing on them while trying to move the course forward. So I decided that mastery learning in Algebra I would best benefit the students in my study.

In this excerpt, there is evidence that various practices were considered, but it is unclear what dilemma these practices might address. As such, it is hard to see how, even with robust data collection and analysis, a real complicating action for the student's Classroom Research Narrative ever existed. In other cases, the rationale behind selecting a practice seemed to be based on convenience. One student noted that, "Unlike several of my classmates, I went into my internship knowing exactly how I wanted to proceed with my inquiry."

No matter the process students undertook for selecting the practices that guided their research, some students seemed to draw few conclusions about the viability of the practices they 
investigated. One student provided a rationale for their study, but in a single paragraph description of his work, never mentioned the outcome of his research:

My inquiry project during my intern semester focused on direct instruction strategies to help students learn their basic multiplication facts. I decided to use this as my action research topic after coming to the conclusion that the majority of my students disliked math and were not fluent with their multiplication tables. I was so shocked because I knew all of my basic multiplication facts by the time I was out of the third grade. It came to mind that I had a parent at home who was drilling me with facts every day after school and a lot of my students did not have these resources. I decided to research strategies that could help the students learn their multiplication tables so that they would be have the skills necessary to move in to more complicated math. I was not shocked that the majority of my students did not like math. I think that the students are not confident with their math skills, which is very discouraging and causes them to have a bad attitude. While this student hints at a dilemma and at conclusions, because he does not consider specific findings or mention the data that might have led to findings, there is doubt as to whether an Inquiry Narrative was truly constructed. There is even more doubt as to whether a Classroom Research Narrative was constructed to evaluate and resolve a research question.

Another student seemed to draw conclusions from her work, but these conclusions have no relationship to any research process:

Recently during my final inquiry project, I also learned that my students are very eager to learn. Because I showed enthusiasm for their learning and for my inquiry project, I believe that this allowed the students to get excited as well and want to learn and improve their own learning. I think there is [a] direct correlation between the teacher's 
enthusiasm and not only how the student feels about the material, but what the student takes home in information as well.

This student seems to have generated a resolution to her Inquiry Narrative. However, it is unclear where this resolution comes from; leaving us to wonder if a related Classroom Research Narrative was actually constructed.

Frequently, students would suggest that their data pointed to problems with the practices they examined, but some of these students would point only to flaws in the analysis or context as reasons for their findings. For example, one student seemed to feel that the lack of success she had with a new practice was based only on the way she assessed the practice:

After the first week I realized that the way in which I was grading students on their vocabulary words did not correlate with semantic impressions. I graded them based on matching 8 of their words and writing a sentence for two words. The entire purpose of semantic impressions is to develop word knowledge through using the word correctly in a story. I strove to find a correlation between implementing semantic impressions into the classroom and an increase in student performance on vocabulary tests; however, I failed to accurately assess their understanding of the vocabulary words.

In this example, the integration of a new teaching strategy, along with data collection to assess the value of the strategy provides complication action in a Classroom Research Narrative. However, does not provide evidence that she was able to evaluate or resolve this complicating action, thereby suggesting that she may be unable to properly construct a Classroom Research Narrative.

Another common indicator that students were not able to think about their own practice throughout the process of engaging in classroom research became evident when narratives 
mentioned clear conflicts between teaching and research. For instance, one student said, "My biggest difficulty throughout the inquiry process was collecting data on top of everything else that needs to be done." Another commented:

I even found at times I was putting more focus on my inquiry than the students themselves. My students are the most important in my classroom and when I found inquiry was getting in the way of their education, I had to lessen the requirements of my inquiry.

In both of these excerpts, we again see the tension between teaching and research that provides the complicating action of a Classroom Research Narrative. However, neither student provides evidence of an ability to evaluate this complicating action; and in the second excerpt it is quite clear that such evidence could not be found.

In each of these examples, students were unable to provide a strong rationale for making use of a teaching practice for their classroom research endeavors, or were unable to make a meaningful judgment about the practices which they used, even after collecting and analyzing data. These examples suggest that even if the students had developed Inquiry Narratives, they were not able to engage in meaningful classroom research as a way to evaluate and resolve the complicating action created by the need to integrate their research and their reaching practice.

\section{Missing Student Learning Elements}

Each classroom research experience embedded in our program has a data analysis component. In each of these experiences, we ask each student to examine the data collected using an analysis that makes sense given the student's research questions, and then present the findings. Despite this emphasis, I uncovered evidence that suggests that many students did not engage in meaningful data analysis activities. 
In some cases, students talked about what they might have learned from their research, without making use of data they collected and analyzed. I encountered numerous examples where students made no reference to the process of interpreting the data used in their findings. In cases where this occurred, narratives included only broad generalizations about research. For example, one student said:

This project was very extensive. I dedicated countless hours in creating lessons based around the inquiry, analyzing data, and collaborating with other teachers and my small group facilitator. Upon its completion, I became very proud and satisfied with my work. It was eye-opening to see my growth as a teacher researcher and my growth in the understanding of inquiry

In this excerpt, the student suggests that perhaps she was able to consider teaching and research together, thus indicating an ability to recognize the complicating action of a Classroom Research Narrative. However, there is no evidence provided which suggests that her data analysis provided evaluation for her Classroom Research Narrative, or how findings led to resolution of the narrative.

Other students made reference to their findings, but did so in a way that called into question how they had arrived at these findings. One student wrote that:

Inquiry required me to look further into student grades and carry out reasoning on student grades. This allowed me to see what little strategies worked among students within the realms of the inquiry as a whole. I was able to identify student areas of improvement while focusing on teaching strategies that succeeded. I was able to see how test grades reflected daily activities and quizzes throughout the semester. 
In this excerpt, the student seems to be confident that he generated some findings related to his research questions. This suggests a possible resolution to his Inquiry Narrative. However, because any reference to data analysis is missing, it is not possible to tell if these findings also represent resolution to a Classroom Research Narrative.

Some students were able to articulate findings as a part of systematic analysis, but then seemed to ignore what their data told them. One student said, "By using this, I have been able to see how differentiated instruction and note taking affected my students. Even though my data did not support significant effectiveness to either one, I know they both can be useful." Student comments like this one are puzzling. Data seems to suggest a finding that the student then ignored. Whether because the student was not confident of the quality of his data analysis, or because the student simply chose to ignore his analysis, there is evidence that this student does not understand the ways in which data analysis should serve as evaluation in a Classroom Research Narrative. This evidence indicates that it is less likely the student will bother to try and construct Classroom Research Narratives in the future.

In each of these examples, students neglected to talk about their data analysis and the ways in which that analysis provided evidence of student learning. In some cases, findings were not mentioned. In other cases, findings were not supported by analysis or were in conflict with the analysis methods used by the students. In each case, the student was unable to demonstrate that future classroom research activities would allow for an understanding of how the practice researched impacted students' learning. Given the inability to demonstrate meaningful data analysis leading to findings, the evaluation and/or resolution necessary in a Classroom Research Narrative is absent, thus making it impossible to determine if these students have developed the practices needed to engage in classroom research in the future. 


\section{Missing Understanding Students Elements}

As part of a rationale for making use of classroom research, we emphasized to our students the need to learn about various practices in a contextually relevant way. As such, we encouraged students to look not only at the overall impact of the practices they implemented through classroom research, but also how individual students were impacted. Even in cases when students' considered the impact of a researched practice on student learning, some students were unable to look at this learning in terms of individual students or students with certain characteristics.

In many cases, I found examples where narratives made blanket judgments about a teaching practice, but made no effort to look more deeply at the impact of the practice on individuals or smaller groups of students. For example, one student said:

At the conclusion of the inquiry period, I administered a posttest in order to understand what, if anything, my students learned about efficiently using map skills. What I learned from this process is that my students did in fact benefit from the daily integration of map skills into the classroom, and that many of the students felt the activities improved their understandings of the subject material. When comparing the results of the pretest and posttest scores in my class periods, I was able to determine that the averages of all of my class periods increased from one examination to the other. In three of my class periods, the average test score increased by one letter grade, with the greatest increase occurring in my second period class, in which the average score increased thirteen percentage points. While the other two class periods that participated in my inquiry did not see such the significant increase in average, the average score increased by six to seven percentage 
points. The results of this inquiry taught me a great deal about my students and the way they learned in the classroom.

In this excerpt, the student is clearly pleased with his findings. Further, these findings appear to be based on systematic data collection and analysis. However, the use of a pre-test and a posttest, accompanied by any teaching strategy would suggest that an increase in scores was likely. That there was no evidence of an attempt to triangulate findings, suggests a limited ability to use data to help develop answers to research questions. This lack of triangulation is further evidenced by the variation in increase across the three class periods examined. As such, we cannot see if these findings represent a true resolution, nor can we see if the methods of analysis used, represent a meaningful way to evaluate the new practice examined.

Similarly, another narrative made reference to learning about students in general. In this case, there is reference to learning about each student, but no evidence this kind of learning occurred:

During the inquiry I conducted in my internship semester, I found that my students learned best through hands-on and engaging activities. They were able to recall letter names and sounds and stayed on task in centers when I implemented my educational games. My students also thrived within a small group setting during centers. I was able to guide a small group center and provided the differentiated instruction that my students needed. Overall, from inquiry I have learned that each of my students is an individual learner that I need to make sure I am meeting the needs of each and every day.

This student begins by suggesting that all her students enjoyed the "hands-on activities." She then goes on to describe how her research allowed her to see how each student has different needs. These outcomes, which should serve as resolution for a Classroom Research Narrative, 
are in conflict, thereby calling into question this student's ability to analyze and interpret data as a way to evaluate a research question.

In other cases, I found that even when data was collected that could have helped preservice teachers better understand their students, this opportunity was missed. For example, one student wrote:

My results from the pre-tests and post-tests showed that there was some increase in the scores on the post-test from some student's but not very many. I think the students that trusted me, their scores went up but you could see that most of the student's still didn't trust me. I was only in the room twice a week which I think played a major role in implementing this as well.

This excerpt is one example where student learning data did not give a preservice teacher the answers he hoped for. While the student's ability to recognize the outcomes of his data analysis is important, his need to then draw conclusions that are not rooted in the data suggests that he only places limited value on data analysis as a way to evaluate a research question. As such, it becomes questionable as to whether he might make use of robust data collection and analysis as a way to consider future research questions.

Another student seems to have uncovered data that could point to an ineffective strategy; however, she chooses to make use of an analysis method that avoids this conclusion:

Then deciphering the data gave me a headache too. For example, my students test scores yielded different results depending on how I looked at them. When just looking at the average score of the three tests there was no real change, but when looking at the letter grades there was a difference. With each test the A's and F's decreased while the B's and C's greatly increased. I chose to put both sets of information in my paper, but to focus 
more on the changes in the letter grades. Deciding how to decipher things like reflections and participation rubrics was very tiring too. There are just so many ways to interpret data, and I struggled with which way to do so.

This student was able to make use of multiple analysis strategies to consider the same data source. However, by focusing on nominal data (letter grades) over ordinal data (class average); the student seems to be more interested in finding a change than actually considering what her data means. This suggests only a limited ability to use data analysis as a way to evaluate, thereby leaving us to wonder if the student will be able to make use of classroom research to resolve dilemmas.

In each of the examples in this chapter, students missed opportunities to use classroom research as a tool to impact their current practice. In some cases, students demonstrated sophisticated perspectives towards inquiry, but without a demonstrated ability to manifest these perspectives through systematic and intentional classroom research, it becomes difficult to know whether these students' future research endeavors will lead to meaningful change. In other cases, students demonstrated an ability to use the practices critical to classroom research, but lacked the sophisticated perspectives necessary to actualize these practices in a meaningful way. Other students were able to demonstrate the practices and perspectives necessary to construct an Inquiry Narrative, but were lacking the practices and perspectives needed to construct the related Classroom Research Narrative.

In a few cases, students neither produced evidence that they could develop an Inquiry Narrative, nor that they could develop a Classroom Research Narrative. One essay was completely off topic, focusing on inquiry learning by students. A second essay was focused almost wholly on providing a scathing critique of the inquiry strand (the student spent four of six 
pages providing suggestions for improvement). In each of these cases, the student did not produce a Life-Long Narrative. In other cases, students simply did not provide evidence of developing perspectives towards inquiry or evidence that they had an ability to systematically and intentionally study their practice through classroom. Because these essays generally represent an absence of evidence, it was difficult to make use of them in this section. Having considered the elements of each of the three narratives outlined thus far, in chapter 8 , I will consider how one student was able to demonstrate an ability to construct each of these narratives. 


\section{Chapter 8: The Exemplar Life-Long Narrative of Brian}

In this section, I consider an essay written by a student I call "Brian.” In his essay, Brian is able to demonstrate sophisticated perspectives towards inquiry. Brian is also able to make use of reflection and action and engage in systematic and intentional classroom research. While Brian's essay is not the perfect example of any one element developed in prior chapters, in totality, Brian's essay demonstrates development of each element. As such, the narrative written by Brian, who was a secondary education major with a specialization in science, can help us to understand how this student has been able to actualize his learning about classroom research in a meaningful way. Brian's essay can also help to illustrate the ways in which multiple Inquiry Narratives and Classroom Research Narratives can lead to an exemplar first chapter of a teacherresearcher's Life-Long Narrative.

For the remainder of this chapter, I will reproduce the essay in its totality, and annotate sections of the text that provide evidence of sophisticated perspectives towards inquiry and manifestations of these perspectives in practice. I use this approach so that readers can consider one way in which the elements of these narratives were developed by a student.

The essay begins with an introduction that demonstrated Brian's understanding of classroom research as a way to use reflective practice in an effort to impact student learning, as well as described how his experiences have helped him to understand classroom research as a viable teaching practice:

As reflective practitioners, teachers try to interpret events occurring in their classrooms and schools and closely examine their everyday decisions to improve their teaching. Reflecting on one's own practice includes practitioner inquiry, and it requires concentrated effort with the ultimate goal of increasing student learning through effective 
instruction. My teaching experiences thus far have given me concrete evidence of the relationship between teaching and the quality of learning.

This introduction serves as an abstract for Brian's Life-Long Narrative by pointing out his understanding of inquiry.

Brian then goes on to demonstrate understanding of the relationship between teacher practice and student learning by writing, "When my students succeed it is partially a reflection on my teaching ability, and when my students perform poorly it calls attention to the appropriate modifications I must make in my teaching practice," thereby further developing his abstract.

As the essay continues, Brian describes his initial understanding of classroom research and the reflection that can serve to guide the research process. In doing so, Brian points to using the literature as a key element in his current understanding of classroom research that was missing from his initial understanding:

My understanding of inquiry has gradually evolved since I began the teacher education program at [University Name]. Three years ago, I had very little knowledge of what inquiry meant or what the inquiry process entailed. I also possessed minimal understanding of the complexity behind intentional reflection. For example, I remember having concerns about my students' learning and considering different teaching strategies. What I did not realize at that time was the importance of reviewing the educational literature to gather information about research-based instruction.

In this excerpt, Brian's reference to the literature as a first step after the emergence of dilemmas, points to making use of inquiry as a way to consider possible solutions. By stating this, Brian mentions dilemmas that will serve as complicating action for his life-long narrative. Inquiry will become the evaluation of these complicating actions. 
As Brian's narrative continues, he also points to his early misconceptions around the ways in which practices for inquiry should be selected for implementation:

Another area that I would consider a weakness at that point in time was my haphazard way of implementing a change in my teaching. Three years ago, I would have thought of something new to try, try it with my students, and conduct a very superficial analysis of whether it had been successful or not.

Here again we see a development in Brian's ability to build an Inquiry Narrative. Brian has multiple dilemmas serving as complicating action over time, but his acquired ability to think beyond happenstance solutions points to using inquiry as a way to evaluate these dilemmas thereby pointing to his development as a reflective practitioner.

Brian then considers his current understanding of the classroom research process. He points to greater sophistication with data collection and analysis, including using data before, during and after implementing a new practice. In this excerpt, Brian demonstrates an understanding of the relationship between dilemmas, research questions, data and findings:

Now that I have had much practice with the inquiry process, my deeper understanding of inquiry has resulted in much more systematic, intentional methods for determining my students' learning. I have learned to collect baseline data before implementing a new instructional strategy so that I can compare levels of student achievement before and after refining my teaching. Instead of waiting to analyze student learning with a summative assessment, I assess the effectiveness of my teaching strategies frequently through formative assessments. I have also realized the importance of ongoing data analysis because of the concept of reflection-on-action. Reflection-on-action occurs as teachers 
critically examine levels of student learning and engagement after a lesson has taken place.

As Brian begins his conversation about data analysis, he makes reference to systematic and intentional methods. This suggests that dilemmas will lead to research questions, rooted in the literature, which will become complicating action in an Inquiry Narrative. Data collection and analysis will be used as evaluation of this complicating action, and because Brian points to systematic and thorough data collection, we begin to see evidence of Brian's ability to construct Classroom Research Narratives to accompany his Inquiry Narratives.

These excerpts provide evidence of Brian's understanding of the processes that guide classroom research. As his narrative continues, Brian applies his understanding of teaching and researching to his own experiences:

As an example, my ongoing data analysis during my spring participant inquiry allowed me to make an immediate modification in my teaching strategy to address a downward trend in student achievement [citation of own work]. Data from this inquiry report showed that my students' reading comprehension scores were decreasing during the course of my study. Because of reflection-on-action, I modified my teaching strategy to include more emphasis on identification of main ideas in reading passages. This modification was followed by positive gains in my students' reading comprehension scores. I believe that this particular example illustrates my improved understanding of intentional reflection and data analysis, and a significant step forward in my adoption of an inquiry stance. My current understanding of inquiry is that it is a continuous process, and I believe that I must re-examine my teaching practices constantly if my instruction is to be effective. 
This text illustrates Brian's general understandings of inquiry and classroom research. Now we begin to see a specific incidence of classroom research. During his mini-inquiry, Brian describes ongoing data collection and analysis. Through this process, Brian modified his teaching practice (identification of main ideas in reading passages), demonstrating that in a Classroom Research Narrative Brian had complicating action, and made use of data analysis to resolve this complicating action. Brian then described how his ability to be a teacher-researcher and shift practice led to "positive gains" that became the resolution of the Classroom Research Narrative constructed during his mini-inquiry. Brian concludes this section of his essay by discussing the ways in which his mini-inquiry allowed him to understand how he could better consider future practice in teaching and research. This shows that his Classroom Research Narrative allowed for resolution of his Inquiry Narrative, and that the ways in which this resolution shaped Brian's understanding of reflective practice, thereby providing coda to the Inquiry Narrative that was developed as part of his mini-inquiry.

As Brian's narrative progresses, the focus shifts to how classroom research has impacted Brian's understanding of his own students. In doing so, Brian talks about how findings from an early experience allowed him to understand the need to consider the learning of individual students:

One of the most important themes I have realized through inquiry is that every student is a unique individual who learns in a unique way. I have come to understand the importance of differentiated instruction and teaching students in the context of their diverse backgrounds and learning styles. My spring participant inquiry involved the implementation of listening passage previews to improve reading fluency, and the implications for teaching that I generated from this study discuss the importance of 
avoiding a "one size fits all" approach to instruction [citation of own work]. I had implemented a research-based teaching strategy that had been effective for increasing students' reading fluency, but the results for my class were widely mixed. Some of the students showed significant improvement, some of them demonstrated no change, and still others showed negative trends in their reading fluency.

In considering the final outcome of his mini-inquiry, Brian provides further evidence of resolution in his Classroom Research Narrative, and how the ways in which his findings impacted future practice, thereby also providing a resolution to his Inquiry Narrative.

These mixed findings reported above allowed Brian to understand the relationship between research-based practices as described in the literature, and the unique contextual circumstances of his classroom. Brian continues to follow this idea by writing:

Because I assumed this "best practice" would be effective with all my learners, it was disappointing to see such wide variability in student performance. As an outcome of this situation, I learned how my students respond differently to a single teaching strategy and how I might differentiate a learning strategy to meet the needs of all my students. From that point forward, I began to adapt teaching strategies to the particular groups of students I was teaching. When I began to notice that some of my students struggled with taking notes, for example, I constructed guided notes and questioned them more frequently during lecture to assess their current levels of understanding. I continue to avoid implementing a "best practice" directly from the literature without first modifying it to fit the unique needs of my own set of students. It is important to utilize research-based teaching practices in the specific context of a particular classroom and a particular group of learners. 
By extending beyond the scope of his mini-inquiry, and talking about his future teaching, Brian provides coda for this Inquiry Narrative. He furthers this coda by talking about the ways in which his future research was impacted. Brian notes that while using the literature is important, it is also important to understand students and context. This suggests that future research questions will be rooted in an understanding of student needs.

As Brian's narrative progresses, he begins to think about the impact of classroom research on his own teaching. Using findings from his internship inquiry, Brian demonstrates how he began to understand the need to assess students' prior knowledge, thereby demonstrating an ability to take some unexpected findings from his data, and derive meaning from these findings in a way that might impact future practice:

I have gained knowledge about my teaching in several ways through the process of inquiry. The first piece I learned about my teaching is that I used to design my learning units without first assessing students' prior knowledge and skills. Because of my intentional reflection on data related to student learning - a part of the inquiry process - I became aware of the reasons for why my students appeared to struggle with learning new content. My intern inquiry report describes the situation I encountered when I neglected to take into account my students' prior literacy skills, and some students struggled with the assigned writing tasks [citation of own work].

The results in this report showed that many of my chemistry students had difficulty communicating about a current issue in science or technology because of their writing skills. I had assumed my students' mastery of grade-level writing skills; therefore, I did not assess this skill before I began my lessons. I now know how crucial it is to determine students' current levels of understanding and prerequisite skills before 
beginning instruction because of the impact it has on future learning. I have learned that the effectiveness of my teaching is dependent on my ability to build from students' prior knowledge and skills. As a result of inquiry, I have informed my teaching practice so that I conduct assessments for learning. In this case, I use knowledge of students' prior skills to design lessons that are more appropriate and meaningful for them than before.

In this section of his essay, Brian begins talking about his internship inquiry. Brian saw that his students were struggling with new content, and these struggles provided a new complicating action in Brian's Life-Long Narrative. As he mentions later in his essay, Brian makes use of nontext resources to help develop students' content understanding. Brian again demonstrates an understanding of the importance of reconciling teaching and research activities, and constructs a writing assessment as a way to collect data and assess students. However, because Brian's students' struggle with writing tasks, this limits the effectiveness of Brian's data. In this case, Brian constructs a Classroom Research Narrative. He constructs a new kind of assessment to address the complicating action of integrating teaching and research activities. The collection of data allows for evaluation, but findings indicate that Brian has difficulty resolving his dilemma. Despite this difficulty, Brian is able to make use of his classroom research as a way to consider future practice. In this way, Brian demonstrates a resolution to the related Inquiry Narrative.

As Brian's narrative continues, he discusses how his classroom research experiences have helped him to understand the complexity of teaching:

Inquiry has helped me grow as an educator by giving me a new perspective on teaching. It has given me a greater understanding of the complexity of teaching, and the exciting possibilities that can be unlocked with the inquiry process. The complexity of teaching derives from many factors which include the variety of students' backgrounds, the 
integration of technology into instruction, the level of parental and community support, the amount of instructional resources and curricular materials, the demands of standardized testing, and many others. Inquiry has granted me a powerful lens with which to view these different factors that affect teaching, and it is a tool that I now use to examine the effects of changing an element of my teaching related to these factors.

In this quote, Brian references the complexity of teaching, demonstrating an understanding that dilemmas will continually present themselves. He further acknowledges inquiry as a way to reconcile these dilemmas, thus providing evidence that he will continue to make use of inquiry as a way to evaluate and provide resolution to the dilemmas he faces.

Brian not only talks about his learning in general terms, he is also able to weave in a specific example from his own research to illustrate how this learning occurred:

For example, I used different types of instructional resources and curricular materials during my intern inquiry as part of my instruction. I moved away from the textbook that is often relied upon for teaching, and I taught students about current issues in science using videos, news articles, and the internet. After analyzing the qualitative data I had collected through journal prompt responses, a theme emerged regarding my students' increased appreciation of the STEM fields [citation of own work]. Inquiry engaged me in using resources beyond the textbook and traditional classroom materials, and it encouraged me to develop new ways of delivering the science curriculum to my students.

Here Brian is providing a specific example of how inquiry was used to evaluate a dilemma. His ability to articulate a specific data collection and analysis process suggests that in addition to making use of inquiry, classroom research was used to evaluate and provide resolution to a research question. As part of this classroom research, Brian considers data collection on new 
practice (complicating action), and then makes use of qualitative analysis as a way to evaluate this practice. His findings (greater student appreciation of STEM fields) serve as resolution of this Classroom Research Narrative, and also provide resolution of the related Inquiry Narrative.

Brian's essay also provides evidence that he understands the value of sharing learning through classroom research, again using his own experiences to illustrate the potential impact of sharing findings:

Inquiry has also helped me grow as an educator as I share my knowledge base of teaching with others and participate in professional conversations about teaching and learning. The dialog among educators as they share their inquiry work has a rippling effect of change in the world of teaching. As a pre-service teacher I have discussed, debated, and explored different teaching practices with others as we share our work informally and formally. Whether it is through casual conversations in the teacher's lounge or through presentations at a conference, the dissemination of inquiry work has expanded the framework from which I base my teaching.

In this quote, Brian shifts back to his overall experiences. His willingness to consider how his own inquiry can impact the work of his colleagues serves as coda for multiple inquiry experiences.

Brian is also able to consider how classroom research can help advance the teaching profession:

The transformation of the teaching profession relies on teachers who are not stagnant in their practice and are interacting with their colleagues about their work. I am amazed with my growth in shaping my own teaching practice through discussions and 
conversations with other educators, and it is humbling to think that I am making my own rippling effects in the field of education with the work I contribute.

Brian provides further coda to his Inquiry Narratives and also begins to demonstrate coda for his Life-Long Narrative.

In considering the ways in which classroom research can be difficult, Brian considers these difficulties as challenges. Among the challenges Brian discusses are the ways in which classroom research demands simultaneous and integrated attention to both teaching and research: Inquiry has been difficult at times because it forces me to critically examine my teaching and engage in careful scrutiny of my work as I ask myself the question, "am I doing enough for my students?" This type of question has been asked before, especially by teachers who understand their profession as intellectual work. I find teaching to be one of the most satisfying, demanding, and sometimes stressful experiences I have known, and one reason for this is that I view my students' learning as my most important responsibility. I am aware of how the quality of my instruction impacts the quality of my students' learning. Inquiry has allowed me to explore and reconsider my instructional practices in a systematic and intentional manner, and it has been challenging at times to maintain this level of rigor because of all the other responsibilities and distractions that can burden a teacher. However, I believe inquiry should be part of the intellectual work of every teacher because of its power to move educators away from the routine ways of teaching. It is intellectually exhausting work at times, but it is more than worth the time and effort when we see our students benefit.

This discussion further demonstrates Brian's understanding that inquiry, especially inquiry that leads to formal classroom research, is time consuming. In this way, Brian recognizes that the 
need to be a teacher-researcher creates complicating action in a Classroom Research Narrative. However, Brian realizes that by evaluating and resolving this complicating action through systematic and intentional data collection and analysis, meaningful findings can be generated that can guide the changes in practice which serve as resolution to an Inquiry Narrative, and can impact the future course of a Life-Long Narrative.

As with almost all students, Brian considers the time it takes to engage in meaningful classroom research. Again, however, Brian talks about the rewards that came from his willingness to take the time necessary to engage in purposeful data collection and analysis, thereby indicating a strong likelihood that his future research endeavors will attend to the steps necessary to yield meaningful findings:

In terms of specific elements of the inquiry process, I would identify the area of data analysis as the most difficult for me. Even though I analyzed data about student learning as I collected it, the amount of information from qualitative and quantitative sources seemed overwhelming at times. Another challenging aspect of data analysis was the process of making sense out of the data and interpreting the results in the context of my particular set of students. For example, my intern inquiry involved a pool of data sources that included roughly 150 pieces of student writing, 60 journal prompt responses, and 60 surveys [citation of own work]. The wealth of information contained within these sources of data required me to extract the meaningful portions that addressed my guiding research questions. Additionally, my interpretation of the data from my students' written responses required me to organize relationships and construct emerging themes. This level of thoughtfulness and deliberation in data analysis has been intensive work, but it is extremely rewarding to assess the impact of instruction on the quality of learning. 
Brian's comments about data collection point to the difficulty in evaluating a Classroom Research Narrative. This excerpt also allows us to see evidence of Brian's realization that coda in a Classroom Research Narrative comes when the findings that serve as resolution are of high quality, thereby allowing for greater confidence in the answers provided to the research questions which serve as the abstract of a Classroom Research Narrative.

At the conclusion of his essay, Brian considers how he will use classroom research in the future. Like many of his peers, Brian mentions perhaps using more informal approaches. However, unlike many of his peers, Brian makes clear that while his writing process may be less formal, his sophisticated understandings of the classroom research process will likely lead to more successful practice:

In the future, the process of inquiry will guide my daily teaching practice as I engage in reflection during and after every lesson. I will continue to examine areas of student needs, create wonderings, review related research, implement and modify new strategies, collect and analyze data, and share what I have learned. This process may occur in a more informal manner when compared to writing formal inquiry reports, but it has become a much more natural part of my everyday instruction. My extensive experiences these past three years have helped me to adopt teacher inquiry as a stance so that I am frequently modifying my teaching practice after reflecting on data related to student learning.

Brian begins this paragraph by considering student needs, wonderings, research, new practice, data, findings, and the impact of these findings. In this way, we see his ability to fully summarize the components of an Inquiry Narrative. While Brian acknowledges that such inquiry may be informal, Brian's previous discussion and examples suggest that he not only understands the 
purpose of inquiry and its processes, but also has the necessary skills to engage in more formal classroom research when necessary.

Brian concludes his narrative the way he begins it, by considering the importance of the literature. In addition to repeating his belief in the value of being a consumer of research, Brian provides further evidence of his sophisticated perspectives towards inquiry by mentioning the importance of discussing existing research with colleagues:

There is a plentiful amount of research grounded in effective methods in science instruction, and as I grow professionally I will continue to try best teaching practices in my classroom. Accessing journal articles and then discussing their content with colleagues will give me new perspectives on teaching, just as they have during my student teaching experiences. My continued reflection and revision of teaching practice has aided, and will continue to aid, the quality of my students' learning.

In this concluding paragraph, we see the extent of the value Brian places on inquiry. His willingness to discuss what he learns with colleagues suggests a commitment to reflective practice. It is this commitment that provides evidence that as Brian continues to develop his LifeLong Narrative; he is likely to continue to construct Inquiry Narratives. Further, Brian's continual mention of research-based practices suggests that many of these Inquiry Narratives will be accompanied by a Classroom Research Narrative.

My goal in this section has been to utilize Brian's essay as a way to depict how one student demonstrated sophisticated perspectives towards inquiry, and an ability to manifest these perspectives in practice. In constructing a first chapter of his Life-Long Narrative, Brian spoke generally about the need to use inquiry, as well as the need for inquiry to sometimes include more formal classroom research structures. Through specific examples, Brian constructed two 
Inquiry Narratives, each accompanied by a Classroom Research Narrative (See Figure 8.1). As such, we can hope that if Brian remains true to his beliefs as he moves through his career, when Brian leaves the profession, the final chapter of his Life-Long Narrative will provide us with evidence of an inquiry stance.

Thus far, I have attempted to provide evidence that can help to answer two of my research questions. I have considered the ways in which some students developed sophisticated perspectives towards inquiry, as well as ways in which other students demonstrated that their perspectives were less sophisticated. I have also considered the ways in which some students' perspectives towards inquiry were manifested in practice, as students used reflection and action, sometimes leading to systematic and intentional classroom research, as a way to evaluate and resolve dilemmas. I also provided evidence that demonstrated ways in which other students failed to demonstrate an ability to manifest their perspectives in this way. In chapter 9, I will consider my third research question by looking at the barriers and facilitators to preservice teachers' development of perspectives toward inquiry. 


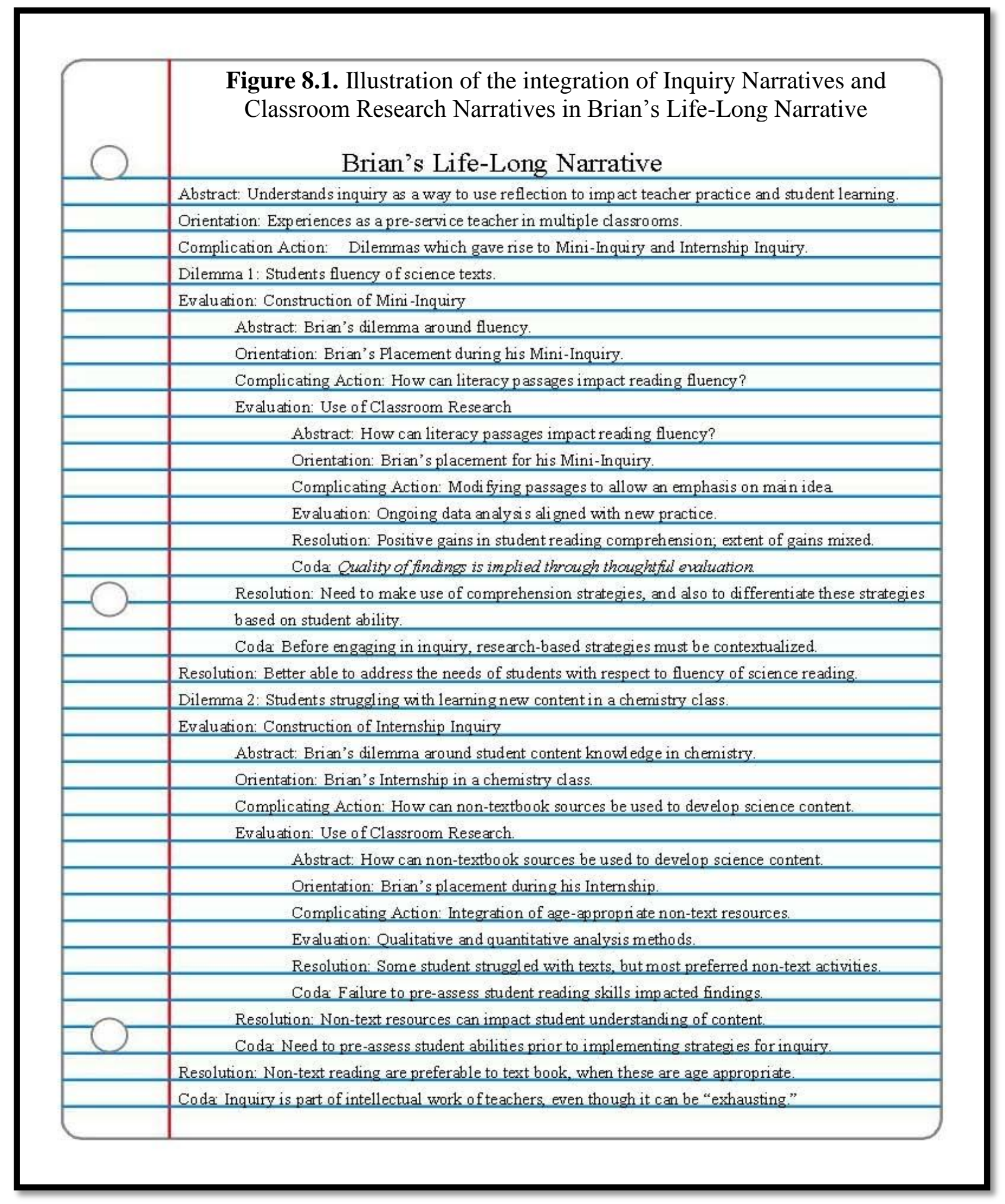




\section{Chapter 9: Barriers and Facilitators to Developing Perspectives towards Inquiry}

In this chapter, I consider my final research question, "What barriers and facilitators impact the development of teachers' perspectives towards inquiry?” In doing so, I provide evidence of these barriers and facilitators as described by students in the first chapters of their Life-Long Narratives. While similar barriers and facilitators existed across students with varying levels of sophistication in their perspectives towards inquiry, there was often a distinction in the ways in which barriers were viewed. In some cases students viewed barriers as factors that might mitigate the use of classroom research in the future, while in other cases barriers were seen as challenges to overcome.

During my analysis, I coded those parts of narratives that addressed the ways in which students' development of perspectives towards inquiry were inhibited by various factors. I further considered the extent to which students were able to work through these factors. Finally, I considered those factors that served to help students in the development of sophisticated prospective towards inquiry through the process of engaging in classroom research. Most often, barriers were mentioned during the section of student narratives in which the author addressed the essay prompt: "In what ways has inquiry proven difficult for you?" However, barriers and facilitators also were discussed by some students as they considered other prompts we asked the students to address in their essays.

Five factors served as barriers and/or facilitators to the development of perspectives towards inquiry: (1) time, (2) wonderings, (3) methodological skills, (4) context, and (5) reflection. In the case of time, wonderings, and methodological skills, these factors were seen as barriers for many students. However, while some students' narratives suggested that these barriers limited the development of perspectives towards inquiry, other students seemed to 
demonstrate development of more sophisticated perspectives towards inquiry by viewing these factors as challenges to overcome. Context was seen by some students as a barrier to developing perspectives towards inquiry, while for others, contextual factors facilitated the development of sophisticated perspectives towards inquiry. Finally, the ability to engage in meaningful reflection served as a facilitator of the process whereby some students developed sophisticated perspectives towards inquiry. For the remainder of this section, I consider these five factors, providing evidence found through my analysis that illustrates how these factors inhibited or facilitated the development of students' perspectives towards inquiry. I begin with time, the most frequently cited of these factors.

\section{Time}

Almost every narrative I examined makes some mention of time. Time served as a barrier during the classroom research experiences of some of our preservice teachers, yet students with more sophisticated perspectives towards inquiry were able to overcome the challenges of time during these experiences. Our students appear to offer four different perspectives of time: (1) time during the program as a barrier; (2) time during the program as a challenge; (3) time as a barrier in the future; and (4) time as a challenge in the future.

\section{Time during Program as a Barrier}

When time was seen as a barrier it was usually framed as a way in which the construction of the program minimized students' abilities to engage in systematic and intentional classroom research. Such factors included time in placements and other program requirements. When thinking about earlier classroom research experiences, the time spent on non-inquiry coursework also proved to make engaging in meaningful research difficult. One student wrote, "It was also hard having University classes during this same time because my time was split up because of 
other work that had to be completed during this time." Another student agreed, noting, "It was also difficult to teach full time for the first time, conduct a research project, collect data, write a paper, and take classes all at the same time." For each of these students, it was difficult to develop as teacher-researchers while also developing as student-teachers.

Even for students who had reached their Internship, time management proved difficult. One student pointed out:

Our largest inquiry project was the same time of taking on full time teaching responsibilities for the first time in our teaching career. Time management is a factor even with senior teachers let alone teachers finding their place in a new classroom. It was hard to find the time for my students, college coursework and inquiry at the same time.

For this student, being a teacher-researcher seemed to be something only a veteran teacher could do well.

Some students suggested that no matter the experience of a teacher, engaging in classroom research becomes problematic when considering all of the unforeseen time demands that arise in real-world classrooms. One student wrote:

The duration of our student teaching was 15 weeks. This period of time was not just dedicated to inquiry but immersing ourselves into full time teaching responsibilities. My inquiry was conducted in 5 of those 15 weeks. I do not believe this is sufficient time to conduct an inquiry. In this instance, I do not believe data for my inquiry was accurate. There are many other factors in the school systems that interfere with data collection and the only way to overcome these factors is to extend the duration of the inquiry. I believe an accurate inquiry, depending on the guiding questions, should be no less than two 
years. This allows there to be a variety of participants and ample time to collect qualitative and quantitative data. There is no way of conducting this type of inquiry as a student.

For this student, the many other things she needed to do in the classroom did not allow her sufficient time to engage in meaningful data collection. She suggests that it is simply not possible to properly attend to all the duties required of a teacher-researcher during a semester of studentteaching.

The amount of time available to collect data was brought up by many students. One wrote:

First and foremost I don't think that there was enough time given to gather a large enough collection of data to be extremely thorough. There was a massive amount of data that was gathered each day that had to be processed, organized, and eventually presented in a short period of time. I felt that this was a hindrance to me because I would have liked to use at least two more units in my research to get a broader spectrum but was unable due to time restraints.

Another student noted:

I had one of the most difficult experiences of my life during my Internship inquiry project. The first problem I ran into was the amount of time I had to complete the research. I only had ten weeks to complete my study. With this limited amount of time, I had a lot of difficulty providing my students with quality time to produce the projects that could allow them to clearly demonstrate their learning of the material. I think if I had more time to conduct my research, my results, which were not clear or conclusive, would have been a lot more telling of whether or not my questions were successfully answered. 
In each of these cases students felt that the amount of time they had in their placement (15 weeks) was insufficient to provide meaningful answers to their research questions.

For other students, the formal nature of the required write-up for the internship inquiry proved to be a hindrance. One student commented that, "I struggled most with finding time to implement all the aspects of inquiry into my teaching, and then also finding the time to reflect and write up a formal research paper.” Another student said:

I would have liked to have used the entire fall semester Intern placement for my research and then completed the project during the Spring semester. I know several people, including myself, who were still gathering data and trying to type up a formal report only weeks or days before it was due because of the time crunch.

In each of these examples, it was less the amount of time needed to collect and analyze data, and more the added task of having to construct a written report that proved to be problematic.

These examples all provide evidence of the time crunch many teachers, especially preservice teachers, face in trying to engage in meaningful classroom research. For each of these students, time provided a clear barrier that was difficult to overcome. While almost all students mentioned this time crunch, some also considered ways in which they overcame the challenge of time.

\section{Time during Program as a Challenge}

In some narratives, students talked about how the scope of classroom research activities helped them to focus on making sure there was alignment between teaching activities and research activities, and provoked them to build on their prior work as they moved through the program. Some students also felt that their classroom research experiences helped them to 
become more organized. One student wrote, "I feel that being able to multi-task last semester, has prepared me for teaching next year."

For other students, the impact of classroom research activities on their time management was more immediate. One student commented:

I believe I learned valuable lessons about time management when I was conducting my study on Bell Ringers and texting. At the beginning of my project, the Bell Ringers were taking fourteen to fifteen minutes to complete each day, and I became upset that so much class time was being used up. I actually even had to adjust my schedule of data collection because this became such a problem. Ultimately, I had to restructure my time management of the Bell Ringers and explain to my students that they needed to be starting on the Bell Ringer as soon as they came into class and not wasting time with eating or talking.

While another noted:

As the days went on, I realized that due to time constraints, meaning, some things either take longer than expected or takes less time than expected, I needed to find a way to better integrate these prompts into my lesson. I came up with using prompts at the beginning of class as an "entry ticket" or using them in the middle of my 90 minute block to check for understanding as well as see how students are reacting to the topic at hand. In each of these examples, students, realizing that time was adversely impacting the practice they were studying, modified their teaching to reflect the many demands on their time.

For other students, the lessons learned during early classroom research, allowed them to more successfully manage time later on. One student explained: 
During the first few pieces of mini-inquiries, I had a sense of what I was doing but did not know fully what was going on. As time went on, I figured it out. Especially in my Intern year, the inquiry process was smooth sailing. The process just took me some time to get used to because implementing inquiry into a classroom can be difficult at first.

Another wrote:

There are many road blocks that a teacher may encounter along the way. The first difficulty that I encountered during my lesson-based inquiry was a lack of inquiry knowledge. When I began that study, I did not feel prepared to fully conduct a successful study. My lack of organization and understanding of inquiry was problematic in the beginning of my project. I felt that I was more prepared when I began my mini-inquiry and final action research project.

Each of these students found that the time spent learning to engage in classroom research allowed them to better manage the time it took to actually do classroom research. For some students, regardless of the time, the end result was worth it. One student summed up this idea by simply writing, "I found that my students appreciate the time and care I put into their learning and they reciprocate that care by putting effort into and taking ownership over their learning." For students with this perspective, there seems to be a stronger likelihood that regardless of time, engaging in classroom research will become a regular part of their practice.

\section{Time in the Future as a Barrier}

Many narratives discussed the amount of time required to engage in formal (formal/informal is used extensively and is interpreted to refer to the ways in which products are constructed) classroom research, postulating that future research endeavors will be largely informal in nature. These comments were often characterized by students making comments 
such as, "I will not use inquiry the way that our teaching program had us use it, because let's just face it, that is way too in-depth and way too time consuming as a full time teacher to do," thereby suggesting that formal classroom research was simply not doable in a real-world classroom. These comments were often made even by students who seemed to value classroom research. One student, after writing about the importance of studying her practice, wrote, "In spite of this, inquiry may not be the best course of action for educators to administer as it can be a time consuming approach and at times frustrating if the desired outcomes fail to emerge." In these examples, it becomes clear that for many students, the time they spent on their preservice classroom research will impact the likelihood that they continue to be teacher-researchers.

Even when students suggested that they would continue to inquire into their practice, there was evidence that this inquiry would be less systematic and intentional than the classroom research they had been asked to do during their time in the program. One student wrote:

While formal inquiry has taught me about oral histories, cross curricular teaching, and vocabulary retention, it has also taught me that inquiry should take place on a daily basis. Research briefs and literature reviews are not exactly necessary for finding best practice. What is important is that documentation and reflection become commonplace in the classroom.

For this student, the notion of reflective practice seems to be valued, while structures critical to classroom research, like reviewing the literature, seemed to be less valuable.

Another student also made direct reference to informal inquiry, writing:

At first, my inquiry will be informal in order to become more comfortable in my new profession. Teachers should always be performing at least informal inquiry in their teaching in order to reach all of their students. To be effective in any career path, you are 
required to question methods and practice new ways of performing a job. There are always new ways of conducting lessons and relaying material to our students.

This excerpt, along with the reflections of many other students, made clear the value of inquiry, while providing an unclear picture of how systematic and intentional these future inquiry activities would be. For other students, there seemed to be more evidence that the value of engaging in classroom research would be worth the necessary investment in time.

\section{Time in the Future as a Challenge}

Some narratives, seeing time as a factor, described strategies that might be used to mitigate the scope of research endeavors. These strategies included various means of collaboration and aligning research with professional development needs. In cases where time was seen as a challenge to be overcome, the potential impact of classroom research was considered worth the time. One student wrote, "Above all, what I have learned the most about my teaching is that, yes it is time consuming, yes the work is endless, but, when you put forth all of this effort, you see the results of this effort mirrored by your students." For this student, the effort is worth the outcome. Another student, after writing about the difficulties inherent in engaging in classroom research, concludes by writing, "I believe inquiry should be part of the intellectual work of every teacher because of its power to move educators away from the routine ways of teaching. It is intellectually exhausting work at times, but it is more than worth the time and effort when we see our students benefit." This comment also suggests the student is willing to invest time when the result of that investment has the potential to benefit students.

Some students sought to think about ways to mitigate the amount of time it might take them to engage in future classroom research. For these students, they often considered collaboration as a way to make classroom research more doable. One student drew on her past 
experiences to illustrate this, commenting that, "I believe inquiry is a team effort and I hope to find colleagues in my future career to guide and collect data. There were pros and cons in conducting an inquiry during my student teaching. Overall the support was the most important aspect of my research." For this student, the support of colleagues seems to be the factor that will determine the extent of her future research endeavors.

Several students noted that in addition to helping with time management, collaboration also could allow groups of teachers to tackle school-wide issues. One student hoped to:

Use action research inquiry in collaborations with other fellow educators in the school, which I am at. By working with other educators in conducting inquiry we can potentially help solve problems that are facing not only a few classroom but problems facing the school as a whole.

Another student took the idea of collaboration a step further by suggesting that:

Although, this might seem overly ambitious, I think it would be great to reflect and conduct a small-scale inquiry project on a daily process by debriefing with another teacher or by writing in a journal about things that went well for the day and things that did not. This is all a form of inquiry, and out of these reflections and talks with other teachers, I hope to discover passions and wonderings that could develop into large-scale formal inquiries.

In these examples, there is evidence that some preservice teachers are beginning to think about classroom research that extends beyond the level of the individual classroom and has the potential to make a larger impact across the school community. 
The use of classroom research as a tool for school-wide professional development was clearly on the mind of some students. One student seems to have already committed to the process, having written that:

I would like to incorporate inquiry into my employer's professional development strategies. Prior to accepting the math position at Riverside High School, located in Charleston, West Virginia, I asked if I would be supported by administration and faculty in my efforts to combine inquiry with the school's professional development efforts. I expressed my belief that inquiry would help enhance teacher knowledge, change teaching practices, and improve student achievement; which goes hand in hand with professional development. The administrators expressed their full support and I accepted the job offer. I am looking forward to introducing Riverside's staff and its professional learning communities to inquiry and the joy it can bring to the classroom and school!

This excerpt suggests that the student has not only found a teaching position, but has made sure that her soon-to-be administrators will allow her the time and space necessary to engage in meaningful classroom research. For students who wrote comments like this, classroom research is clearly something they will value as part of their everyday practice. For these beginning teachers, it then becomes critical that the classroom research they engage in is properly developed.

\section{Wonderings}

In chapter 5, I provided evidence that the wonderings of many students demonstrated development of sophisticated perspectives towards inquiry. These students were able to consider their own needs as preservice teachers, their own passions and the learning needs of their students. In chapter 7, I provided evidence that for other students, one or more of these elements 
was missing during the process of framing dilemmas as wonderings. This section considers the ways in which constructing wonderings served as a barrier, as well as ways students were able to see the process of constructing wonderings as a challenge to overcome.

\section{Wonderings as a Barrier}

Many students talked about the difficulty in crafting wonderings. When framed as a barrier, issues included having preconceived wonderings that became contextually inappropriate, having too many wonderings, and having wonderings that required more sophisticated research skills, more time, or more resources to investigate then were available. Many students begin their discussion of the parts of classroom research that proved difficult for them by saying things like, "There were definitely a few parts which I found to be difficult in completing; to start simply thinking up a wondering that I want to conduct in my class." Often, students then went on to describe these difficulties in detail.

For many students, finding a wondering was not so much a problem, as was deciding which wondering to focus on further. One student wrote that, "The first challenge that I faced was narrowing my ideas and choosing a wondering that would be most beneficial for my class." Another student commented:

Picking the wondering was tough because there are many different parts of the classroom that I wanted to look at and try to "better" however I could only pick one to conduct research on. Therefore I wanted to pick an aspect of the classroom that I have been thinking about for a while that was how I came up with the mini-report and final report wonderings I did. 
These students seemed to have been able to notice several dilemmas that had the potential to provide the basis for classroom research, but had difficulty deciding which dilemma was best suited to investigate first.

For other students, deciding which wondering to focus on was a process that involved looking forward to the kind of research that would be required. One student had to consider the methods that would be required, noting, "It was at this time that I struggled most with my understanding of inquiry. It was not a struggle over the process of inquiry, but over the quality of research I could conduct with such strong limitations to the process." In this case, the student had to consider what was possible within the confines of the classroom research process. While she was not specific as to what limitations on the process she was referring to, another student's essay provides one possible answer. When writing about trying to settle on a wondering this student wrote, "The problem at this time, now that I reflect on the experience, is that it was difficult to see true problems and how they could be changed with such limited time in the classroom." Again, it becomes evident that even before research began, time was on the minds of many students.

For some students the context in which they would engage in classroom research was also an important factor that made the process of finding a wondering more difficult. One student wrote:

When the time came for me to report to my Professional Development School, I was excited to share my ideas for inquiry with my mentor teacher. He did not seem quite as enthused about this particular idea. While he did not tell me to not pursue this idea, he was quite concerned about the difficulty that would be involved. He does not teach using an immersion style; therefore, it would be quite a change for the students to experience 
complete immersion into the language. There was also the problem of what to do after I completed my internship. My mentor teacher would either have to continue to use this method or transition the students back to his usual style. For these reasons, I chose to not move forward with this research.

For this student, the process of finding a wondering seemed to be going smoothly until he realized the way that investigating this wondering would impact the classroom in which he was placed. This necessitated a shift in thinking about ways to study his own practice that would be easier for his mentor teacher to continue once the student's internship had concluded.

Whatever the reason, many students had difficulty determining which wondering they would focus on as the basis for their classroom research. These students focused more on the barriers to finding a wondering than they did on the process by which they could overcame their difficulties. For other students however, the difficulties of finding a wondering proved to be less of a barrier and more of a challenge to be overcome.

\section{Wonderings as a Challenge}

In some cases, students spoke about the difficulties in finding wonderings as an impetus for them to focus on the literature or collect "baseline" (used broadly to include pre-surveys, preassessments, observations, etc.) data. Other students considered collaboration as a way to settle on a wondering. One student wrote:

Figuring out what my inquiry was going to be, I looked to my mentor teacher for help. After countless hours of deliberation I came up with a great idea for a social studies classroom. "How do writing prompts in the social studies class effect student engagement, behavior, motivation and achievement?" 
While this student is unclear as to the "deliberation" process, she is clear that support from her mentor teacher helped in this process.

Other students seemed to return to the basic ideas of student learning needs, professional practice needs and passion that were part of their learning in early seminar experiences. The needs of students were highlighted by a student that noted, "Therefore the teacher needs to have a baseline of how the class is scoring on tests or acting in class. Then implement the wondering and compare the student learning (test scores, or student actions)." The idea of a teacher's passions was especially helpful for a student that wrote:

I remember developing more wonderings, and I also looked deeper into my passions in teaching. I came up with more and more wonderings, but my mind always seemed to travel back to my thoughts about student engagement. As for passion, I never really thought that it could take so many forms. During one seminar, we discussed a list of different passions related to teaching. I automatically thought that I would feel equally strong about all of them; however, I surprisingly was drawn to two in particular. Just by being exposed to these passions, thinking about them, and reflecting on my classroom experiences I discovered that I was most passionate about the students and my content, mathematics. I had powerful feelings about these two aspects of education, and these feelings pointed me in the direction of my future research.

This example provides a clear description of how one student was able to consider her own passions as a teacher, and how these passions helped to frame the wondering that would guide her classroom research. For students whot made comments like this one, earlier learning about the process of finding a wondering helped to frame the development of subsequent classroom research experiences. Another focus of early learning experiences that seemed to be a significant 
factor in the success of subsequent classroom research experiences was developing a methodology to examine research questions.

\section{Methodological Skills}

In chapter 6, I provided evidence that demonstrated how some students were able to engage in classroom research that integrated teaching and research, and was framed by systematic and intentional data collection and analysis. In chapter 7, I provided evidence of the various ways in which a lack of methodological sophistication served to limit the impact of some students' classroom research experiences. In this section, I examine ways in which poor methodological choices served as a barrier to the classroom research process. I further consider the ways in which some students were able to view the process of designing and implementing a sound methodology as a challenge to be overcome, thus resulting in more systematic and intentional classroom research.

\section{Methodological Skills as a Barrier}

Many narratives described difficulties in collecting and analyzing data. Often students described how they ultimately lamented the data-related decisions made during the design of their research, especially when findings were disappointing. Even the process of selecting which students to collect data on often proved difficult. One student commented:

Another major issue I had was the size of the group I was able to study during my research. I found early that the amount of students that were in class on a daily basis and completed all of the necessary assignments was a very small fraction compared to the amount of total students in my classes. Since I had to drastically limit the size of my study, my results were inconclusive and biased toward students who were already performing well in my class. 
For this student, the desire to collect a significant amount of data on each student, combined with the lack of availability of this data for all students, proved to have a significant impact on his eventual findings. While framed as an issue of sample selection, it is likely that part of the problem this student faced was related to the data he wanted to collect.

The task of collecting data proved difficult for many students like one who wrote, "My biggest difficulty throughout the inquiry process was collecting data on top of everything else that needs to be done." For this student the time needed to collect meaningful data seemed to interfere with everyday practice. Another student was more specific in describing the difficulties with data collection, commenting:

The only difficult part in the inquiry process is collecting data. Grades are the easiest data collection; because it is something we are already doing as teacher to assess students. Trying to collect participation observations, student responses, interviews, with students, and implementing different instructions is hard to do. All these data collections take up extra time from the teacher.

This student seemed to understand the importance of collecting various kinds of data. However, she also highlights the balancing act that a teacher must perform between the amount of data they want to collect and the amount of data collection that is feasible.

For many students, even after they managed to collect all the data they had planned on gathering, figuring out what to do with the data proved problematic. One student commented, “Another way which inquiry was difficult was analyzing the data that I collected. This was hard because I have all the data that I felt was needed now had to determine what the data meant." For this student, the process of findings answers in a pile of data proved difficult. Students who collected qualitative data seemed more likely to struggle with analysis. One student said of her 
qualitative data, "I found this data helpful in my research but a little more difficult to interpret because the results are in the eye of the reader." This comment provides evidence of the difficulties many students faced as they were exposed to qualitative analysis for the first time.

In each of these examples, student struggled with methodological considerations.

Whether selecting a sample, collecting data, analyzing data, or a combination of these factors, the process of finding answers to research questions in the data they collected was a barrier to the overall success of their classroom research experiences. The students in these examples seemed to be focused on this barrier, while other students went on to describe the ways in which they either overcame, or planned to overcome the challenges of working with data.

\section{Methodological Skills as a Challenge}

For students who viewed methodological considerations as a challenge to be overcome, classroom research experiences provoked them to become more open to how they organized and analyzed common forms of classroom data. Some of these students were also provoked to be more open to using other kinds of data (especially qualitative). One student learned to value the process of collecting survey data directly from students, noting:

I will implement student surveys in all of my classes regarding course material in the future, even when not conducting inquiry. There is no better way of identifying your students' opinions and background knowledge of their education. I felt this also gave my students a sense of empowerment in their education. Students are not frequently asked their opinion of course material or teaching strategies.

For this student, the value of student feedback was seen not only as an important part of engaging in classroom research, but also an invaluable way to monitor students' feelings about their learning. 
For other students, the realization that data collection plans can sometimes be impacted by circumstances beyond a teacher-researcher's control allowed them to understand one reason why it is good to rely on multiple kinds of data. One student wrote about the value of multiple data sources saying:

This came up during my final report with students telling me that the night or day before the test something happened which caused the students to be less focused on the test. So it is important for teachers to realize that "life happens" and student grades can be affected so the teacher needs to be aware of this... But inquiry reports drilled this into my head. Through student surveys I got into the heads of the students and saw what they liked and didn't like in my teaching style."

This student's comments suggest that when circumstances caused some of his assessment data to be impacted by outside factors, he was able to use survey data as a way to better contextualize his findings.

Classroom research experiences also seemed to help some students develop new assessment strategies. One student learned the value of using diagnostic and formative assessments:

I have learned to collect baseline data before implementing a new instructional strategy so that I can compare levels of student achievement before and after refining my teaching. Instead of waiting to analyze student learning with a summative assessment, I assess the effectiveness of my teaching strategies frequently through formative assessments.

In this case the student found that he now had a way to examine student progress before and during a unit. 
For another student classroom research allowed a shift in the ways in which she looked at existing forms of data:

Conducting inquiry has also allowed me to better track student grades. Inquiry required me to look further into student grades and carry out reasoning on student grades. This allowed me to see what little strategies worked among students within the realms of the inquiry as a whole. I was able to identify student areas of improvement while focusing on teaching strategies that succeeded. I was able to see how test grades reflected daily activities and quizzes throughout the semester. I was also able to focus on students struggling in one area.

While this student was still focused primarily on summative assessment data, she realized that there were many ways to look at the results of her students' tests to better understand how her students were progressing.

In these examples, students were able to use the various methodological skills they had learned to make better choices with respect to their data collection and analysis. In some cases, students were also able to consider how classroom research had shaped their assessment practices. For these students, the challenge of using data to help answer research questions seems to have been overcome. However, even with the ability to design methodologically sound classroom research, a context which supported teacher-research was a critical factor in the success of classroom research experiences.

\section{Context}

While those of us who developed and supported our students' classroom research experiences collaborated in an effort to provide a consistent set of experiences, each student's classroom research activities were conducted in unique educational contexts. In some cases, 
these contexts served as a barrier to preservice teachers' development of sophisticated perspectives towards inquiry. For other students, the contexts in which they engaged in various classroom research experiences, served to support the development of sophisticated perspectives towards inquiry. This section examines the various ways in which contextual factors served as both a barrier to, and facilitator of, the process of engaging in classroom research.

\section{Contextual Factors as a Barrier}

There are examples of students who felt their learning was inhibited by the perspectives of their mentor teachers, by the processes within which they learned about classroom research, or by conflict between expectations for their teaching and expectations for their research. Conflicting expectations were prevalent in early-program experiences. Many students echoed the sentiments of a peer who wrote, "This was a major concern I had in the early days of inquiry; I felt that I would lose focus on my lessons because I was so concerned with the action research." These conflicting expectations were often exacerbated by the design of the program. A student commented:

Yes, I was able to better acquaint myself with the action research process, but as far as my own inquiry it proved to be a waste of time. It is not a knock on inquiry or the university stressing its importance; it is knock on how it was presented to its participants in its program. There needs to be a way that WVU's five year program can make it so that all of the students involved can spend all their time at their main placement.

For this student, even though most placements were at the same public school, moving around from classroom to classroom proved troublesome.

Once students began their internship inquiry, the lack of clear deadlines during the semester was problematic for some students. One wrote: 
I felt that there wasn't enough structure to the process and that lack of structure is what hurt me in the beginning of my project. The fact that there were optional parts that were due at certain times was not helpful because I wasn't motivated to do the work because I knew that I wouldn't be graded. You have to remember that during this process we are all still students ourselves and there has to be some incentive to accomplish a goal.

Another noted:

In relation to the inquiry process, by making these things optional, when it came time for our final write-ups to be due in December, the majority if not all of the 2011 Class was scrambling trying to get everything written, edited and polished before the midnight deadline. While yes we should have been more responsible and taken advantage of the peer review sessions, I feel as if these assignments were mandatory, the final product would be better.

For these students, the rigor of engaging in classroom research and formally reporting on the results would have been easier to address with more clear deadlines.

For some students, the design of the program was less problematic than the relationship they had with their mentor teachers. One student wrote:

Finally, the biggest and toughest issue I had to deal with during my inquiry was my mentor teacher. He was completely unaccepting and unresponsive to the ideas and techniques I wanted to introduce and use in my classroom. This severely limited my ability to conduct my research, gain the respect of my students, and succeed in doing what I wanted to do in my classroom.

This example demonstrates how some students felt limited by the environment created by their mentors. The quote on page 192, well used to provide evidence of a student's difficulty in 
finding a wondering, is another illustration of how some mentor teachers proved to be a barrier to student success. While the design of the program, along with the mentor teachers and supervisors who worked with students were sometimes seen as barriers to students' development of perspectives towards inquiry, in many other cases, the program and those who worked with students were seen in a much more positive light.

\section{Contextual Factors as a Facilitator}

There were frequent examples of students who felt that the mentoring they received, the ways in which they learned about classroom research, and the flexibility they were given to try new things had a positive impact on their learning. In some cases, mentors actually facilitated the research process directly. One student wrote of their mentor teacher, "She helped collect data while I was teaching. In other circumstances, I may not have been able to accrue this data because I would be too busy instructing." The willingness of this student's mentor teacher to take an active role in data collection allowed her intern greater flexibility in using classroom research to answer a research question.

Often, the role of supervisors was to help students find their way through the classroom research process. One student wrote:

When the Spring of Participant year rolled around and we began to go through more and more seminars about inquiry, I began to feel that it would be a time consuming process. Luckily for me though, a professor of mine put this fear to rest slightly. Professor [name withheld] told my EDUC 400 [Instructional Design and Assessment] class that the key thing to inquiry is that when done correctly it should be A PART of your teaching and not something separate; that you have to think about outside of your teaching. 
This student was able to recall a specific incident where the encouragement of a course instructor helped her to better understand how to integrate teaching and research tasks.

For many students, rather than focus on specific instructors, mentors or supervisors, they instead focused on the design of the program as a facilitator of classroom research. One student said of the program:

While many teacher education programs focus on pedagogy, content, and classroom management, the [program] seamlessly integrates inquiry and curriculum design into their program. This early introduction and emphasis on the teacher as researcher allows teacher education candidates to enter the academic conversation as equals.

This student felt that the integration of classroom research into other program experiences allowed for seamless learning.

Other students focused on the learning that occurred across their time in the program. One wrote of their learning:

In general, I consider myself very fortunate to have received an education that emphasizes the importance of inquiry. As I have grown through this program, my understanding and appreciation for inquiry has also grown. During my time in this program I have had many opportunities to practice inquiry and to see how the research will affect my teaching. From simple wonderings to large-scale research projects, I have been able to explore how to take something that I am questioning and seek out the answers.

Another said:

I want to make the way I teach math more problem-based, and I want to require more student thought. These ideas have been brought to me in a class, but without my 
experience with inquiry I do not think I would ever think to actually try them. Now, I have the confidence, ability, and inquiring mind to always be trying new things. Through all of my time in the program, I have learned how to strive to be the best teacher possible which will have a positive effect on the students I have in my classroom.

In these examples two students considered how their learning experiences contributed to their developing understanding of classroom research. The first student focuses primarily on learning during her time in the program, while the second student moves beyond the program, considering how he might make use of his learning in the future. These examples demonstrate how the design of the program, and of the inquiry strand, facilitated the classroom research experiences of many students. While many students appreciated the design of the program, the most frequently cited facilitator to students' development of sophisticated perspectives towards inquiry was not the program itself, but instead the idea of reflective practice, a key theme in the program's curriculum.

\section{Reflection as a Facilitator}

As discussed in chapter 2, reflective practice is noted as critical to engaging in meaningful classroom research. Further, as described in chapter 3, we sought to emphasize reflective practice across the various learning experiences in the inquiry strand of our program. In constructing their essays, many students spoke about the growth of their understanding of reflective practice during their time in the program. For many students, this understanding allowed them to be more critical of their practice and of the practices they learned about and saw modeled. This section considers the ways in which students who demonstrated an understanding of reflection, were able to use reflection during classroom research experiences in ways that helped support development of sophisticated perspectives towards inquiry. 


\section{Classroom Research as Impetus for Reflection}

For many students, classroom research experiences provided an impetus for reflection. As one student succinctly wrote, "I believe that I learned so much because inquiry forced me to reflect, as should all good educators." While this student seemed to appreciate being forced to reflect, others focused more on what such reflection led to. One student commented:

As one can tell by reading the prior paragraphs, I definitely plan on using inquiry in my classroom. Inquiry has been a useful tool for me. It helps me reflect and research on things that I wonder about in my teaching. It has given me the tools to not just reflect, but to reflect and put my findings into action.

This student was able to make use of reflection, along with the classroom research skills they developed, to put their reflections into action.

The reflection that occurred during their classroom research experiences was of great importance to many students, including one that wrote:

Inquiry has helped me reflect on my own teaching. I have learned so much about my instruction, passion, strengths, and weaknesses. I learned that I used direct instruction too much in my classes. After reflecting on my daily journals that I used in my inquiry project, I saw that students were becoming disinterested on the days that I would use direct instruction. After using different strategies and activities, I saw that student engagement rose. I learned through this inquiry process that I needed to vary my instruction more.

Another student added:

I have not learned as much about my teaching as I have about my students from conducting inquiry, but the new knowledge is noteworthy. I was better able to reflect 
upon my work and teaching strategies. With formal reflection, I was able to constantly look back on teaching strategies and attitudes implemented in my teaching. I was also able to gain student opinion of my teaching through pre and post surveys. I learned that student opinion on teaching styles is important in self-reflection and assessing my teaching abilities. It is important to reflect on your own teaching methods and create new beliefs about education"

In each of these examples, the process of reflecting on teaching proved helpful. While both students seemed to focus primarily on the data collected as part of their classroom research, the second quote takes the process of reflecting on data, and draws larger conclusions about the role of students in assessing the quality of teaching. These examples suggest that their authors are beginning to see the value of being reflective practitioners.

Some students were rather explicit about their development as reflective practitioners. One student noted:

Another thing that inquiry allowed me to realize about my teaching is that I am a reflective practitioner. Before I conducted a large scale action research project, I was never aware of how much I am constantly reflecting. As I began to formally reflect through observation notes during my inquiry project, I realized how often I unconsciously reflect. Upon the completion of each lesson, I nonchalantly think to myself what went well and what changes could be made. I now understand the importance of reflection and am not able to reflect more formally.

White another wrote:

As reflective practitioners, teachers try to interpret events occurring in their classrooms and schools and closely examine their everyday decisions to improve their teaching. 
Reflecting on one's own practice includes practitioner inquiry, and it requires

concentrated effort with the ultimate goal of increasing student learning through effective instruction.

In each of these excerpts, students wrote specifically about being a reflective practitioner. For the first student, classroom research proved helpful in better allowing her to formalize her reflections. For the second student, there was an emphasis on using classroom research as a way to act on these reflections. By considering the interaction between reflection and action, many students began to see how inquiry can often be a cyclical process.

\section{Inquiry as a Cyclical Process}

While most students wrote about several of their classroom research experiences during the time that they were in the program, many also considered what they learned across these experiences. Many of these students' essays suggested an understanding that the process of studying their practice, regardless of the outcomes, was of value. One student, though disappointed with the outcomes from his internship inquiry, still was encouraged, noting:

More importantly, I have learned that it is ok to fail. We can learn more from defeat than victory. My action research this semester produced inconclusive results. It's important not to be discouraged, but to take strength in the effort and the process.

For this student the value of engaging in classroom research seemed to outweigh the disappointment with his findings. Another student began to see the cyclical nature of studying her practice when she commented:

I had more questions when I was done with my study than when I began: was the studentled instruction what had helped my students, or was it the short-term, smaller assessments that they were better at? Would they have still scored as well on a unit test like the unit 
before it? I had obviously left too many variables. This was when I truly began to see the merit of formal inquiry.

For this student, while her classroom research experiences as a preservice teacher may have concluded, she seems to already have uncovered wonderings to pursue as a practicing teacher. In some cases, through a deeper understanding of classroom research, the value of having an inquiry stance became apparent. One student wrote:

After meeting each week with my peers in an action research small group, I realized that inquiry is not just a process, but a stance that effective teachers need to take. Teachers should constantly be reflecting on their practices, but also collecting data to assess the practices objectively.

For this student, the idea of reflection is seen as important, but the ability to use data as a way to consider the impact of practice suggests that by engaging in classroom research, he has also begun to discover how reflection and action can work together to allow for a robust examination of practice.

In this chapter, I have examined some of the barriers students faced as they engaged in classroom research. For some students these barriers seemed difficult to overcome, while other students found ways to work through the many challenges they faced as developing teacherresearchers. Many students were also able to consider some of the ways in which their learning about classroom research was facilitated by people, structures and by learning to become reflective practitioners. The examples provided in this chapter provide evidence that there are barriers to developing perspectives towards inquiry, ways to overcome these barriers, and additional structures that serve to facilitate the process of developing perspectives towards inquiry. Having identified the key elements that both lead to the development of sophisticated 
perspectives towards inquiry, and allow for these perspectives to be manifested in practice, in chapter 10, I will synthesize the findings presented in chapter 4 through chapter 9 . 


\section{Chapter 10: Synthesis of Findings}

In chapter 5 through chapter 9, I made use of evidence produced from my analysis of students' inquiry synthesis essays to answer three research questions. In doing so, I demonstrated how students with sophisticated perspectives towards inquiry, and an ability to manifest these perspectives in practice, developed Life-Long Narratives that included Inquiry Narratives and Classroom Research Narratives. I also provided evidence of the barriers and facilitators to the development of perspectives towards inquiry.

In this chapter, I synthesize the findings reported in these five chapters. I outline four perspectives that can serve as a foundation for preservice teachers who might someday develop an inquiry stance. I also describe five practices that allow preservice teachers to leverage their perspectives towards inquiry and engage in systematic and intentional classroom research. By making use of evidence from my study, including evidence of the barriers and facilitators to developing perspectives towards inquiry, I now seek to align my findings with the literature, and contribute new knowledge that can inform those who support the development of teacherresearchers.

\section{Perspectives towards Inquiry}

One of the central purposes of my study was to consider how preservice teachers might develop perspectives towards inquiry that could allow them to someday develop an inquiry stance. Although my analysis underscores the difficulty in untangling practices critical to classroom research from the perspectives which can guide these practices, I have identified four perspectives that were evident in the work of students with sophisticated perspectives towards inquiry: (1) reflection is an overarching practice that ties other practices together, (2) reflection should lead to action, (3) inquiry should lead to classroom research, and (4) inquiry is a cyclical 
process. These perspectives, summarized in Table 10.1, facilitate the development of Inquiry

Narratives and Classroom Research Narratives, and support the practices that are central to narrative construction.

Table 10.1: Summary of perspectives towards inquiry required to provoke classroom research

\begin{tabular}{lll}
\hline Perspective & Allows for Creation of & Related Practices \\
\hline $\begin{array}{l}\text { Reflective practice guides the } \\
\text { work of teachers }\end{array}$ & $\begin{array}{l}\text { Inquiry Narrative and } \\
\text { Classroom Research Narrative }\end{array}$ & $\begin{array}{l}\text { All practices provoke } \\
\text { reflection and all practices } \\
\text { require reflection }\end{array}$ \\
$\begin{array}{l}\text { Reflection should lead to } \\
\text { action }\end{array}$ & Inquiry Narrative & $\begin{array}{l}\text { Find dilemma, construct } \\
\text { research questions, design } \\
\text { methodology, use data to } \\
\text { consider teacher practice and } \\
\text { student learning }\end{array}$ \\
$\begin{array}{l}\text { Inquiry should lead to } \\
\text { classroom research }\end{array}$ & $\begin{array}{l}\text { All embedded in Inquiry } \\
\text { Narrative, and enhanced } \\
\text { ability to design a } \\
\text { methodology, use data to } \\
\text { classroom Research Narrative } \\
\text { student learning, which lead to } \\
\text { quality research }\end{array}$ \\
$\begin{array}{ll}\text { Inquiry is a cyclical process } \\
\text { continuously refined }\end{array}$ & $\begin{array}{l}\text { Multiple Narratives based on a } \\
\text { wondering }\end{array}$ & $\begin{array}{l}\text { Use data to consider teacher } \\
\text { practice and student learning }\end{array}$ \\
\hline
\end{tabular}

\section{Reflection as an Overarching Practice}

Reflection is embedded in each of the three narratives of a teacher-researcher, and is central to each of the practices that make up these narratives. As such, reflection can be seen as an overarching practice that guides teacher-researchers as they engage in classroom research. Reflection was frequently cited by our students as a facilitator to their learning. Students highlighted a reciprocal relationship between reflection and classroom research, noting that not 
only did reflection guide their research, but also that classroom research helped provoke them to reflect more frequently and purposefully.

Teachers who make the conscious decision to reflect on a dilemma, avoid the trial-anderror approach to improving practice, only when they are clearly able to define the nature of the problem they face (Dewey, 1916). Guided by Schön's (1983) notions of a reflective practitioner, we sought to emphasize the importance of reflection at each step of the classroom research process. While many students wrote extensively about their dependence on reflection to help evaluate and resolve dilemmas, some students did not make clear the role that reflection played in leading them to engage in classroom research. If teachers are unable or unwilling to reflect on the dilemmas they face, there is little to suggest that they will make use of classroom research to resolve these dilemmas.

Many students wrote about being forced to reflect, or spoke about reflection in ways that suggested the constant barrage of reflective activities they had been asked to engage in (including the essays that served as data for my study), had led them to view reflection as a required task, rather than an important tool for professional learning. While the literature on classroom research makes clear the importance of reflection (Chubbick, 2010; Dana \& YendolHoppey, 2009; Price \& Valli, 2005), and of mentoring and scaffolding preservice teachers' reflection (Ax et al., 2008; Grushka et al., 2005; Zeichner \& Liston, 1996), Hall (2009) calls for those working with teachers to provide as much autonomy as possible, allowing teacherresearchers to make their own choices. Thus, while it is important to continually emphasize the need for reflection, it is important that preservice teachers recognize the intrinsic benefits of reflection on their practice, and do not begin to see reflection as an assignment. Helping teachers to see this value is especially important to those hoping to cultivate teacher-researchers, as 
evidence from my study supports the work of others who consider reflective practice as the foundation on which classroom research is built.

\section{Reflection Leading to Action}

In framing my findings, I described a process whereby students constructed an Inquiry Narrative as they engaged in reflection and action to evaluate and resolve the dilemmas they faced in the classroom. Each of the elements of the Inquiry Narrative requires a teacher to be willing to not only reflect on their practice, but also to act on this reflection. Perhaps, most importantly, if a teacher is to engage in inquiry, they must be willing to allow the dilemmas that serve as complicating actions in a Life-Long Narrative to lead them to the development of an Inquiry Narrative.

While reflection can be seen as a practice that has great value, acting on reflection is a critical step to engaging in classroom research. Data from my study suggests that many students were quite adept at engaging in the research necessary to systematically and intentionally study their practice. However, some of these students did not demonstrate the perspectives towards inquiry that might provoke them to engage in classroom research in the future. Without the belief that reflection should lead to action, even teachers with strong research skills are unlikely to utilize these skills as a way to study their own practice.

\section{Inquiry Leads to Classroom Research}

My analysis led to evidence that suggests some students were able to integrate teaching and research practice and engage in systematic and intentional classroom research, thereby allowing for the construction of a Classroom Research Narrative. While the reflection and action necessary to construct an Inquiry Narrative demonstrates the development of some perspectives towards inquiry, those students who also demonstrate a willingness to think more purposefully 
about the ways in which they integrated new teaching practice with systematic and intentional data collection and analysis, provided the most evidence of having developed the perspectives necessary to actualize an inquiry stance.

In distinguishing between inquiry and classroom research, my intent has not been to minimize the impact of less formal forms of inquiry. We encourage our preservice teachers to continually investigate their wonderings, fully aware that even the most adept teacherresearchers would be unable to use classroom research as a way to resolve each of the dilemmas they faced. Instead, by differentiating between an Inquiry Narrative and a Classroom Research Narrative, I have attempted to demonstrate the variability in the depth and breadth of the studies engaged in by our students. Thus while each Inquiry Narrative need not be accompanied by a Classroom Research Narrative, preservice teachers with sophisticated perspectives towards inquiry should be willing to engage in classroom research that is systematic and intentional, when such research has the potential to impact their practice, their students' learning, and contribute to the professional learning of their colleagues.

\section{Inquiry is a Cyclical Process}

In framing my findings, I described a process whereby students constructed Inquiry Narratives as a way to evaluate and resolve the dilemmas they faced in the classroom. I further described how some students also constructed a Classroom Research Narrative as a way to evaluate and resolve the research questions that emerged in their Inquiry Narratives. Recognizing the cyclical nature of inquiry, I have suggested that the coda of an Inquiry Narrative not only serves to provide resolution for a dilemma, but also can inform the further inquiry of a teacherresearcher. Given this, if a teacher- researcher makes use of reflection and action as part of the process of evaluating and resolving a dilemma through inquiry, whether or not this inquiry 
includes the use of classroom research, the learning that occurs should lead to new wonderings. In this way, teacher-researchers with sophisticated perspectives towards inquiry rely not only on the dilemmas that arise from their existing practice, but also on dilemmas that arise from their inquiry experiences.

Students who demonstrated sophisticated perspectives towards inquiry used the process of classroom research to improve their teaching, and to better understand the cyclical process of inquiry, thereby changing the ways in which these students approached their teaching and research practices. However, findings from my study point to the difficulty of helping preservice teachers understand the cyclical nature of inquiry. Many students lamented that because each new classroom research experience aligned with a new field experience, it was difficult for them to allow the same dilemma to provoke multiple inquiry experiences. While it may often be impossible for teacher education programs to offer a series of contextually-linked experiences, it is important that preservice teachers be encouraged to consider how their learning in one experience might lead them to reconsider their own practice, and the ways in which they might study their practice. Thus while we may lament a preservice teacher's laser-focus on a dilemma that is no longer contextually relevant, we should also be encouraged when preservice teachers' classroom research experiences provoke them to want to further study a specific dilemma, as a desire to do so demonstrates an understanding of inquiry as a cyclical process.

\section{Practices Allowing for Narrative Elements and Dependent on Perspectives}

In the previous section, I outlined four perspectives that, when developed together, can provoke a teacher to systematically and intentionally study their practice. These perspectives, while critical, only provide the impetus for teacher-researchers to act on the dilemmas they face. If preservice teachers are going to be able to make use of these perspectives during their careers, 
they need to be able to make use of the practices that guide systematic and intentional classroom research.

Through my analysis, I was able to see evidence of six practices that are central to classroom research: (1) finding wonderings, (2) constructing research questions, (3) designing a methodology, (4) using data to consider teacher practice and student learning, (5) and making work public. In this section I summarize each of these practices, as well as the ways in which some preservice teachers were able to demonstrate an ability to engage in these practices. I also consider the supports that allowed for development of these practices, the barriers that inhibited their development, and the consequences for developing teacher-researchers unable to make use of these practices (See Table 10.2). In doing so, I pay special attention to evidence that adds to the existing literature on classroom research.

\section{Finding Wonderings}

Our students began each classroom research experience by focusing on a wondering. These wonderings emerged as our students reflected on their teaching practice, thereby identifying dilemmas that arose out of the complexity of the classroom. Preservice teachers who were able to develop wonderings, often demonstrated an ability to consider their own practice, their students' learning, and their passions as a teacher. Doing so often gave rise to multiple dilemmas, and it then became necessary for the student to select a dilemma that could provoke further study. 
Table 10.2: Summary of practices required to engage in classroom research

\begin{tabular}{|c|c|c|c|c|}
\hline Practice & $\begin{array}{l}\text { Embedded } \\
\text { Practices }\end{array}$ & Supports & Barriers & If Missing \\
\hline $\begin{array}{l}\text { Findings } \\
\text { Wonderings }\end{array}$ & $\begin{array}{l}\text { Considering } \\
\text { practice, passion } \\
\text { and student } \\
\text { learning } \\
\text { Selecting a } \\
\text { dilemma to focus } \\
\text { on }\end{array}$ & $\begin{array}{l}\text { Learning to } \\
\text { problematize } \\
\text { practice } \\
\text { Ability to see } \\
\text { dilemmas in } \\
\text { practice } \\
\text { Understanding } \\
\text { of practice }\end{array}$ & $\begin{array}{l}\text { Time in placements } \\
\text { Other requirements } \\
\text { while in } \\
\text { placements } \\
\text { Coursework } \\
\text { Selecting } \\
\text { something doable }\end{array}$ & $\begin{array}{l}\text { Contrived } \\
\text { wonderings } \\
\text { No entry into } \\
\text { Inquiry cycle }\end{array}$ \\
\hline $\begin{array}{l}\text { Constructing } \\
\text { Research } \\
\text { Questions }\end{array}$ & $\begin{array}{l}\text { Using the } \\
\text { literature } \\
\text { Synthesizing } \\
\text { learning in field } \\
\text { placements and in } \\
\text { coursework }\end{array}$ & $\begin{array}{l}\text { Learning to } \\
\text { search literature } \\
\text { Using learned } \\
\text { practice to } \\
\text { guide study }\end{array}$ & $\begin{array}{l}\text { Stigma of literature } \\
\text { reviews } \\
\text { Inability to } \\
\text { synthesize Inability } \\
\text { to connect theory } \\
\text { and practice }\end{array}$ & $\begin{array}{l}\text { Happenstance } \\
\text { practice } \\
\text { Lack of } \\
\text { guidance for } \\
\text { study }\end{array}$ \\
\hline $\begin{array}{l}\text { Designing a } \\
\text { Methodology }\end{array}$ & $\begin{array}{l}\text { Planning teaching } \\
\text { practice } \\
\text { Planning research } \\
\text { Integrating } \\
\text { teaching and } \\
\text { research }\end{array}$ & $\begin{array}{l}\text { Research } \\
\text { experience } \\
\text { Derive data } \\
\text { from multiple } \\
\text { sources in } \\
\text { multiple ways } \\
\text { Learning to } \\
\text { value } \\
\text { qualitative } \\
\text { research }\end{array}$ & $\begin{array}{l}\text { Difficulty of } \\
\text { teaching and } \\
\text { collecting data } \\
\text { Limited analysis } \\
\text { skills Lack of time } \\
\text { to analyze data }\end{array}$ & $\begin{array}{l}\text { Poor } \\
\text { implementation } \\
\text { of practice } \\
\text { Poor data } \\
\text { Poor analysis }\end{array}$ \\
\hline $\begin{array}{l}\text { Using Data to } \\
\text { Consider } \\
\text { Teacher } \\
\text { Practice/Student } \\
\text { Learning }\end{array}$ & $\begin{array}{l}\text { Triangulate } \\
\text { findings } \\
\text { Consider what } \\
\text { findings say about } \\
\text { practice/learning } \\
\text { Use findings to } \\
\text { make instructional } \\
\text { decisions } \\
\text { Focus on } \\
\text { individual students } \\
\text { Consider student } \\
\text { viewpoints }\end{array}$ & $\begin{array}{l}\text { Focus on } \\
\text { Interpreting } \\
\text { data } \\
\text { Involving } \\
\text { students } \\
\text { Belief in data }\end{array}$ & $\begin{array}{l}\text { Poor data } \\
\text { Limited time } \\
\text { Focus on students } \\
\text { or practice only }\end{array}$ & $\begin{array}{l}\text { Ignore findings } \\
\text { Frustration with } \\
\text { research End } \\
\text { inquiry cycle }\end{array}$ \\
\hline $\begin{array}{l}\text { Making Work } \\
\text { Public }\end{array}$ & $\begin{array}{l}\text { Formalize } \\
\text { research } \\
\text { Share with others }\end{array}$ & $\begin{array}{l}\text { Time to } \\
\text { formalize } \\
\text { Structures to } \\
\text { share }\end{array}$ & $\begin{array}{l}\text { Writing/Presenting } \\
\text { skills } \\
\text { Quality of research }\end{array}$ & $\begin{array}{l}\text { Learning limited } \\
\text { to individual } \\
\text { Lack of } \\
\text { recognition }\end{array}$ \\
\hline
\end{tabular}


Our students indicated that the early experiences we provided allowed them to better problematize their practice, although the time spent in early field placements sometimes made it difficult for students to select a dilemma they could reasonably investigate. This was especially true given the other demands placed on students' time in the field, as classroom research activities competed with other required coursework, especially coursework that was embedded in those placements.

While some students had difficulty selecting a dilemma to investigate, many of our students wrote about the overly-simplistic nature of their initial dilemmas. This evidence serves as a reminder that the ability of a teacher to reflect on their practice is limited by that teacher's understandings of what practice is. Burant et al. (2007) write that reflection can only begin when preservice teachers challenge their existing notions of practice. Thus, while our students often ascribed their difficulty finding wonderings to insufficient time, because we began asking students to problematize practice so early in their preservice experiences, many students may not yet have had an opportunity to acquire the professional knowledge necessary to challenge their beliefs about practice. In cases where students were unable to craft a wondering rooted in a realworld dilemma, the use of a contrived wondering made it nearly impossible for them to enter the inquiry cycle, thereby stunting the development of their perspectives towards inquiry.

\section{Constructing Research Questions}

Once students crafted a wondering, we encouraged them to make use of existing research as a way to consider how they might address their wondering through new practice. This process allowed for students to construct research questions. While students who demonstrated an ability to develop research questions often referred to their review of existing research, it is also 
important to emphasize that many students used the learning they were constructing through coursework and field placements as a stepping stone to these reviews.

Evidence from my study suggests that many students saw the process of investigating the literature as a reason why their future inquiries would be less formal. Given this, encouraging students to begin with practices they are seeing modeled as a provocation to explore existing research, might serve to help preservice teachers move away from the belief that literature reviews and term papers are synonymous, thereby allowing for preservice teachers to become critical consumers of research.

No matter the approach used to guide a review of the literature, preservice teachers must learn to synthesize what they read and then situate this learning in contextually-relevant practice. Kosuned and Mikkola (2002) emphasize the need for faculty to mentor those who have little experience examining existing research, and my findings support this assertion. When our students were unable to make use of the literature to guide the development of research questions, they often had an insufficient understanding of the practices they studied, thereby further diminishing their ability to integrate teaching and research practice.

\section{Designing Methodology}

Once a research question has been constructed, teacher-researchers next need to construct a methodology that allows for the implementation and study of a new practice. In traditional forms of research, development of research questions is followed by a methodology that is focused on data collection and analysis. In classroom research, this methodology is still required; however teacher-researchers must also align their methodologies with the implementation of new practice. Engaging in a new practice can alone prove difficult. When a teacher also needs to 
collect and analyze data to consider the impact of this practice, the process becomes more difficult, especially for a preservice teacher.

Data from my study suggests that many students implemented new practices while evaluating the impact of these practices using inappropriate data sources (like pre-existing classroom assessments). Students often made a concerted effort to engage in data collection that was aligned with their teaching, however, even when this effort was made, students often lamented the poor choices they made with respect to data collection and analysis. These students demonstrated that they had the perspectives necessary to provoke them to try and integrate their teaching and research, but lacked the practices necessary to accomplish this integration. In other cases, findings suggest that students relied on existing structures to guide data collection and analysis, thereby suggesting that some students were unable to see the value in implementing data collection and analysis structures that were aligned with the new practices they intended to study.

While the research practices needed to systematically and intentionally study ones teaching are central to learning how to engage in classroom research, Dawson and Dana (2007) caution that these practices must be developed within the framework of improving teaching. Data from my study suggests that in their early classroom research experiences, many teachers were unable to fully implement new practices. This suggests that we may have asked too much, a conclusion aligned with research Dr. Rutherford and I (2011) engaged in previously. This research, which made use of some of the earlier reflections by the students whose work I studied, highlighted the need to provide multiple experiences that allow students to understand the various attributes of quality classroom research. While most students were able to talk about some of the data collection and analysis tools they used as part of their research, even in later 
placements (where our students were in a classroom full-time), many had difficulty implementing new practices, and selecting data sources that could guide their study of these practices. These findings emphasize the difficulty of learning to implement a practice, developing ways to study the practice, and then engaging in data collection and analysis. Overcoming this difficulty is important as students who had difficulty integrating their work as teachers with their work as researchers, often were unable to accomplish either task.

\section{Using Data to Consider Professional Practice and Student Learning}

According to Christenson (2004), the findings generated from classroom research should serve first as a form of professional development. However, Ax et al. (2008) emphasizes the need for preservice teachers to not only focus on their own learning, but also the learning of their students. While the nature of our students' essays did not allow for me to make explicit judgments related to student learning, the findings of my study suggest that some of our students were able to consider their own practice, and were able to learn about their own students. These preservice teachers demonstrated an ability to situate their own learning in the classroom, as well as an ability to use the findings of their research to consider the ways in which the changes they made to their practice impacted the learning of their students (McGee \& Lawrence, 2009). Other students seemed to have difficulty making sense of their findings, even in cases where the data they analyzed was sufficient to draw meaningful conclusions.

Even when preservice teachers are able to implement new practices in ways that allow for systematic and intentional study, they must still be able to make sense of the data they collect. Dawson suggests that classroom research may allow for teachers to move beyond the "logistical and managerial" tasks associated with practice, thereby focusing more intently on "student learning outcomes" (p.266). While we placed significant emphasis on using data as a way to 
consider impact on student learning, my data suggests that many students had difficulty making sense of their data. Some students focused on only a fraction of the data they collected, while others misinterpreted their data.

While my analysis suggests that we need to place greater emphasis on helping our students analyze and interpret their data, evidence from my study also provides an important way in which preservice teachers might be able to better understand their data. Some students reported that through the use of data collection tools such as surveys and interviews, they were able to not only learn about their students, but were also able to learn from their students. Often, when preservice teachers made clear to their students that they were studying their practice, these preservice teachers were able to collect and analyze data that both contributed to their study, and develop stronger relationships with their students. When preservice teachers are unable to make sense of their data, they are likely to become frustrated, and thus are less likely to continue to engage in systematic and intentional study of their practice in the future. However, when our students were able to use their findings in a way that impacted their practice and their students' learning, evidence suggests that classroom research became a powerful tool for professional learning.

\section{Making Work Public}

We asked our students to make their work public in two distinct ways. First, we asked them to construct formalized written reports that detailed their studies. Second, each student was able to present their work at a conference, attended by public school faculty, university faculty, and other preservice teachers. Our students lamented the limited time that they had to write their reports, and many students viewed the writing process as a hoop they were required to jump 
through. Our students reacted much more favorably to being able to present their work to other educators.

Because we held our conference several months after students completed their reports, our preservice teachers had significantly more time to prepare for their presentations. While time may have been a key factor in our students' preference for presenting their work over writing about their work, many students saw the conference as an empowering experience whereby they were able to help others to learn about the knowledge constructed through their work (Hall, 2009).

While we support students as they develop their reports and conference presentations, there was only minimal discussion in students' essays that described other ways in which the outcomes of their classroom research were shared. This suggests that part of learning how to engage in classroom research is learning how to share findings in ways that can impact both teacher-researchers and those with whom they work. Rust and Meyers (2006) suggests that for practicing teachers, sharing their work is the most important part of the classroom research cycle. Thus it is important for those who work with preservice teachers to not only prepare their students to do classroom research, but also prepare them to share their research with their colleagues, supervisors and others. This not only allows teacher-researchers to contribute to the professional learning of others, but also allows these teachers to receive the support and recognition that can provoke them to continue to study their practice.

\section{Summary of Findings}

The findings presented beginning in chapter 5, help to provide answers to each of my research questions. In chapter 5, I examined how some students were able to develop an Inquiry Narrative, thereby providing evidence of how preservice teachers learn to make use of reflection 
and action to evaluate and resolve dilemmas. In chapter 6, I examined the ways in which some students were able to develop a Classroom Research Narrative by engaging in systematic and intentional classroom research. In these two chapters, I also provided evidence of how some students developed perspectives towards inquiry that were sophisticated enough to provoke them to construct Inquiry Narratives and Classroom Research Narratives. In chapter 7, I examined evidence that suggested many students were limited in their development of perspectives towards inquiry. I also examined evidence that suggested that some students, regardless of the sophistication of their perspectives towards inquiry, were unable to demonstrate that they had developed the practices necessary to construct Inquiry Narratives or Classroom Research Narratives. In chapter 8, I considered the narrative of Brian, who was one of only a handful of students to construct a Life-Long Narrative that included full Inquiry Narratives and Classroom Research Narratives. In chapter 9, I considered the barriers and facilitators that existed as students worked through the process of learning and doing classroom research. Finally, in this chapter, I have sought to synthesize my findings, illuminating four perspectives and five practices that are central to engaging in classroom research.

In chapter 11, I will consider the implications of my study for those facilitating and engaging in classroom research, keeping in mind its limitations. Finally, I will provide suggestions for future research that can help us to better understand how teachers, whether practicing or preservice, can develop sophisticated perspectives towards inquiry; manifest these perspectives in practice, sometimes making use of systematic and intentional classroom research; and perhaps eventually construct a Life-Long Narrative that indicates the development of an inquiry stance. 


\section{Chapter 11: Implications and Conclusions}

My impetus for engaging in this study was to better understand the ways in which the preservice teachers we worked with developed as teacher-researchers, so that I could inform my own practice, and the existing knowledge base on classroom research. In doing so, I sought to provide a clearer picture of the perspectives and practices that are necessary for teachers to eventually develop an inquiry stance towards their classroom teaching practice. Recognizing that Cochran Smith and Lytle (2009) make clear that an inquiry stance "carries across educational contexts and various points in one's professional career" (p. 5), I focused on the development of those perspectives towards inquiry which could provide the foundation necessary for reflective practitioners to make use of systematic and intentional classroom research throughout their career.

In this study, I used the literature on classroom research and my own experiences to construct three research questions. I wondered how preservice teachers developed perspectives towards inquiry through preservice classroom research experiences. I also asked how these developing perspectives towards inquiry were manifested in practice as preservice teachers engaged in classroom research. Finally, I wondered what barriers and facilitators existed to developing perspectives towards inquiry. To answer these questions I examined essays written by 83 students at the conclusion of their preservice program. Making use of narrative analysis, I came to see these essays as the first chapter of a Life-Long Narrative. I found that this narrative described how each student developed as a teacher, with an emphasis on how they addressed the dilemmas of teacher practice and student learning they faced. I also found two additional types of narratives embedded in many students' essays. Many students developed one or more Inquiry Narratives that outlined how they made use of reflection and action in an effort to resolve the 
dilemmas they faced. Some students also developed Classroom Research Narratives, describing systematic and intentional study of new practices designed to address the needs of students. In this chapter, I consider the implications of my study for those who facilitate, engage in, and study classroom research; especially those who seek to help preservice teachers enter the profession equipped to someday develop an inquiry stance.

\section{Implications}

In focusing on the implications of my study, I considered the relationship between the practices necessary for preservice teachers to demonstrate the levels of sophistication evidenced by Brian's Life-Long Narrative and the perspectives that allow preservice teachers like Brian to make use of the practices they acquire. I also considered the students who were unable to demonstrate this level of sophistication. By reflecting on my findings, I provide four important implications for those who seek to develop teacher-researchers: (1) emphasizing all important perspectives and practices; (2) helping preservice teachers to see barriers as challenges; (3) constructing structures that facilitate perspectives towards inquiry; and (4) promoting practicing teachers' development of an inquiry stance. The first three of these implications relate primarily to the ways in which preservice teachers learn to engage in classroom research, while the forth extends beyond the confines of preservice teacher education, recognizing that an inquiry stance “carries across educational contexts and various points in one's professional career" (CochranSmith \& Lytle, 2009, p. 5). In this section, I consider each of these implications, and make specific recommendations that are aligned with the findings of my study, and that can guide those who seek to help develop teacher-researchers. 


\section{Emphasizing all Perspectives and Practices}

The findings of my study support and extend our understanding of how preservice teachers develop perspectives towards inquiry, and help us to see how students learn the practices that allow them to engage in classroom research. Perhaps most importantly, my study demonstrates the relationship between these perspectives and practices. Given the interconnectedness of the perspectives and practices critical to classroom research, each perspective and practice should receive significant attention during the process of developing the learning of preservice teachers.

There was significant variation in the extent to which the essays I analyzed provided evidence that students had learned to become teacher-researchers. In chapter 7, I refer to the fractured narratives created by students who were lacking some of the critical perspectives and practices necessary to develop Inquiry Narratives and Classroom Research Narratives. The elements of these narratives are closely related. For instance, even if a preservice teacher was able to integrate their teaching and research in a meaningful way, if this integration was the product of a poorly constructed research question, it is doubtful that the findings generated allowed for rich professional learning.

The interrelatedness of the elements of each narrative underscores the importance of providing students with opportunities to develop all of the practices critical to classroom research. My study suggests that by stretching learning experiences out across the three years of our students' preservice program, we allowed for many students to learn from their mistakes, thus allowing for this learning to guide our students in their future classroom research experiences. In an effort to support simultaneous development of sophisticated perspectives towards inquiry and the practices necessary to actualize perspectives through classroom research, 
teacher educators would be well served to closely consider how perspectives and practices are developed and the ways in which this development is supported by programmatic structures.

\section{Recommendation \#1: The complexity and interconnectedness of perspectives and} practices needs to be recognized and considered in light of individual learning contexts and

individual learners. In examining our students' essays, some students seemed to grasp the perspectives necessary to engage in classroom research, while struggling with the practices that could allow them to do this research. Other students seemed to be able to make use of the necessary practices, but never developed the perspectives that are needed to provoke teacherresearchers to study their practice. Given these findings, it is important that both perspectives and practices are emphasized at each step of the learning process. If students fail to learn the practices critical to classroom research, they are likely to become frustrated with their inability to resolve the dilemmas they investigate. Further, if students fail to develop perspectives towards inquiry, they are unlikely to engage in the reflection necessary to provoke them to engage in classroom research.

If teacher educators are going to maximize their students' potential to develop perspectives and practices, it is important to first understand individual students, making sure to continually monitor the ways in which students develop their understandings not only of classroom research, but also of teaching practice writ large. In monitoring the evolving understandings of preservice teachers, it is also important to understand the variations in learning that occur when preservice teachers learn from different instructors, have field placements in divergent settings, and come from unique backgrounds, as each of these factors has the potential to shape the learning of individual preservice teachers. 
In addition to monitoring the progress of individual students, experiences that provoke the development of perspectives towards inquiry should be tailored to individual learners, and should attend to the contextual differences that are present within individual teacher education programs, especially those that support large numbers of preservice educators. Further, experiences should also allow for preservice teachers to learn and implement the practices which support classroom research. These experiences should be focused initially on emphasizing the importance of individual practices, and should seek to leverage formative assessment to help diagnose and correct misconceptions. Because developing and implementing these experiences is such a complex task, crafting and evaluating experiences should extend beyond those who are explicitly responsible for classroom research experiences, thereby allowing for shared decisionmaking across individual teacher education programs.

Recommendation \#2: If classroom research is to be a central component of teacher education, then teacher education programs need to adjust to meet the needs of preservice teacher-researchers rather than just including a new course or experience. Despite the depth and breadth of experiences provided to the preservice teachers we worked with, many of our students still had difficulty reconciling their learning about classroom research with their learning about other practices. This suggests that while stranding classroom research experiences into multiple clinical placements is a good first step, greater integration of classroom research into other courses and experiences is also needed.

If teacher education programs are going to commit to develop teacher-researchers, these programs should endeavor to eventually make teaching and researcher seamless enough that research is seen by preservice teachers as a natural part of teacher practice. Accomplishing this integration is likely to prove challenging, especially in contexts where decisions about course 
delivery and clinical experiences are left primarily to individual course instructors and field supervisors. Even when teacher education faculty often make collaborative decisions, it is imperative that there is a shared understanding of classroom research and the perspectives and practices which allow for the cultivation of teacher-researchers. The collaboration needed to design experiences that can allow for preservice teachers to understand and engage in classroom research, though intensive, can serve as a model for the collaboration that can support teacherresearchers in the field.

If students are unable (or unwilling) to systematically and intentionally study their practice in an effort to solve dilemmas, then they will not construct Inquiry Narratives or Classroom Research Narratives as part of future drafts of their Life-Long Narrative. This means that even if these students are able to recognize dilemmas, they will have to consider a different way to evaluate and resolve the dilemmas they face, a way that may preference their own personal needs, rather than their obligations as professionals.

Those who seek to develop teacher-researchers should consider ways to help their students develop perspectives towards inquiry, and learn to make use of the practices necessary to engage in classroom research. Without this learning, the fractured narratives evident in many of our students essays will likely result in teachers who are unable or unwilling to resolve dilemmas through classroom research.

\section{Empowering Preservice Teachers to see Barriers as Challenges}

The findings of my study support prior research that underscores the need for teacherresearchers to be afforded the time and space to develop and explore the practices and perspectives necessary to engage in classroom research. My findings suggest that time, a lack of methodological expertise, and contextual barriers can limit the development of perspectives 
towards inquiry. However, my findings also provide evidence that when students are able to develop sophisticated perspectives towards inquiry, these perspectives provokes them to see barriers as challenges, empowering them to overcome barriers and to study their practice in meaningful ways. Given these findings, those who work with preservice teachers should focus on helping them to recognize and overcome barriers. In attending to this, considering individual students and contexts, as discussed in the previous section, is critical. Data from my study also points to the need for greater focus on time and methodological expertise.

\section{Recommendation \#3: The perversity of time as an issue needs to be addressed and}

\section{structures that provide preservice teachers sufficient time to develop as teacher-}

researchers need to be created. Time is mentioned repeatedly in the literature on classroom

research. Time is also mentioned in nearly every essay I analyzed. Given that the stranded nature of our students' experiences likely represents the upper limit of how much time a teacher education program can devote to classroom research, it may be impossible to eliminate time as a factor that can inhibit the development of sophisticated perspectives towards inquiry. However, when we were able to provide enough time for our students to develop more sophisticated perspectives towards inquiry, these students were then empowered to overcome barriers on their own.

In considering time, those who design and facilitate classroom research experiences should focus on the time required for preservice teachers to learn, implement and reflect on important practices. Many of our students pointed to their mini-inquiry as an important experience that shaped their ability to engage in semester-long classroom research. This suggests that in addition to allowing preservice teachers an opportunity to try out the practices they learn, there should be opportunities to learn from initial mistakes before engaging in more robust 
research experiences. Providing multiple opportunities requires a greater investment of time, but this investment can lead to tangible results when students have the expertise to engage in more systematic classroom research.

\section{Recommendation \#4: There needs to be greater attention to methodological} expertise in pre-service teacher education, even for students not pursuing advanced degree.

Preservice teachers should learn how to analyze data in ways that align with their research questions. While a teacher may only need to plug in a "grade" from an assessment completed by their students, a teacher-researcher may need to investigate their students' work in much greater depth. Teacher-researchers should learn how to derive meaning from types of data they are most likely to use. Learning activities should focus on making meaning out of students work, observations, surveys, interviews, and student performance data. Those facilitating these experiences may be best served by first allowing preservice teachers to look at data as a group, before providing opportunities for students to identify, collect and analyze data specific to their contexts. While data analysis, especially qualitative analysis, may warrant significant attention in the learning process, drawing inferences from analyzed data should also be part of preservice teachers' experiences working with data.

The difficulty of learning how to engage in quality research suggests that when feasible, methodological coursework should be a part of preservice programs, including those that cater to undergraduates. Additionally, programs can assess when students are asked, or could be asked, to engage in data collection (i.e. observations, interviews, examining student work, etc.), and in doing so make sure that these experiences include opportunities for students to analyze and report on the data they collect. These experiences should also be scaffolded so that preservice 
teachers can learn to overcome the methodological challenges they face, and are empowered to seek support when working with data.

My findings suggest that it is critical to recognize that just as students differ in their ability to develop perspectives towards inquiry, students also differ in their ability to overcome barriers. Given this, those of us who facilitate classroom research, should seek to understand the common barriers that exist in all contexts and those that may be specific to particular programs. Further, we should recognize the specific barriers faced by our students and understand the ability of individual students to overcome these barriers. My study suggests that if we are able to help our students overcome barriers, eventually, students will develop perspectives that provoke them to see barriers as challenges, and will then find ways to overcome these challenges. When preservice teachers learn to overcome the challenges they face, it seems far more likely that they will evolve into teacher-researchers who are able to find the time necessary to engage in highquality classroom research.

\section{Creating Structures that Facilitate Perspectives towards Inquiry}

Throughout this narrative, I have used the term teacher-researcher to refer to teachers who are able to make research a part of their everyday practice. Findings from my study suggest that as preservice teachers learn to engage in classroom research, they often find it difficult to focus simultaneously on their field experiences and traditional coursework activities. These struggles are especially common when the requirements of students' mentor teachers, field supervisors, and course instructors are not aligned. While university-based shared decisionmaking can help to align the requirements of course instructors and field experiences, universities must also be willing to collaborate with their public school partners to further align experiences. While context will likely play a large role in the specific structures that can support 
the development of perspectives towards inquiry, in general, two important themes emerge that should guide development of these structures.

\section{Recommendation \#5: Mentor teachers need to be active participants in the research}

\section{of their mentees, and need to have the expertise to make a meaningful contribution to this}

learning. My analysis uncovered evidence of our students' classroom research being supported by their mentor teachers. In some cases this support came largely from encouragement, while in other cases mentor teachers took a more active role. When mentor teachers were actively involved in the design and implementation of our students' classroom research, students benefitted from this involvement.

Other students, when considering the role of their mentor teachers in the design and implementation of classroom research, described their mentor teachers as apathetic, or even resistant. In these cases, mentor teachers were a contextual barrier to the development of perspectives towards inquiry. While teacher educators may lament mentor teachers that inhibit the classroom research of preservice teachers, it is important to properly diagnose the source of this resistance or apathy. In doing so, teacher educators need to consider the extent to which they, through a lack of sustained support, contribute to circumstances where preservice teachers are placed with mentors who are ill-equipped to help cultivate teacher-researchers.

If classroom research is to be a central theme of teacher education, then their needs to be clear communication of expectations not only for preservice teachers, but also for those who mentor them. These expectations should be documented, and structures should exist that allow for mentors to learn how to support their mentees. Further, mentor teachers should be provided a mechanism whereby they can interact directly with university faculty who are responsible for 
supervising classroom research experiences. These mechanisms are critical, and require strong school-university relationships.

\section{Recommendation \#6: The relationship between university and schools needs to}

support classroom research, and PDS can provide this relationship. If mentor teachers are to actively support the classroom research of preservice teachers, then these mentors need to be provided with a clear set of expectations, as well as the knowledge and skills necessary to meet these expectations. While many programs provide expectations in the form of written documentation, structures which allow for continued communication across institutions can support a stronger culture of inquiry in the classrooms and schools where preservice teachers engage in classroom research experiences.

This communication needs to be structured so that school and university stake-holders are seen as equal partners in the development of teacher-researchers. While mentors need to adjust their own practice to meet the needs of their mentees, university-based teacher educators need to also understand the many other demands of mentor teachers, and must be willing to consider these demands when constructing experiences for preservice teachers.

One possible structure that can support shared decision-making is the creation of systematic school-university partnerships, like those that exist in PDS networks. As described in Chapter 3, PDS partnerships allow for a university, and the public schools the university works with, to collaboratively design and deliver robust teacher education experiences. Shared decision-making is a central tenant of PDS work, as is the notion of boundary-spanning; where university faculty take an active role in public schools while inservice teachers assume greater responsibility for delivery of content that has been traditionally taught by university faculty. In addition to supporting the development of preservice teacher-researchers, PDS can allow for 
practicing teachers to receive the support necessary to continue to develop as teacher-

researchers, thereby maximizing the potential for these teachers to develop an inquiry stance.

\section{Promoting the Development of an Inquiry Stance}

At the conclusion of their Life-Long Narratives, some of the preservice teachers who had developed sophisticated perspectives towards inquiry began to look ahead at ways in which they might build on their preservice experiences. These students demonstrate the greatest potential for eventually developing an inquiry stance. The Life-Long Narrative of Brian suggests that he has entered the profession with the perspectives towards inquiry necessary to develop an inquiry stance. His narrative also suggests that he has an understanding of the practices necessary to systematically and intentionally study his practice. If subsequent drafts of Brian's Life-Long Narrative are to suggest the development of an inquiry stance, it will be critical that structures are in place that can support his continued engagement in classroom research. Structures like time, collaboration, and recognition for teacher-researchers can support the continued growth of teacher-researchers in the field. Further, administrators can allow for the continued growth of teacher-researchers by providing opportunities for job-embedded professional development. In doing so, schools can also allow for the development of teacher-researchers, who may eventually develop an inquiry stance towards their teaching and who are capable of mentoring preservice teacher-researchers.

\section{Recommendation \#7: Job-embedded professional development should include}

further support for classroom research activities. In the same ways that Dr. Rutherford and I sought to develop structures that could support the research experiences of our students, principals and other administrators need to ensure that they support the work of teacherresearchers. In doing so, administrators should emphasize the importance of teacher-constructed 
knowledge in allowing for contextualized professional learning. Further, it is important that structures that allow for the continued development of teacher-researchers be provided, especially structures that encourage collaboration. These structures should seek to include practicing teachers at various points in the career cycle, and should capitalize on the work of experienced teacher-researchers to provoke others to engage in classroom research.

Findings from my study revealed that some of our students have a desire to collaborate with colleagues to address dilemmas that extend beyond the walls of a single classroom. Others spoke of wanting to help their colleagues learn to see the value of engaging in classroom research, and sharing the learning that comes from this research. The ability of these nowpracticing teachers to realize goals that can allow them to become teacher leaders will be largely dependent on the structures in place at the schools where they teach. When novice teachers work in contexts that support their continued development as teacher-researchers, there is a potential for these teachers to progress towards an inquiry stance. Further, these teachers can then provide the active mentoring identified by our students as a facilitator to the development of their perspectives towards inquiry.

\section{Recommendation \#8: The ability to mentor preservice teachers needs to be} supported and encouraged by school-level administrators. Many students made explicit the impact their mentor teachers had on their classroom research experiences. Implicit in these students' discussions about their classroom research experiences, was the need for mentor teachers who understand classroom research. Generally, mentors had a positive impact on their mentees, but in some cases, apathy and resistance by mentors had an adverse impact on our students' classroom research, and thus served to mitigate the development of these students' 
perspectives towards inquiry. Ideally, teacher education programs should seek to place their students with mentors who are themselves, teacher-researchers.

While preservice programs are free to construct minimum requirements for mentors, it is incumbent on partner schools to emphasize structures that can allow their teachers to meet these mentoring requirements. If schools and universities can collaboratively design and support structures that allow for practicing teachers to value and make use of classroom research, then it becomes possible to allow for preservice teachers to be mentored by teacher-researchers. If provided the opportunity to work with a mentor who already has sophisticated perspectives towards inquiry and an ability to manifest these perspectives in practice, preservice teachers are able to see these practices and perspectives modeled in a real-world context and thus are more likely to begin to see classroom research as part of the daily work of teachers.

In this section I have suggested the ways in which my findings have implications for those who work with preservice teachers, and have provided recommendations for those who seek to cultivate teacher-researchers. While my research is most likely to inform the work of those who most directly help preservice teachers to become teacher-researchers, these recommendations can also inform the work of those who coordinate teacher education programs, teach courses in these programs, and those who mentor preservice teachers in the field. I have also suggested how those who supervise practicing teachers can both support and extend the learning of teacher-researchers. I now shift my focus to those who study classroom research, considering how my study might inform the work of others seeking to better understand how preservice teachers develop perspectives towards inquiry and the practices that allow them to capitalize on these perspectives. 


\section{Future Research}

In studying the work of our preservice teachers, it was my intent to inform my own practice as a facilitator of preservice teachers' learning to understand and engage in classroom research. I also sought to inform the literature on classroom research, especially the literature on preservice teacher research. While this work has impacted my own practice, thereby provoking me to believe that my research can inform the work of others, I am left with many additional questions. By considering these questions now, I hope to lay the foundation for my own continued study, and simultaneously encourage others to build off of this work.

In this section I will focus on future directions for research which may complement or confound the findings of this study. I will first recognize the limitations of my study. Then, I will consider ways in which the design of my study might be altered and expanded. In doing so, I emphasize the need for research that examines the work of teacher-researchers over time, as these teachers engage in classroom research that leads to the development of multiple products and is undertaken with the intent of producing multiple outcomes.

\section{Limitations}

The findings of this study have been generated through a carefully crafted methodology, and are based on research questions developed through a thorough examination of the literature, and on my own experiences facilitating experiences whereby preservice teachers learn about and engage in classroom research. However, from the outset, I recognized limitations in this study that would impact my findings, and the conclusions drawn from these findings. Having completed my analysis, reported findings, and considered the implications of these findings, I now return to the limitations of my study in an effort to both situate findings and conclusions, and to guide future study. 
When describing my research to a former student, he suggested that I was conducting an action research project on my own teaching of action research. This study is not action research, given that while Dr. Rutherford and I were responsible for the development of the classroom research experiences that helped some of our students to develop sophisticated perspectives towards inquiry, I did not conceive of this study until after these experiences had ended. None the less, some of the same factors that can impact the findings of action research were also present in this study.

Most notably among these factors is the alignment between my own perspectives on classroom research as a teacher educator, and the perspectives that I looked for in this study. While Schön's work on reflective practitioners and Cochran-Smith and Lytle's work on inquiry as stance are both seminal in the literature on classroom research, I recognize that the ways in which I interpreted this literature not only guided the development of this study, but also guided the experiences Dr. Rutherford and I developed. Thus, while I feel that Brian's narrative represents the development of sophisticated perspectives towards inquiry manifested through systematic and intentional study, Brian's explicit use of the phrases "reflective practitioner" and "inquiry stance" may also represent his understanding of the extent to which Dr. Rutherford and I would value the use of those phrases in any document that synthesizes one of our student's learning.

The use of our students' inquiry synthesis essays as the sole data source for this study also serves as a limitation. In developing this study, I wanted to capture the work of as many students in one cohort of our program as possible. My initial review of potential data sources suggested that the synthesis essays would be the most appropriate source of data given my research questions, but I recognize there were many other potential options. Further, I could have 
selected a smaller sample of students from the cohort, and then focused on multiple products produced by these students. Thus, while reducing the size of my sample might have eliminated Brian as a participant in this study, as well as some of his peers who also demonstrated sophisticated perspectives towards inquiry, my use of a single product from each student has prevented me from examining the extent to which the perspectives expressed by Brian in his synthesis essay, align with the other products he produced over three years of learning about classroom research.

\section{Additional Research}

Considering the findings of my study, its limitations, and the existing literature, several possibilities for expanding on my study become apparent. While these ideas will be central to my continued research, findings generated from my current and future research need to be considered in relationship to the work of others. In addition to similar studies conducted in divergent contexts, there is also a need for studies that examine various products produced by preservice teachers during their classroom research experiences. Additionally, there is a need for research that seeks to compare the ways in which the perspectives towards inquiry developed by preservice teachers align with the practices employed by these teachers once they begin their careers. Finally, there is a need for research that seeks to examine the relationship between how preservice teachers' see the effect of their classroom research on their students' learning and the learning of these students as measured using other forms of data.

Looking inside inquiry narratives and classroom research narratives. As previously mentioned, I sought to examine the work of as many students as possible in my study, and found that the inquiry synthesis essays of our students allowed for an in-depth analysis of the development of perspectives towards inquiry in a large number of students. However, there were 
many possible data sources I could have utilized. It would be helpful to examine the actual reports written by our students, each detailing a specific classroom research experience, in an effort to see if the ways students wrote about these experiences in their synthesis essays aligned with the ways they wrote about the experiences as they occurred. It would also be helpful to examine some of the less formal products produced by students, in an effort capture their learning as it occurred.

In addition to examining various student products, research that looks across a series of products would allow for a better understanding of how perspectives towards inquiry develop over time. These studies could also be supported by research that looks directly at students, through observations and interviews, rather than looking at the work they produced. Each kind of research would help to triangulate the findings of this study, and provide additional nuance that could help to inform the literature as to how preservice teachers develop perspectives towards inquiry. Additionally, making use of one of these potential research projects to study students' learning in different contexts, could allow for a more robust understanding of the structures that provide the most value to preservice teachers as they develop perspectives towards inquiry.

Following preservice teachers into the field. As I began to look more closely at Brian’s Life-Long Narrative, I immediately wondered if he has begun to construct new Inquiry Narratives and Classroom Research Narratives since he entered the profession. If so, were these narratives indicative of continued progress towards an inquiry stance? If not, what barriers were interfering with Brian's continued emphasis on making use of classroom research? I could ask these same questions about each student who seemed to have developed sophisticated perspectives towards inquiry, and who made use of systematic and intentional classroom 
research. I could also ask similar questions about students whose perspectives towards inquiry were less sophisticated, or whose classroom research was less robust.

While there is a sizeable body of research on the classroom research experiences of practicing teachers, and a growing body of research on the experiences of preservice teachers, there is very little research that examines the development of perspectives towards inquiry in preservice teachers, and then follows this development once these teachers begin their careers. This longitudinal research would allow those of us who work with preservice teachers to understand how the learning we facilitate translates into the practice of our graduates. This research would also allow those who supervise practicing teachers to consider the impact of various contexts on the continued development of practicing teachers. Perhaps most importantly, by researching the development of perspectives towards inquiry over time, we may be able to understand how a novice teacher-researcher can eventually develop an inquiry stance.

Providing coda for the classroom research of our students. In developing the Classroom Research Narrative, I suggested that coda for this narrative comes from a teacherresearcher's own assessment of the quality of their work. While our students wrote about their findings, and the ways they learned from these findings, how students ultimately felt about their work is indicative of the kind of reflection that most teachers, or researchers, or professionals are unwilling to share. However, while the coda of a teacher-researchers' Classroom Research Narrative may be private, we can seek other ways to better understand the quality of classroom research.

When we supervise our preservice teachers during each field experience, we rely on our students to determine the impact of their individual classroom research on their students' learning. While we can provide support as our students select research questions, choose 
practices to implement and data sources to study these practices, collect and analyze data, and write-up and report findings, we are not in the classroom with them as they engage in teaching and research activities. Given this, it would be beneficial to couple research that seeks to examine the ways in which teacher-researchers implement and study new practices, with research that directly examines the impact of the practices implemented as a result of classroom research on students. While one of the goals for encouraging teachers to engage in classroom research is to allow them to develop contextually-relevant professional knowledge, comparing the ways in which teachers determine the impact of their work with the way others may look at impact, can help lead to the development of more refined processes for supporting the classroom research of preservice teachers.

In this section I have suggested some directions for future research, using the limitations of my study as a basis for these suggestions. While I hope that this study can inform the work of others, it is only the first step in what I hope will be a line of research that I can sustain for many years. In this way, I am seeking to re-enter the cycle of inquiry, making use of what I have learned from my research, to guide my future practice and my future research. In this way, the narrative I have constructed can be seen as one chapter of my own Life-Long Narrative.

\section{Jason's Life-Long Narrative}

In writing this dissertation, I have used a narrative approach. By writing in the first person and referring to participants as "our students," I have adhered to a constructionist epistemology by recognizing that my findings were the result of the way I made sense of our students' essays, and that these essays were based on the ways these students constructed their own realities. Because I have written a narrative that is based on my experiences as a researcher, 
and because my research was provoked by my experiences as a teacher, there are close parallels between this narrative, and the narratives constructed by our students.

This study was born out of a dilemma. I came to value the importance of classroom research as an important tool for teachers. I also felt strongly that by providing our students with the foundation necessary for them to develop an inquiry stance, we could help our students and the teaching profession. Despite this, I wrestled with how I could help students develop as teacher-researchers, given the structural limitations of teacher education programs and the countless other practices our students needed to learn. Further, I wanted to better understand how a teacher educator, even with the good fortune of having three years to work with his students, could prepare them to have a worldview that could sustain them throughout a career.

Given this dilemma, I began with a practice I understood reasonably well, and focused on the literature I knew. I then turned to the literature I did not know, synthesizing this research in a way that could help me consider the building blocks of an inquiry stance. This process led me to three research questions. Wanting to produce definitive results, I began by using the same illadvised, all-consuming approach to designing my study that often plagues the work of our students. After being reigned-in by the experienced researchers on my committee, I settled for a well thought out first step to resolving my dilemma, rather than a poorly conceived attempt at a definitive resolution.

With a mountain of data to choose from, I decided to focus on a narrative, written by our students not long before they graduated. I felt that this artifact would be well suited to my research questions, as most of our students, by this point, were less concerned about perfect scores, and more concerned with what they could take away from their preservice preparation that would help them in the next phase of their careers. I further decided that I wanted to capture 
as many perspectives as possible, sacrificing the depth that could have come from looking at many products, for the breadth that came from looking at a single product.

While I had no teaching practice to implement, my data analysis and interpretation was constantly on my mind as I worked with successive cohorts of students. Thus, while I was attempting to use my research to evaluate and resolve my dilemma, I was simultaneously evaluating my teaching, seeking to take what I was learning through my study, and immediately using this learning to impact my practice.

In the end, the findings of my study have, in many cases, reinforced the research of others, and have emphasized the importance of practices I already valued. However, there were some findings that I hope will add to our understanding of classroom research, and that have significantly impacted the way I view my role as a preservice teacher educator. While the ways in which perspectives and practices intertwine have provoked me to rethink how I facilitate my students' learning, one particular finding has led me to think more than any other. As I began to code our students' essays, I found repeated examples in which our students talked about learning from their students, and how this learning led to improved teacher-student relationships.

As Dr. Rutherford and I made change after change to the inquiry strand, we continually asked our students to provide feedback. From well thought-out, detailed descriptions by our students of how our teaching was impacting their learning, to concise but important responses to open ended-questions stuck on the end of an assignment, to survey responses that criticized, amongst other things, the way I dressed and spoke during seminars, we obtained a mountain of feedback from students. While students sometimes grumbled about the endless "exit tickets" and "surveys," they were good sports, and I felt like we collected meaningful data. What I have now 
come to realize is that our continual willingness to share our research with our students, provoked our students to share their research with their students.

The most important evidence that has guided my evolving emphasis on feedback has been our students' inquiry synthesis essays. The way these essays were written, with students sharing their successes and failures, providing kudos and critiques of the inquiry stand, and speaking about the value, even when minimal, they placed on classroom research, has greatly informed my own professional learning. I believe that by demonstrating to students the value of feedback as data, and then allowing them to discover this value in their own contexts, we allowed for our students' essays to become a data source that could lead to rich findings.

The findings of this study have, and will have an impact on my teaching. Further, I am looking forward to continuing to research the classroom research experiences of our students. Some of my ideas for this continued research were outlined in this chapter, and some will likely not even be conceived for several years. I will however continue to investigate the dilemma that guided this study, and this study will inform each of these future studies. Through this continued research, it is my hope that I can continue to inform the literature on classroom research, my own teaching practice and the practice of my colleagues, and in doing so, continue to inform future chapters of my own Life-Long Narrative. 


\section{References}

Adelman, C. (1993). Kurt Lewin and the origins of action research. Educational Action Researcher, 1(1), 7.25 .

Agar, M. \& Hobbs, J. R. (1982). Interpreting discourse: Coherence and the analysis of ethnographic interviews. Discourse Processes, 8(1), 1-31.

Allard, C. C., Goldblatt, P. F., Kemball, J. I., Kendrick, S. A., Millen, K. J., \& Smith, D. M. (2007). Becoming a reflective community of practice. Reflective Practice, 8(3), 299-314.

Atay, D. (2008). Teacher research for professional development. ELT Journal: English Language Teachers Journal, 62(2), 139-147.

Avis, J. (2003). Work-based knowledge, evidence-informed practice and education. British Journal of Educational Studies, 51(4), 369.

Ax, J., Ponte, P., \& Brouwer, N. (2008). Action research in initial teacher education: an explorative study. Educational Action Research, 16(1), 55-72.

Bartlett, S., \& Burton, D. (2006). Practitioner research or descriptions of classroom practice? A discussion of teachers investigating their classrooms. Educational Action Research, 14(3), 395-405.

Basile, C. G. \& Sands, D. (2009). Lessons learned and building intellectual capital. In C. Basile (Ed.). Intellectual capital: The intangible assets of professional development schools (pp. 113-120). Albany, NY: SUNY Press.

Baumann, J. F., \& Duffy, A. M. (2001). Teacher-researcher methodology: Themes, variations, and possibilities. Reading Teacher, 54(6), 608.

Baumfield, V., \& Butterworth, M. (2007). Creating and translating knowledge about teaching and learning in collaborative school-university research partnerships: an analysis of what 
is exchanged across the partnerships, by whom and how. Teachers \& Teaching, 13(4), 411-427.

Blackman, M. B. (1992). The afterlife of the life history. Journal of Narrative and Life History, 2(1), 1-9.

Borg, S. (2009). English Language Teachers' Conceptions of Research. Applied Linguistics, 30(3), 358-388.

Borko, H., Whitcomb, J. A., \& Byrnes, K. (2008). Genres of research in teacher education. In M. Cochran-Smith, S. Feiman-Nemser, D. J. McIntyre, \& K. E. Demers (Eds.), Handbook of research on teacher education ( $3^{\text {rd }} \mathrm{ed}$, pp. 1017-1049). New York: Routledge/Taylor \& Francis Group.

Bradley-Levine, J., Smith, J., \& Carr, K. (2009). The role of action research in empowering teachers to change their practice. Journal of Ethnographic \& Qualitative Research, 3(3), $152-161$.

Brock, C., Helman, L., \& Patchen, C. (2005). Learning to conduct teacher research: Exploring the development of mediated understandings. Teachers \& Teaching, 11(1), 73-94.

Brookhart, S. M., Moss, C. M., \& Long, B. A. (2010). Teacher inquiry into formative assessment practices in remedial reading classrooms. Assessment in Education: Principles, Policy \& Practice, $17(1), 41-58$.

Brown, M., \& Macatangay, A. (2002). The impact of action research for professional development: Case studies in two Manchester schools. Westminster Studies in Education, $25(1), 35-45$. 
Burant, T. J., Gray, C., Ndaw, E., McKinney-Keys, V., \& Allen, G. (2007). Part I: Advancing the conversation: The rhythms of a teacher research group. Multicultural Perspectives, 9(1), 10-18.

Capobianco, B. M., \& Feldman, A. (2006). Promoting quality for teacher action research: lessons learned from science teachers' action research. Educational Action Research, 14(4), $497-$ 512.

Cardno, C. (2006). Leading change from within: action research to strengthen curriculum leadership in a primary school. School Leadership \& Management, 26(5), 453-471.

Caro-Bruce, C. (2008). Action research. In (L. B. Easton Ed.), Powerful designs for professional learning (2 ${ }^{\text {nd }}$ ed.). (pp. 63-70). Oxford, OH: National Staff Development Council.

Caro-Bruce, C., Flessner, R., Klehr, M., \& Zeichner, K. (2007). Creating equitable classrooms through action research. Thousand Oaks, CA: Corwin Press

Carroll, E. E., Skinner, C. H., McCleary, D. F., von Mizener, B. H., \& Bliss, S. L. (2009). Analysis of author affiliation across four school psychology journals from 2000 to 2008: Where is the practitioner research? Psychology in the Schools, 46(7), 627-635.

Christenson, M. A. (2004). Teaching multiple perspectives on environmental issues in elementary classrooms: A Story of Teacher Inquiry. Journal of Environmental Education, $35(4), 3-16$.

Chubbuck, S. M. (2010). Individual and structural orientations in socially just teaching: Conceptualization, implementation, and collaborative effort. Journal of Teacher Education, 61(3), 197-210. 
Clayton, S., O'Brien, M., Burton, D., Campbell, A., Qualter, A., \& Varga-Atkins, T. (2008). 'I know it's not proper research, but...: How 'professionals' understandings of research can frustrate its potential for CPD. Educational Action Research, 16(1), 73-84.

Cochran-Smith, M., \& Lytle, S. L. (1993). Inside/outside: Teacher research and knowledge. New York: Teachers College Press.

Cochran-Smith, M., \& Lytle, S. L. (1999). The teacher research movement: A decade later. Educational Researcher, 28(7), 15-25.

Cocharn-Smith, M., \& Lytle, S. L. (2009). Inquiry as stance: Practitioner research for the next generation. New York: Teachers College Press.

Corden, R. (2002). Developing reflective writers in primary schools: Findings from partnership research. Educational Review, 54(3), 249-276.

Crotty, M. (1998). The Foundations of Social Research: Meanings and perspective in the research process. Thousand Oaks, CA: SAGE Publications, Inc.

Dana, N. F. \& Yendol-Hoppey, D. (2008). The reflective educator's guide to professional development: Coaching inquiry-oriented learning communities. Thousand Oaks, Calif.: Corwin Press.

Dana, N. F. \& Yendol-Hoppey, D. (2009). The reflective educator's guide to classroom research: Learning to teach and teaching to learn through practitioner inquiry (2nd ed.). Thousand Oaks, Calif.: Corwin Press.

Danielson, C. (2006). Teacher leadership that strengthens professional practice. Alexandria, VA: Association for Supervision and Curriculum Development. 
Davis, M., Kiely, R., \& Askham, J. (2009). InSITEs into practitioner research: Findings from a research-based ESOL teacher professional development programme. Studies in the Education of Adults, 41(2), 118-137.

Dawson, K. (2006). Teacher inquiry: A vehicle to merge prospective teachers' experience and reflection during curriculum-based, technology-enhanced field experiences. Journal of Research on Technology in Education, 38(3), 265-292.

Dawson, K., \& Dana, N. F. (2007). When curriculum-based, technology-enhanced field experiences and teacher inquiry coalesce: An opportunity for conceptual change? British Journal of Educational Technology, 38(4), 656-667.

Desimone, L. (2002). How can comprehensive school reform models be successfully implemented? Review of Educational Research, 72(3), 433-479.

Dewey, J. (1904). The relation of theory to practice in the education of teachers. In C. A. McMurray (Ed.), Yearbook of the National Society for the Scientific Study of Education Vol. 3(1). (pp. 1-64). Chicago: University of Chicago Press.

Dewey, J. (1916). Democracy in Education. New York: Macmillan.

Elliott, J. (2007). Assessing the quality of action research. Research Papers in Education, 22(2), 229-246.

Erickson, F. (1986). Qualitative methods in research on teaching. In M. C. Whitcock (Ed.), Handbook of research on teaching ( $3^{\text {rd }}$ ed., pp. 119-161). New York: Macmillan.

Fals-Borda, O. (1987). The application of participatory action research in Latin America. International Sociology, 2(4), 329-347.

Foreman-Peck, L., \& Murray, J. (2008). Action research and policy. Journal of Philosophy of Education, 42, 145-163. 
Freire, P. (1970). Pedagogy of the oppressed. New York: Seabury.

Gall, M. D., Gall, J. P., \& Borg, W. R. (2007). Educational research: An introduction ( $8^{\text {th }}$ ed.). New York: Pearson.

Galletta, A., \& Jones, V. (2010). “Why are you doing this?” Questions on purpose, structure, and outcomes in participatory action research engaging youth and teacher candidates. Educational Studies, 46(3), 337-357.

Gewirtz, S., Shapiro, J., Maguire, M., Mahony, P., \& Cribb, A. (2009). Doing teacher research: A qualitative analysis of purposes, processes and experiences. Educational Action Research, 17(4), 567-583.

Glanz, J. (1999). A primer on action research for the school administrator. The Clearing House, 72(5), 301-304

Grbich, C. (2007). Qualitative data analysis: An introduction. London: SAGE Publications. Greene, M. (1995). Releasing the imagination. San Francisco: Jossey-Bass.

Groundwater-Smith, S., \& Mockler, N. (2007). Ethics in practitioner research: An issue of quality. Research Papers in Education, 22(2), 199-211.

Grushka, K., McLeod, J. H., \& Reynolds, R. (2005). Reflecting upon reflection: Theory and practice in one Australian university teacher education program. Reflective Practice, 6(2), $239-246$.

Guba, E. G. \& Lincoln, Y. S. (1989). Fourth generation evaluation. Newbury Park, CA: Sage Publications.

Hahs-Vaughn, D. L., \& Yanowitz, K. L. (2009). Who is conducting teacher research? Journal of Educational Research, 102(6), 415-426. 
Haigh, M., \& Dixon, H. (2007). 'Why am I doing these things?': Engaging in classroom-based inquiry around formative assessment. Journal of In-Service Education, 33(3), 359-376.

Hall, E. (2009). Engaging in and engaging with research: teacher inquiry and development. Teachers \& Teaching, 15(6), 669-681.

Hayes, S. B. \& Smith, J. J. (2011, April). Becoming teacher researchers: How engaging in practitioner inquiry influences the identities and practices of prospective teachers. Paper presented at the annual conference of the American Education Research Association, New Orleans, LA.

Hayes, S. B., Smith, J. J., \& Curtis, R. (2010, April). Inquiring together: What preservice teachers and teacher educators learned about action research/practitioner research. Paper presented at the annual conference of the American Education Research Association, Denver, CO.

Hussein, J. W. (2007). Developing teacher educators: a technocratic rationality versus critical practical inquiry - the Ethiopian experience. Journal of In-Service Education, 33(2), 209235.

James, E. A. (2006). A study of participatory action research as professional development for educators in areas of educational disadvantage. Educational Action Research, 14(4), 525533.

Jaworski, B. (2003). Research practice into/influencing mathematics teaching and learning development: Towards a theoretical framework based on co-learning partnerships. Educational Studies in Mathematics, 54(2/3), 249-282.

Jones, S., \& Tanner, H. (2002). Teachers' interpretations of effective whole-class interactive teaching in secondary mathematics classrooms. Educational Studies, 28(3), 265-274. 
Kamler, B., \& Comber, B. (2008). Making a difference: Early career English teachers research their practice. Changing English: Studies in Culture \& Education, 15(1), 65-76.

Kesson, K., Traugh, C., \& Perez III, F. (2006). Descriptive inquiry as contemplative practice. Teachers College Record, 108(9), 1862-1880.

Keyes, C. R. (2000). The early childhood teacher's voice in the research community. International Journal of Early Years Education, 8(1), 3-14.

Kincheloe, J. L. (1991). Teachers as researchers: Qualitative inquiry as a path to empowerment. London: Falmer Press.

Kirkwood, M., \& Christie, D. (2006). The role of the teacher researcher in continuing professional development. British Journal of Educational Studies, 54(4), 429-448.

Koro-Ljungberg, M., Yendol-Hoppey, D., Smith, J. J., \& Hayes, S. B. (2009). (E)pistemological awareness, instantiation of methods, and uniformed methodological ambiguity in qualitative research projects. Educational Researcher, 38(9), 687-699.

Kosunen, T., \& Mikkola, A. (2002). Building a science of teaching: How objectives and reality meet in Finnish teacher education. European Journal of Teacher Education, 25(2/3), 135150.

Kraft, N. P. (2002). Teacher research as a way to engage in critical reflection: A case study. Reflective Practice, 3(2), 175-189.

Labov, W. (1972). The transformation of experience in narrative syntax. In W. Labov (Ed.) Language in the inner city: Studies in the Black English vernacular (pp. 354-396). Philadelphia: University of Pennsylvania Press.

Lewin, K. (1946). Action research and minority problems. Journal of Social Issues, 2(4), 34-46. Lewin, K. (1948). Resolving social conflicts. New York: Harper \& Row. 
Lieberman, A. (2009). Inquiring teachers: Making experience and knowledge public. Teachers College Record, 111(8), 1876-1881.

Lieberman, A., \& Miller, L. (2001). Teachers caught in the action: Professional development that matters. New York: Teachers College Press.

Lieblich, A., Tuval-Mashiach, R., \& Zilber, T. (1998). Narrative research. Thousand Oaks, CA: SAGE.

Lincoln, Y. S., \& Guba, E. G. (1985). Naturalistic inquiry. Beverly Hills, CA: SAGE.

Luckcock, T. (2007). Theoretical resource. Educational Action Research, 15(1), 127-145.

Lytle, S. L., Portnoy, D., Waff, D., \& Buckley, M. (2009). Teacher research in urban Philadelphia: Twenty years working within, against, and beyond the system. Educational Action Research, 17(1), 23-42.

Marcos, J. J. M., Miguel, E. S., \& Tillema, H. (2009). Teacher reflection on action: What is said (in research) and what is done (in teaching). Reflective Practice, 10(2), 191-204.

Marcos, J. J. M., Sánchez, E., \& Tillema, H. (2008). Teachers reflecting on their work: Articulating what is said about what is done. Teachers \& Teaching, 14(2), 95-114.

McGee, A., \& Lawrence, A. (2009). Teacher educators inquiring into their own practice. Professional Development in Education, 35(1), 139-157.

McLaughlin, C., \& Black-Hawkins, K. (2007). School-university partnerships for educational research - distinctions, dilemmas and challenges. Curriculum Journal, 18(3), 327-341.

Montecinos, C. (2009). Reforming educational reform: Teachers' union leading teacher research in Chile. Educational Action Research, 17(1), 133-142.

Moss, G., Springer, T., \& Dehr, K. (2008). Guided reflection protocol as narrative inquiry and teacher professional development. Reflective Practice, 9(4), 497-508. 
Murray, J. (2010). Towards a new language of scholarship in teacher educators' professional learning? Professional Development in Education, 36(1/2), 197-209.

National Association for Professional Development Schools (2008). What it means to be a professional development school. Retrieved from http://www.napds.org/9\%20Essentials/statement.pdf.

National Council for Accreditation of Teacher Education, Washington, DC. (2001). Standards for Professional Development Schools. Retrieved from http://www.ncate.org/ProfessionalDevelopmentSchools/tabid/497/Default.aspx.

Orland-Barak, L. (2009). Unpacking variety in practitioner inquiry on teaching and teacher education. Educational Action Research, 17(1), 111-119.

Patton, M. Q. (2002). Qualitative research \& evaluation methods $\left(3^{\text {rd }}\right.$ ed). Thousand Oaks, CA: SAGE.

Paulsen, M. B. (2001). The relation between research and the scholarship of teaching. New Directions for Teaching \& Learning, 2001(86), 19-29.

Phillips, D. K. \& Carr, K. (2010). Becoming a teacher through action research ( $2^{\text {nd }}$ ed). New York: Routledge.

Pilkington, R. M. (2009). Practitioner research in education: The critical perspectives of doctoral students. Studies in the Education of Adults, 41(2), 154-174.

Poetter, T. S., Badiali, B., \& Hammond, D. J. (2000). Growing teacher inquiry: Collaboration in a partner school. Peabody Journal of Education (0161956X), 75(3), 161-175.

Polanyi, M. (1958). Personal knowledge: Towards a post-critical philosophy. Chicago: University of Chicago Press. 
Postholm, M. B. (2009). Research and development work: Developing teachers as researchers or just teachers? Educational Action Research, 17(4), 551-565.

Prestage, S., Perks, P., \& Soares, A. (2003). Developing critical intelligence: Tensions in the DfES model for best practice research scholarship. Educational Review, 55(1), 55-63.

Price, J. N., \& Valli, L. (2005). Preservice teachers becoming agents of change. Journal of Teacher Education, 56(1), 57-72.

Riessman, C. K. (1993). Narrative analysis. Newberry Park, CA: SAGE.

Robinson, M. (2009). Practitioner inquiry in South African schools: What, how and why (not). Educational Action Research, 17(1), 121-131.

Rogers, D., Bolick, C. M., Anderson, A., Gordon, E., Manfra, M. M., \& Yow, J. (2007). "It's about the kids": Transforming teacher-student relationships through action research. Clearing House, 80(5), 217-222.

Rosiek, J., \& Atkinson, B. (2005). Bridging the divides: The need for a pragmatic semiotics of teacher knowledge research. Educational Theory, 55(4), 421-442.

Rust, F., \& Meyers, E. (2006). The bright side: Teacher research in the context of educational reform and policy-making. Teachers \& Teaching, 12(1), 69-86.

Ruthven, K. (2005). Improving the development and warranting of good practice in teaching. Cambridge Journal of Education, 35(3), 407-426.

Schmertzing, R. (2007). Expert researchers and school practitioners: An historical perspective on the marginalization of practitioner research and the silencing of practitioner voices. Journal of Education, 188(1), 1-24.

Schön, D. A. (1983). The reflective practitioner: How professionals think in action. New York: Basic Books. 
Schön, D. A. (1987). Educating the reflective practitioner. San Francisco: Jossey-Bass.

Simons, H., Kushner, S., Jones, K., \& James, D. (2003). From evidence-based practice to practice-based evidence: The idea of situated generalisation. Research Papers in Education, 18(4), 347-364.

Smith, J. J. (2010). The teaching profession? Considering the professional characteristics of teaching. Manuscript in preparation.

Smith, J. J. (2011, April). Teachers as policy actors: Conceptualizing a new outlet for policy change. Paper presented at the annual conference of the American Education Research Association, New Orleans, LA.

Smith, J. J., Yendol-Hoppey, D., \& Milam, R. S. (2010). Reflectivity within the teacher research cycle: Promoting teachers' progress towards an Inquiry Stance. In E. G. Plutorak (Ed.), The purposes, practices and professionalism of teacher reflectivity. Lanham, MD: Rowman \& Littlefield.

Smith, K., \& Sela, O. (2005). Action research as a bridge between pre-service teacher education and in-service professional development for students and teacher educators. European Journal of Teacher Education, 28(3), 293-310.

Stenhouse, L. (1981). What counts as research? British Journal of Educational Studies, 29(2), 103-114.

Sweeney, A. E. (2003). Articulating the relationships between theory and practice in science teaching: A model for teacher professional development. Teachers \& Teaching, 9(2), 107.

Teitel, L. (2003). The professional development schools handbook. Thousand Oaks, CA: Corwin Press. 
Thompson, P. (2007). Developing classroom talk through practitioner research. Educational Action Research, 15(1), 41-60.

Vogrinc, J., \& Zuljan, M. V. (2009). Action research in schools - an important factor in teachers' professional development. Educational Studies 35(1), 53-63.

Watkins, A. (2006). So what exactly do teacher-researchers think about doing research? Support for Learning, 21(1), 12-18.

Weber, M. (1949). Methodology of social sciences. Glencoe, IL: Free Press.

Yendol-Hoppey, D. Y. \& Dana, N. F. (2010). Powerful professional development: Building expertise within the four walls of your school. Thousand Oaks, CA: Corwin Press.

Zeichner, K. (2007). Accumulating knowledge across self-studies in teacher education. Journal of Teacher Education, 58(1), 36-46.

Zeichner, K. M., \& Liston, D. P. (1996). Reflective teaching: An introduction. Mahwah, NJ: L. Erlbaum Associates.

Zeichner, K., \& Noffke, S. (2001). Practitioner research. In V. Richardson (Ed.), Handbook of research on teaching (4th ed., pp. 298-332). Washington, DC: American Educational Research Association. 


\title{
Appendix A: Assignment Description for Inquiry Synthesis Essay
}

\author{
Inquiry Synthesis Essay
}

\section{Rationale}

Throughout your time in the program, you have attended 15 inquiry seminars, conducted a lesson-based inquiry, mini-inquiry, and semester long inquiry, prepared (or are preparing) a presentation of your research, and have seen others present their work. While you may have approached each of these activities as another item on a seemingly endless checklist, for most of you, your work says something more. Through your work for EDUC 600, as well as countless other activities throughout your time in the program, you have made some progress towards developing an "Inquiry Stance" towards teaching. As you prepare to graduate, your final task is to critically consider your experiences related to inquiry, including instances where you collected and/or analyzed data in both formal and informal ways. After you reflect on these experiences, you will write about what you have learned, how you have changed, and what you want to accomplish moving forward.

\section{Essay}

You will construct an essay which responds to the following prompts:

1. How has your understanding of inquiry changed over the last three years?

2. What have you learned about your students from inquiry?

3. What have you learned about your teaching from inquiry?

4. How has inquiry helped you grow as an educator?

5. In what ways has inquiry proven difficult for you?

6. How do you plan to use inquiry in your future practice?

Your essay will be written in narrative form, and should be between 2000 and 3000 words. You should utilize APA format, and utilize appropriate writing conventions.

You should, at least, use data from your mini-inquiry report and your final inquiry report You should also make reference to specific examples from your teaching and inquiry experiences that help to illustrate your points. You should be self-critical, considering the strengths and weaknesses of your work. You should critically consider the theories and processes which guide inquiry, but avoid discussing inquiry as a "course."

You should make sure to address the six prompts above, but not feel limited to only discuss those prompts.

This activity will be graded holistically - with the grade being based on your ability to address the six prompts, provide supporting data and examples, write with appropriate voice and tone, and attend to proper writing conventions. 


\section{Appendix B: Program Requirements Aligned with State Certification and University Graduation Requirements}

\section{Part I: Admission to Pre-Education}

High school students interested in teaching careers should seek admission to the pre-education program when applying to the University. Students may also seek admission to pre-education at any point between entry and successful completion of 59 hours of approved University coursework. To be admitted to pre-education, a student must:

1. Have an ACT score of 23, an SAT math and verbal combined score of 1030, or a high school GPA of 3.0.

2. Students transferring into teacher education must also have an acceptable University GPA.

Note: Since formal admission into teacher education cannot occur until 59 hours have been completed, those students admitted to education are designated pre-education students; the general admission requirements for teacher education are described below.

\section{Part II: Admission to Teacher Education}

Students are admitted to teacher education only in the spring semester. Admissions to teacher education are limited to the capacities of [specific content areas].

General Requirements for Admission:

1. Complete a minimum of 59 hours of approved University coursework.

2. Achieve a 2.75 grade point average (GPA) computed on all approved University work attempted

3. Achieve a 3.0 GPA on all work completed in professional education

4. Achieve a 2.5 GPA in [content area] coursework

5. no grade below a $\mathrm{C}$ on all work completed in professional education

6. Pass Praxis Pre-Professional Skills Tests (Reading - 174 or 321 computer test, Writing 172 or 319 computer test, Math -172 or 317 computer test) OR score 1125 on the SAT OR score 26 on the ACT

7. Submit a written portfolio which includes (a) a statement that all general requirements for admission into teacher education have been met, (b) letters of recommendation from faculty in education, (c) letters of recommendation from faculty in the subject area one wishes to teach, (d) evaluation from volunteer experience, (e) passing scores on the PPST, and (f) transcript.

8. Complete successfully EDUC 200: Professional Inquiry in Education and all its prerequisites.

9. Complete an approved volunteer or work experience with children or youth. 


\section{Part III: Admission Process}

Applications for admission to teacher education are accepted and reviewed in the spring semester. Students are normally admitted to teacher education in the fourth semester. The credentials of qualified pre-education students from [University] will be reviewed by the admissions committee, and students are admitted to the specialization of their choice in order of decreasing portfolio scores until the specialization reaches its capacity. Minority students may be given special consideration for admission to the major. Admissions decisions are based on meeting the minimum requirements outlined in Part II, the space available within the [content specialization], and space available within PDS partner schools. Determinations of admission beyond minimum requirements are made by ranking candidates using the formula outlines below.

\section{Grade Point Average}

The "cut-off" is 2.75 , though 2.6 will be used to create the eligible pool. In the event a student is admitted with less than a 2.75 , s/he will be provisionally admitted with one semester to raise the G.P.A. to a 2.75 . GPA will be rated on a 15 point scale.

\section{Praxis Pre-Professional Skills Test (PPST)}

The PPST score will be rated from the passing scores up. PPST scores are based on three areas: Reading, Writing, and Mathematics. Each area has a maximum score of 190. The passing scores area: Reading - 174; Writing - 172; Mathematics - 172. For the 2001 admissions process, students may use a computer test format, and this test has different score ranges and passing scores. For the computer test, the maximum score is 340. The passing scores for the computer tests are: Reading - 321; Writing - 319; Mathematics - 317. If a student scores 1125 or above on the SAT or 26 ACT Composite Score, the PPST is waived. PPST scores are assessed on a 15 point scale.

The PPST portfolio score will be the average of the 3 area scores. Failure to pass will result in a " 0 " in the weighting scale. Students who are admitted without having met the threshold score will be provisional admissions, and will have one semester to meet the score requirement.

\section{Writing Samples}

The writing sample is the Volunteer Paper from EDUC 200. Each person will receive 15 points for a paper present and 0 for no paper.

\section{Volunteer Logs}

Students will submit their logs from their volunteer experiences, and the summary documentation and evaluation from the volunteer experiences supervisors. If volunteer daily logs are present, the student will receive 15 points. If the overall log is present, the student will receive an additional 15 points. 


\section{Volunteer Evaluations}

Some supervisors' evaluations will each be rated on a 5-point scale. An average evaluation score will be calculated from the supervisor's "Evaluation of Volunteer Experiences."

Some supervisors' evaluations will each be rated on a 3-point scale. An average evaluation score will be calculated from the supervisor's "Evaluation of Volunteer Experiences."

\section{Recommendations}

Students may include recommendation letters. These will be of particular importance in borderline cases.

Weighting Scale for the Portfolio Components

\begin{tabular}{|l|c|c|c|}
\hline Item & Range & $\begin{array}{c}\text { Point } \\
\text { Values }\end{array}$ & Potential Point Total \\
\hline Overall GPA & $2.6-4.0$ & $1-15(\mathrm{x} 4)$ & 60 \\
\hline PPST & & $1-15$ & 15 \\
\hline Volunteer Paper & 0 or 15 & 15 & 15 \\
\hline Volunteer Experience Evaluations & $1-5$ & $1-15$ & 15 \\
\hline Volunteer Daily Logs & 0 or 15 & 15 & 15 \\
\hline Volunteer Summary Information & 0 or 15 & 15 & 15 \\
\hline Totals & & & 135 \\
\hline
\end{tabular}

\section{Part V: General Retention Requirements}

1. Maintain a 2.75 GPA grade point average in all hours attempted,

2. Maintain a 2.50 GPA in area(s) of specialization

3. No grade below a $\mathrm{C}$ on all work completed in professional education.

4. [Applicable ETS Praxis subject area test Score]

5. Complete all undergraduate coursework by the end of the eighth semester

\section{Part VI: Graduate/Certification Requirements}

1. Comply with the general regulations of the University concerning entrance, advanced standing, classification, examination, grades, grade points, etc.

2. Complete required courses and the minimum hours of approved courses in education.

3. [Adhere to the patterns prescribed in completing the subject specialization(s). ]

4. [Complete requirements for the approved baccalaureate in subject specialization (for prospective secondary teachers) or multidisciplinary studies (for prospective elementary teachers and secondary science teachers). ]

5. Present a minimum of 158 hours of approved college credit. (Thirty of these must be approved graduate hours.) A general average of 2.75 as described under General Requirements for Professional Certification must be attained for the undergraduate hours with a GPA of at least 3.0 in the graduate hours.

6. Submit an acceptable professional portfolio. 


\section{Appendix C: Syllabus for the Inquiry Strand and The Teacher as Researcher \\ EDUC 600: THE TEACHER AS RESEARCHER \\ Intern Year Syllabus: Class of 2011}

Fall, 2011

\section{[2010-2011 Practitioner Inquiry (Action Research) Faculty Removed] \\ Course Coordinators}

For Students with Elementary Education Majors: [Dr. Rutherford]

For Students with Secondary Education Majors: Jason Jude Smith

\section{Course Objectives and Anticipated Outcomes}

1. The Teacher will cultivate inquiry as a stance toward their/our educational practices.

a. The Novice Teacher will understand the purposes and advantages of reflective practice for their teaching and student learning.

b. The Novice Teacher will engage in purposeful and critical reflection of their teaching.

c. The Novice Teacher will use their reflections as a catalyst for supporting their professional development and transforming their own practice, as well as the ways we do school.

2. The Teacher will consider ways in which to improve their practice in order to promote student learning.

a. The Novice Teacher will engage in reflection and consider alternative approaches/practices in order to meet the learning needs of all students.

b. The Novice Teacher will search for and identify relevant literature to understand the implications changes in teaching practice may have for student learning. 
c. The Novice Teacher will craft inquiry questions to investigate approaches which, based on reflection and review of the literature, they believe will promote student learning and improve their professional practice.

\section{The Teacher will collect and analyze data appropriate in order to inform their} teaching practice and support their students' learning.

a. The Novice Teacher will choose appropriate data sources aligned with their inquiry questions.

b. The Novice Teacher will collect data as a part of their teaching practices and responsibilities.

c. The Novice Teacher will analyze their data and make changes in their practice that are based on their findings and benefit their students.

\section{The Teacher will craft formal inquiries into their teaching practice.}

a. The Novice Teacher will create inquiry briefs which organize and guide their inquiry.

b. The Novice Teacher will engage in inquiry systematically, in an effort to answer research questions that inform their practice.

c. The Novice Teacher will formalize inquiry findings so that readers of their research can determine whether or not the findings are transferable to other contexts.

d. The Novice Teacher will disseminate findings with all stakeholders in an effort to provoke critical reflection and educational reform.

\section{Required Texts}


Dana, N.F. \& Yendol-Hoppey, D. (2009). The reflective educators guide to classroom research $\left(2^{\text {nd }}\right.$ ed.). Thousand Oaks, CA: Corwin Press.

_ (2009). Publication manual of the American Psychological Association $\left(6^{\text {th }}\right.$ ed.). Washington, DC: American Psychological Association.

\title{
[Program-wide Software Requirements Removed]
}

\begin{abstract}
Assignments
Admission and Exit Tickets: Throughout their Participant and Intern Years

Admission Tickets will require pre-service teachers to reflect and make sense of assigned readings and/or activities in a previous seminar. Pre-service teachers may also be required to bring artifacts, such as data, as a part of their Admission Tickets. Exit Tickets will require preservice teachers to analyze, synthesize, and evaluate class discussions and learning activities, to make theory practice connections, and/or to make connections among texts and between their texts and real world experiences.
\end{abstract}

\section{Mini Inquiry: Lesson Plan Revision (Participant Year, Fall semester)}

Pre-service teachers will generate wonderings based on a lesson they have taught or experiences they have had at their PDS. They will design a mini inquiry and create a research brief, collect and analyze data, identify the implications of their findings for their teaching, and reflect on the process of designing and conducting inquiry.

\section{Formal Mini Inquiry: Participant, Spring semester}

Based on their passions, observations, data collection and/or collaboration with their mentor teachers, pre-service teachers will design and conduct an inquiry for a minimum of 2-3 weeks. Pre-service teachers will review the literature (at least 3 resources) create a research brief, collect and analyze data, identify the implications of their inquiry for their own practice, and write up their inquiry so that it can be shared with others. Pre-service teachers are encouraged to share their inquiries with their peers and PDS and [University] colleagues.

\section{Internship Inquiry: Intern Year, Fall semester}

Based on their passions, observations, data collection and/or collaboration with their mentor teachers, pre-service teachers will design and conduct an inquiry for a minimum of 5-6 weeks. Students will review the literature (at least 5 resources) create a research brief, collect and analyze data, identify the implications of their inquiry for their own practice, as well as their recommendations for how me might transform our educational practices, and write up their inquiry so that it can be shared with others. Pre-service teachers will need approvals from their PDS mentor teacher and teacher education coordinator, [University] liaison, and small group facilitator before they begin their inquiries. They may also serve as peer reviewers for members of their small group. Pre-service teachers are always encouraged to share their inquiries with their peers and PDS and [University] colleagues. 


\section{Inquiry Celebration Presentation: Intern Year, Spring semester}

Pre-service teachers will create a powerpoint presentation in which they share the inquiries they conducted during their internships (Fall semester). Presentations should include information about their research questions, participants, data collection and analysis, findings, implications, and future research. Pre-service teachers will present their inquiries for their peers and PDS and [University] colleagues at the Inquiry Celebration in April.

\section{Inquiry Stance Development: Intern Year, Spring semester (as part of EDUC 602)}

Pre-service teachers will reflect on how designing and conducting inquiries have influenced their development of inquiry as stance. They will share how their understandings of research have changed over the course of the past 3 years and how inquiry has become an integral part of their work as teachers. Pre-service teachers will explore how inquiry might be used as a tool for their own professional development in the service of student learning. They will also discuss the implications of engaging in inquiry for transforming our educational practices in order to meet the needs and improve the life chances of all students/stakeholders. Pre-service teachers will connect their experiences over the past 3 years to the teacher identities they are constructing, e.g., reflective practitioner, teacher researcher, advocate, and/or change agent.

\section{An electronic copy of all assignments is to be emailed to your small group facilitator before class begins on the date the assignment is due.}




\section{Grading}

\begin{tabular}{|c|c|c|}
\hline Component & Percent & Notes \\
\hline $\begin{array}{l}\text { Inquiry } 1 \text { - Mini Inquiry: Lesson } \\
\text { Plan revision (Participant Fall } \\
\text { semester) }\end{array}$ & 25 & Research Brief and Exit Ticket 2011-06 \\
\hline $\begin{array}{l}\text { Inquiry } 2 \text { - Formal Mini-Inquiry } \\
\text { (Participant Spring semester) }\end{array}$ & 25 & Research Brief and Write Up \\
\hline $\begin{array}{l}\text { Inquiry } 3 \text { - Internship Inquiry } \\
\text { (Intern Fall semester) }\end{array}$ & 25 & Research Brief and Write Up \\
\hline $\begin{array}{l}\text { Admission/Exit Tickets (Tutor } \\
\text { and Participant years) }\end{array}$ & 25 & \\
\hline $\begin{array}{l}\text { Inquiry Stance Development } \\
\text { Artifact (Intern Spring semester) }\end{array}$ & & Grade will be given for EDUC 602 \\
\hline $\begin{array}{l}\text { Seminar Attendance } \\
\text { (Tutor, Participant, and Intern } \\
\text { years) }\end{array}$ & \multicolumn{2}{|c|}{$\begin{array}{l}10 \% \text { deduction for each absence after } 2 \text { (see } \\
\text { below) }\end{array}$} \\
\hline
\end{tabular}

\section{[Social Justice Statement Removed]}

\section{[Criminal Background Information \& Procedure Removed]}

\section{Important Dates to Remember}

\begin{tabular}{|l|l|}
\hline Date & Assignment Due/Event \\
\hline August 31, 2010 & $\begin{array}{l}\text { Admission Ticket 2011-11: Data collection (observations and student } \\
\text { work samples) }\end{array}$ \\
\hline September 7, 2010 & Description of PDS Context for Write Up \\
\hline September 14, 2010 & Admission Ticket 2011-12: Review of Literature for Write Up \\
\hline September 21, 2010 & Research Brief \\
\hline September 28, 2010 & Approval Sheet \\
\hline October 12, 2010 & Introduction and Data Sources/Collection sections for Write Up \\
\hline October 19, 2010 & Admission Ticket 2011-14: Bring all your data to analyze \\
\hline November 30, 2010 & $\begin{array}{l}\text { Data Analysis, Findings and Discussion, Conclusions and Implications } \\
\text { sections for formative feedback (OPTIONAL) }\end{array}$ \\
\hline December 14, 2010 & Final Draft of Write Up due by 9 am \\
\hline TBA & Inquiry Powerpoint Presentation \\
\hline TBA & Development of Inquiry as Stance: Reflection \\
\hline April 22, 2011 & Inquiry Celebration \\
\hline
\end{tabular}




\section{Important Dates to Remember: SPECIAL EDUCATION COHORT}

\begin{tabular}{|l|l|}
\hline Date & Assignment Due/Event \\
\hline September 7,2010 & Description of PDS Context for Write Up \\
\hline October 5, 2010 & $\begin{array}{l}\text { Admission Ticket 2011-11: Data collection (observations and student } \\
\text { work samples) }\end{array}$ \\
\hline October 16, 2010 & Research Brief \\
\hline October 19,2010 & Approval Sheet \\
\hline October 19,2010 & Admission Ticket 2011-14: Bring all your data to analyze \\
\hline October 26, 2010 & Introduction and Data Sources/Collection sections for Write Up \\
\hline November 30, 2010 & $\begin{array}{l}\text { Data Analysis, Findings and Discussion, Conclusions and Implications } \\
\text { sections for formative feedback (OPTIONAL) }\end{array}$ \\
\hline December 14,2010 & Final Draft of Write Up due by 9 am \\
\hline TBA & Inquiry Powerpoint Presentation \\
\hline TBA & Development of Inquiry as Stance: Reflection \\
\hline April 22, 2011 & Inquiry Celebration \\
\hline
\end{tabular}

\section{Course Schedule}

The assignments and readings listed for each week are to be completed before you attend the seminar. Meaningful engagement in class activities will require you to have completed these assignments and readings. Please note: The official meeting time of the course is Tuesday from 4:00 to 6:50pm. Seminars are numbered beginning with 2011-10. The 2011 refers to your graduation year and the number 10 refers to the seminar number. Seminars 1 through 9 were your Tutor and Participant seminars. A tentative course schedule follows. 


\section{COURSE SCHEDULE}

This schedule may change at the instructor's discretion. Students will be notified of any relevant changes.

\begin{tabular}{|c|c|c|}
\hline $\begin{array}{c}\text { Seminar \# } \\
\text { Date \& Time }\end{array}$ & Topics & Readings/Assignments Due \\
\hline $\begin{array}{l}\text { Seminar 2011-10 } \\
\text { August 24, 2010 } \\
\text { 4:15 pm-6:50 pm }\end{array}$ & $\begin{array}{l}\text { Orientation } \\
\text { Large Group (All Interns): } \\
\text { Introduction of Small Group } \\
\text { Facilitators } \\
\text { Goals for Practitioner Inquiry } \\
\text { Small Groups: } \\
\text { Review of Intern Year Syllabus } \\
\text { Introduction to APA Publication } \\
\text { Manual 6 }{ }^{\text {th }} \text { Edition } \\
\text { Reflection on/Defining } \\
\text { Inquiry....concept maps...how to } \\
\text { make it a part of your practice } \\
\text { Review of inquiry process: Initial } \\
\text { data collection and analysis, } \\
\text { identifying a wondering. } \\
\text { Critiquing Write-Ups }\end{array}$ & $\begin{array}{l}\text { Bring any questions you } \\
\text { have from conducting your } \\
\text { inquiry during Spring, } 2010 .\end{array}$ \\
\hline $\begin{array}{l}\text { Seminar 2011-11 } \\
\text { August 31, 2010 } \\
\text { 4:15 pm-6:50 pm } \\
\text { Special Education } \\
\text { students do no need to } \\
\text { attend this seminar }\end{array}$ & $\begin{array}{l}\text { Emergent Research Questions and } \\
\text { Data } \\
\text { Small Groups: } \\
\text { Discuss data } \\
\text { collection....successes/barriers } \\
\text { Analyze observation data and } \\
\text { student work samples } \\
\text { Discuss influence of context on } \\
\text { teaching and learning } \\
\text { Identify emerging wonderings and } \\
\text { frame possible research } \\
\text { questions....assess according to } \\
\text { "Wondering Litmus Test" } \\
\text { Knowledge for, in, and of practice } \\
\text { Reviewing the literature }\end{array}$ & $\begin{array}{l}\text { - Read or re- read Dana \& } \\
\text { Yendol-Hoppey Chapter } \\
2 \\
\text { - Bring observation data } \\
\text { and student work } \\
\text { samples (related to the } \\
\text { content area/strategy } \\
\text { you might explore) } \\
\text { Admission Ticket 2011- } \\
\text { 11 }\end{array}$ \\
\hline September 7, 2010 & $\begin{array}{c}\text { No seminar meeting } \\
\text { Decide on research question(s). }\end{array}$ & - Description of context \\
\hline
\end{tabular}




\begin{tabular}{|l|l|l|}
\hline $\begin{array}{l}\text { Special Education } \\
\text { students DO need to } \\
\text { submit this assignment. }\end{array}$ & $\begin{array}{l}\text { Discuss with your mentor teacher, } \\
\text { PDS coordinator, and [University] } \\
\text { liaison and get initial approval. } \\
\text { Begin/continue review of literature } \\
\text { related to your question }\end{array}$ & $\begin{array}{l}\text { for final write up is } \\
\text { due...submit an } \\
\text { electronic copy to your } \\
\text { small group facilitator. }\end{array}$ \\
\hline
\end{tabular}




\begin{tabular}{|c|c|c|}
\hline $\begin{array}{l}\text { Seminar 2011-12 } \\
\text { September 14, } 2010 \\
\text { 4:15 pm-6:50 pm } \\
\text { Special Education } \\
\text { students do not need to } \\
\text { attend this seminar }\end{array}$ & $\begin{array}{l}\quad \text { Writing a Research Brief } \\
\text { Small Groups: } \\
\text { Who are your participants? } \\
\text { Choosing data sources to answer } \\
\text { your research question(s) } \\
\text { Organizing and managing data } \\
\text { Analyzing as you go } \\
\text { Constructing identities as teachers } \\
\text { and researchers } \\
\text { Writing your Research Brief }\end{array}$ & 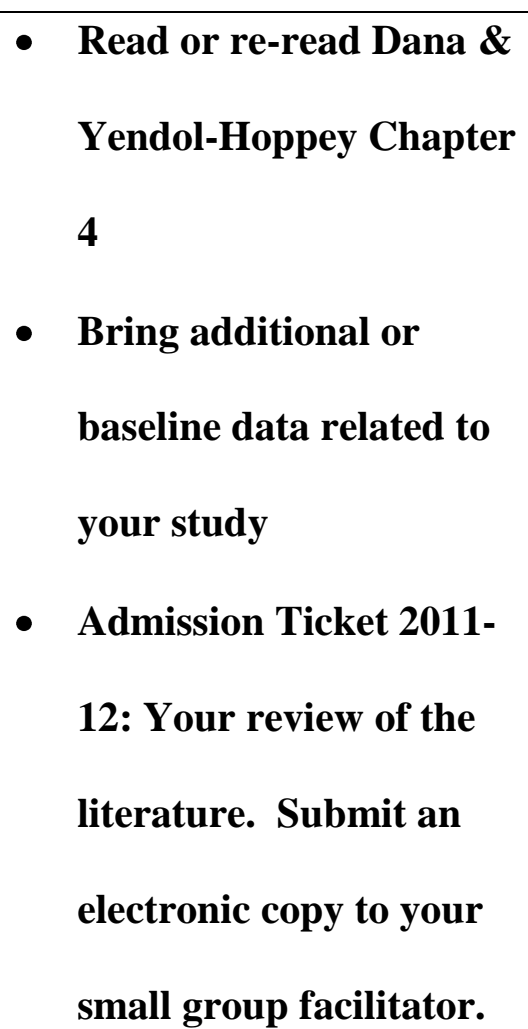 \\
\hline September 21, 2010 & $\begin{array}{l}\text { No seminar meeting } \\
\text { Share your research brief } \\
\text { with your mentor teacher, PDS } \\
\text { coordinator, and [University] } \\
\text { liaison and get their approvals for } \\
\text { your study. Bring signed approval } \\
\text { sheet to next seminar meeting, } \\
\text { September 28, 2010. }\end{array}$ & $\begin{array}{l}\text { Research Brief due } \\
\text { September 23, } 2010 . \\
\text { Submit an electronic } \\
\text { copy to your small group } \\
\text { facilitator. }\end{array}$ \\
\hline $\begin{array}{l}\text { Seminar 2011-13 } \\
\text { September 28, 2010 } \\
\text { 4:15 pm-5:30 pm } \\
\text { Special Education } \\
\text { students need to attend } \\
\text { from 5:30-6:50 pm. }\end{array}$ & \begin{tabular}{l}
\multicolumn{1}{c}{ Engaging in Inquiry } \\
Small Groups: \\
Discussion and review of research \\
briefs...final approvals \\
The role of "critical reflection" in \\
inquiry \\
Create peer critical friends groups
\end{tabular} & $\begin{array}{l}\text { - Read Hatton \& Smith } \\
\text { article on reflection. } \\
\text { - Approval sheet with all } \\
\text { signatures }\end{array}$ \\
\hline $\begin{array}{l}\text { October 5, } 2010 \\
\text { No seminar meeting }\end{array}$ & $\begin{array}{l}\text { Special Education students will } \\
\text { attend a seminar session from } \\
\text { 4:15-6:50 pm. }\end{array}$ & \\
\hline $\begin{array}{l}\text { October 12, } 2010 \\
\text { No seminar meeting }\end{array}$ & $\begin{array}{l}\text { Special Education students will } \\
\text { attend a seminar session from }\end{array}$ & - Introduction and Data \\
\hline
\end{tabular}




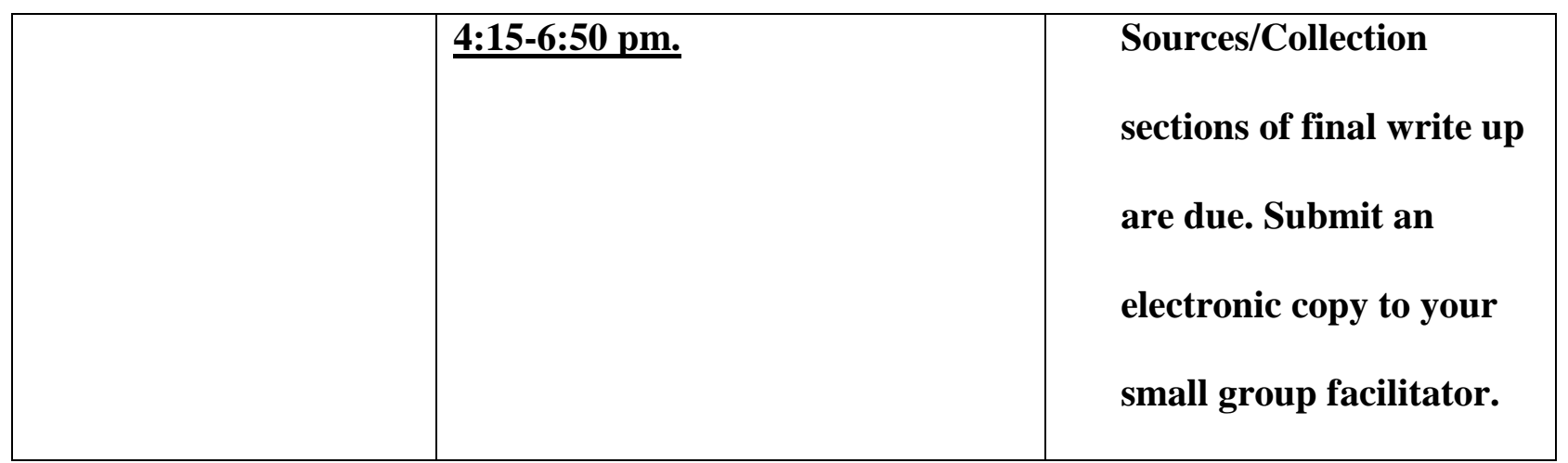




\begin{tabular}{|c|c|c|}
\hline $\begin{array}{l}\text { Seminar 2011-14 } \\
\text { October 19, } 2010 \\
\text { 4:15 pm-6:50 pm }\end{array}$ & $\begin{array}{l}\quad \text { Data Analysis } \\
\text { Large Groups (Elementary and } \\
\text { Secondary): Introduction to } \\
\text { Quantitative and Qualitative } \\
\text { Analysis } \\
\text { Small Groups: Analyze and } \\
\text { represent your data } \\
\text { How are your students being } \\
\text { affected by your study? } \\
\text { What are you learning/getting out of } \\
\text { your study? } \\
\text { Evaluate data sources: What changes } \\
\text { might you make to your study? }\end{array}$ & $\begin{array}{l}\text { Read or re-read Dana \& } \\
\text { Yendol-Hoppey Chapter } \\
5 \\
\text { - } \\
\text { Bring any and all pieces } \\
\text { of data you need to } \\
\text { analyze } \\
\text { - Admission Ticket } \\
\text { - } 2011-14\end{array}$ \\
\hline $\begin{array}{l}\text { Seminar 2011-15 } \\
\text { November 16, } 2010 \\
\text { 4:15 pm-6:50 pm }\end{array}$ & $\begin{array}{l}\text { Data Analysis \& Writing Up Your } \\
\text { Inquiry } \\
\text { Small Groups: } \\
\text { Discussion of write-up formats } \\
\text { Continue to analyze and represent } \\
\text { your data. } \\
\text { Discussion of your } \\
\text { findings....implications for your } \\
\text { practice and the practices of others. }\end{array}$ & $\begin{array}{ll} & \text { Read or re-read Dana \& } \\
\text { Yendol-Hoppey Chapter } \\
6 \\
\text { - Bring any and all pieces } \\
\text { of data you need to } \\
\text { analyze } \\
\text { Bring feedback from } \\
\text { your mentor teacher, } \\
\text { PDS coordinator, } \\
\text { [University] liaison }\end{array}$ \\
\hline $\begin{array}{l}\text { November 30, } 2010 \\
\text { 4:15 pm-6:50 pm }\end{array}$ & $\begin{array}{l}\text { Additional Help Session } \\
\text { If you are in need of additional help } \\
\text { with analysis and writing up...meet } \\
\text { with your small group facilitator or } \\
\text { your critical friends group. }\end{array}$ & $\begin{array}{l}\text { If you wish feedback on } \\
\text { your Analysis and } \\
\text { Discussion sections, submit } \\
\text { and electronic copy of these } \\
\text { sections to your small group } \\
\text { facilitator on November 30, } \\
2010 \text {. }\end{array}$ \\
\hline Seminar 2011-16 & Learning with/from Research & - Read or re-read Dana \& \\
\hline
\end{tabular}




\begin{tabular}{|c|c|c|}
\hline $\begin{array}{l}\text { December 7, } 2010 \\
\text { 4:15 pm-6:50 pm }\end{array}$ & $\begin{array}{l}\text { Small Groups: } \\
\text { Peer review of write-ups } \\
\text { Discussion of the role of inquiry in } \\
\text { today's schools } \\
\text { Considering issues of equity and } \\
\text { context } \\
\text { Inquiry for policy change } \\
\text { Reflection on engaging in } \\
\text { inquiry....concept maps...discussion } \\
\text { of transformation of teacher and } \\
\text { research identities, practices, etc. } \\
\text { Developing a portfolio related to } \\
\text { inquiry }\end{array}$ & $\begin{array}{l}\text { Yendol-Hoppey Chapter } \\
7 \\
\text { - Bring your write up }\end{array}$ \\
\hline December 14, 2010 & $\begin{array}{l}\text { No seminar meeting } \\
\text { Share your write-up with your } \\
\text { mentor teacher, PDS coordinator, } \\
\text { and [University] liaison. Record } \\
\text { any additional feedback you receive. }\end{array}$ & $\begin{array}{l}\text { Final write ups are due by } \\
\text { midnight, December } 14, \\
2010 \text {. }\end{array}$ \\
\hline $\begin{array}{l}\text { Seminar 2011-17 } \\
\text { February 2011, TBA } \\
\text { A part of EDUC } 602\end{array}$ & $\begin{array}{l}\text { Reflection on Teacher and } \\
\text { Researcher Identities } \\
\text { Cultivating Inquiry as Stance... what } \\
\text { you've learned, where you are in } \\
\text { this process } \\
\text { How to prepare a presentation for } \\
\text { the Celebration }\end{array}$ & $\begin{array}{l}\text { See Dana \& Yendol-Hoppey } \\
\text { Chapter } 8\end{array}$ \\
\hline $\begin{array}{l}\text { Seminar 2011-18 } \\
\text { March, 2011, TBA } \\
\text { A part of EDUC } 602 \\
\end{array}$ & $\begin{array}{l}\text { Presenting Your Inquiry } \\
\text { How to present your inquiry } \\
\text { How to benefit from a conference }\end{array}$ & \\
\hline April 22, 2011 & $\begin{array}{l}\text { Inquiry Celebration } \\
\end{array}$ & \\
\hline
\end{tabular}




\title{
Appendix D: Exit Ticket for Tutors First Inquiry Activity
}

\author{
Exit Ticket 2011-1
}

\section{Introduction to Inquiry}

\section{Reflecting on your Passions and Wonderings \\ As part of your EDUC 312 Practicum, you have been asked to construct two lesson plans. For this Exit Ticket, you will be working with one of those lesson plans. You should complete this Exit Ticket by April 17, bring a copy with you to your seminar, and submit a copy electronically to [email address removed]}

1. Select one of your lesson plans.

2. In light of what you have learned about the 8 Passions, consider a "wondering" you have based on your teaching of the lesson you crafted.

3. Write a 1 page (typed, 12pt font, double-spaced, 1" margins) reflection outlining the wondering that has risen out of your constructing and teaching the lesson.

4. Be sure to include the following:

a. The title of the lesson.

b. The grade level and subject area.

c. The wondering you have.

d. The passion(s) which have led to the wondering.

e. How you might investigate the wondering further.

Example: If you taught a lesson to $8^{\text {th }}$ graders about multiplying fractions, you might be concerned that your students were not engaged while you were introducing the basic concept. In this case you would reflect about your wondering (why students were not engaged during direct instruction about multiplying fractions). This wondering might be motivated by: (1) your passion for using effective teaching strategies (strategies), (2) your passion for demonstrating that knowing how to multiply fractions is an important tool for life (content), or (3) your passion for improving the math skills of kids in the rural PDS you are teaching your lesson at, because you know from life experience that many kids in these schools do not get the support they need in concepts like fraction multiplication (context). Then you might discuss how you could vary the lesson to spark more student interest in the material you presented during your lesson. 


\section{Appendix E: Mini-Inquiry Assignment Description \\ Participant Inquiry Write-up Instructions}

What you will need:

1. Your Inquiry Brief

2. Your Data and your Data Analysis

3. Your APA Manual

What you will do:

1. Write about your Inquiry using your brief as a guide.

2. Write your findings using your analyzed data.

3. Write your conclusions based on your reflections.

4. Format your paper using your APA manual.

How you will be graded:

1. Did you craft a wondering, a purpose, look at literature, plan to collect data, collect data, analyze your data, generate findings, and come to some conclusions?

2. How 'good' your findings are will not be a factor in your grade. The focus is on the process not the product?

3. Did you make an effort to follow APA format and use proper writing mechanics?

\section{Requirements:}

1. Write-up is 4-6 pages plus a title page and reference list in APA format.

2. Follows the template included.

3. Is written in narrative form (use $1^{\text {st }}$ person).

4. Includes figures (charts/graphs) and tables where needed.

5. Is completed on time. 
6. Includes directions for future research in your conclusions section.

\section{Tips:}

1. Use your research brief to guide your work.

2. Use the APA manual to guide formatting.

3. Use The reflective educator's guide to classroom research to guide content (Chapters 6 and 7).

4. Have someone review your write-up before you submit it.

\section{Submission:}

1. Save your Write-up as [LastName]_Spring_Inquiry

2. Email to [Address Removed]

3. Put "Participant Inquiry" in the heading of your email 


\section{Appendix F: Internship Inquiry Write-up Instructions \\ Internship Inquiry Write-up Instructions}

What you will need:

4. Your Research Brief

5. Your Data and your Data Analysis

6. Your APA Manual

What you will do:

5. Describe the design of your Inquiry (passion for and purpose of your research, connections to the literature, your context, your research questions, data collection sources and strategies, data analysis methods) using your brief as a guide.

6. Represent and discuss your findings using your analyzed data.

7. Based on your reflections, describe the conclusions you reached about the implications of what you learned from inquiry for your future practice, as well as the practice of others. Describe the research you wish to pursue in the future.

8. Format your paper using your APA manual.

How you will be graded:

You will be graded according to the criteria in the rubric which follows the template for the write up.

Requirements:

7. Write up follows the conventions and formatting of APA.

8. Follows the template included.

9. Is written in narrative form (use $1^{\text {st }}$ person).

10. Includes figures (charts/graphs) and tables where needed. 
11. Is completed on time.

Tips:

5. Use your research brief to guide your work.

6. Use the APA manual to guide formatting.

7. Use The reflective educator's guide to classroom research to guide content (Chapters 6 and 7).

8. Have someone review your write-up and make any necessary revisions before you submit it.

Submission:

4. Submit and electronic copy of your inquiry to your small group facilitator.

5. Put "Participant Inquiry" in the heading of your email 


\section{Appendix G: Template for Internship Inquiry Write-up}

Title

Your name, area of specialization

Your PDS, grade level and/or content 
Title of Report

Introduce your project. What is the topic of interest or the purpose of your study? Why are you interested in/what is your passion for your topic? In other words, how did conducting this study relate to your teaching and what you wished to learn in order to become a more effective educator (the teacher you want to be)?

What literature (knowledge for practice) did you use to inform your study (Cite 4-5 sources; 5 sources are necessary for a "distinguished rating) and how did the literature influence your decisions about what you would study and how you designed your inquiry? Why should other educators be interested in your study? Provide a reasonable argument for why you wanted to explore the topic.

Your conclusion for this section is your research questions. Thus, the following questions guided my study....begin with your overarching question, followed by any subquestions.

\section{Methodology}

This is a very important section and it needs to accurately describe/reflect the strategies your implemented and your research process. Begin by describing what you implemented....how did you implement the strategy, etc. You want to provide a detailed description so that someone reading your report could replicate what you did. Describe your timeline (this should be in a narrative form, rather than as a table) that depicts what you did in your teaching and what data you collected to assess student learning and inform your teaching.

\section{The Research Context}

Describe the setting (school, grade level, your particular class(es) - you know much more now that you are in your setting. Include information that is relevant to answering your research 
questions and making sense of your inquiry. This may include where you school is located, demographic information related to the school in general and your classroom in particular, a description of the physical layout of your classroom, and other information you deem pertinent.

\section{Participants}

Describe the participants. With whom did you work? Include characteristics that are related to your research (learning needs, general achievement, special needs - what are the characteristics you considered in your project?) If you focused on a particular sample, describe those students here and explain how/why you selected this sample.

\section{Data Sources and Collection}

What served as data? Describe each of the data sources you collected and explain how each helped you answer your research questions. If you used particular instruments to collect data, include an example of each instrument in appendices. Refer to any instruments you used (surveys, evaluation forms, assessments, journal prompts) in your text.

Describe your data collection schedule. Discuss when/how often you collected each of your data sources. Also describe any changes you made in what data you collected.

\section{Data Analysis}

Describe your ongoing data analysis....how you analyzed your data while you were teaching. Describe any additional analyses you conducted to include in this report. Note: Do not put any findings here.

\section{Findings and Discussion}

This is the section in which you explain what you learned from analyzing your data. You will describe and discuss findings that help you to "answer" or provide insight into your research 
What were your results (display in narrative, tables, figures, charts, etc. in ways that will help your readers understand the significance of your results)? Be sure to provide additional excerpts from your data that illustrate your findings. What do your findings mean? How are your findings connected to your wondering(s)? How are your findings connected to related research? Be sure to discuss the range of your findings. For instance, you might find that your strategy was not helpful for some of your students and you want to describe and discuss these findings, as well as to consider how you might need to modify the strategies you implemented in order to meet the needs of these students.

\section{A Note about Tables and Figures}

When you insert a table or figure into your narrative, label and title it according to APA guidelines. There should be a sentence in your narrative that introduces the table or figure before you insert it. There should also be a discussion of what is found in the table or figure immediately following its insertion. It is also important to further illustrate and explain the findings that are represented in the table or figure with excerpts (quotes) from your data.

\section{Conclusions and Implications for Practice}

What did you learn... about teaching and learning? What answers did your findings provide for the questions you asked? How will you use your findings in to inform your teaching? What recommendations would you make to other teachers about their practices? What other wonderings emerged? What might you inquire about in the future?

In addition to including the basic parts of a traditional research report, as listed above, your report should:

1. Provide a substantive discussion of your project, reflect a high quality research process, 
and make clear connections between your topic, research questions, related research, methodology, results and conclusions.

2. Address a general audience in a lively and engaging voice, using an appropriate tone.

3. Demonstrate a good grasp of standard writing conventions (grammar, spelling, capitalization, punctuation) and specialized conventions (subtitles, bullets, sidebars and other graphic devices) to enhance layout and readability. > 


\section{References}

Provide complete bibliographic information for references cited in the proposal. There should be at least five (5) references from a variety of sources (research and practitioner journals, books, book chapters, websites). The references should be current (within the last 10 years, with

preference given to those within the last 5 years). The references must reflect APA $\left(5^{\text {th }}\right.$ ed. $)$

format. For APA style guidelines visit: http://owl.english.purdue.edu/owl/resource/560/01/

or visit the Towers Bookstore and purchase the following "Cliff Notes" style sheet:

SparkCharts (2004). Research style and usage APA/MLA. USA: Spark Educational Publishing.

Here are some sample APA reference formats:

Journal articles (the second example is one that was accessed online)

Sophian, C. (1988). Early development in children's understanding of number: Inferences about numerosity and one-to-one correspondence. Child Development, 59, 1397-1414.

Sophian, C. (1988). Early development in children's understanding of number: Inferences about numerosity and one-to-one correspondence [Electronic Version]. Child Development, 59, 1397-1414.

\section{Entire Book}

Gallistel, C. R. (1990). The organization of learning. Cambridge, MA: MIT Press.

\section{Chapter in a Book}

Gallistel, C. R., Brown, A. L., Carey, S., Gelman, R. \& Keil, F. C. (1991). Lessons from animal learning for the study of cognitive development. In S. Carey \& R. Gelman (Eds.), The epigenesis of mind: Essays on biology and cognition. Hillsdale, NJ: Lawrence Erlbaum Associates, Inc. 


\section{Appendix H: Rubric for Internship Inquiry}

\begin{tabular}{|c|c|c|c|}
\hline Criteria & Unacceptable & Acceptable & Distinguished \\
\hline $\begin{array}{l}\text { Purpose of/Passion } \\
\text { for study }\end{array}$ & $\begin{array}{l}\text { Teacher researcher does } \\
\text { not explain the dilemma } \\
\text { or tension that led to the } \\
\text { wonderings/research } \\
\text { questions. The purpose } \\
\text { of the study is not clearly } \\
\text { articulated and/or } \\
\text { connected to the teacher } \\
\text { researcher's goals for } \\
\text { his/her own learning. }\end{array}$ & $\begin{array}{l}\text { Teacher researcher explains } \\
\text { the dilemma or tension that } \\
\text { led to the } \\
\text { wonderings/research } \\
\text { questions. The purpose of the } \\
\text { study is clearly articulated and } \\
\text { connected to the teacher } \\
\text { researcher's goals for his/her } \\
\text { own learning. }\end{array}$ & $\begin{array}{l}\text { Teacher researcher provides a } \\
\text { detailed explanation of the } \\
\text { dilemma or tension that led to } \\
\text { the wonderings/research } \\
\text { questions. The purpose of the } \\
\text { study is clearly articulated and } \\
\text { connected to the teacher } \\
\text { researcher's goals for his/her } \\
\text { own learning. }\end{array}$ \\
\hline $\begin{array}{l}\text { Review of } \\
\text { Literature }\end{array}$ & $\begin{array}{l}\text { Wonderings/research } \\
\text { questions are not clearly } \\
\text { connected to the } \\
\text { literature and/or the } \\
\text { literature that was } \\
\text { reviewed was not } \\
\text { relevant or credible. } \\
\text { Discussion of how the } \\
\text { literature informed } \\
\text { his/her inquiry is } \\
\text { incomplete or missing. } \\
\text { Cited } 3 \text { or less sources. }\end{array}$ & $\begin{array}{l}\text { Wonderings/research } \\
\text { questions are connected to } \\
\text { relevant and credible } \\
\text { literature from the field. } \\
\text { Teacher researcher provides } \\
\text { an explanation of how the } \\
\text { literature is connected to } \\
\text { his/her wonderings/research } \\
\text { questions and discusses how } \\
\text { the literature informed his/her } \\
\text { inquiry.. At least } 4 \text { sources are } \\
\text { cited. }\end{array}$ & $\begin{array}{l}\text { Wonderings/research questions } \\
\text { are connected to relevant and } \\
\text { credible literature from the } \\
\text { field. Teacher researcher } \\
\text { provides a detailed explanation } \\
\text { of how the literature is } \\
\text { connected to his/her } \\
\text { wonderings/research questions } \\
\text { and discusses, in detail, how } \\
\text { the literature informed his/her } \\
\text { inquiry. At least } 5 \text { sources are } \\
\text { cited. }\end{array}$ \\
\hline Methodology & $\begin{array}{l}\text { Description of the } \\
\text { strategies and assessment } \\
\text { that were implemented } \\
\text { and/or the timeline for } \\
\text { the study are lacking or } \\
\text { incomplete. }\end{array}$ & $\begin{array}{l}\text { Teacher researcher provides a } \\
\text { description of the strategies } \\
\text { and assessments they } \\
\text { implemented, as well as a } \\
\text { timeline for how the inquiry } \\
\text { proceeded. }\end{array}$ & $\begin{array}{l}\text { Teacher researcher provides a } \\
\text { detailed description of the } \\
\text { strategies and assessments they } \\
\text { implemented, as well as a } \\
\text { timeline for how the inquiry } \\
\text { proceeded. }\end{array}$ \\
\hline $\begin{array}{l}\text { The Research } \\
\text { Context }\end{array}$ & $\begin{array}{l}\text { Contextual information is } \\
\text { incomplete or lacking or } \\
\text { is not clearly connected } \\
\text { to understanding the } \\
\text { inquiry design and } \\
\text { findings. }\end{array}$ & $\begin{array}{l}\text { Teacher researcher provides } \\
\text { necessary information about } \\
\text { the context in which the } \\
\text { inquiry took place. This may } \\
\text { include, but not be limited to } \\
\text { information about the school, } \\
\text { district, classroom, content, } \\
\text { curriculum. The contextual } \\
\text { information that is provided } \\
\text { may be connected and } \\
\text { important to understanding } \\
\text { the inquiry design and } \\
\text { findings. }\end{array}$ & $\begin{array}{l}\text { Teacher researcher provides } \\
\text { thorough information about the } \\
\text { context in which the inquiry } \\
\text { took place. This may include, } \\
\text { but not be limited to } \\
\text { information about the school, } \\
\text { district, classroom, content, } \\
\text { curriculum. The contextual } \\
\text { information that is provided is } \\
\text { clearly connected and } \\
\text { important to understanding the } \\
\text { inquiry design and findings. }\end{array}$ \\
\hline
\end{tabular}




\begin{tabular}{|c|c|c|c|}
\hline Criteria & Unacceptable & Acceptable & Distinguished \\
\hline Participants & $\begin{array}{l}\text { Information about } \\
\text { participants is incomplete } \\
\text { or missing. Rationale for } \\
\text { sampling is incomplete } \\
\text { or not included. }\end{array}$ & $\begin{array}{l}\text { Teacher researcher provides } \\
\text { information about the } \\
\text { participants who were chosen } \\
\text { for the inquiry. This may } \\
\text { include but not be limited to } \\
\text { information about gender, } \\
\text { achievement, special needs, } \\
\text { learning styles, ethnicity, etc. } \\
\text { If the teacher researcher } \\
\text { focused on a particular } \\
\text { sample, a description of how } \\
\text { the participants were chosen } \\
\text { and a rationale for choosing a } \\
\text { sample are explained. }\end{array}$ & $\begin{array}{l}\text { Teacher researcher provides } \\
\text { complete information about the } \\
\text { participants who were chosen } \\
\text { for the inquiry. This may } \\
\text { include but not be limited to } \\
\text { information about gender, } \\
\text { achievement, special needs, } \\
\text { learning styles, ethnicity, etc. } \\
\text { If the teacher researcher } \\
\text { focused on a particular sample, } \\
\text { a description of how the } \\
\text { participants were chosen and a } \\
\text { rationale for choosing a sample } \\
\text { are clearly explained. }\end{array}$ \\
\hline $\begin{array}{l}\text { Data Sources \& } \\
\text { Collection }\end{array}$ & $\begin{array}{l}\text { Data sources are not } \\
\text { clearly explained and/or } \\
\text { may not be a logical } \\
\text { choice in relation to the } \\
\text { teacher researcher's } \\
\text { question(s). An } \\
\text { explanation of the data } \\
\text { collection procedures and } \\
\text { examples of any } \\
\text { collection instruments } \\
\text { may be incomplete or } \\
\text { missing. }\end{array}$ & $\begin{array}{l}\text { Teacher researchers collect } \\
\text { data from multiple sources. } \\
\text { Each data collection strategy } \\
\text { employed is explained and is } \\
\text { a logical choice in relation to } \\
\text { the teacher researcher's } \\
\text { question(s). Teacher } \\
\text { researchers provide an } \\
\text { explanation of all data } \\
\text { collection procedures as well } \\
\text { as examples of any collection } \\
\text { instruments (in appendices). }\end{array}$ & $\begin{array}{l}\text { Teacher researcher collects data } \\
\text { from multiple sources. Each } \\
\text { data collection strategy } \\
\text { employed is clearly explained } \\
\text { and is a logical choice in } \\
\text { relation to the teacher } \\
\text { researcher's question(s). } \\
\text { Teacher researcher provides a } \\
\text { detailed explanation of all data } \\
\text { collection procedures as well as } \\
\text { examples of any collection } \\
\text { instruments (in appendices). }\end{array}$ \\
\hline Data Analysis & $\begin{array}{l}\text { Explanation of data } \\
\text { analysis methods are } \\
\text { incomplete or missing. }\end{array}$ & $\begin{array}{l}\text { Teacher researcher provides } \\
\text { an explanation of all data } \\
\text { analysis methods (quantitative } \\
\text { and qualitative), including } \\
\text { initial, interim, and final } \\
\text { analyses. }\end{array}$ & $\begin{array}{l}\text { Teacher researcher provides a } \\
\text { detailed explanation of all data } \\
\text { analysis methods (quantitative } \\
\text { and qualitative), including } \\
\text { initial, interim, and final } \\
\text { analyses. }\end{array}$ \\
\hline $\begin{array}{l}\text { Data } \\
\text { Representation }\end{array}$ & $\begin{array}{l}\text { Data may not be } \\
\text { represented completely } \\
\text { and appropriately. } \\
\text { Tables and figures reflect } \\
\text { errors in formatting. }\end{array}$ & $\begin{array}{l}\text { Teacher researcher represents } \\
\text { his/her data in narratives, } \\
\text { tables, and/or figures. Tables } \\
\text { and figures are formatted } \\
\text { according to APA. }\end{array}$ & $\begin{array}{l}\text { Teacher researcher completely } \\
\text { and appropriately represents } \\
\text { his/her data in narratives, } \\
\text { tables, and/or figures. Tables } \\
\text { and figures are formatted } \\
\text { according to APA. }\end{array}$ \\
\hline
\end{tabular}




\begin{tabular}{|c|c|c|c|}
\hline Criteria & Unacceptable & Acceptable & Distinguished \\
\hline $\begin{array}{l}\text { Findings \& } \\
\text { Discussion }\end{array}$ & $\begin{array}{l}\text { Findings are discussed } \\
\text { but are not always } \\
\text { support by data. } \\
\text { Discrepant data is } \\
\text { ignored or if discussed is } \\
\text { not explained. } \\
\text { Connections to the } \\
\text { literature are incomplete } \\
\text { or lacking. }\end{array}$ & $\begin{array}{l}\text { Teacher researcher articulates } \\
\text { clear, thoughtful statements } \\
\text { about what he/she learned } \\
\text { through designing and } \\
\text { conducting his/her inquiry. } \\
\text { Most findings are supported } \\
\text { by data. If relevant, data that } \\
\text { did not appear to fit with what } \\
\text { is being claimed is included, } \\
\text { with possible explanations for } \\
\text { the discrepant data. Teacher } \\
\text { researcher connects the } \\
\text { literature and other relevant } \\
\text { experiences to his/her } \\
\text { discussion of the findings. }\end{array}$ & $\begin{array}{l}\text { Teacher researcher articulates } \\
\text { clear, thoughtful statements } \\
\text { about what he/she learned } \\
\text { through designing and } \\
\text { conducting his/her inquiry. } \\
\text { Each finding is supported in } \\
\text { detail, by data. If relevant, data } \\
\text { that did not appear to fit with } \\
\text { what is being claimed is } \\
\text { included, with possible } \\
\text { explanations for the discrepant } \\
\text { data. Teacher researcher } \\
\text { connects the literature and other } \\
\text { relevant experiences to his/her } \\
\text { discussion of the findings. }\end{array}$ \\
\hline $\begin{array}{l}\text { Conclusions \& } \\
\text { Implications for } \\
\text { Practice }\end{array}$ & & $\begin{array}{l}\text { Teacher research includes a } \\
\text { personal reflection on what } \\
\text { was learned about the process } \\
\text { of inquiry and details } \\
\text { examples of instructional } \\
\text { changes they have made or } \\
\text { will consider making based on } \\
\text { what they learned. Changes } \\
\text { in practice flow logically from } \\
\text { the teacher researcher's } \\
\text { reflections on what they have } \\
\text { learned. He/she discusses } \\
\text { how other professionals might } \\
\text { make use of the study and } \\
\text { supports the recommendations } \\
\text { with findings/data. Teacher } \\
\text { researcher discusses } \\
\text { actions/inquiries that might be } \\
\text { pursued in the future. }\end{array}$ & $\begin{array}{l}\text { Teacher research includes a } \\
\text { personal reflection on what was } \\
\text { learned about the process of } \\
\text { inquiry and details examples of } \\
\text { instructional changes they have } \\
\text { made or will consider making } \\
\text { based on what they learned. } \\
\text { Changes in practice flow } \\
\text { logically from the teacher } \\
\text { researcher's reflections on what } \\
\text { they have learned. He/she } \\
\text { discusses how other } \\
\text { professionals might make use } \\
\text { of the study and supports the } \\
\text { recommendations with } \\
\text { findings/data. Teacher } \\
\text { researcher discusses } \\
\text { actions/inquiries that might be } \\
\text { pursued in the future. }\end{array}$ \\
\hline
\end{tabular}




\begin{tabular}{|c|c|c|c|}
\hline Criteria & Unacceptable & Acceptable & Distinguished \\
\hline Voice & $\begin{array}{l}\text { Teacher researcher's } \\
\text { enthusiasm and passion } \\
\text { for the inquiry are } \\
\text { minimally or not evident. } \\
\text { His/Her role as a teacher } \\
\text { is not evident in the voice } \\
\text { the teacher researcher } \\
\text { adopts. Voice is prosaic } \\
\text { and inconsistent and/or } \\
\text { inappropriate for the } \\
\text { purpose and audience. }\end{array}$ & $\begin{array}{l}\text { Teacher researcher's } \\
\text { enthusiasm and passion for } \\
\text { the inquiry are sometimes } \\
\text { evident throughout the write- } \\
\text { up. His/Her role as a teacher } \\
\text { is sometimes, but not always } \\
\text { evident in the voice the } \\
\text { teacher researcher adopts. } \\
\text { Voice is mostly lively and } \\
\text { engaging, but does not } \\
\text { overshadow the substance of } \\
\text { the paper. }\end{array}$ & $\begin{array}{l}\text { Teacher researcher's } \\
\text { enthusiasm and passion for the } \\
\text { inquiry are evident throughout } \\
\text { the write-up. His/Her role as a } \\
\text { teacher is evident in the voice } \\
\text { the teacher researcher adopts. } \\
\text { Voice is lively and engaging, } \\
\text { but does not overshadow the } \\
\text { substance of the paper. }\end{array}$ \\
\hline $\begin{array}{l}\text { Formatting \& } \\
\text { Conventions } \\
\text { (APA) }\end{array}$ & $\begin{array}{l}\text { Errors in conventions are } \\
\text { common and impair } \\
\text { readability of the inquiry. } \\
\text { Basic layout of the text } \\
\text { may be visually } \\
\text { confusing; difficult to } \\
\text { identify key points at a } \\
\text { glance. Graphic devices } \\
\text { are seldom used or their } \\
\text { connection to the text is } \\
\text { not clear. Citations are } \\
\text { missing, incomplete, or } \\
\text { incorrect. Inconsistent } \\
\text { use of tenses. }\end{array}$ & $\begin{array}{l}\text { Some errors with conventions } \\
\text { and/or formatting. Basic } \\
\text { layout of the text is designed } \\
\text { to direct the reader's attention } \\
\text { to key points. Titles, } \\
\text { subtitles, bullets, and similar } \\
\text { devices sometimes enhance } \\
\text { the organization of the text. } \\
\text { Graphic devices such as } \\
\text { charts, graphs, tables. or } \\
\text { figures are fairly clear and } \\
\text { supportive of the text. } \\
\text { Citations, titles, and graphics } \\
\text { adhere to APA guidelines } \\
\text { (one or two errors). } \\
\text { Consistent use of past or } \\
\text { present tense. }\end{array}$ & $\begin{array}{l}\text { Minimal errors with } \\
\text { conventions and/or formatting. } \\
\text { Basic layout of the text is } \\
\text { designed to direct the reader's } \\
\text { attention to key points. Titles, } \\
\text { subtitles, bullets, and similar } \\
\text { devices enhance the } \\
\text { organization of the text. } \\
\text { Graphic devices such as charts, } \\
\text { graphs, tables. or figures are } \\
\text { clear, helpful, visually } \\
\text { appealing, and support of the } \\
\text { text. Citations, titles, and } \\
\text { graphics adhere to APA } \\
\text { guidelines. Consistent use of } \\
\text { past or present tense. }\end{array}$ \\
\hline
\end{tabular}


Appendix I: Sample Research Brief

Name:

PDS:

Tentative Title of Project:

\section{Research \\ Purpose/Audience:}

Why do I want to study this? Who will be

interested in my study?

For whom am I

conducting this study?

Review of Literature

(Knowledge of

Practice) Summarize

the main points of the articles (at least 5)

you've read that you

used to design your

study.

Research Question(s):

What do I want to

study? What

subquestions do I have?

What I Will Be Trying

\begin{tabular}{|l|l|l|} 
& \multicolumn{2}{|l|}{} \\
& \multicolumn{2}{|l|}{ Qualitative Data } \\
\hline $\begin{array}{l}\text { Data Collection: What } \\
\text { data will I collect? How } \\
\text { will I collect data? }\end{array}$ & Quantitative Data & \\
\cline { 2 - 3 } & & \\
& & \\
\end{tabular}




\begin{tabular}{|c|c|}
\hline $\begin{array}{l}\text { Data analysis: How } \\
\text { will I analyze my data? }\end{array}$ & $\begin{array}{l}\text { You might record your initial ideas about data analysis and complete } \\
\text { in more detail later in the semester. }\end{array}$ \\
\hline $\begin{array}{l}\text { Tentative Timeline: } \\
\text { When will I complete } \\
\text { the different phases of } \\
\text { my study? }\end{array}$ & \\
\hline $\begin{array}{l}\text { Support/Collaboration } \\
\text { Who will help me } \\
\text { sustain this project? }\end{array}$ & \\
\hline $\begin{array}{l}\text { Permissions: What } \\
\text { permissions do I need to } \\
\text { collect? Are there } \\
\text { ethical issues to } \\
\text { consider? }\end{array}$ & \\
\hline $\begin{array}{l}\text { Other Resources to } \\
\text { Explore: Journal } \\
\text { articles/books I want to } \\
\text { read/consult. }\end{array}$ & \\
\hline $\begin{array}{l}\text { Issues I'm Struggling } \\
\text { With: Concerns I have } \\
\text { about conducting the } \\
\text { study }\end{array}$ & \\
\hline $\begin{array}{l}\text { Reflection Before } \\
\text { Beginning My Study }\end{array}$ & \\
\hline
\end{tabular}




\section{Appendix J: Syllabus for The Teacher as Leader \\ EDUC 602 - THE TEACHER AS LEADER \\ Spring 2011}

\section{[Instructors Removed] \\ [Course Meeting Locations Removed]}

\section{Course Description}

This course is designed to support your transition from prospective teacher to professional practice and to promote your understanding of the importance of assuming teacher leadership roles in the profession, as well as to begin developing the tools to engage in teacher leadership. Specifically, this course focuses on understanding the current scholarship about the leadership roles that teacher leaders, within a PDS, pursue as they facilitate teacher learning and school renewal. After a brief introduction to all areas, you will be able to focus on one of the following: (1) teacher as exemplary practitioner, (2) teacher as curriculum decision-maker, (3) teacher as researcher, (4) teacher as advocate and change agent, and (5) teacher as facilitator of jobembedded professional development.

\section{COURSE POLICIES AND PROCEDURES}

\section{Section Selection}

During weeks 2-6 you will be introduced to each of the five sections being offered. In week six, you will rank your choice of sections and spend the rest of the semester focusing on the topic of interest to you. We will do our best to match you with your top choices, but we cannot make any guarantees. You will only have the evening of Wednesday, February $16^{\text {th }}$ to rank your choices. Assignments will be made on Thursday, February $17^{\text {th }}$. If you do not choose a section on February $16^{\text {th }}$, you will be assigned at the discretion of the course instructors.

\section{Grading}

\begin{tabular}{|l|l|}
\hline Assignment & Percentage \\
\hline Introductory Week Assignments (Weeks 2-6) & 10 \\
\hline Section Work (e.g., exemplary practitioner) & 75 \\
\hline Inquiry Synthesis & 15 \\
\hline
\end{tabular}




\section{Major Course Assignment: Inquiry Synthesis Essay}

Rationale: Throughout your time in the program, you have attended 15 inquiry seminars, conducted a lesson-based inquiry, mini-inquiry, and semester long inquiry, prepared (or are preparing) a presentation of your research, and have seen others present their work. While you may have approached each of these activities as another item on a seemingly endless checklist, for most of you, your work says something more. Through your work for EDUC 600, as well as countless other activities throughout your time in the program, you have made some progress towards developing an "Inquiry Stance" towards teaching. As you prepare to graduate, your final task is to critically consider your experiences related to inquiry, including instances in which you collected and/or analyzed data in both formal and informal ways. After you reflect on these experiences, you will write about what you have learned, how you have changed, and what you want to accomplish moving forward.

You will construct an essay which responds to the following prompts:

1. How has your understanding of inquiry changed over the last three years?

2. What have you learned about your students though inquiry?

3. What have you learned about your teaching though inquiry?

4. How has inquiry helped you become the educator you want to be?

5. In what ways has inquiry proven difficult for you.....and how did you address those challenges?

6. How do you plan to use inquiry in your future practice...to make it a part of your teaching?

- Your essay will be written in narrative form, and should be between 2000 and 3000 words.

- You should utilize APA format, and appropriate writing conventions.

- You should also make reference to specific examples from your teaching and inquiry experiences that help to illustrate your points, as well as how you've made use of knowledge for practice (the literature) to understand and engage in inquiry. At a 
minimum, you should use data from your mini-inquiry report and your final inquiry

report

- You should be self-critical, considering the strengths and weaknesses of your work.

- You should critically consider the theories and processes which guide inquiry, but avoid discussing inquiry as a "course."

- You should make sure to address the six prompts above, but not feel limited by them.

We encourage you to discuss other aspects of your learning that are not necessarily addressed by the prompts.

This Assignment will be worth $15 \%$ of your total grade for EDUC 602 . Your Essay will be due, via email to your small group facilitator for EDUC 600, on April 6, 2011 by 11:59pm. This activity will be graded holistically - and your grade will be based on your ability to address the six prompts, provide supporting data and examples, write with appropriate voice and tone, and attend to proper writing conventions.

\section{Attendance}

Attendance is mandatory! Grades will be lowered as per the table below with the following exception: University-related events, Days of Special Concern, and at the instructors' discretion. Important personal commitments will be excused without counting as an absence if they are reported to the instructor by February $1^{\text {st }}$. For other absences, there is no need to contact the instructor, as all absences are treated the same.

\begin{tabular}{ll}
\hline Number of Absences & Grade Deduction \\
\hline $\mathbf{0 , 1}$ & None \\
$\mathbf{2}$ & 1 letter grade \\
$\mathbf{3}$ & 2 letter grades \\
$\mathbf{4}$ or more & F will be given if student does \\
& not withdraw \\
\hline
\end{tabular}

\section{Class Session Cancellation}

If weather or another emergency closes the University, an announcement will be posted immediately on various web sites, including [Web Sites]. Cancellations for this course or your specific section will be announced through your individual [email] account and/or a note will be posted on the door. In all emergency situations, however, we rely on individuals to make the best decisions for themselves about their safety. 


\section{Late Work}

Each assignment has a due date. Assignments are to be turned in by the due date. Under extenuating circumstances, and at the discretion of the course instructor, an extension may be given provided a request is made via email before the due date.

\section{[Academic Integrity Policy Removed]}

\section{[Program] Matriculation}

Students must earn at least a grade of "C" in all professional education courses to remain in the five-year teacher education program. Earning a grade less than " $\mathrm{C}$ " will result in the student being removed from the program. In this event, the student must contact [Program Coordinator] immediately.

Students who arrange to receive a grade of "I" (incomplete) must complete all requirements to change the incomplete to a grade prior to the beginning of the next semester. If the student does NOT get the grade of "I" changed to a passing grade, the student will NOT be able to matriculate to the next semester of courses. In this event, the student must contact [Program Coordinator] immediately.

Students must maintain at least a 3.0 grade point average in Year-5 to remain in the five-year teacher education program. If the GPA falls below 3.0, the student will NOT be allowed to graduate. In this event, the student must contact [Program Coordinator] immediately.

\section{Non-Discrimination}

In addition to standard non-discrimination policies that prohibit discrimination based on membership in various identity groups, we seek to encourage intellectual and professional growth and development. Any element of the course (or your specific section) that limits intellectual and professional growth and development through any form of discrimination should be brought to our attention.

\section{Disability Accommodations Statement}

If you are a person with a disability and anticipate needing any type of accommodation in order to participate in this class. Please advise us and make appropriate arrangement with [Disability Services].

\section{[Criminal Background Information \& Procedure Removed]}




\section{GROUP COURSE SCHEDULE}

The table below provides the course schedule for the first six weeks of the semester. Course schedules for specific sections are provided in a subsequent section.

\begin{tabular}{lll}
\hline Session Date & Session Topic & Readings or Products Due \\
\hline January 12 & Review Syllabus & Darling-Hammond, L., Bullmaster, M. L. \& \\
& Introduction to Teacher & Cobb, V. L. (1995, September). "Rethinking \\
& Leadership & Teacher Leadership through Professional \\
& ALH 406 & Development Schools." The Elementary \\
& School Journal, 96(1), pp. 87-106. \\
& \\
& 5:00-5: 20 PM Elementary & \\
&
\end{tabular}

\section{January 19-February 16}

During weeks 2-6, please report to your registered section. Different faculty members will come to you.

\begin{tabular}{|c|c|c|}
\hline & \multicolumn{2}{|l|}{ Exemplary Practice } \\
\hline & Curriculum Decision-making & AFT Report on Standards-Based Instruction \\
\hline & Inquiry/Reflection & $\begin{array}{l}\text { Nieto, S., Gordon, S., \& Yearwood, J. (2002). } \\
\text { Teachers' experiences in a critical inquiry } \\
\text { group: A conversation in } 3 \text { voices. Teaching } \\
\text { Education, 13(3), 341-355. Posted on } \\
\text { eCampus. This article is to be read before } \\
\text { class. }\end{array}$ \\
\hline & & $\begin{array}{l}\text { Bring a lesson you have taught and would like } \\
\text { to discuss with your peers. }\end{array}$ \\
\hline & & $\begin{array}{l}\text { Bring a scholarly article of your choice that } \\
\text { you have read and is related to one of your } \\
\text { teaching interests and/or work you are doing } \\
\text { during your contract. }\end{array}$ \\
\hline & & $\begin{array}{l}\text { A reflection on your learning in this session } \\
\text { will be due via email to Sharon by the Friday } \\
\text { following your session. }\end{array}$ \\
\hline & Advocacy & $\begin{array}{l}\text { Whang, P. A., \& Waters, G. A. (2001). } \\
\text { Transformational spaces in teacher education: } \\
\text { Map(ing) a pedagogy linked to a practice of } \\
\text { freedom. Journal of Teacher Education, 52, } \\
\text { 197-210. }\end{array}$ \\
\hline & $\begin{array}{l}\text { Job-embedded Professional } \\
\text { Development }\end{array}$ & \\
\hline April 27 & Final Presentations & \\
\hline
\end{tabular}


For weeks 2-6 you will report to the classroom assigned to your registered section. Topics will rotate as follows:

\begin{tabular}{|l|l|l|l|l|l|}
\hline Date/Location & PER 315 & ALH 711 & ALH 612 & ALH 406 & ALH 703 \\
\hline Jan. 19 & $\begin{array}{l}\text { Exemplary } \\
\text { Practitioner }\end{array}$ & $\begin{array}{l}\text { Professional } \\
\text { Development }\end{array}$ & Advocacy & $\begin{array}{l}\text { Inquiry/ } \\
\text { Reflection }\end{array}$ & Curriculum \\
\hline Jan. 26 & Curriculum & $\begin{array}{l}\text { Exemplary } \\
\text { Practitioner }\end{array}$ & $\begin{array}{l}\text { Professional } \\
\text { Development }\end{array}$ & Advocacy & $\begin{array}{l}\text { Inquiry/ } \\
\text { Reflection }\end{array}$ \\
\hline Feb. 2 & $\begin{array}{l}\text { Inquiry/ } \\
\text { Reflection }\end{array}$ & Curriculum & $\begin{array}{l}\text { Exemplary } \\
\text { Practitioner }\end{array}$ & $\begin{array}{l}\text { Professional } \\
\text { Development }\end{array}$ & Advocacy \\
\hline Feb. 9 & Advocacy & $\begin{array}{l}\text { Inquiry/ } \\
\text { Reflection }\end{array}$ & Curriculum & $\begin{array}{l}\text { Exemplary } \\
\text { Practitioner }\end{array}$ & $\begin{array}{l}\text { Professional } \\
\text { Development }\end{array}$ \\
\hline Feb. 16 & $\begin{array}{l}\text { Professional } \\
\text { Development }\end{array}$ & Advocacy & $\begin{array}{l}\text { Inquiry/ } \\
\text { Reflection }\end{array}$ & Curriculum & $\begin{array}{l}\text { Exemplary } \\
\text { Practitioner }\end{array}$ \\
\hline
\end{tabular}

[Individual Section Activities Removed] 


\section{Appendix K: Cover Letter for Informed Consent}

April 27, 2011

Dear Interns:

As most of you know, in addition to my teaching, seminar facilitation and liaison work, I am also pursuing my Doctorate. I am in the process of working on my dissertation proposal, and in coordination with my Doctoral Committee I have decided to research evidence of inquiry stance development in pre-service teachers. My intended research sample is the 2011 Cohort of the [Program Name Removed].

We often use examples from previous cohorts to guide the work of students in the Program, but because I will be using products created by the Class of 2011 for research, I need to have your informed consent before I can use your work. Please note the specifics below and then complete the Informed Consent Document which follows.

- Participation is optional, and if I do not have your explicit approval, your work will not be used. You can also opt-out at any time. You must be 18 years of age to participate.

- I will not know if you have consented to participate until after you graduate. Returned consent forms will be kept by [Name Removed] and will remain in an envelope until May 16, 2011.

- Your decision to participate will be kept confidential and will in no way affect your relationship with the [Program Name Removed], [ University Name Removed], or the [PDS Network Name Removed].

- If you do participate, your name will be removed from any document that will be analyzed by me. Thus I will not know whose work I am viewing (Note: for students I have worked with directly, I may recognize you as the author of some documents).

- My dissertation and any related publications will not include any student names or identifying information, nor will I provide this information to anyone.

- Your work will only be used for my research. I will not make any attempt to evaluate the validity of the grade you were given or otherwise attempt to "reassess" your work.

- You will have the option to be notified when any product of this research is made available.

- You will also have the option to participate in any further research related to your Inquiry work.

- [University Name Removed] Institutional Review Board acknowledgement of this project is on file.

If you have any questions, please do not hesitate to contact me at Jason.Smith@ mail.wvu.edu. You may also contact [Names of Committee Members Removed], both of whom are on my Doctoral Committee and thus supervising this research.

Sincerely,

Jason Jude Smith 


\section{Appendix L: Notice of Informed Consent}

Name:

Date:

By signing below, I certify that Jason Jude Smith has my consent to use documents constructed by me during my time as a student in EDUC 600, in the [Name of Program Removed]. These documents may include: inquiry write-ups, admission/exit tickets, research briefs, and other activities related to the Inquiry Strand of the [Program Name Removed]. I further certify that I am 18 years or older, that I received a cover letter and that I am aware that [University Name Removed] Institutional Review Board acknowledgement of this project is on file.

I understand that my name will be removed from any documents which are used for analysis and that my name will not be used in any products which arise out of this research. I further understand that participation is voluntary, and certify that my decision to participate was not the product of any coercion.

I understand that I have the right to be notified prior to the publication of any products which result from this research and I also have the right to be notified of any additional research projects which may arise from this work. By giving my consent now, I am in no way committing to participate in any future research. I also have the right to opt-out at any time.

I hereby give consent for my work to be used as described above.

I decline to allow my work to be used as described above.

Signature: Date:

Optional Information

I would like to be contacted via email when any product of this research is published.

I would like to be contacted via email if additional opportunities to participate in research related to my work become available.

Email Address: 


\section{Appendix M: Example of Memoing during Second Round of Coding}

\begin{tabular}{|c|c|}
\hline 13 & $\begin{array}{l}\text { This case has very little reference to actual findings, although a few of the projects are } \\
\text { alluded to. There is significant reference made to learning how to conduct meaningful } \\
\text { inquiry. Several coded examples in this essay help to demonstrate this focus on the } \\
\text { product, including an emphasis on making use of collaboration, and on conducting } \\
\text { formal inquiries which occur over a period of time (over a year) and are then shared } \\
\text { with others. }\end{array}$ \\
\hline 14 & $\begin{array}{l}\text { There is a real focus on the progression of learning about inquiry - an epiphany has } \\
\text { been coded as the understanding of inquiry seemed to come about during the internship. } \\
\text { There is more of a focus on the process of inquiry, and there is a lot of mention of using } \\
\text { journaling and looking at test scores as inquiry practices. There is also a focus on } \\
\text { learning about students. }\end{array}$ \\
\hline 15 & $\begin{array}{l}\text { There is an attempt to pick out all of the key components of inquiry and talk about the } \\
\text { continual process of inquiry. However, there is conflicting stories which undermine the } \\
\text { actual beliefs about inquiry (example related to using the literature is coded). Further, } \\
\text { there is little discussion of the outcomes from inquiry experiences. }\end{array}$ \\
\hline 16 & $\begin{array}{l}\text { There is a mix of process and product elements here. While there is significant } \\
\text { discussion about the various inquiry experiences, there is also rich discussion as to the } \\
\text { impact of these experiences, as well as the learning that occurred, on future teaching. A } \\
\text { coded epiphany illustrates how even after the process was done (for the program) } \\
\text { learning about inquiry was occurring. }\end{array}$ \\
\hline 17 & $\begin{array}{l}\text { This essay demonstrates the learning that occurred through inquiry, and the product of } \\
\text { this learning. Further, there is also a cohesive discussion of the ways in which learning } \\
\text { will impact future teaching. This perspective is supported by discussions (coded as an } \\
\text { example) of the difficulties of engaging in inquiry which focus on challenges to } \\
\text { overcome, rather than barriers to future inquiry. }\end{array}$ \\
\hline 18 & $\begin{array}{l}\text { This essay is organized chronologically, rather than by the prompts provided. As such, } \\
\text { the focus tends to be on the process of learning to do inquiry through experience. There } \\
\text { is however a rather strong conclusion that hints of future inquiry, and also discusses the } \\
\text { importance of inquiry as a professional tool. }\end{array}$ \\
\hline 19 & $\begin{array}{l}\text { There is a clear discussion of growth through experience. This growth is evident in the } \\
\text { two coded examples which discuss not being able to define inquiry at first, and then } \\
\text { asking about the role of inquiry in a job interview a few years later. There are a few } \\
\text { references to the actual substance of individual projects, but these are framed mostly as } \\
\text { part of a larger growth process. }\end{array}$ \\
\hline 20 & $\begin{array}{l}\text { There is a lot of discussion about the paper, the seminars, and other experiences, that } \\
\text { place a heavy emphasis on the outcomes of the inquiry strand. There is some mention of } \\
\text { being able to actualize this learning, but these comments are undermined by two coded } \\
\text { examples (confounding evidence) where such comments are contradicted. There is an } \\
\text { excellent comment at the end about the potential that an inquiry stance is in some ways } \\
\text { innate. }\end{array}$ \\
\hline
\end{tabular}




\section{Appendix N: Organization of Codes using the Labov Narrative Elements}

\begin{tabular}{|c|c|}
\hline Code & Description \\
\hline \multicolumn{2}{|l|}{ Abstract } \\
\hline Scope of Learning Inquiry & $\begin{array}{c}\text { General statements related to the learning process through time } \\
\text { in program }\end{array}$ \\
\hline $\begin{array}{l}\text { Previous Understanding of } \\
\text { Inquiry }\end{array}$ & Stories related to student from peers about "The AR" \\
\hline $\begin{array}{l}\text { Initial Understanding of } \\
\text { Inquiry } \\
\end{array}$ & $\begin{array}{l}\text { Understandings of Inquiry and/or research at the onset of } \\
\text { learning }\end{array}$ \\
\hline \multicolumn{2}{|l|}{ Orientation } \\
\hline Early Seminars & Initial Seminars (Foundational) \\
\hline Late Seminars & Later Seminars (Application) \\
\hline Compare to Other Programs & $\begin{array}{l}\text { Mentions of experiences related to "typical" program } \\
\text { experiences }\end{array}$ \\
\hline Tutor Placements & References to any practicum experience during Y3 \\
\hline Participant Inquiry & Fall of Participant year \\
\hline Mini-Inquiry & Spring of Participant year \\
\hline Internship & Fall of Intern year \\
\hline Inquiry Conference & References specifically to Inquiry Conference \\
\hline Other Places/Times & Contract Experiences/Conferences/Etc. \\
\hline Future Practice & Plans for future teaching. \\
\hline \multicolumn{2}{|l|}{ Complicating Action } \\
\hline Test Changes in Practice & Use of Inquiry to examine EXISTING practice \\
\hline Data Collection & Collection of data for Inquiry \\
\hline Data Analysis & Analysis of data for Inquiry \\
\hline Conflict Teaching-Research & Inquiry as an impediment to other teaching duties \\
\hline Wonderings & Choosing a topic or question \\
\hline Time (During Projects) & Time as a factor during inquiry process \\
\hline Unexpected Findings & Surprising findings from inquiry \\
\hline Practices for Inquiry & New practices which arise from inquiry work \\
\hline Use of Literature & Use of existing scholarship \\
\hline Difficulty w/ Data Analysis & Problems with data analysis \\
\hline Writing Report & Mentions of formalizing work per requirements \\
\hline \multicolumn{2}{|l|}{ Evaluation } \\
\hline Intimidated by Research & General references to research being difficult \\
\hline Open Ended Process & $\begin{array}{l}\text { References to inquiry as formal/informal/large-scale/small- } \\
\text { scale }\end{array}$ \\
\hline Best Practice & Use of best practices as a result of, or impetus for inquiry \\
\hline $\begin{array}{l}\text { Becoming a Teacher- } \\
\text { Researcher }\end{array}$ & $\begin{array}{l}\text { Comments which suggest understanding of teacher-researcher } \\
\text { as a singular role }\end{array}$ \\
\hline Use of Actual Data & Use of actual data from an inquiry experience \\
\hline
\end{tabular}




\begin{tabular}{|c|c|}
\hline Code & Description \\
\hline Learning from Facilitator & Comments describing interaction with facilitator \\
\hline Learning for Peers & Comments describing interaction with other preservice teachers \\
\hline Learning from Mentors & Comments describing interactions with mentors \\
\hline Time (Impact on Future) & Time as a factor related to future practice \\
\hline Issues with Learning Inquiry & $\begin{array}{l}\text { Problems or concerns about the learning process within the } \\
\text { program }\end{array}$ \\
\hline Learning from Students & $\begin{array}{l}\text { Comments describing interaction with preservice teacher's } \\
\text { students in placement }\end{array}$ \\
\hline Reflective Practice & $\begin{array}{l}\text { Implicit or explicit discussions of reflection during the inquiry } \\
\text { process }\end{array}$ \\
\hline Personal Connections & $\begin{array}{c}\text { Mention of other people/experiences which impacted inquiry } \\
\text { processes }\end{array}$ \\
\hline \multicolumn{2}{|l|}{ Resolution } \\
\hline $\begin{array}{l}\text { Current Understanding of } \\
\text { Research }\end{array}$ & Descriptions of current understanding of research \\
\hline Variation in Data & Surprising outcomes or complications related to data \\
\hline Student Learning & Impact of inquiry work on student learning \\
\hline Outcomes from Inquiry & $\begin{array}{c}\text { Changes in mindset as a result of inquiry (not actual classroom } \\
\text { practice) }\end{array}$ \\
\hline Learning about Students & $\begin{array}{l}\text { Discussions of enhanced understanding of students through } \\
\text { inquiry }\end{array}$ \\
\hline Impact of Inquiry on Teaching & Changes in classroom practice as a result of inquiry \\
\hline Collaboration in Future & $\begin{array}{l}\text { Comments which consider collaboration as a part of future } \\
\text { practice }\end{array}$ \\
\hline Student-Teacher Relationships & $\begin{array}{l}\text { Impact of inquiry (likely through sharing) on relationships with } \\
\text { actual students }\end{array}$ \\
\hline Sharing Findings & Sharing findings in formal or informal ways \\
\hline Data-based Instruction & $\begin{array}{l}\text { Comments pointing to the role of data in classroom practice } \\
\text { (with or without formal inquiry) }\end{array}$ \\
\hline \multicolumn{2}{|l|}{ Coda } \\
\hline Emergent Wonderings & Mentions of future research questions \\
\hline Finality/Happy & Personal comments (i.e. I'm glad it's over) \\
\hline Professionalism & $\begin{array}{l}\text { Explicit/implicit mention of teaching as a professional and } \\
\text { intellectual endeavor }\end{array}$ \\
\hline Personal Messages & Messages intended for the assessor of essay \\
\hline Teaching Inquiry to Others & Desire to spread understanding of inquiry to others \\
\hline
\end{tabular}

